How climate and land use determine the hydrology of Lake Naivasha Basin

Vincent Omondi Odongo 
Graduation committee:

\section{Chair:}

Prof.dr.ir. A. Veldkamp University of Twente

Promoter:

Prof.dr. Z. Su

University of Twente

Co-promoter:

Dr.ir. C. van der Tol

University of Twente

\section{Members:}

Prof.dr. A. van der Veen

University of Twente

Prof.dr.ing. W. Verhoef

University of Twente

Prof.dr. J.D. Albertson

Cornell University, Ithaca, USA

Prof.dr. L. Jia

Chinese Academy of Sciences, China

Prof.dr. J.O. Onyando

Egerton University, Kenya

Dr. A. Olioso

INRA, Avignon, France

ITC dissertation number 291 ITC, P.O. Box 217, 7500 AA Enschede, The Netherlands

ISBN 978-90-365-4233-3

DOI $10.3990 / 1.9789036542333$

Cover designed by Benno Masselink

Printed by ITC Printing Department

Copyright (c) 2016 by V.O. Odongo

TUE FACULTY OF GEO-INFORMATION SCIENCE AND EARTH OBSERVATION 


\title{
How climate and land use determine the hydrology of Lake Naivasha Basin
}

DISSERTATION

\author{
to obtain \\ the degree of doctor at the University of Twente, \\ on the authority of the rector magnificus, \\ prof.dr. H. Brinksma, \\ on account of the decision of the graduation committee, \\ to be publicly defended \\ on Thursday $3^{\text {rd }}$ November 2016 at 16.45 hrs
}

by

Vincent Omondi Odongo

born on 13-05-1977

in Nakuru, Kenya 
This thesis is approved by

Prof. dr. Zhongbo Su, promoter

Dr. Christiaan van der Tol, co-promoter 


\section{Acknowledgements}

This thesis was an outcome of support received from many organizations, institutions and people. I acknowledge the funding received from NWO-WOTRO for funds that supported this thesis research through the Earth Observation and Integrated Assessment (EOIA) of Lake Naivasha Project. I also acknowledge ITC-fellowship and ESA-Tiger project for supporting the latter part of this work. I appreciate the support of Water Resources Management Authority (WRMA) for the support with data and their hospitable staff who were at the forefront to assisting with logistics during fieldwork. I acknowledge Kenya Wildlife Service (KWS) and Kenya Wildlife Service Training Institute (KWSTI) for providing the access to their sites where the flux measurement equipment were installed. Specifically, the support of Prof. George Otiang'a Owiti is greatly acknowledged. It is through your support that KWSTI and ITC partnership remains great and continues to date.

I would like to express my special appreciation and thanks to my promotor Prof. Dr. Bob Su, you have been a tremendous mentor for me. I would like to thank you for encouraging my research and for allowing me to grow as a research scientist. I also would like to thank my co-promotor Dr. Christiaan van der Tol. Your advice on both research as well as on my career have been priceless. I thank Drs. Robert Becht for his support and mentorship throughout my MSc to PhD studies. Your support and belief in me is unmatched. I appreciate the support of Dr. Zoltan Vekerdy and Ir. Arno van Lieshout during the latter part of this thesis. Your contribution and support was timely and much needed.

The EOIA Naivasha project team led by Prof. Anne van der Veen and Prof. Japheth Onyando provided invaluable support that made my work harmonious and were always there to support when needed. I also acknowledge the contribution and support of Prof. Nzula Kitaka, Prof. George Khroda and Prof. Jude Mathooko during the many scientific and stakeholder presentations we had in Naivasha, Dr. Pieter van Oel is thanked for the many valuable scientific debates, arguments, discussions and most importantly the fun times we had in Naivasha and the Netherlands with the rest of the team members. Dr. Dawit Mulatu, Dr. Francis Kamau, Job Ogada and Dr. Jane Ndung'u are appreciated for the many wonderful times spent together and the support shared. I appreciate the support and times spent with the EOIA MSc. Students who participated in the project: Frank Meins, Mark Cornelissen and Rick Hogeboom. I wish to thank co-authors who also contributed and significantly participated in my work and led to publication of some of the chapters in this thesis. I acknowledge the valuable constructive criticisms by Prof. Andrew Skidmore and Dr. Thomas Groen that led to publication of Chapter 5. I acknowledge the contribution of Dr. Joost Hoedjes and Dr. Ghimire Chandra that led to the publication of Chapter 4. I also appreciate the contribution of Dr. Joris Timmermans and Dr. Xuelong Chen on working with SEBS.

Many thanks and appreciation to Dominic Wambua who was of great assistance during my field work. Your local knowledge was unparralled and significant during data collection. The many friends I met and interacted with made ITC an enabling social environment and my stay enjoyable: Dr. Tagel Gidey, Dr. Jennifer Kinoti, Dr. Shadrack Ngene, Dr. Zacharia Kuria and Dr. Abel 
Ramoelo. I wish to express my gratitude to Tina Butt-Castro and Anke de Koning, Loes Colenbrander and Marion Pierik for the attention and care they continually exuded. I acknowledge the resourcefulness of Murat Ucer in helping with testing the field equipment and also responding in time when I had technical issues with the equipment in the field.

A special thanks to my family. Words cannot express how grateful I am for all the sacrifices you made on my behalf. To Uncle John and Family, a big thank you cannot tell it all, but I appreciate your tremendous support and for always being there for me. I would also like to thank all of my friends who supported me to strive towards my goal and were always there in the moments when there was no one to answer my queries. 


\section{Table of Contents}

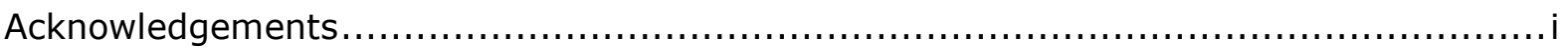

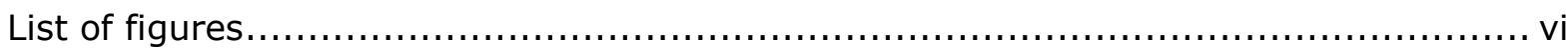

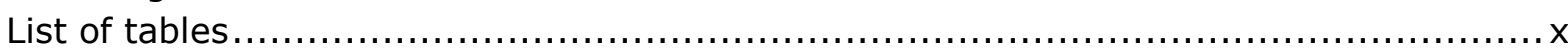

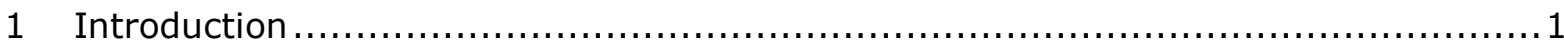

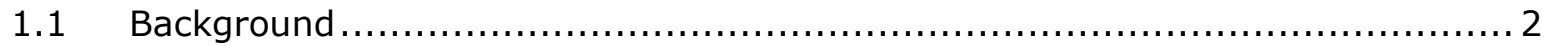

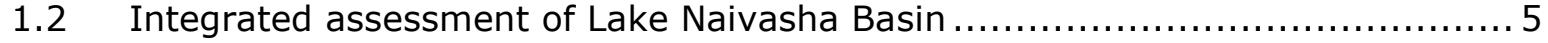

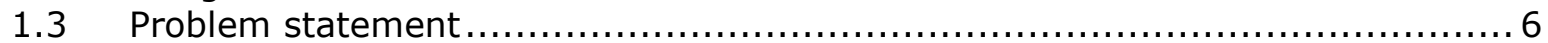

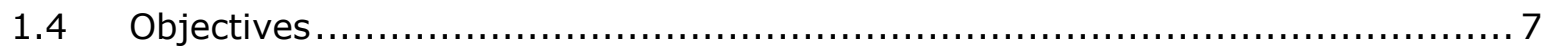

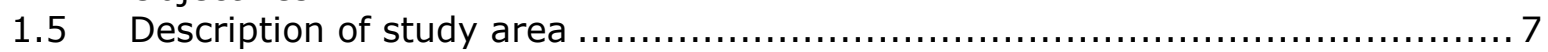

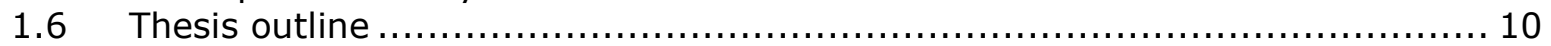

2 A characterisation of hydro-climatological trends and variability in the Lake Naivasha

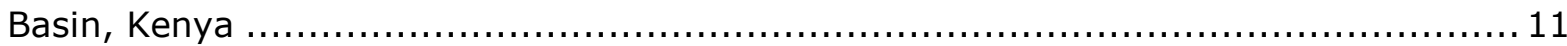

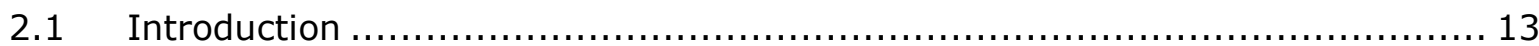

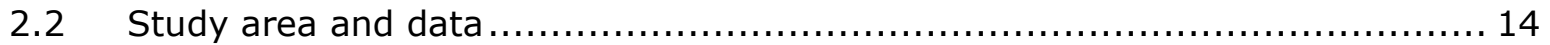

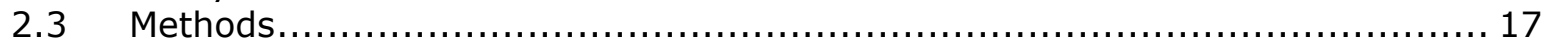

2.3.1 Lake volume change and water balance analysis ............................ 17

2.3.2 Change point analysis........................................................... 19

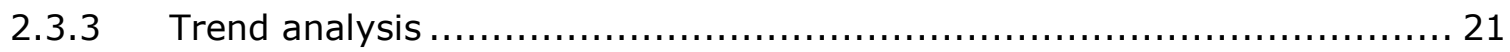

2.3.4 Trend analysis under STP hypothesis ...................................... 22

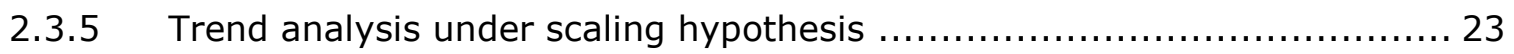

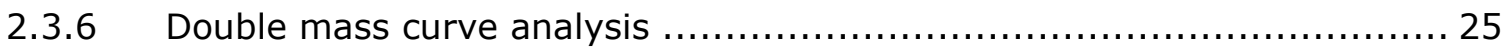

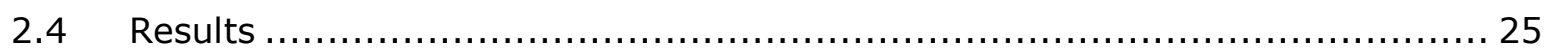

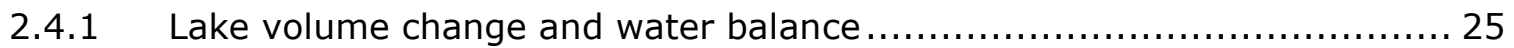

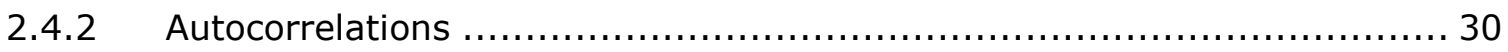

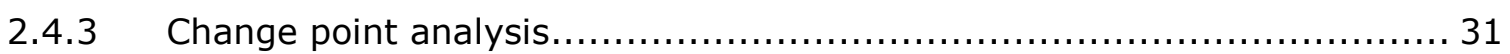

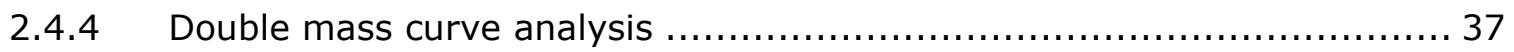

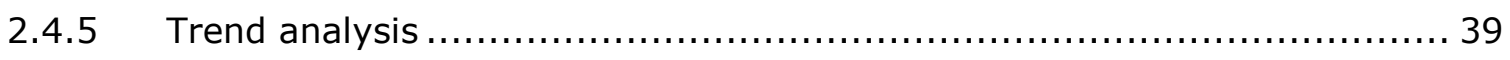

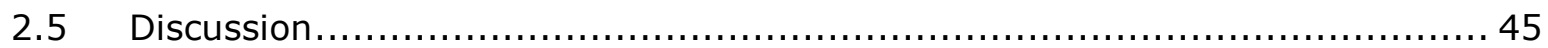

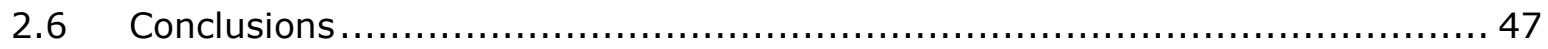

3 Estimating the evaporative water loss of different land use and land cover in the

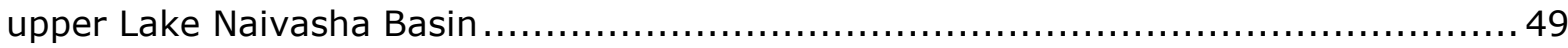

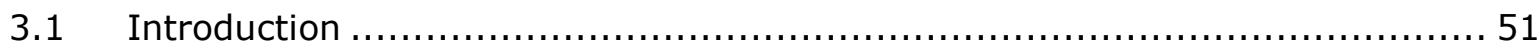

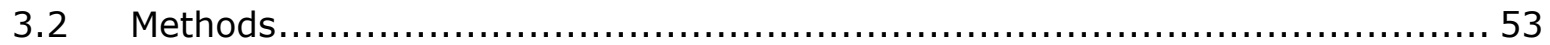

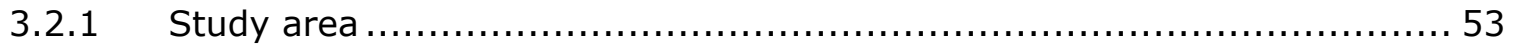

3.2.2 Ground instrumentation and data processing ............................. 54

3.2.3 Remote sensing products and meteorological data .......................... 55

3.2.4 Observed runoff and precipitation data ................................. 56

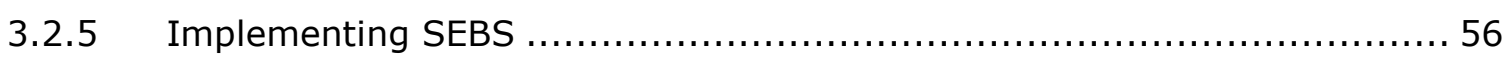

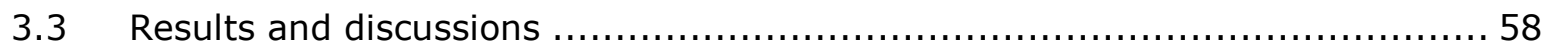

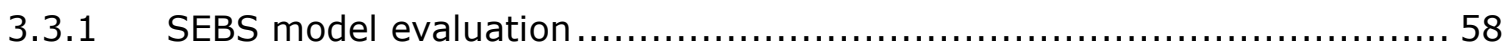

3.3.2 Estimating evaporative water use of different land uses ....................65 


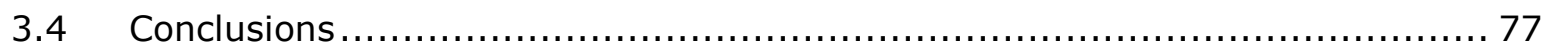
4 Energy partitioning and its controls over a heterogeneous semi-arid Shrubland Ecosystem in the Lake Naivasha Basin, Kenya ........................................... 79

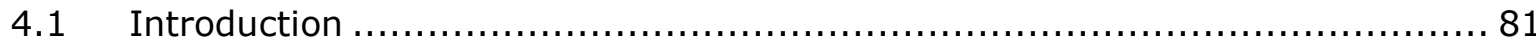

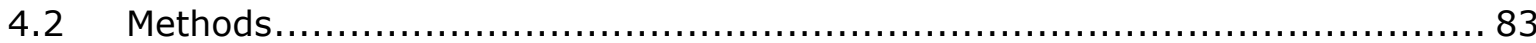

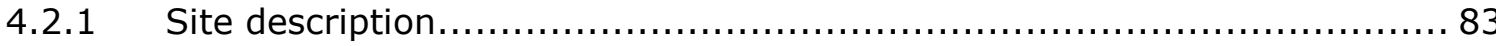

4.2.2 Micrometeorological measurements and data acquisition .................... 85

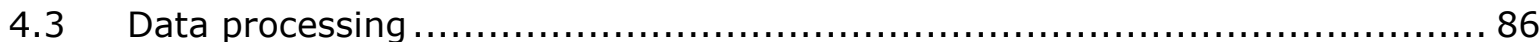

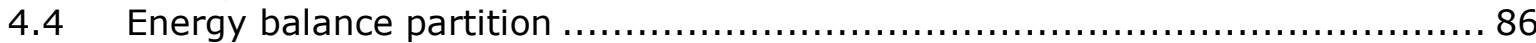

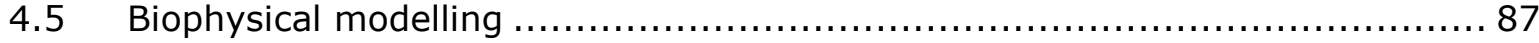

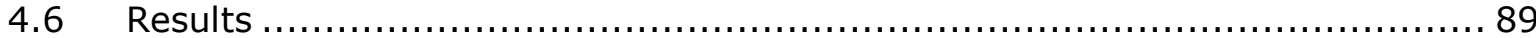

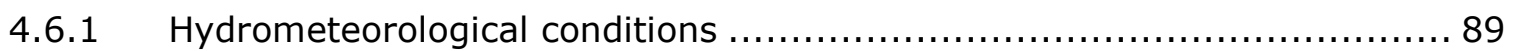

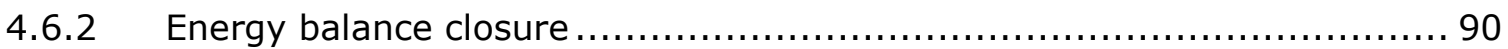

4.6.3 Seasonal variations in energy partitioning and evapotranspiration........... 94

4.6.4 Climatic and biological control of energy partitioning ...................... 101

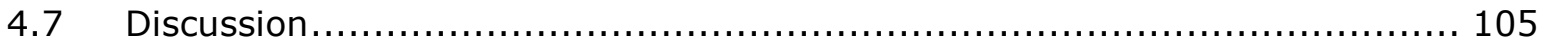

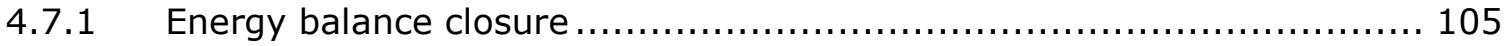

4.7.2 Seasonal changes in energy fluxes and evapotranspiration................ 106

4.7.3 Climatic and biological control of energy partitioning ...................... 110

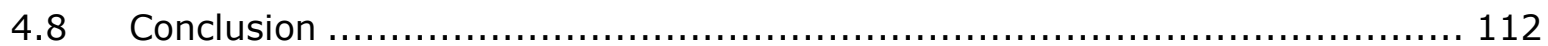

5 Coupling socio-economic factors and eco-hydrological processes using a cascade-

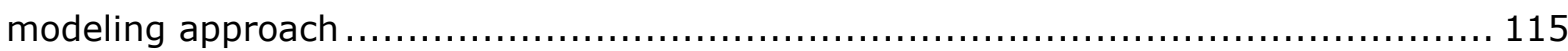

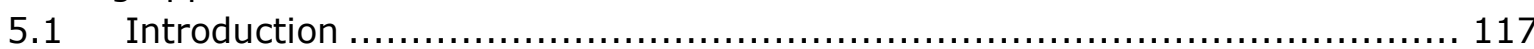

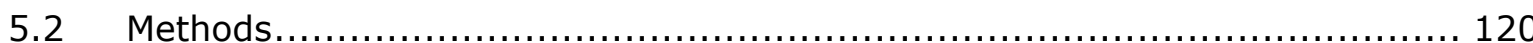

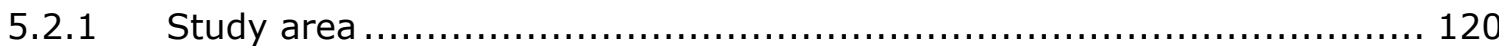

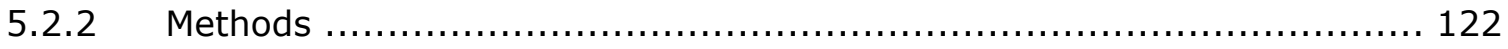

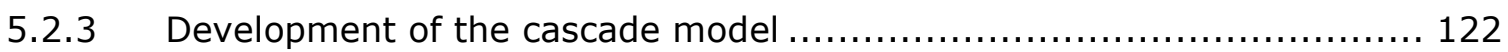

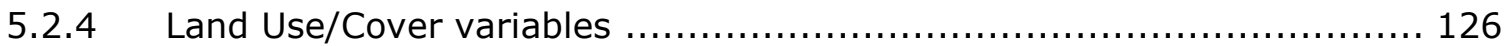

5.2.5 Image classification and accuracy assessment ............................ 126

5.2.6 Socio Economic variables and Pearson correlation ......................... 127

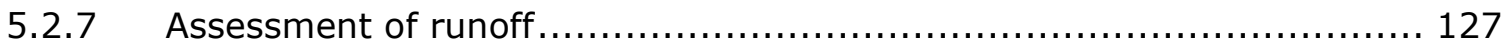

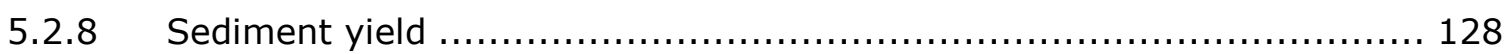

5.2.9 Biodiversity in the fringe zone of the lake............................... 129

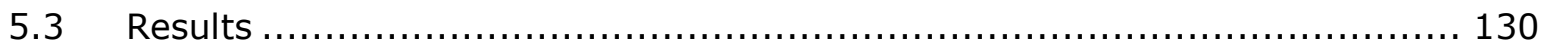

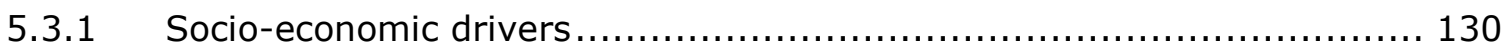

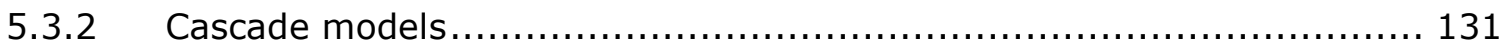

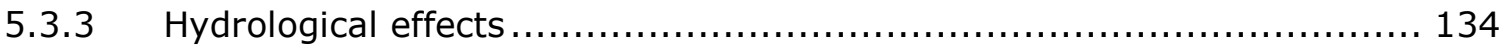

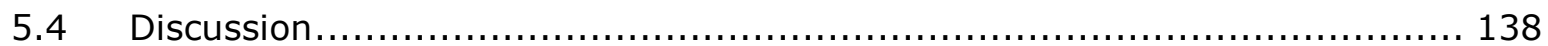

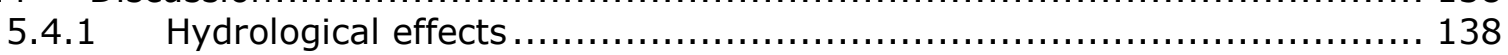

5.4.2 Biodiversity effects: total biomass density of large herbivores mammals 140

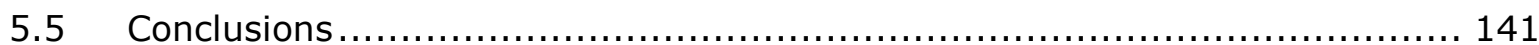

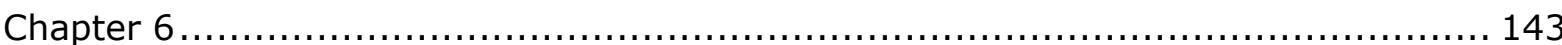




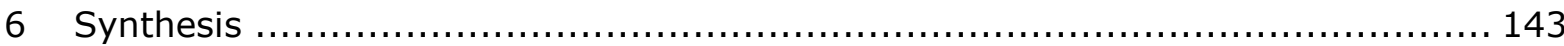

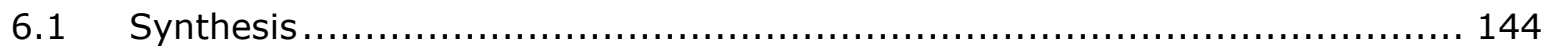

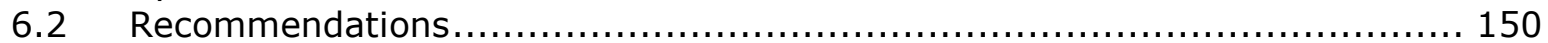

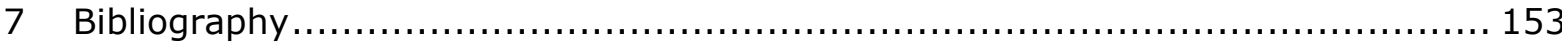

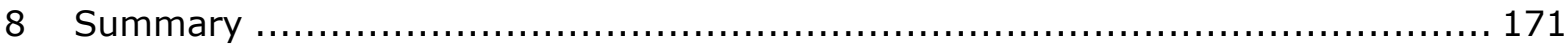

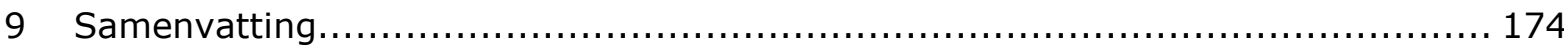

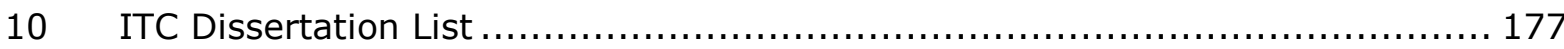

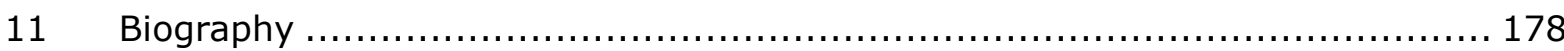




\section{List of figures}

Figure 1-1: Schematization of key indicators of sustainability assessed in the Earth Observation and Integrated Assessment of Lake Naivasha (EOIA) project (van Oel et al.,

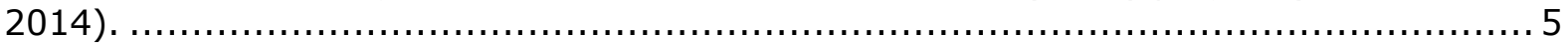
Figure 1-2: Lake Naivasha Basin showing its main rivers and the location of

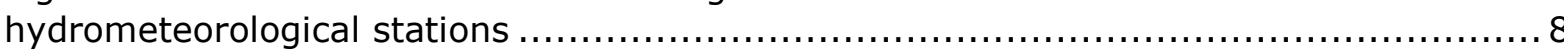
Figure 1-3: Monthly average climatic conditions of temperature and rainfall for Lake

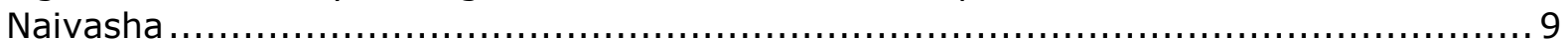

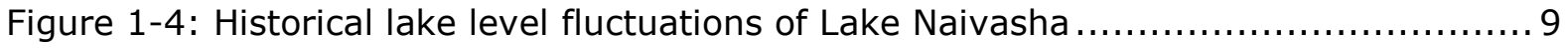
Figure 2-1: Location of Lake Naivasha Basin showing the drainage network including

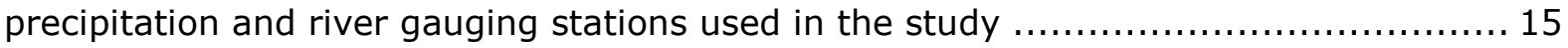
Figure 2-2: Time series of annual water balance components of Lake Naivasha between 1960 and 2010

Figure 2-3: Correlation between observed annual lake volume change and computed annual lake volume change. Where high input flows resulted in small lake volume changes, these were treated as outliers. The thin line represents the regression line fitted to lake volume change data without taking the outliers into consideration ..........28 Figure 2-4: Time series of observed and re-constructed lake volumes...................... 29 Figure 2-5: Annual time series of observed and re-constructed lake volumes.............. 29 Figure 2-6: Sample autocorrelation function of the water balance components: (a) precipitation, (b) runoff volume, (c) evaporation, and (d) lake volume (1960-2010). The dotted lines form the upper and lower confident boundaries at $a=0.05 \ldots \ldots \ldots \ldots \ldots . . . .30$ Figure 2-7: Cross correlation functions (CCFs) comparing the water balance components (a) precipitation (b) runoff volume and (c) evaporation with lake volume change (19602010). The dotted lines form the upper and lower confident boundaries at $a=0.05 \ldots 31$ Figure 2-8: Abrupt shifts (top) and posterior probability distribution (bottom) of the mean, maximum, and minimum annual precipitation, as well as for the months March/April/May/June and the months October/November/December, respectively, at station 9036272 located at the Turasha sub-catchment ................................. 33 Figure 2-9: Abrupt shifts (top) and posterior probability distribution (bottom) of the mean, maximum, and minimum annual runoff, as well as the annual runoff in the months March/April/May/June and the months October/November/December, respectively, for the Gilgil River sub-catchment (at station 2GA03) ....................... 35 Figure 2-10: Posterior probability distribution of abrupt change points of annual (a) observed mean lake volumes and (b) re-constructed lake volumes....................... 36 Figure 2-11: Double cumulative curve for annual precipitation and total outflow of the combined Malewa (at 2GB05) and Turasha (at 2GC04) sub-catchments ................... 37 Figure 2-12: Double mass curve for annual precipitation and minimum outflow of Gilgil

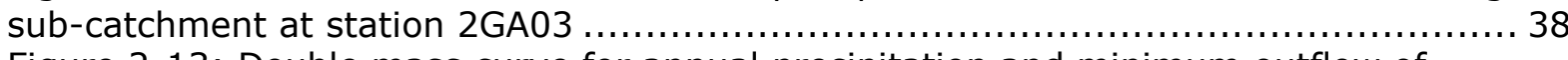
Figure 2-13: Double mass curve for annual precipitation and minimum outflow of Turasha sub-catchment at station 2GC04. Open circles represent cumulative minimum river flows with dam abstraction included. Solid circles represent cumulative minimum river flows as observed without abstractions...

Figure 2-14: Double mass curve of annual lake volume change and total input into the lake. The difference between the $1: 1$ line and the cumulative curve is the cumulative

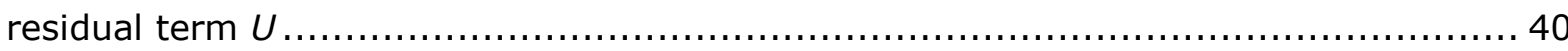
Figure 3-1: Comparison of SEBS performance in simulating monthly fluxes against

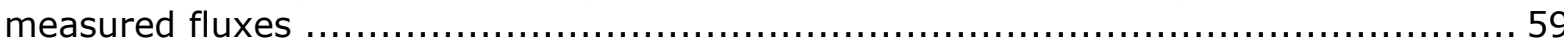
Figure 3-2: Comparison of mean monthly measured air temperature and ECMWF air temperature (left) measured surface temperature and MODIS land surface temperature

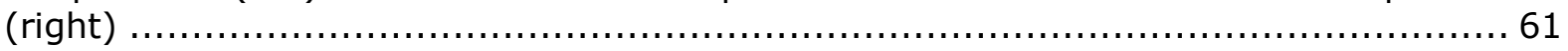


Figure 3-3: Flux footprint analysis following Hsieh et al. (2000) around the flux tower. Under stable conditions the flux footprint was within $5000 \mathrm{~m}$ radius of the tower while during unstable conditions the flux footprint was within $450 \mathrm{~m}$ of the measurement tower.

Figure 3-4: Monthly comparison of sensible heat flux between SEBS simulation and sonic anemometer measurement using ground measured data for 2012 ......................63 63 Figure 3-5: Effect of varying $\mathrm{kB}^{-1}$ on simulated sensible heat flux against measured

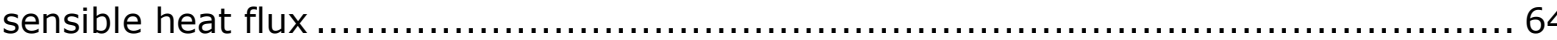

Figure 3-6: Land use/land cover maps in Lake Naivasha Basin ........................... 67

Figure 3-7: Spatial distribution maps of ET in Lake Naivasha Basin ....................... 68 Figure 3-8: Land use/cover changes in the upper Lake Naivasha basin from 2003 to

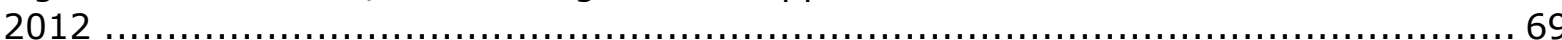

Figure 3-9: Annual trends in evapotranspiration of different land use/cover in upper Lake

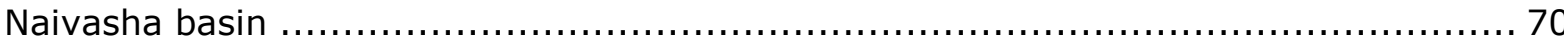
Figure 3-10: Annual trends in LST of the different land use/cover in upper Lake Naivasha

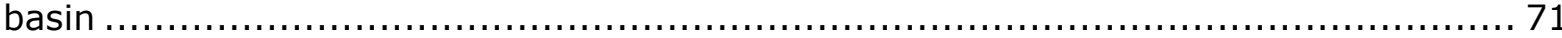

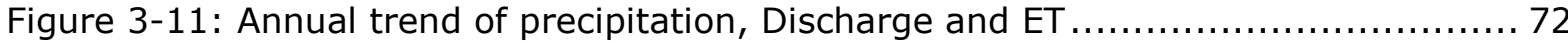
Figure 3-12: Annual trend of ET alongside (a) $R_{n}$ and air temperature (b) difference between air temperature and surface temperature $(\delta \mathrm{T})$ and actual vapor pressure (Ea)

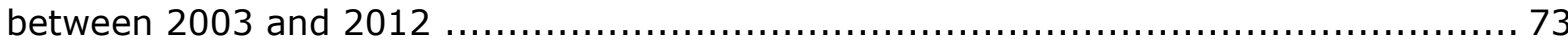
Figure 3-13: Monthly trends of SEBS derived evapotranspiration for dominant land

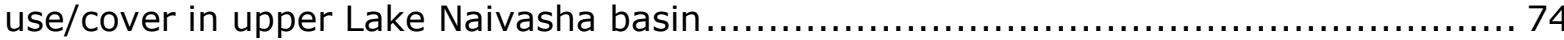

Figure 3-14: Monthly averaged trends of LST, ET and net radiation .................... 75

Figure 3-15: Monthly averaged trends of precipitation, discharge and ET ................ 75

Figure 3-16: Relationship between 10-year monthly averages of $\delta T$ and ET .............. 76

Figure 3-17: Relationship between 10-year monthly averages of net radiation and ET. 76 Figure 4-1: Location of meteorological flux tower in the lake Naivasha Basin .............. 84 Figure 4-2: Summaries of daily (a) total precipitation $(P)$, (b) Volumetric soil water content $(S W C)$ and hourly $(\mathrm{c})$ air temperature $\left(T_{a}\right)$ and $(\mathrm{d})$ vapor pressure deficit $(V P D)$ at $1.8 \mathrm{~m}$ from $1^{\text {st }}$ January 2012 to $31^{\text {st }}$ December 2014 . The black line in $2 \mathrm{c}$ and $2 \mathrm{~d}$ represents the weekly moving average

Figure 4-3: Energy balance closure of 30-min sum of turbulent fluxes (H+LE) against available energy (Rn - Go) for year (a) 2012 (b) 2013 and (c) 2014. The solid line indicates $1: 1$ relationship

Figure 4-4: Comparison of $L E$ estimated using the Bowen ratio method and that measured using the eddy covariance technique during the period the LI-7500 was

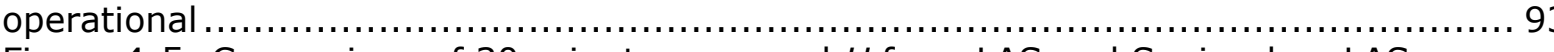
Figure 4-5: Comparison of 30-minute averaged $H$ from LAS and Sonic when LAS was

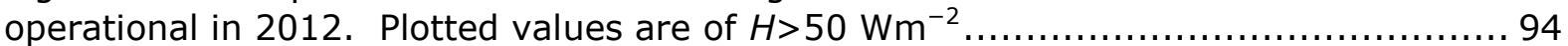
Figure 4-6: Monthly diurnal pattern of energy fluxes of $R_{n}, G_{0}, H, L E$ and $C$ for the period 2012-2014 95 Figure 4-7: Seasonal midday (10:00-14:00 hr) values of the (a) ratio of energy partition of sensible heat flux to net radiation $\left(H / R_{n}\right)$ (b) ratio of energy partition of latent heat flux to net radiation $\left(L E / R_{n}\right)$ (c) Bowen ratio $(\beta)$ from January 2012 to December 2014. The black line is the 4-hr moving average 98 Figure 4-8: Seasonal trend of Priestley-Taylor a coefficient for the period 2012-2014. The black line represents the weekly moving average ................................ 102 Figure 4-9: Relationship between midday (10:00-14:00 h) Priestley-Taylor............. 103 Figure 4-10: Seasonal pattern of (a) MODIS observed and HANTS smoothed LAI trend and midday $(10: 00-14: 00 \mathrm{~h})$ monthly patterns of $(\mathrm{b})$ canopy surface conductance $\left(g_{s}\right)$ (c) decoupling coefficient $(\Omega)$ for the period 2012-2014. 104 
Figure 4-12: The relationship between monthly leaf area index (LAI) and monthly midday surface conductance (gs) ...................................................... 104 Figure 4-12: Relationship between monthly mean canopy conductance, (gs) and mean

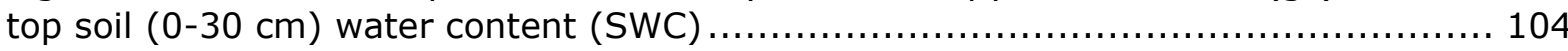
Figure 4-13: The relationship between midday vapor pressure deficit (VPD) and canopy surface conductance ( $g s$ ) during the 3 -year measurement period ......................... 105 Figure 4-14: Average monthly (a) Precipitation (b) Soil water content (c) Net radiation (d) Latent energy flux and (e) sensible heat flux for the 3-year observation period. For ease of comparison with the data from 2012 and 2013, the 2014 wet season period when precipitation, soil water content, net radiation and latent energy flux were lowest is shaded in grey. 108 Figure 4-15: Average monthly (a) Vapor pressure deficit (b) air temperature (c) Bowen ratio during the 3-year observation period. The shaded gray regions highlight the wet season period when vapor pressure deficit, air temperature and Bowen ratio were highest for year 2014 in comparison to year 2012 and 2013.

Figure 5-1: A conceptual framework illustrating a path diagram of a hypothesized cascade model that predicts lake storage change. The links, $r_{1}, r_{2}, r_{3}$ and $r_{4}$ represent the pathways through which factor influences are propagated through entities and

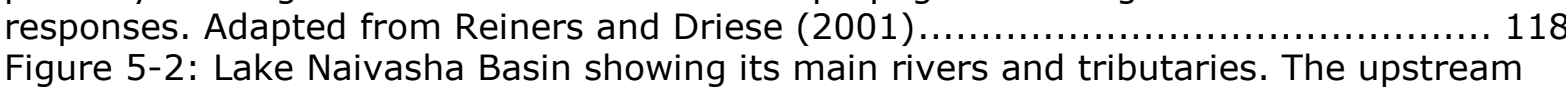
area forms part of the hydrologically active area contributing majority of the flows

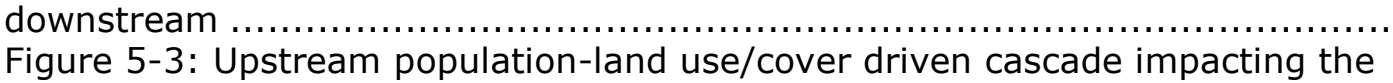
hydrological system of the basin. Upstream population is the main trigger of land use/cover activities that transform the surface for hydrological changes. Precipitation is the exogenous variable that provides water to the transformed surface as runoff. Sedimentation and lake storage are the response of the system due to upstream effects. $+/$ - sign indicate direction of change of the variable or effect............................ 124 Figure 5-4: Downstream cascade driven mainly by horticultural sector and population increase impacting the eco-hydrological system of the basin. Lake precipitation is an exogenous variable that contributes to the lake storage changes and ungulate biomass downstream. Lake levels are exogenous variable that influence Ungulate biomass. Lake storage is the response with flower export volume being the trigger of the system. +/-

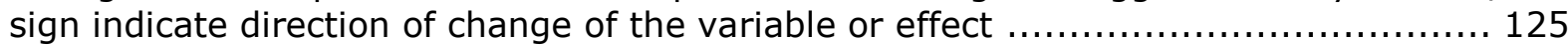
Figure 5-5: Upstream path diagram quantifying the cascade effects of upstream population on hydrological variables. Numbers along the arrows are standardized path correlation coefficients and represent the direct bivariate effect of the two linked variables. Bold and italicized numbers on the edges of effect and response variables represent the multiple correlation coefficients that describe the multivariate strength of the preceding model. Bounding boxes labeled $1 \mathrm{~A}-1 \mathrm{C}$ are the significant cascade models.

Figure 5-6: Downstream horticultural/irrigation driven cascade impacting the lake storage change. The horticultural and irrigation commercial agriculture activities are the main triggers of hydrological changes. Numbers along the arrows are standardized path correlation coefficients and represent the direct bivariate effect of the two linked variables. Bold and italicized numbers on the edges of effect and response variables represent the multiple correlation coefficients that describe the multivariate strength of the preceding model. Bounding boxes labeled 2A-2B are the significant cascade models

Figure 5-7: Total herbivore biomass density for 12 years on ranches adjacent to Lake Naivasha 134 
Figure 5-8: Evolution of annual runoff coefficient for Lake Naivasha Basin between 1960 and 2010

Figure 5-9: Variation of monthly precipitation (left) and direct runoff (right) generation from upstream of Lake Naivasha Basin ............................................... 136 Figure 5-10: Monthly total runoff (left) and lake level change (right) for periods 1 (1960$1985)$ and $2(1985-2010)$ for Lake Naivasha Basin ..................................... 137 Figure 5-11: Temporal changes of land use and land cover in upstream parts of the Lake Naivasha Basin 139

Figure 6-1: Total cloud fraction and aerosol scattering index over Lake Naivasha basin between 1980 and 2016. The two high peaks in 1982 and 1991 of the aerosol scattering index are an influence of the volcanic eruptions of El Chichón and Mt. Pinatubo respectively which released volumes of volcanic dust into the atmosphere that circled the globe weeks after the eruption took place 146 Figure 6-2: Overall trend in the \% deviation of wind speed over Lake Naivasha basin from 1980 to 2015 (relative to the mean value for the period 1980-2015) 148 


\section{List of tables}

Table 1-1: Spatial dimensions of land use impacts on different hydrological components 3 Table 2-1: Overview of the percentage of gaps in data coverage of Lake Naivasha Basin river gauging stations. Stations highlighted in grey indicate the stations with high data coverage $(<20 \%$ gaps) used in this study ................................................. 17 Table 2-2: Year of occurrence and, in brackets, number of abrupt shift points observed for both precipitation and runoff; shading indicates the occurrence of abrupt shifts ..... 32 Table 2-3: Modified MK trend results under STP and LTP assumption for precipitation stations. Significant trends are in bold type and marked with the symbolt 41 Table 2-4 : Modified MK trend results under STP and LTP assumption for discharge stations and lake volumes. Significant trends are in bold type and marked with the symbol +

Table 3-1: Summary of remote sensing and meteorological data used in the study .... 55 Table 4-1: Slope, intercept, $R^{2}$ and the energy balance ratio $(E B R)$ of the half-hourly energy balance closure.

Table 4-2: Table 2: Monthly and annual summaries of energy balance components, equilibrium $L E$ and potential $L E$, and key hydrometeorological factors at the study site 96 Table 4-3: Monthly and annual summaries of energy balance partition, Priestley-Taylor coefficient (a), actual ET, potential ET, and percent of actual ET to potential ET and

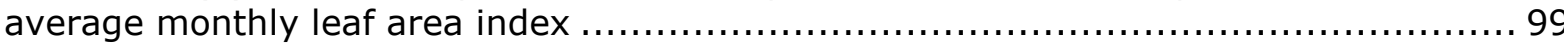
Table 5-1: Detail on the surveyed mammal species and the ranches/blocks ............. 129

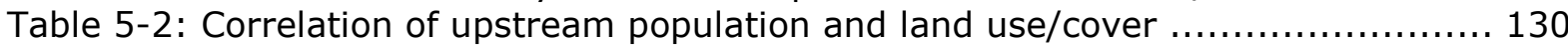
Table 5-3: Table 3: Correlation of downstream population and land use/cover .......... 130 Table 5-4: Chi-square measures of model fit for the significant cascades 
1 Introduction 


\subsection{Background}

Land use/cover and climate are two of the most important factors that determine the hydrological processes of catchments. The impacts of land use/cover on water resources within a catchment depend on both physical and socio-economic factors. Physical factors include climate, geology and topography while socio-economic factors include management practices and infrastructural development as determined by the economic ability and awareness of humans within a catchment (Kiersch, 2001). The scale, spatial and temporal, at which the impacts of land use/cover and climate are observable and relevant, is a recognized fundamental problem in hydrology and subject of on-going research (Archer, 2003; Li et al., 2009; Sivapalan and Kalma, 1995).

Many insights into consequences of land use on hydrology and surface energy balance have been gained at small spatial scales $\left(<100 \mathrm{~km}^{2}\right.$ ) (DeFries and Eshleman, 2004; Kiersch, 2001; Lambin and Geist, 2006; Tollan, 2002). Details of such studies date back to the first catchment experiments conducted between 1908-1920's by Bates (1921) at Wagon Wheel Gap in Southwestern Colorado, US. The experiments evaluated the effects of harvesting on the timing and volume of stream flow, erosion, and sediment (Bates, 1921). Many other catchment experiments have been documented in scholarly articles by a number of researchers (e.g. Andreassian, 2004; Best et al., 2003; Bosch and Hewlett, 1982; Brown et al., 2005; Hibbert, 1967; Zhang et al., 1999).

At larger scales, the observable impacts of land use/cover changes on basin hydrology have been relatively few (e.g. Costa et al., 2003; Siriwardena et al., 2006; Zhang and Schilling, 2006). Nonuniform variations in land uses within catchments, vegetation regeneration at various stages, and spatial and temporal variation in rainfall, are some of the factors that inhibit consistent conclusions from large catchments (Archer, 2003; Siriwardena et al., 2006). Specifically, as the scale of the basin increases so has been the increased mixed effects of climate and land use/cover changes at these scales making it difficult to discriminate the influence of land use/cover changes from that of climate (van Dijk et al., 2012). As an example, the spatial dimensions of land use impacts on hydrological responses are summarised in Table 1-1. 
Table 1-1: Spatial dimensions of land use impacts on different hydrological components

\begin{tabular}{l|cccccc}
\hline \multirow{2}{*}{ Impact } & \multicolumn{7}{c}{ Basin size $\left(\mathrm{km}^{2}\right)$} \\
\cline { 2 - 6 } Average flow & 0.1 & 1 & 10 & 100 & 1000 & $\geq 10000$ \\
Peak flow & $\times$ & $\times$ & $\times$ & $\times$ & $\bullet$ & $\bullet$ \\
Base flow & $\times$ & $\times$ & $\times$ & $\times$ & $\bullet$ & $\bullet$ \\
Groundwater recharge & $\times$ & $\times$ & $\times$ & $\times$ & $\bullet$ & $\bullet$ \\
Sediment load & $\times$ & $\times$ & $\times$ & $\times$ & $\bullet$ & $\bullet$ \\
Nutrients & $\times$ & $\times$ & $\times$ & $\times$ & $\bullet$ & $\bullet$ \\
Organic matter & $\times$ & $\times$ & $\times$ & $\times$ & $\times$ & $\bullet$ \\
Pathogens & $\times$ & $\times$ & $\times$ & $\times$ & $\bullet$ & $\bullet$ \\
Salinity & $\times$ & $\times$ & $\times$ & $\bullet$ & $\bullet$ & $\bullet$ \\
Pesticides & $\times$ & $\times$ & $\times$ & $\times$ & $\times$ & $\times$ \\
Heavy metals & $\times$ & $\times$ & $\times$ & $\times$ & $\times$ & $\times$ \\
Thermal regime & $\times$ & $\times$ & $\times$ & $\times$ & $\times$ & $\times$ \\
\hline
\end{tabular}

Legend: $\times$ : Observable impact; $\bullet$ : No observable impact. Source: Kiersch (2001)

Though hydrological impacts of land use change and climate variation occur at all spatial scales, studies at regional and local scales are more relevant to provide important information to local socio-economic developments and basin management where political and technical decisions can be taken to avoid critical developments that impact negatively on the environment and society (Jin et al., 2009; Lahmer et al., 2001). Ascertaining the combined effect of land use/cover and climate variability due to non-linear relationships, multiple causation, lack of mechanistic understanding of hydrologic response of catchments and lag effects together pose major research challenges (Allan, 2004a; Jin et al., 2009; Tollan, 2002). Distinguishing effects of land use changes from concurrent climate variability are expected to increase in importance as human induced socio-economic influence on catchments intensifies (Jiafu et al., 2015; Lioubimtseva et al., 2005; Tollan, 2002).

To evaluate and distinguish these effects there is need for long term data records for catchments. These long-term hydro-meteorological data series exhibit non-stationarity caused by perturbations which give insight in catchment sensitivity and which are important for strategic planning and risk aversion in water resources management for catchments. The availability of long-term records of hydro-meteorological data allows for detection of changes in the river systems. Subsequently, possible factors that influence the detected changes can be determined. The detection of these changes is of scientific and practical importance in water resource management and is regarded as 
a permanent exercise requiring continuous update, concurrently with availability of data (Kundzewicz, 2004; Kundzewicz and Robson, 2004). The problem is, however, that the time scale of some of the changing processes may be a realization of other overlapping processes occurring at much larger time scales.

While high temporal and spatial variability of hydrologic responses to land use changes are well recognized (Andreassian, 2004; Tollan, 2002), nearly all the classical paired catchment experiments have been conducted on catchments with homogenous land use (Costa et al., 2003; Lørup et al., 1998). The land use changes have also been at least more than $20 \%$ in areal extent in the catchment experiments, the generally assumed threshold value that changes in water fluxes can be detected by hydrometric measurements (Bosch and Hewlett, 1982; Brown et al., 2005; Stednick, 1996; Wang et al., 2009). In larger catchments with mixed land cover and with small proportional land use changes, it is more difficult to quantify the hydrological responses to land use changes. A challenge persists that has made human-induced land use changes at large basins not to be well understood (Bruijnzeel, 2004; DeFries and Eshleman, 2004; Lørup et al., 1998).

It is also important to note that analyses of land use and climate impacts on basin hydrology are usually critically dependent on methodology and different approaches have been reported in the literature. These approaches can be categorised into three groups: paired catchment approach, time series analysis and hydrological modelling. Paired catchment approaches are often considered ideal because they compensate for climatic variability in small experimental catchments (Jin et al., 2009). However, the method is practically impossible to apply in medium or large catchments, because of the difficulty in finding two similar medium or large-sized catchments (Lørup et al., 1998). Time series analysis is a statistical method that is simple to implement because hydrological effects of environmental change can be analysed without considering the physical mechanisms controlling catchment hydrological processes. This is contrary to hydrological models that provide a framework to conceptualize and investigate relationships between land use, climate and water resources because they relate model parameters directly to physically observable land surface processes (Jothityangkoon et al., 2001; Leavesley, 1994; Legesse et al., 2003).

Furthermore, data constraints especially in Sub-Saharan Africa have also hampered progress towards understanding the effects of land use and climate on hydrological responses in much of these regions. Since land use changes mirror the impacts of human activities (Houghton et al., 1999; Schneider and Eugster, 2005), it is also necessary to identify mechanisms that translate these human perturbations into structural and functional changes that are important in informing on socio-economic decisions of management and conservation of catchments (Burcher et al., 
Chapter 1 2007). Identifying such mechanisms extends our understanding of the associated trigger factors that allow for informed management of such systems.

\subsection{Integrated assessment of Lake Naivasha Basin}

This thesis is part of Earth Observation and Integrated Assessment of Lake Naivasha basin (EOIA) project. The project focuses on use of Earth Observation (EO) and derivative geo-information tools to overcome socio-economic inequity in a collaborative stakeholder setting. The innovation applied couples EO via individual models to Integrated Assessment. The project aimed at combining information from EO with standard secondary data, to allow for physical and social analyses necessary to allow stakeholders deliberate about their common future. The scientific tool applied a system description based on an Integrated Assessment (IA) that aimed at integrating knowledge over a range of relevant disciplines (Figure 1-1), with the aim of providing new information on how complex real-world systems might behave, thus enabling sound decision-making (van Oel et al., 2014). Cross-sectoral implications that might be missed in more traditional assessments can therefore be more explicitly explored in ways that are meaningful to stakeholders.
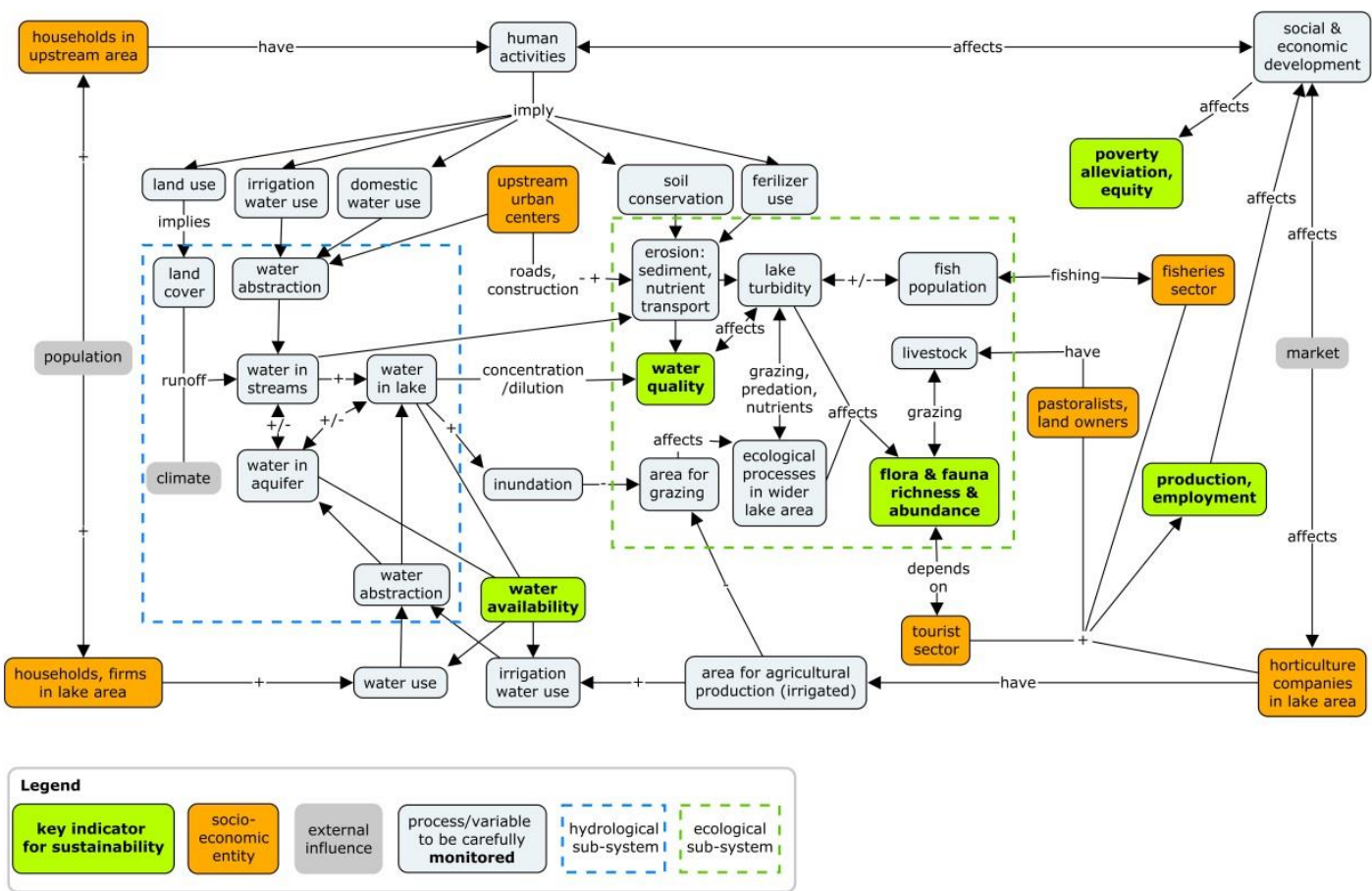

Figure 1-1: Schematization of key indicators of sustainability assessed in the Earth Observation and Integrated Assessment of Lake Naivasha (EOIA) project (van Oel et al., 2014). 


\subsection{Problem statement}

Impacts of land use changes on hydrology are well understood at small scale studies. However, observable changes at larger scales are compounded by mixed effects of climate and land use/cover changes in addition to counteracting processes in other parts of the catchment to warrant any conclusive generalizations. As such, the problem of scale remains unresolved and a subject of ongoing research in understanding the impacts of land use and climate on catchment hydrological processes. Archer (2003) explains that at small scales, processes such as interception, infiltration and storage dominate whereas channel processes assume a greater role in the stream hydrograph as the catchment size increases. It is also important to understand the influence of land cover (e.g. surface conductance and leaf area seasonality) and climatic factors (e.g. radiation, air temperature and vapour pressure) that determine water demand and control evapotranspiration patterns during wet and dry conditions at the local to catchment scales. While dominance of different processes varies at different spatial scales, there is also variation with time scale. Certain processes maybe a realization of other overlapping processes prevailing at much larger time scales. Also, the question of how socio-economic factors influence land use and the subsequent impacts on hydrological systems remain largely unknown especially in tropical basins.

Lake Naivasha is an example of such a tropical basin which has been subject to wide fluctuations of water levels over time and has almost dried in the past years (Abiya, 1996; Gaudet, 1977a; Verschuren et al., 2000). Increasing water demand and land use changes exacerbated by population increase in combination with natural fluctuations have been suggested as possible causes of the occasional strong decreases of the lake water levels (Olaka et al., 2010; Ondimu and Murase, 2007; Otiang'a-Owiti and Oswe, 2007; Trauth et al., 2010). However, the problem in attributing the causes of these fluctuations to climate and/or land use has not been resolved and there is a lack of knowledge in understanding (1) the contribution of drivers of land use and land cover changes to the hydrological processes of the basin,.(2) the spatial and temporal scale at which the changes in land use and hydrological fluxes occur and also (3) the land use and climatic factors that determine water demand and control the seasonal evapotranspiration demand at the local to catchment scales. Therefore, studies towards understanding hydrological processes at the local and catchment scales as influenced by humans, on land use as well as climate, are relevant towards providing important information on local socio-economic developments and basin management strategies. 


\subsection{Objectives}

The main aim of this thesis was to quantify the impacts of climate and land use on the hydrological response of Lake Naivasha Basin and identify controlling factors prevailing at different observable scales (at local site and catchment spatial scale; and at short and long term time scales)

The specific objectives of this study were;

- To detect long-term monotonic trends and step (abrupt) changes in stream flow, lake volumes and precipitation resulting from climatic fluctuations and land use changes

- Evaluate the evapotranspiration trend of the different land use/cover classes in the upper Lake Naivasha and its climatic controls

- Evaluate the energy balance and partitioning of a heterogeneous landscape and identify the biophysical and climatic controlling factors

- Investigate the impacts of socio-economic factors on eco-hydrological regime of Lake Naivasha Basin

\subsection{Description of study area}

The Lake Naivasha basin is situated in the Kenyan Rift Valley at a latitude of $0^{\circ} 09^{\prime}$ to $0^{\circ} 55^{\prime} \mathrm{S}$ and a longitude of $36^{\circ} 09^{\prime}$ to $36^{\circ} 24^{\prime} \mathrm{E}$ (Figure 1-2). The maximum altitude is about $3990 \mathrm{~m}$ above mean sea level (a.m.s.I.) on the eastern side of the Aberdare Mountains and the minimum altitude about $1980 \mathrm{~m}$ a.m.s.l. near the lake. The basin area is approximately $3400 \mathrm{~km}^{2}$ in size, with the lake area covering approximately $169 \mathrm{~km}^{2}$. There are three major sub-basins, i.e. Gilgil, Malewa and Turasha. The Turasha sub-basin has been dammed up and supplying an average of 18000 $\mathrm{m}^{3} \mathrm{~d}^{-1}$ of water to outside the Lake Naivasha basin since 1992 (Nakamura et al., 2001).

Climatic conditions in the study area vary due to considerable differences in altitude and relief. The daily average temperature ranges from 8 to $30^{\circ} \mathrm{C}$. The rainfall regime within the catchment is influenced by local relief, with the catchment being in the rain shadow of the Aberdare Mountains to the East and the Mau Escarpment to the West. There are two rainy seasons: the 'long rains' occur between March and June (MAMJ) and the 'short rains' between October and December (OND). Annual lake levels are mostly influenced by these two rainy seasons (Vincent et al., 1979). On average the low land areas towards and near the lake experience an annual total rainfall of 610 $\mathrm{mm}$ and the wettest slopes of the Aberdare Mountains receive up to $1525 \mathrm{~mm}$ of rain a year. Figure 1-3 shows the monthly variation in climatic conditions around Lake Naivasha. 
Chapter 1

Increasing water demand and land use changes exacerbated by population increase in combination with natural fluctuations (Figure 1-4) have led to occasionally strong decreases of the lake water levels (Olaka et al., 2010; Ondimu and Murase, 2007; Otiang'a-Owiti and Oswe, 2007; Trauth et al., 2010). Low lake levels made the lake ecosystem vulnerable and its fragility is a challenge to conservationists and scientists (Becht and Harper, 2002; Becht et al., 2006; Gherardi et al., 2011; Harper and Mavuti, 2004; Harper et al., 2011). The lake is a RAMSAR wetland (Ramsar, 1996) despite supporting important economic activities including fishing, agriculture, power generation, domestic water supply and tourism (Becht et al., 2005). The catchment population has increased five folds from $\sim 250,000$ persons in 1980 to over 600,000 persons in 2009 (KNBS, 2009). The demand for water by the horticultural sector and the growing population have recently increased substantially (van Oel et al. 2013), and at the same time land-use changes have affected the water balance and put the ecosystem under pressure (Otiang'a-Owiti \& Oswe, 2007).

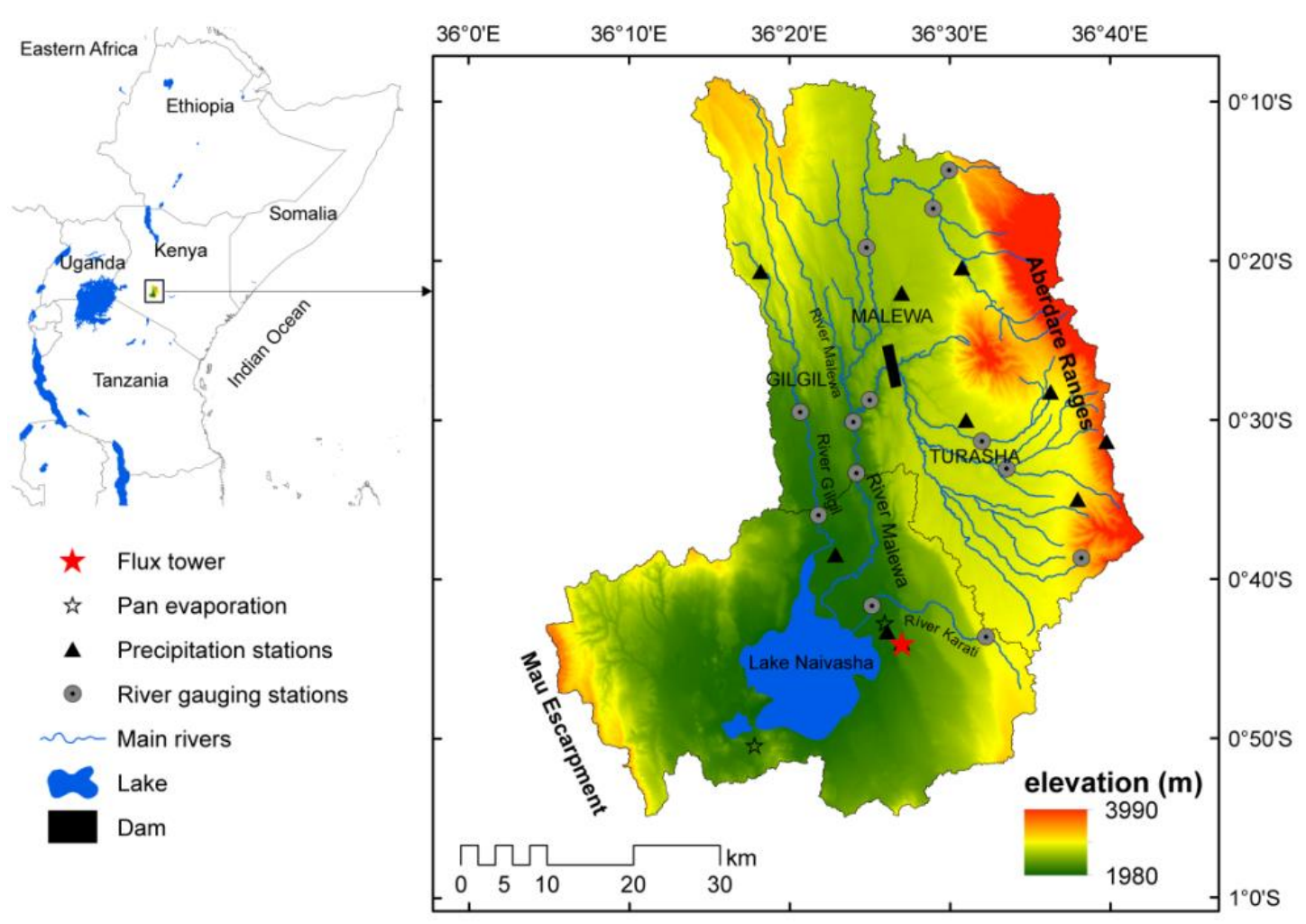

Figure 1-2: Lake Naivasha Basin showing its main rivers and the location of hydrometeorological stations 


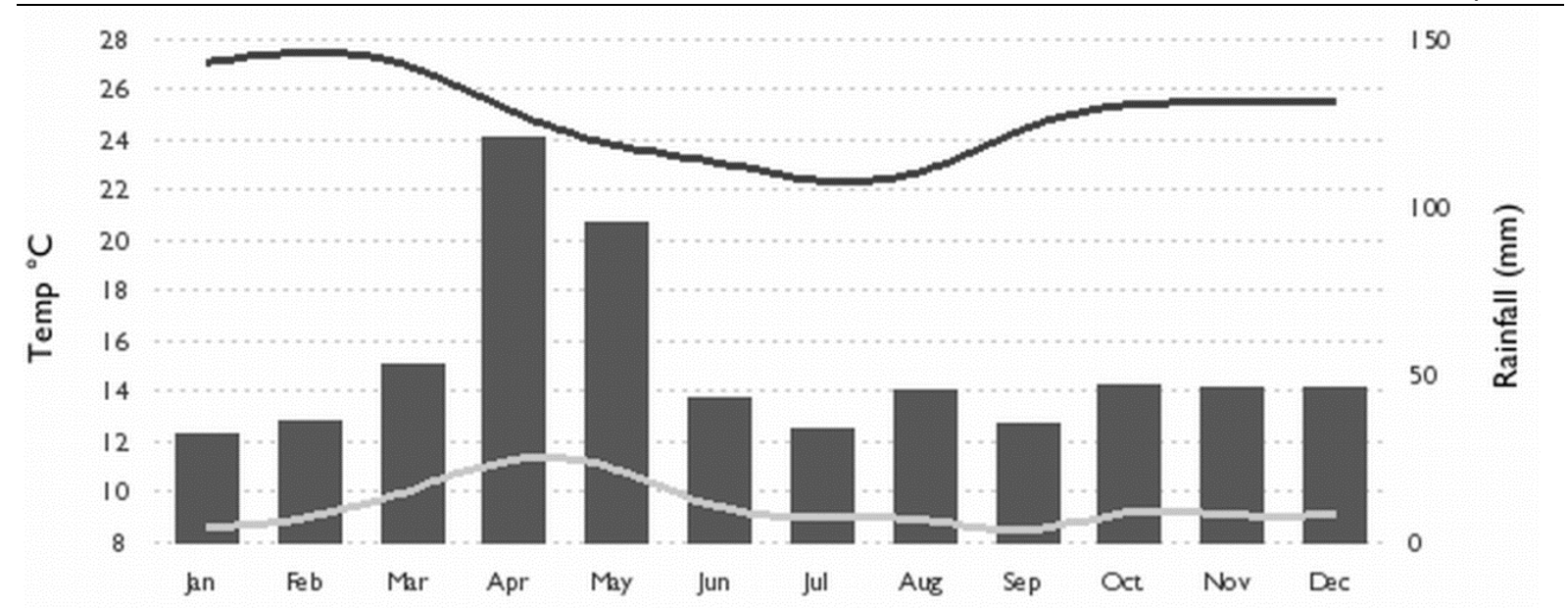

Rainfall Min. Temp Max. Temp.

Figure 1-3: Monthly average climatic conditions of temperature and rainfall for Lake Naivasha

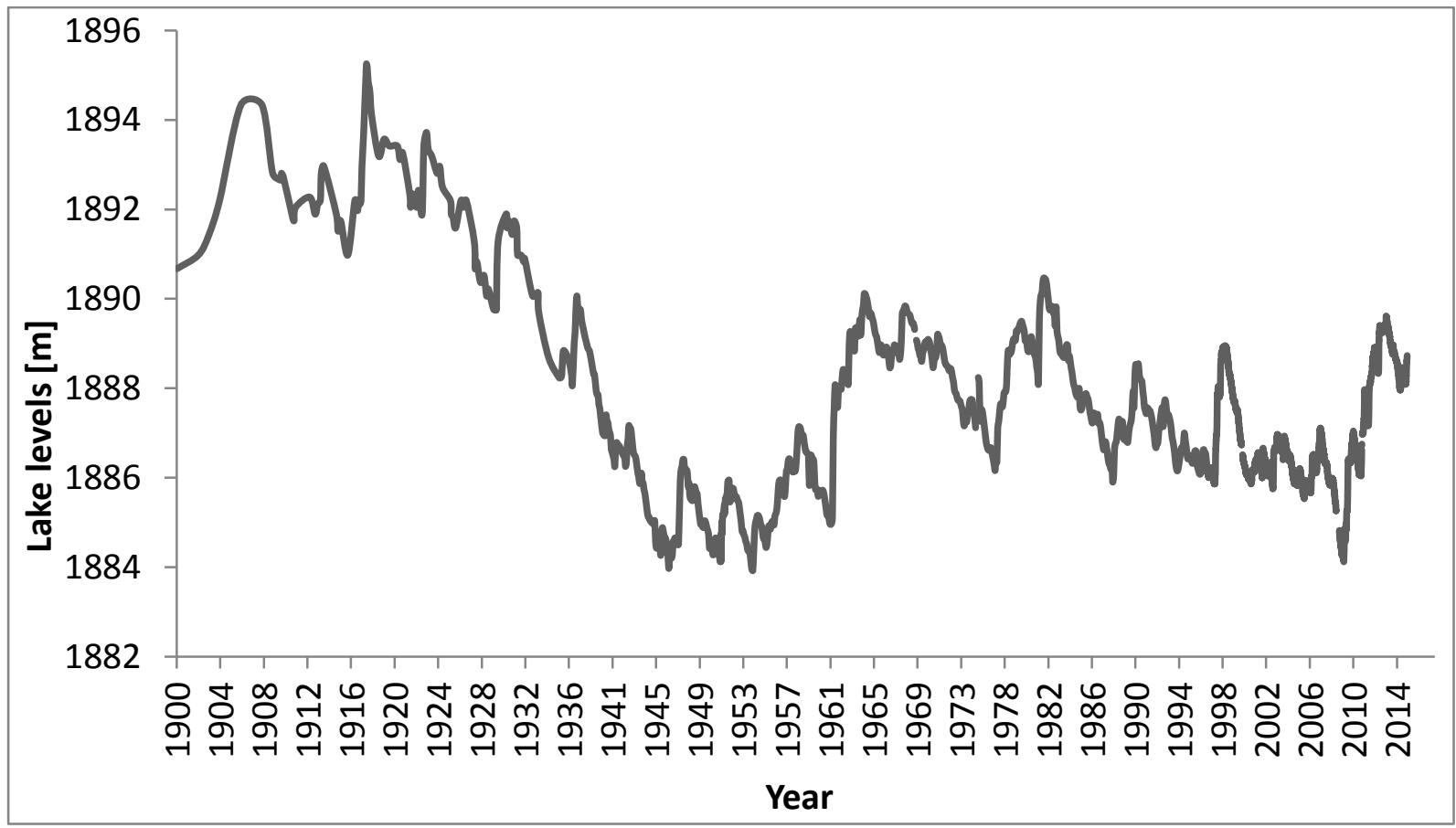

Figure 1-4: Historical lake level fluctuations of Lake Naivasha 


\subsection{Thesis outline}

This thesis consists of six chapters. Chapter one introduces the scientific background and provides statement of the problem, description of the study area and defines the research objectives.

Chapter two investigates the possible existence of abrupt changes and trends in the water balance components of the Lake Naivasha basin caused by either human or natural factors.

Chapter three evaluates the evaporative losses of different land use and land cover classes, their trends and climatic controls in Lake Naivasha basin using the Surface Energy Balance System (SEBS) in combination with Moderate-resolution Imaging Spectroradiometer (MODIS) and European Centre for Medium-Range Weather Forecasts (ECMWF) Interim Re-Analysis (ERAInterim) data.

Chapter four evaluates the energy balance and partitioning of a heterogeneous semi-arid landscape in the lower part of Lake Naivasha Basin to identify the biological and environmental factors that control the seasonal and interannual energy partitioning of this ecosystem.

Chapter five presents a framework for quantifying the impacts of socio-economic factors on ecohydrological regime of Lake Naivasha Basin using a cascade modelling approach.

Chapter Six presents a synthesis of the findings from the research work and the concluding remarks and discusses future research directions. 


\section{A characterisation of hydro-climatological trends and variability in the Lake Naivasha Basin, Kenya*}

\footnotetext{
${ }^{*}$ This chapter is based on:

Odongo, V. O., van der Tol, C., van Oel, P. R., Meins, F. M., Becht, R., Onyando, J. O., \& Su, Z. (2015). Characterisation of hydroclimatological trends and variability in the Lake Naivasha basin, Kenya. Hydrological Processes, 29(15), 3276-3293. doi:10.1002/hyp.10443
} 


\begin{abstract}
Recent hydro-climatological trends and variability characteristics were investigated for the Lake Naivasha Basin with the aim of understanding the changes in water balance components and their evolution over the past 50 years. Using Bayesian change point analysis proposed by Barry and Hartigan (1993) and modified Mann-Kendall tests time series of annual mean, maximum, minimum, and seasonal precipitation and flow, as well as annual mean lake volumes were analyzed for the period 1960-2010 to uncover possible abrupt shifts and gradual trends. Double cumulative curve analysis was used to investigate changes in hydrological response attributable to either human influence or climatic variability. The results indicate a significant decline in lake volumes at a mean rate of $9.35 \times 10^{6} \mathrm{~m}^{3} \mathrm{year}^{-1}$. Most of the river gauging stations showed no evidence of trends in the annual mean and maximum flows as well as seasonal flows. Annual minimum flows, however, showed abrupt shifts and significant (upward/downward) trends at the main outlet stations. Precipitation in the basin showed no evidence of abrupt shifts, but a few stations showed gradual decline. The observed changes in precipitation could not explain the decline in both minimum flows and lake volumes. The findings show no evidence of any impact of climate change for the Lake Naivasha basin over the past 50 years. This implies that other factors, such as changes in land cover and infrastructure development, have been responsible for the observed changes in stream flow and lake volumes.
\end{abstract}

Key words: Bayesian change point, trend detection, Double mass curve analysis, modified Mann Kendall, Lake Naivasha Basin 


\subsection{Introduction}

The unique endorheic basins in the East African Rift Valley are known to be sensitive to perturbations in hydro-climatological conditions (Harper et al., 1990; Olaka et al., 2010). For example, the salinity, ecology and water levels of the lakes are sensitive to inflows, and increasing stream flow may lead to increased sediment and nutrient discharge downstream, affecting the ecology of the lakes (Odongo et al., 2013).

Lake Naivasha is one of the East African Rift Valley lakes that has experienced increased economic activity and water demand (Odongo et al., 2014; van Oel et al. 2013), as well as land cover changes and dam construction in the upper parts of the basin. In addition, the lake may have been affected by long-term changes in the local climate (Olaka et al., 2010). The lake is an endorheic basin of critical importance listed under the RAMSAR wetland convention (Ramsar, 1996). Lake levels have been fluctuating notably, showing an overall decline over the past century (Becht and Harper, 2002). Attempts to understand the causes and impacts of the decline have been subject of debate among scientists and water managers (van Oel et al., 2014).

Like other hydro-climatological variables, the lake level changes are stochastic, and may exhibit non-stationarity. The understanding of the non-stationarity in hydro-climatological data caused by perturbations is important for water resources management, since it provides insight in the sensitivity of catchments, which is relevant for strategic planning and risk aversion. This is certainly the case in the Lake Naivasha basin, where development of water systems, such as dam construction, has taken place (Lins and Cohn, 2011).

A way of looking at this statistically is to analyze two forms of non-stationarity: (1) Estimating a trend by fitting a linear function to the data and (2) Examining evidence of abrupt changes caused by a significant shift in the mean of the observed data. Numerous studies have investigated the presence of trends and variability in hydro-climatological data (e.g. Ehsanzadeh and Adamowski, 2010; Ehsanzadeh et al., 2011; Hamed, 2008; Hamed and Rao, 1998; Khaliq et al., 2009; Kumar et al., 2009; Markovic and Koch, 2013). A number of these studies have attributed the existence of trends to climate change (Burn, 1994; Ehsanzadeh and Adamowski, 2010).

The problem with trend detection is that whether or not statistical significance is found depends on the hypothesis regarding the stochastic nature of the process (e.g. von Storch and Zwiers, 1999). Cohn and Lins (2005) also noted this concern and stated that "from a practical standpoint it may be preferable to acknowledge that the concept of statistical significance is meaningless when discussing poorly understood systems". While it is generally assumed that non-stationary behavior 
Chapter 2

follows a monotonic (unidirectional) trend and/or an abrupt shift, much of the trend could just be a realization of a wider window in which observations occur (Koutsoyiannis, 2006). Consequently, any statistical interpretation may change when the window of observation is widened (Cohn and Lins, 2005; Hamed, 2008; Koutsoyiannis, 2002; Koutsoyiannis, 2003).

Interacting physical processes may cause short and long term persistence of the time series. The interdependence of consecutive hydrological observations may prevail at shorter time scales (smaller windows), leading to past flows correlating closely with present flows (Koutsoyiannis, 2006). This correlation behavior is known as short-range memory or short-term persistence (STP), defined as the situation where the autocorrelation of a variable declines exponentially with time (Koutsoyiannis, 2005). For large timescales (larger windows) another form of dependency exists, known as long term persistence (LTP) (Koutsoyiannis, 2005; Koutsoyiannis, 2006). This behavior is also known as the "Hurst Phenomenon" after Hurst (1951) and refers to the tendency of wet years to cluster into wet periods and dry years to cluster into dry periods. It has been suggested that LTP occurs in many natural processes (Koutsoyiannis, 2002). Not accounting for LTP in trend analysis of hydro-climatological time series data has been shown to lead to incorrect conclusions regarding the causes of the variations, which has consequences for the decision making in water resources management (Hamed, 2008; Hamed and Rao, 1998; Khaliq et al., 2009). Integrating the LTP assumption enables accurate determination of the nature and causative forces of nonstationary behavior of hydro-climatological records (Ehsanzadeh et al., 2012; Koutsoyiannis, 2006). In the case of the Lake Naivasha basin, water balance components that may be attributed to the decline in the lake volumes over the past 50 years have not been studied.

In this chapter, therefore, the water balance components of the Lake Naivasha basin were analyzed for presence of trends. Specifically, the study aimed at investigating the possible existence of (a) abrupt changes, and (b) trends in rainfall, inflows, and volumes of the lake in Lake Naivasha basin caused by either human or natural factors.

\subsection{Study area and data}

The Lake Naivasha basin is situated in the Kenyan Rift Valley at a latitude of $0^{\circ} 09^{\prime}$ to $0^{\circ} 55^{\prime} \mathrm{S}$ and a longitude of $36^{\circ} 09^{\prime}$ to $36^{\circ} 24^{\prime} \mathrm{E}$ (Figure 2-1). The maximum altitude is about $3990 \mathrm{~m}$ above mean sea level (a.m.s.I.) on the eastern side of the Aberdare Mountains and the minimum altitude is about $1980 \mathrm{~m}$ a.m.s.l. near the lake. The basin area is approximately $3500 \mathrm{~km}^{2}$ in size, with the lake area covering approximately $169 \mathrm{~km}^{2}$. There are three major sub-basins, i.e. Gilgil, Malewa and Turasha. Since 1992 a dam constructed in Turasha sub-basin has been supplying an average 
Chapter 2 of $1.8 \times 10^{3} \mathrm{~m}^{3} \mathrm{~d}^{-1}\left(\sim 6.6 \times 10^{6} \mathrm{~m}^{3} \mathrm{y}^{-1}\right)$ of water to Lake Nakuru basin, which is outside the Lake Naivasha basin (Nakamura et al., 2001).

Climatic conditions in the study area vary due to considerable differences in altitude and relief. The daily average temperature ranges from 8 to $30{ }^{\circ} \mathrm{C}$. The rainfall regime within the catchment is influenced by local relief, with the catchment being in the rain shadow of the Aberdare Mountains to the East and the Mau Escarpment to the West. There are two rainy seasons: the 'long rains' occurring between March and June (MAMJ) and the 'short rains' which occur between October and December (OND). Annual lake levels are mostly influenced by these two rainy seasons (Vincent et al., 1979). On average the low land areas towards and near the lake experience an annual total rainfall of $610 \mathrm{~mm}$ and the wettest slopes of the Aberdare Mountains receive up to $1525 \mathrm{~mm}$ of rain a year. Figure 1-3 shows the monthly variation in climatic conditions over Lake Naivasha basin.

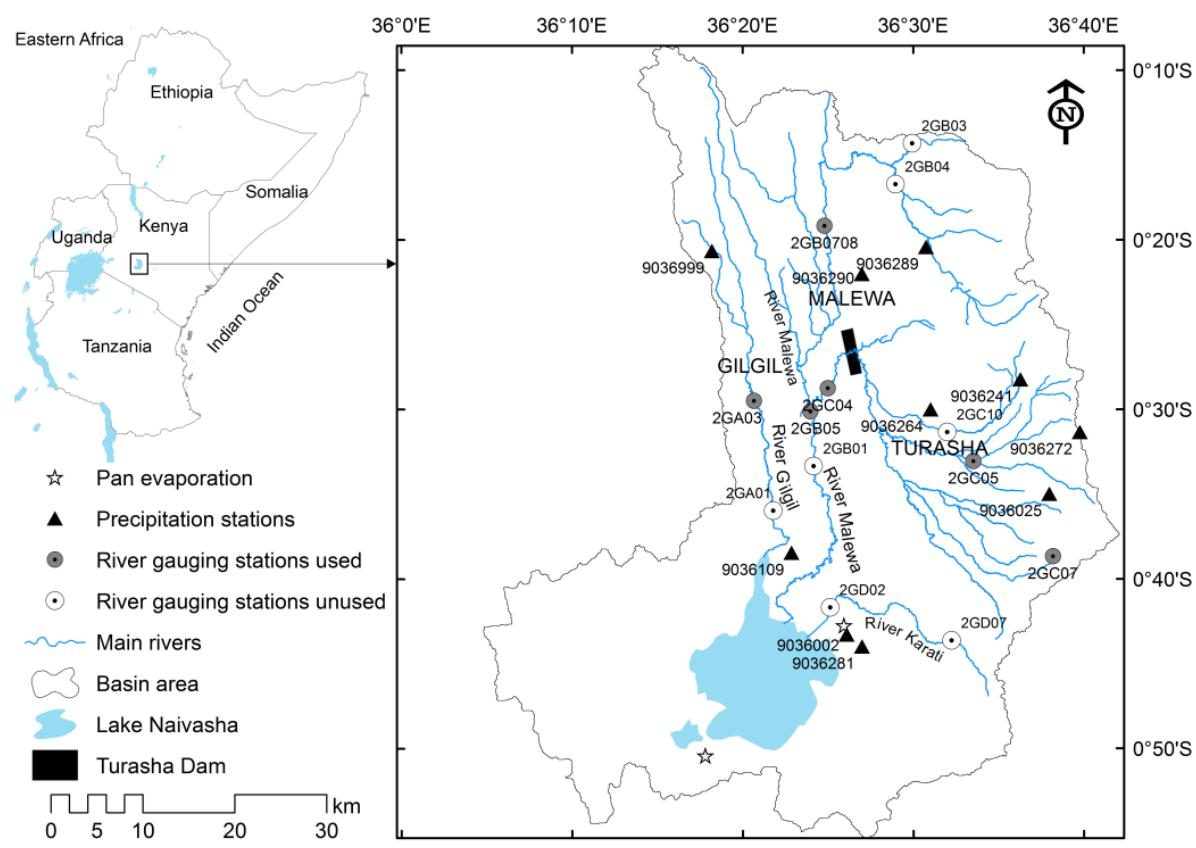

Figure 2-1: Location of Lake Naivasha Basin showing the drainage network including precipitation and river gauging stations used in the study

Stream flow data from three major sub-catchments of the Naivasha Basin were obtained from the Water Resources Management Authority (WRMA) of Kenya. Most of the gauging stations (Figure 2-1) started recording flow levels consistently from around 1960 onwards. Water level 
Chapter 2

readings were converted into discharges $\left(\mathrm{m}^{3} \mathrm{~s}^{-1}\right)$ using rating curves based on high flow and low flow measurements performed by the WRMA and its predecessors between 1958 and 2010 . Subsequently, six river gauging stations (Table 2-1) that had less than $20 \%$ missing data were considered in this study after filling for the missing data following the method of Hughes and Smakhtin (1996).

Precipitation data were obtained from the Kenya Meteorological Department (KMD). Ten key rainfall stations within the basin that had data from 1957 to 2010 were chosen for this study (Figure 2-1).

Pan evaporation near the lake was monitored from 1958 to 1990 by the Ministry of Water of Kenya. After 1990 the monitoring was discontinued. However, Oserian flower farm weather station closest to the lake started pan evaporation monitoring in 1991. All pan evaporation data were multiplied by a pan coefficient of 0.8 (Ase et al., 1986) to estimate the lake evaporation.

Lake level records of the Lake Naivasha are available from the year 1898 onwards. From 1952 lake levels were recorded monthly, unlike the early recording period when observations were only recorded a few times per year. Consistent daily lake level monitoring started in 1997. All hydrometeorological data were aggregated into monthly values and then into annual mean, minimum, maximum, and seasonal (MAMJ and OND) values before being subjected to non-stationarity analysis. 
Table 2-1: Overview of the percentage of gaps in data coverage of Lake Naivasha Basin river gauging stations. Stations highlighted in grey indicate the stations with high data coverage $(<20 \%$ gaps) used in this study

\begin{tabular}{|c|c|}
\hline Stations & Percentage of gaps $1960-2010$ \\
\hline $2 \mathrm{GA} 01$ & $89 \%$ \\
\hline $2 \mathrm{GA} 03$ & $7 \%$ \\
\hline 2GA05 & $49 \%$ \\
\hline 2GA06 & $22 \%$ \\
\hline 2GB01 & $44 \%$ \\
\hline $2 \mathrm{~GB} 03$ & $72 \%$ \\
\hline 2GB04 & $34 \%$ \\
\hline 2GB05 & $17 \%$ \\
\hline 2GB08 & $7 \%$ \\
\hline 2GC04 & $7 \%$ \\
\hline 2GC05 & $7 \%$ \\
\hline 2GC07 & $6 \%$ \\
\hline $2 \mathrm{GC} 10$ & $56 \%$ \\
\hline 2GD02 & $52 \%$ \\
\hline 2GD07 & $48 \%$ \\
\hline
\end{tabular}

\subsection{Methods}

A preliminary analysis of lake volume variation and water balance was conducted to demonstrate the inter-relationship between the water balance components. The water balance components were then subjected to change point and trend analysis. In this study abrupt changes were investigated using Bayesian change point analysis proposed by Barry and Hartigan (1993). Compared to classical statistics, Bayesian approaches have the advantage of providing comprehensive information on the uncertainty of detected changes. Gradual changes were investigated using modified Mann Kendall (MMK) procedure recommended in Hamed (2008). Double mass curve analysis was performed to explore to which extent any observable change could be attributed to climate variation or anthropogenic influence.

\subsubsection{Lake volume change and water balance analysis}

The analysis of change in lake volume was based on measurements performed every year in mid January, since January is the driest period of the year in the basin. Following the water balance continuity equation, the change in lake volume can be written as:

$$
\frac{\Delta V}{\Delta t}=P+\left(Q_{i}-Q_{o}\right)-E-G \pm \varepsilon \quad\left[m^{3} y r^{-1}\right]
$$


Chapter 2

where $\frac{\Delta V}{\Delta t}$ is the annual change in lake volume, $P$ is the annual precipitation over the lake, $Q_{i}$ is the annual runoff inflow into the lake, $Q_{0}$ is the annual runoff outflow from the lake, $E$ is the annual evaporation from the lake surface, $G$ is the net water loss from the lake by processes other than evaporation $(E)$ and outflow, $\left(Q_{o}\right)$ (flux into the groundwater plus abstraction) and $\varepsilon$ is the error term associated with uncertainties in the water balance. In the case of Lake Naivasha there is no visible outlet and is thus unknown. Therefore in this study both $G$ and $Q_{0}$ are unknown. For this reason, $G, Q_{0}$ and $\varepsilon$ were lumped into an unknown residual term $(U)$. Therefore Equation $(2-1)$ was reduced to the following form,

$$
\frac{\Delta V}{\Delta t}=P+Q_{i}-E+U \quad\left[m^{3} y r^{-1}\right]
$$

where $U=Q_{o}+G \pm \varepsilon$. Following the approach of van Oel et al. (2013), the changes in lake level (in $\mathrm{m})$ to actual volumes $\left(\mathrm{m}^{3}\right)$ were recalculated, using the height-area-volume relation presented by Ase et al. (1986). Lake evaporation and precipitation over the lake were all converted into volumes by multiplying by the lake area using the same relationship.

Considering that the observed changes in lake volume reflect the inflow and outflow for a given year, it is possible to re-construct yearly lake volumes using the observed lake volume of a previous year as benchmark and adding present year inflow and outflow. The re-constructed lake volumes for year $t=1,2, \ldots, n$ can then be computed as follows:

$$
V^{t}=V_{o b s}{ }^{t-1}+P^{t}+Q^{t}-E^{t} \quad\left[m^{3}\right]
$$

where $V^{t}$ is the re-constructed lake volume at the end of the present year $t, V_{o b s}{ }^{t-1}$ is the observed total lake volume at the end of the previous year $t-1, P^{t}$ is the annual total precipitation over the lake, $Q^{t}$ is the annual total runoff inflow into the lake and $E^{t}$ is the annual total evaporation from the lake surface. The superscript $t$ covers the period starting at the end of year $t$ - 1 to the end of year $t$. The reconstructed lake volume, $V^{t}$, inherently include the unknown residual loss term $(U)$ for the current year while the observed lake volumes do not include the unknown residual loss term $(U)$. The difference between the observed and reconstructed lake volumes indicated the magnitude of the changes in the unknown term $(U)$ of the water balance.

The reconstructed lake volumes were then compared against the observed lake volumes to distinguish any changes attributable to $G, Q_{0}$ and abstractions from the lake. Both observed lake volume series and re-constructed lake volume series were analyzed for evidence of significant abrupt and gradual trends using the Bayesian change point analysis and the MMK test. 
Chapter 2

The inter-relations between the water balance components were investigated using the cross correlation functions (CCF). Additionally, autocorrelation functions (ACF) were used to observe any evidence of serial correlation in the components.

\subsubsection{Change point analysis}

The Bayesian model of multiple change point detection (Barry and Hartigan, 1993) adopted in this study allows for computation of posterior probabilities of a number of change points and the posterior mean of the parameters based on an efficient recursion technique (Fearnhead, 2006). The notations presented here are similar to those of Barry and Hartigan (1993).

For time series observations $X_{1}, X_{2}, \ldots, X_{n}$, the method makes inference when there is an unknown partition, $\rho=\left(i_{0}, i_{1}, \ldots, i_{b}\right)$ of a set $b$ into contiguous blocks; $\left[X_{1}, \ldots, X_{i_{1}}\right],\left[X_{i_{1}+1}, \ldots, X_{i_{2}}\right], \ldots,\left[X_{i_{b-1}+1}, \ldots, X_{i_{b}}\right]$, such that $0=i_{0}<i_{1}<i_{2}<\cdots<i_{b}=n$, and the means are equal within each block. Each observation is a member of one set only and observations in different sets of a partition are independent. The $i_{1}, i_{2}, \ldots, i_{b}$ refer to the endpoints of blocks which form a Markov chain. The model assumes that observations $X_{1}, X_{2}, \ldots, X_{n}$ are independent, $X_{i} \sim N\left(\mu_{i}, \sigma^{2}\right)$, and that the probability of a change point at position $i$ is $p$, independent at each $i$. The prior distribution of the mean $\left(\mu_{i j}\right)$ for the block beginning at position $i+1$ and ending at position $j$ is chosen as $N\left(\mu_{0}, \sigma_{0}^{2} /(j-i)\right)$. It is the expectation that larger deviations of $\mu_{0}$ are more likely to be detected in short blocks than in long blocks. As a consequence, it is not feasible to identify small deviations in short blocks, a presumption that is built into the prior probabilities (Barry and Hartigan, 1993).

Let $c_{[i j]}$ be the prior cohesion associated with the block $[i j]=\{i+1, \ldots, j\}, j>i$ that represents the degree of similarity among the observations in $X_{[i j]}$. Following Yao (1984), the prior cohesion for block $[i j]$ is given by

$$
c_{[i j]}= \begin{cases}p(1-p)^{j-i-1} & \text { if } j<n \\ (1-p)^{j-i-1} & \text { if } j=n\end{cases}
$$

The prior cohesion corresponds to the probability that a new change takes place after $j-i$ instants, given a change occurring at the instant $i$. The cohesions can be interpreted as transition probabilities in the Markov chain defined by the endpoints of the blocks in a partition (Loschi and Cruz, 2002).

To generate partitions of data a Markov Chain Monte Carlo (MCMC) technique developed by Erdman and Emerson (2008), which simulates a Markov chain sequence of partitions converging to 
the posterior distribution, is implemented. It follows that any generated partition $\rho$ may be associated with some value of $U=\left(U_{1}, \ldots, U_{n-1}\right)$ in which the random variable $U_{i}$, reflects occurrence or non-occurrence of a change point at time $i$, that is

$$
U_{i}= \begin{cases}1 & \text { if } \mu_{i}=\mu_{i+1} \\ 0 & \text { if } \mu_{i} \neq \mu_{i+1}\end{cases}
$$

where $i=1, \ldots, n-1$. By initializing $U_{i}=0$ for all $i<n$, a value of $U_{i}$ is drawn from the conditional distribution of $U_{i}$ given the data and the current partition.

Following Barry and Hartigan (1993), for $i \geq 2$ and with $b$ denoting the number of blocks obtained if $U_{i}=0$, conditional on $U_{j}$ for $i \neq j$, the transitional probability of change at position $i+1$ is computed as follows:

$$
\begin{gathered}
\frac{p_{i}}{1-p_{i}}=\frac{P\left(U_{i}=1 \mid X, U_{j}, j \neq i\right)}{P\left(U_{i}=0 \mid X, U_{j}, j \neq i\right)} \\
=\frac{\left[\int_{0}^{p_{0}} P^{b}(1-p)^{n-b-1} d p\right]\left[\int_{0}^{w_{0}} \frac{w^{b / 2}}{\left(W_{1}+B_{1} w\right)^{(n-1) / 2}} d w\right]}{\left[\int_{0}^{p_{0}} P^{b-1}(1-p)^{n-b} d p\right]\left[\int_{0}^{w_{0}} \frac{w^{(b-1) / 2}}{\left(W_{0}+B_{0} w\right)^{(n-1) / 2}} d w\right]}
\end{gathered}
$$

where $X$ represents the data, $W_{0}$ and $B_{0}$ are the within block and between block sum of squares, respectively, obtained with $U_{i}=0$. Similarly, $W_{1}$ and $B_{1}$ are the within block and between block sum of squares, respectively, obtained with $U_{i}=1$.

After iterating through the data the posterior means of $\mu_{i}$ are updated for the current partition $\rho$ and $X$ using

$$
\mu_{i}=(1-w) \bar{X}_{i j}+w \mu_{0}
$$

where $w=\sigma^{2} /\left(\sigma_{0}^{2}+\sigma^{2}\right)$ and $\sigma_{0}^{2}$ is obtained from prior distribution of $\mu_{j}$ chosen as $N\left(\mu_{0}, \sigma_{0}^{2} /(j-i)\right)$ for block $i j$. Barry and Hartigan (1993) recommend 50 to 500 iterations for adequate approximation of the posterior mean. In this study 500 iterations were used for the approximation of the posterior mean, following Erdman and Emerson (2008). Details on the complete formulation and procedure of the Bayesian change model have been described in Barry and Hartigan (1993). 


\subsubsection{Trend analysis}

The Mann-Kendall (MK) trend test (Kendall, 1975; Mann, 1945) for uncorrelated independent random data was used. Necessary modifications that account for serial correlation and scaling phenomena, as recommended and suggested by a number of authors, were adopted (e.g. Ehsanzadeh and Adamowski, 2010; Hamed, 2008; Hamed and Rao, 1998; Khaliq et al., 2009; Koutsoyiannis, 2003; Koutsoyiannis, 2006). The modifications adopted to distinguish trend in the hydro-climatological series were based on the assumptions: (1) short-term persistence (STP) and (2) long-term persistence (LTP). Both assumptions were adopted in this study to avoid misdiagnosing a trend, which might exist according to the STP assumption but not according to the LTP assumption (Khaliq et al., 2009).

The MK statistic $S$ is given by:

$$
S=\sum_{i=1}^{n-1} \sum_{j=i+1}^{n} \operatorname{sgn}\left(x_{j}-x_{i}\right)
$$

where $x_{i}$ and $x_{j}$ are sequential data values and $n$ is the total number of data values in the time series and $\operatorname{sgn}\left(x_{j}-x_{i}\right)$ is the sign function given as:

$$
\operatorname{sgn}\left(x_{j}-x_{i}\right)=\left\{\begin{aligned}
1 & \text { if } x_{j}-x_{i}>0 \\
0 & \text { if } x_{j}-x_{i}=0 \\
-1 & \text { if } x_{j}-x_{i}<0
\end{aligned}\right.
$$

A positive $S$ indicates an increasing trend and a negative $S$ indicates a decreasing trend. Following suggestions by Mann (1945) and Kendall (1975), the statistic $S$ is approximately normally distributed for $n \geq 8$ with the mean and variance given by:

$$
\begin{gathered}
E(S)=0 \\
V(S)=n(n-1)(2 n+5) / 18
\end{gathered}
$$

When tied ranks (equal observations) exist in the data, the variance of $S$ is reduced to

$$
V(S)=n(n-1)(2 n+5) / 18-\sum_{j=1}^{m} t_{j}\left(t_{j}-1\right)\left(2 t_{j}+5\right) / 18
$$

where $m$ is the number of groups of tied ranks each with $t_{j}$ tied observations. The standardized test statistic $Z_{c}$ is computed as: 


$$
Z_{c}= \begin{cases}\frac{S-1}{\sqrt{V(S)}} & \text { if } S>0 \\ 0 & \text { if } S=0 \\ \frac{S+1}{\sqrt{V(S)}} & \text { if } S<0\end{cases}
$$

The $Z_{c}$ follows a standard normal distribution. The null hypothesis that there is no trend will be

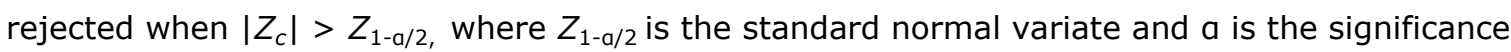
level for the test. In this study, a significance level of $a=0.05$ was used.

\subsubsection{Trend analysis under STP hypothesis}

The effective sample size (ESS) approach proposed by Hamed and Rao (1998) was adopted to correct for variance estimation used in Equation (2-4) after removal of the trend using Sen's robust slope estimator (Sen, 1968), which is given by

$$
s_{0}=\operatorname{median}\left(\frac{X_{j}-X_{i}}{j-i}\right) \forall i<j
$$

where $x_{i}$ and $x_{j}$ are the data at time $i$ and $j$ in the series. Under STP assumption, correction for the tied ranks using Equation (2-6) was unnecessary. Instead, the variance estimate in Equation (2-7) was corrected for autocorrelation according to:

$$
V^{*}(S)=\eta V(S)
$$

where $\eta$ is the correction due to autocorrelation, approximated as

$$
\eta=1+\frac{2}{n(n-1)(n-2)} \times \sum_{i=1}^{n-1}(n-i)(n-i-1)(n-i-2) \rho_{s}(i)
$$

where $\rho_{s}(i)$ is the autocorrelation function of the ranks of observations and $\mathrm{n}$ is the actual number of observations. The values of $\rho_{s}(i)$ must first be calculated after subtracting the Sen's trend estimator derived using Equation (2-12) (Sen, 1968; Zetterqvist, 1991). Insignificant values of $\rho_{s}(i)$ will have an adverse effect on the accuracy of the estimated variance of $\mathbf{S}$ (Hamed and Rao, 1998). Therefore, during implementation of the test caution was observed by pre-setting the significance level at $a=0.05$ for autocorrelations in Equation (2-14). As such only significant 
autocorrelations were included in the calculations. Substituting Equation (2-13) in Equation (2-11) allows for testing of trends under the STP assumption.

\subsubsection{Trend analysis under scaling hypothesis}

Trend detection under the LTP assumption was conducted following the method proposed by Hamed (2008). The Hurst coefficient, $H$, (Hurst, 1951) of the hydro-climatological data series was first estimated using the maximum likelihood (ML) method proposed by McLeod and Hipel (1978). Following Hamed (2008) the hydro-climatological data series was first detrended using the Sen's robust slope estimator (Sen, 1968) in Equation (2-12). The equivalent normal variates, $z_{t}$, of rank of the detrended series were then computed using Equation (2-15).

$$
z_{t}=\Phi^{-1}\left(\frac{R_{t}}{n+1}\right)
$$

where $\Phi^{-1}$ is the inverse of the standard normal distribution function, $n$ is the number of observations and $R_{t}$ is the rank of detrended observations. Next, the correlation matrix, $\mathrm{C}_{\mathrm{n}}(H)$, was computed for a given $H$ using Equation (2-16).

$$
\begin{aligned}
& \mathrm{C}_{\mathrm{n}}(H)=\left[\rho_{|j-i|}\right], \text { for } i=1: n, j=1: n \text { and } \\
& \rho_{l}=0.5\left(|l+1|^{2 H}-2|l|^{2 H}+|l-1|^{2 H}\right)
\end{aligned}
$$

where $\rho_{l}$ is the autocorrelation function of lag / for a given $H$. Finally, $H$ was obtained by maximizing the log likelihood function of $H$ shown in Equation (2-17).

$$
\log L\left(\mu, \gamma_{0}, H\right)=-\frac{1}{2} \log \left|C_{n}(H)\right|-\frac{z^{T}\left[C_{n}(H)\right]^{-1} z}{2 \gamma_{0}}-\frac{n}{2} \log \gamma_{0}
$$

where $H$ is the Hurst coefficient of the hydro-climatological data series, $\left|C_{n}(H)\right|$ is the determinant of the correlation matrix, $C_{n}(H), z^{T}$ is the transpose vector of the equivalent normal variates, $z_{t}, \gamma_{0}$ is the variance of $z_{t}$, and, $z$ is a vector of $z_{t}$, computed from Equation (2-15). The value of $H$ may vary between 0 and 1 . When $H=0.5$ the variables are independent, but when $H>0.5$ the variables show presence of long memory or a persistent process (Montanari et al., 1997). Values of $H<0.5$ correspond to a negative dependence or an anti-persistent process (Koutsoyiannis, 2010; Montanari et al., 1997). 
Chapter 2

Considering that the mean $\mu=0$ for the normal variates $z_{t}$, and $\gamma_{0}$ is a constant, the ML estimate of the scaling coefficient $H$ can then be obtained by maximizing Equation $(2-17)$, which is then reduced to

$$
\log L(H)=-\frac{1}{2} \log \left|C_{n}(H)\right|-\frac{Z^{T}\left[C_{n}(H)\right]^{-1} z}{2 \gamma_{0}}
$$

Following Hamed (2008) the significance of the estimated $H$ obtained using Equation (2-18) can be tested using

$$
\begin{array}{r}
\mu_{H}=0.5-2.874 n^{-0.9067} \\
\sigma_{H}=0.77654 n^{-0.5}-0.0062
\end{array}
$$

If $H$ is not significant, then the modified MK test under STP assumption is accepted. Otherwise, a modified standard deviation (Equation 2-20) of the MK statistic $S$ integrating the scaling assumption under LTP is computed based on methodology proposed by Ehsanzadeh and Adamowski (2010):

$$
\begin{gathered}
\tilde{s}=\sqrt{V(S)}=\sigma \sqrt{\frac{n-0.5}{n-n^{2 H-1}}} \\
=\sqrt{\frac{n-0.5}{n-n^{2 H-1}}} \times \sqrt{n(n-1)(2 n+5) / 18-\sum_{j=1}^{m} t_{j}\left(t_{j}-1\right)\left(2 t_{j}+5\right) / 18}
\end{gathered}
$$

The revised standard deviation was then used in Equation (2-11). Equation (2-20) is unbiased for a known $H$ and different in form to the one suggested by Hamed (2008), which needs correction for bias. If the trend at this point (after correction for LTP) is found to be significant then the null hypothesis, which assumes that there is no trend, is rejected.

For Turasha dam, where the amount of water abstraction was known, evidence of trends was reinvestigated by assuming a scenario without abstraction of water from the dam. In other words, here the known amount of extracted water was 'added' to the observed discharge. Double mass curve analysis was then used to investigate the cause of changes. This was done by correlating the cumulative averages of the water balance components. 


\subsubsection{Double mass curve analysis}

Double mass curve analysis was used to investigate changes in hydrological response attributable to human influences or changes in surface conditions. The double mass curve between precipitation and total flow from the sub-catchments is given as:

$$
\mathrm{X}(\mathrm{t})=\sum_{\mathrm{i}=1}^{\mathrm{t}} \mathrm{P}_{\mathrm{ui}}, \quad \mathrm{Y}(\mathrm{t})=\sum_{\mathrm{i}=1}^{\mathrm{t}} \mathrm{Q}_{\mathrm{ui}}, \quad \mathrm{t}=1,2, \ldots, \mathrm{n}
$$

where $\mathrm{X}(\mathrm{t})$ and $\mathrm{Y}(\mathrm{t})$ are the cumulative annual precipitation and total flows, respectively, of the upstream sub-catchments. $P_{\mathrm{u} i}(\mathrm{~mm})$ is the annual precipitation in the upstream catchment region for year $i$, computed using mean precipitation data recorded in upstream stations; $Q_{u i}$, is the total flow from upstream sub-catchments into the lake for year $i$.

As long as the hydrological response does not change, the double mass curve produces a straight line. The inflection of the curve is indicative of changes in the rainfall-runoff relation, which could be caused by measurement errors, human-induced abstraction or changes in surface hydrology due to land cover change. The difference between the curve and the regression straight line extrapolated to approximate natural conditions gives the cumulative change in flow caused by mentioned effects:

$$
\Delta \mathrm{W}_{\mathrm{t}}=\mathrm{Y}^{\prime}(\mathrm{t})-\mathrm{Y}(\mathrm{t})
$$

where $\Delta \mathrm{W}_{\mathrm{t}}$ is the cumulative change in flow in year $\mathrm{t}$ and $\mathrm{Y}^{\prime}(\mathrm{t})$ is the estimated cumulative flow in year $t$, extrapolated by a straight regression line from flow under approximate natural conditions (Huo et al., 2008).

\subsection{Results}

\subsubsection{Lake volume change and water balance}

Figure 2-2 shows the time series of annual lake water balance components and the re-constructed lake volumes from 1960 to 2010. Precipitation showed no general trend in decrease or increase during this period. Lake volumes showed periods of increase (e.g. early 1960s) and decline (e.g. late 1980s) while evaporation showed a general decreasing trend. Lake evaporation is correlated to lake volumes due its dependence on lake area. River discharges showed great variability, with peak values between 1987 and 1998. The residual term, $U$, was less variable than river discharges in absolute sense, but also peaked between 1987 and 1998, and was higher on average in the 2000s compared to the period before 1987. 
Chapter 2 The inter-annual changes in observed and computed lake volumes had a correlation of $R^{2}=0.66$ $(p<0.05)$ (Figure $2-3)$. In a few cases, high input flows resulted in small lake volume changes. These anomalies in inflow stemmed from Gilgil River data in years without exceptional rainfall. In those cases the inflows even exceeded the rainfall equivalent in the Gilgil catchment, suggesting measurement error in the inflows. 


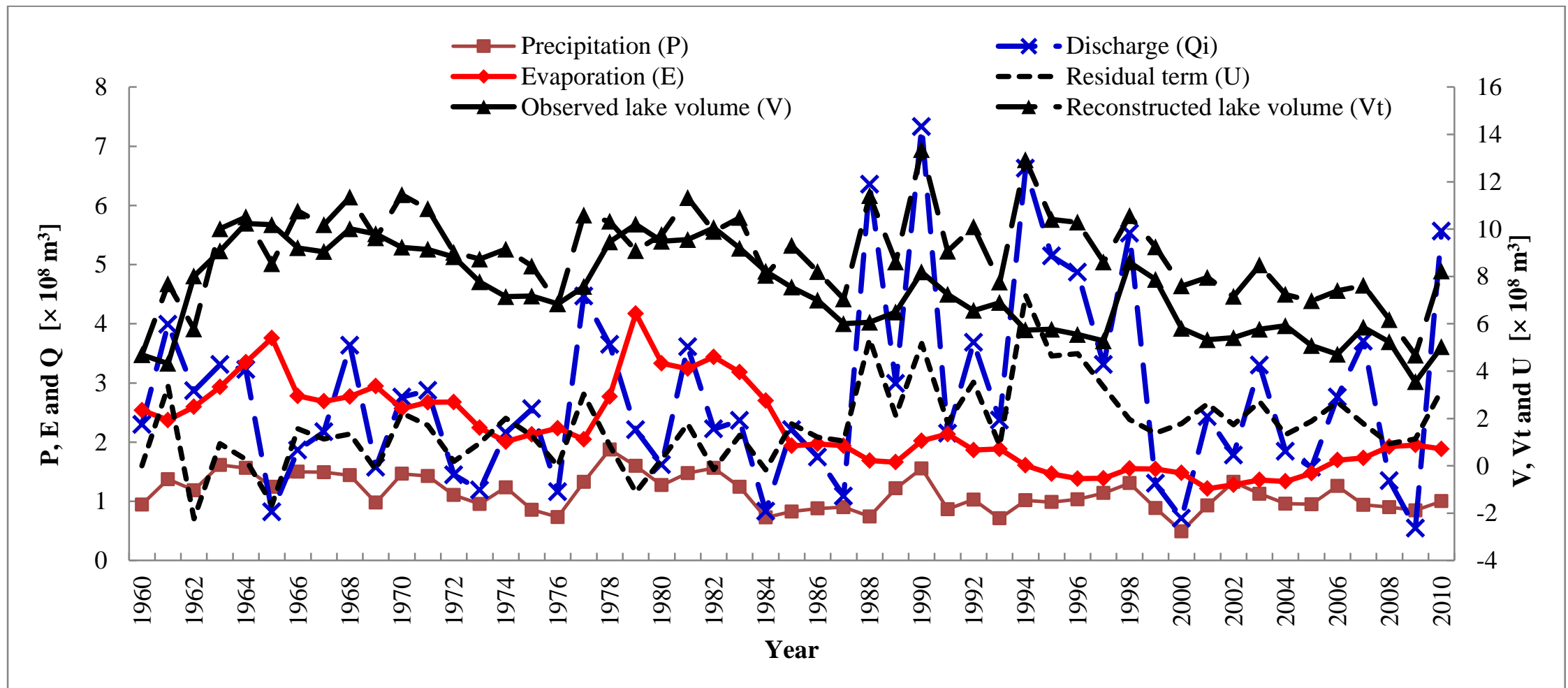

Figure 2-2: Time series of annual water balance components of Lake Naivasha between 1960 and 2010 


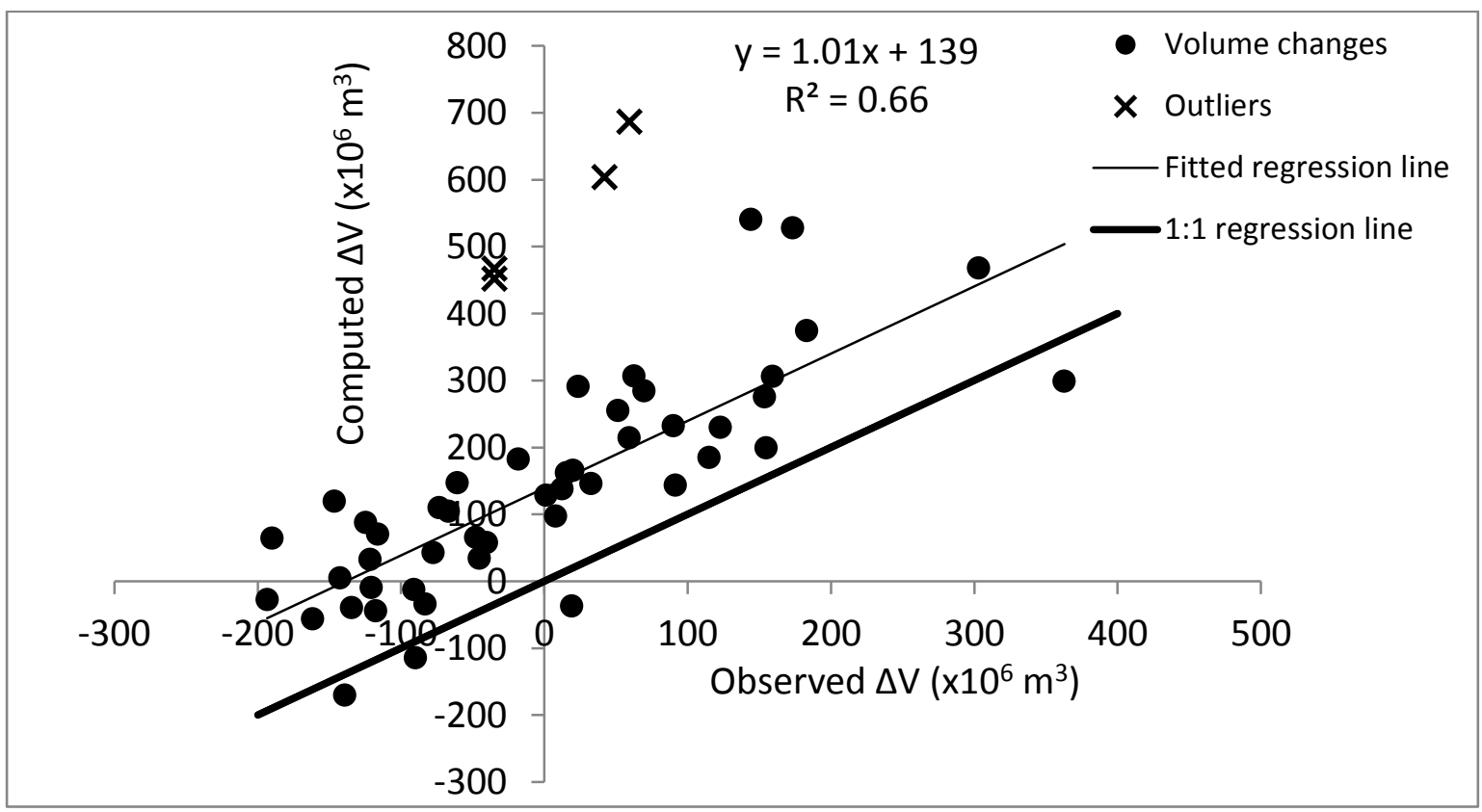

Figure 2-3: Correlation between observed annual lake volume change and computed annual lake volume change. Where high input flows resulted in small lake volume changes, these were treated as outliers. The thin line represents the regression line fitted to lake volume change data without taking the outliers into consideration

The average $U$ was $139 \times 10^{6} \mathrm{~m}^{3}$ (equivalent to $0.82 \mathrm{~m}$ of lake level at the mean lake area) for the 50 years that were analyzed. The trend of the reconstructed lake volumes was insignificant $\left(S_{o}=-\right.$ $\left.4.42 \times 10^{6} \mathrm{~m} \mathrm{year}^{-1} ;-0.03 \mathrm{~m} \mathrm{year}^{-1}, p>0.05\right)$, while the trend of the observed lake volumes exhibited a significant decline $\left(S_{0}=-9.35 \times 10^{6} \mathrm{~m}^{3} \mathrm{year}^{-1} ;-0.06 \mathrm{~m} \mathrm{year}^{-1}, p<0.05\right)$ (Figure 2-4). The annual changes in lake volume were mostly correlated to the runoff inflow $\left(R^{2}=0.61, p<0.05\right)$, but they hardly depended on the lake evaporation $\left(R^{2}=0.05, p>0.05\right)$ and precipitation $\left(R^{2}=0.13\right.$, $p>0.05$ ) (Figure 2-5). The poor correlation of both lake surface evaporation and precipitation to the change in lake volumes suggests that they were insignificant in explaining lake volume changes. The observed pan evaporation data show that the lake has experienced an average evaporation rate of approximately $2.26 \times 10^{8} \mathrm{~m}^{3} \mathrm{year}^{-1}$ (equivalent to $1.32 \mathrm{~m}$ annually) over the past 50 years. 


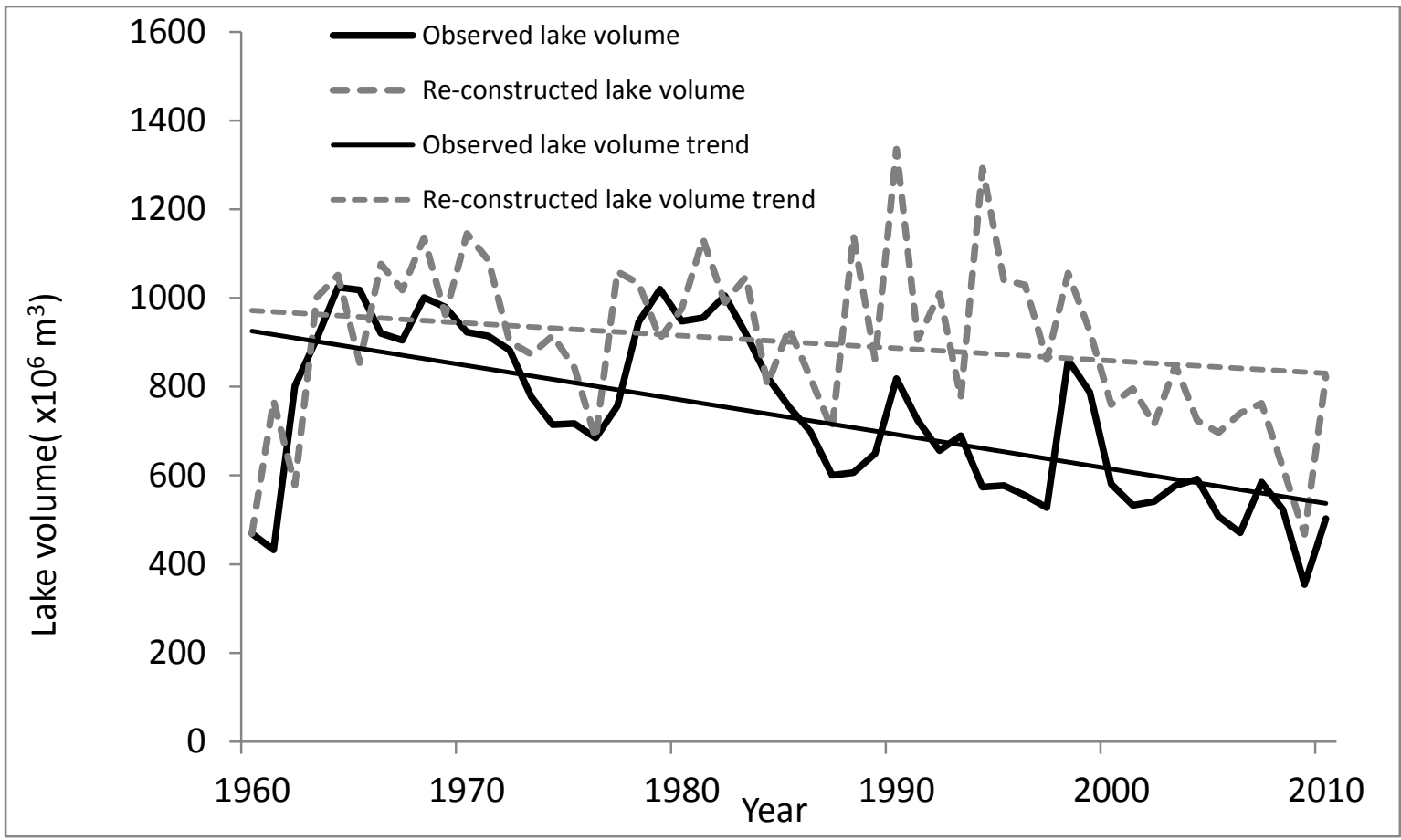

Figure 2-4: Time series of observed and re-constructed lake volumes

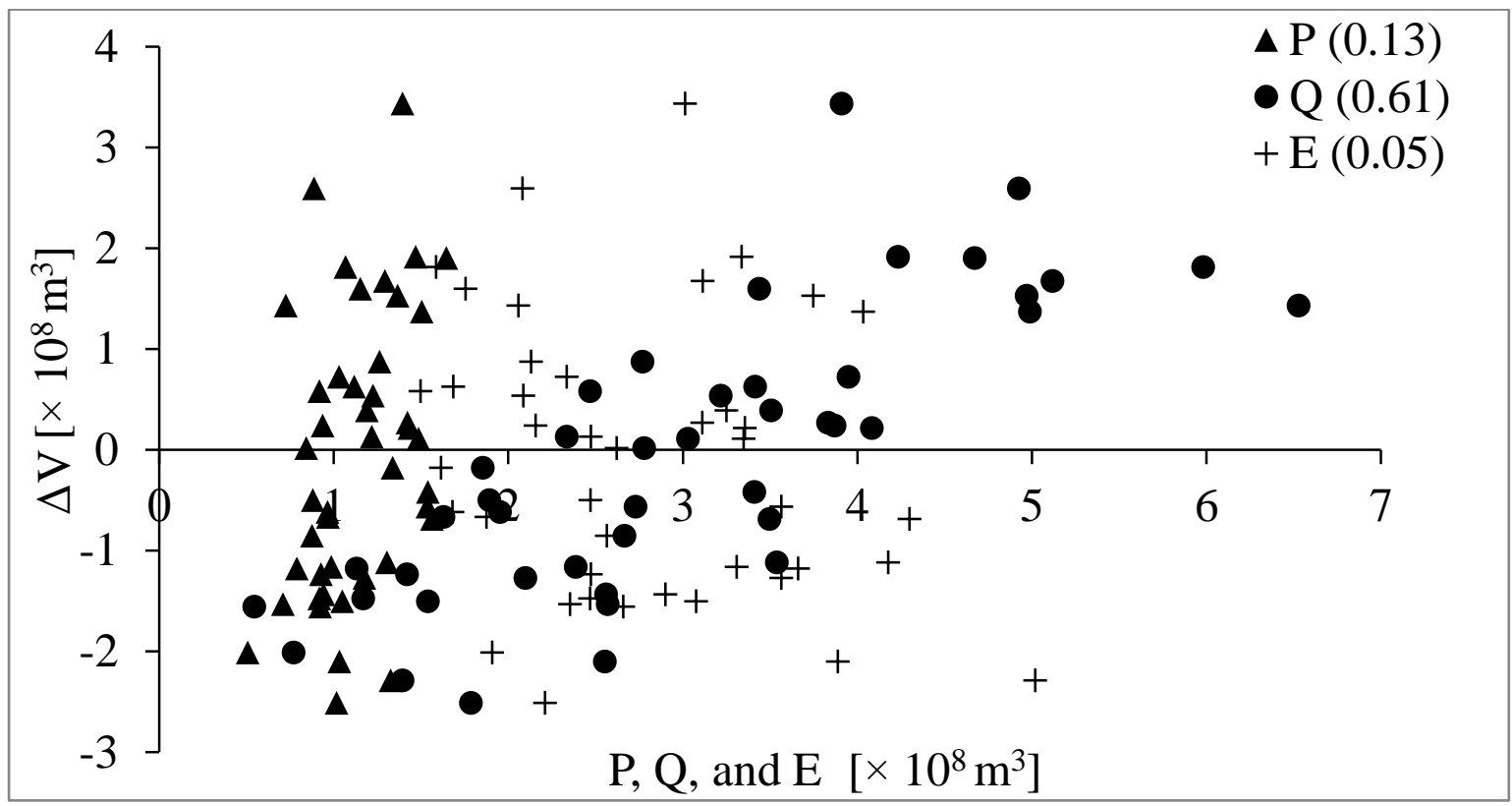

Figure 2-5: Annual time series of observed and re-constructed lake volumes 


\subsubsection{Autocorrelations}

Precipitation over the lake and runoff inflow into the lake exhibited insignificant serial correlation for all lags $(r<0.3, p>0.05)$. However, lake volume and evaporation series exhibited strong serial correlation for all lags, indicative of long-term persistence (Figure 2-6). This is expected because lake volumes have memory, while lake evaporation is proportional to lake area. Cross correlation functions revealed that total inflow into the lake was more strongly correlated $(r=0.69, p<0.05)$ to lake volume changes than precipitation $(r=0.49, p<0.05)$ over the lake or lake evaporation $(r=-$ $0.042, p>0.05$ ) (Figure 2-7).
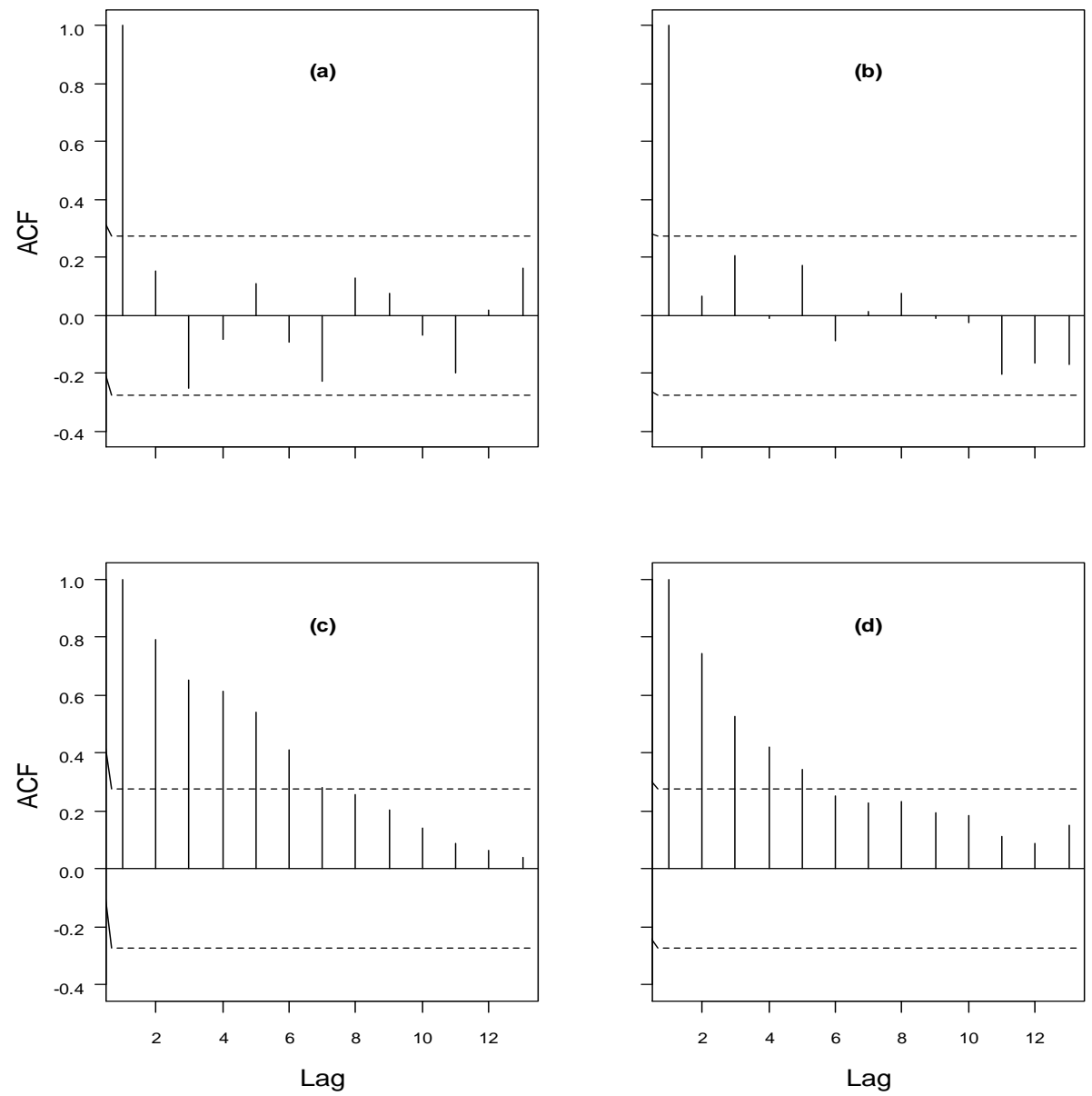

Figure 2-6: Sample autocorrelation function of the water balance components: (a) precipitation, (b) runoff volume, (c) evaporation, and (d) lake volume (1960-2010). The dotted lines form the upper and lower confident boundaries at $a=0.05$ 

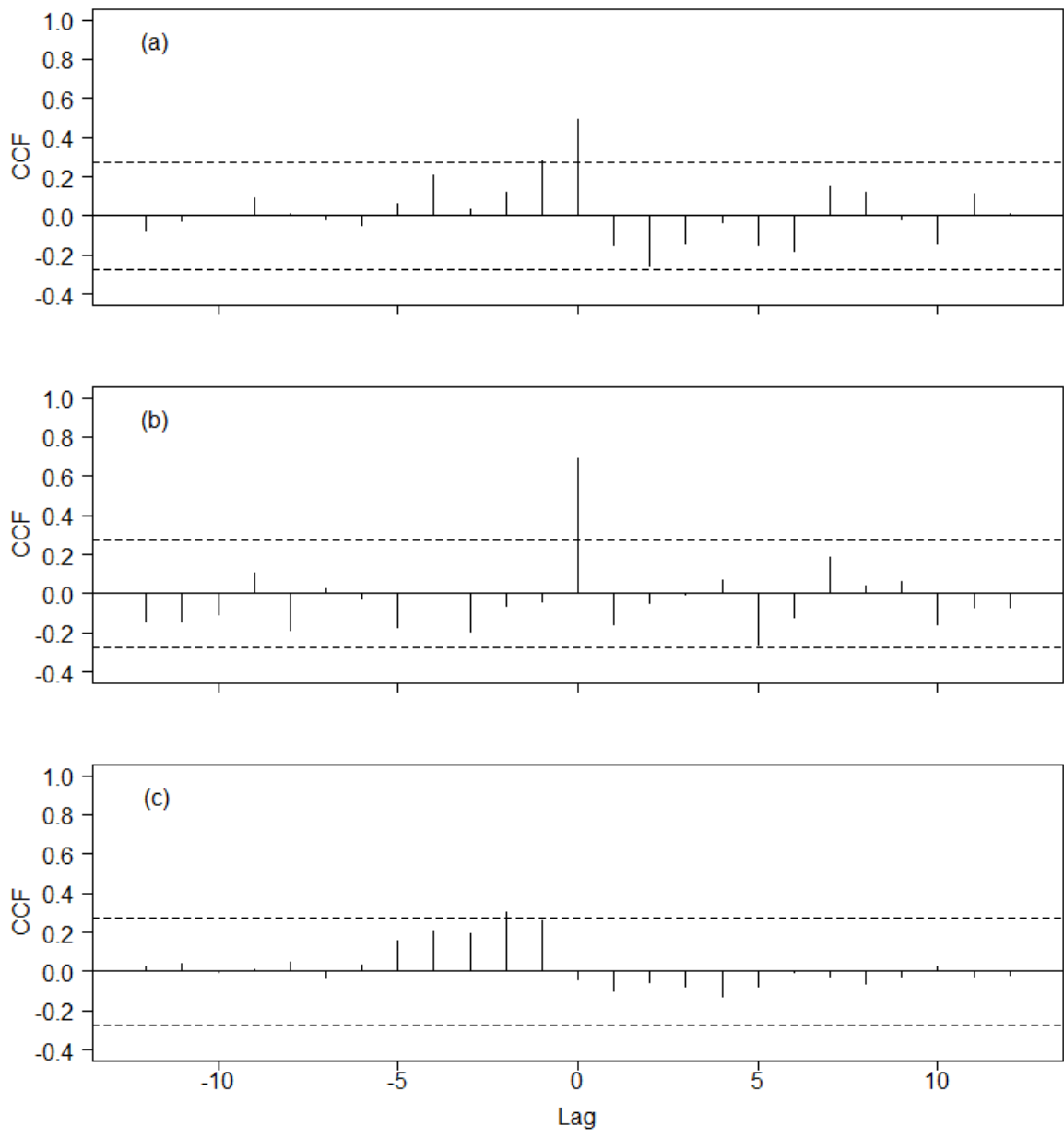

Figure 2-7: Cross correlation functions (CCFs) comparing the water balance components (a) precipitation (b) runoff volume and (c) evaporation with lake volume change (1960-2010). The dotted lines form the upper and lower confident boundaries at $a=0.05$

\subsubsection{Change point analysis}

Bayesian change point analysis of the precipitation for nine out of the ten stations showed no evidence of abrupt changes in the annual mean, maximum, or seasonal MAMJ and OND precipitation. The probability of abrupt changes was low. A few abrupt changes were observed in the annual minimum precipitation over the past 50 years. Table 2-2 shows some evidence of abrupt changes;

Figure 2-8 shows an example of the station located in the Turasha sub-catchment that has experienced a number of abrupt changes in its precipitation series. 
Table 2-2: Year of occurrence and, in brackets, number of abrupt shift points observed for both precipitation and runoff; shading indicates the occurrence of abrupt shifts

\begin{tabular}{|c|c|c|c|c|c|c|c|c|c|c|c|c|}
\hline \multirow[b]{2}{*}{ Sub-basin } & \multirow[b]{2}{*}{ Station } & \multirow[b]{2}{*}{ Mean } & \multicolumn{3}{|c|}{ Runoff } & \multirow[b]{2}{*}{ OND } & \multirow[b]{2}{*}{ Station } & \multirow[b]{2}{*}{ Mean } & \multirow[b]{2}{*}{ Max } & \multicolumn{2}{|c|}{ Precipitation } & \multirow[b]{2}{*}{ OND } \\
\hline & & & Max & Min & MAMJ & & & & & Min & MAMJ & \\
\hline Gilgil & 2GA03 & $1988(1)$ & 0 & $\begin{array}{l}\text { 1969, } \\
1989(2)\end{array}$ & $1988(1)$ & $\begin{array}{l}1988, \\
1990(1)\end{array}$ & 9036999 & 0 & 0 & 0 & 0 & 0 \\
\hline \multirow[t]{2}{*}{ Malewa } & 2GB05 & 0 & 0 & $\begin{array}{l}1969 \\
1988, \\
2000 \text { (3) }\end{array}$ & 0 & 0 & 9036289 & 0 & 0 & $1965(1)$ & 0 & 0 \\
\hline & 2GB08 & 0 & 0 & $\begin{array}{l}1969 \\
1988 \\
2000\end{array}$ & 0 & 0 & 9036290 & 0 & 0 & $\begin{array}{l}1965 \\
2002(1)\end{array}$ & 0 & 0 \\
\hline \multirow[t]{4}{*}{ Turasha } & 2GC04 & $\begin{array}{l}\text { 1990, } \\
\text { 1999(2) }\end{array}$ & $\begin{array}{l}\text { 1990, } \\
1999(2)\end{array}$ & $\begin{array}{l}1963, \\
1999(2)\end{array}$ & 0 & 0 & 9036241 & 0 & 0 & 0 & 0 & 0 \\
\hline & 2GC05 & 0 & 0 & 0 & 0 & 0 & 9036264 & 0 & 0 & $\begin{array}{l}1962 \\
2001(2)\end{array}$ & 0 & 0 \\
\hline & 2GC07 & 0 & 0 & 0 & 0 & 0 & 9036272 & $\begin{array}{l}\text { 1961, } \\
1974, \\
1999(3)\end{array}$ & 0 & $\begin{array}{l}\text { 1965, } \\
1997(2)\end{array}$ & 0 & 0 \\
\hline & & & & & & & 9036025 & 0 & 0 & 1981(1) & 0 & 0 \\
\hline \multirow[t]{3}{*}{ Lower basin } & & & & & & & 9036002 & 0 & 0 & 0 & 0 & 0 \\
\hline & & & & & & & 9036109 & 0 & 0 & 1977(1) & 0 & 0 \\
\hline & & & & & & & 9036281 & 0 & 0 & 0 & 0 & 0 \\
\hline $\begin{array}{l}\text { Stations wi } \\
\text { abrupt shift }\end{array}$ & & 67 & 83 & 33 & 83 & 83 & & 90 & 100 & 40 & 100 & 100 \\
\hline
\end{tabular}




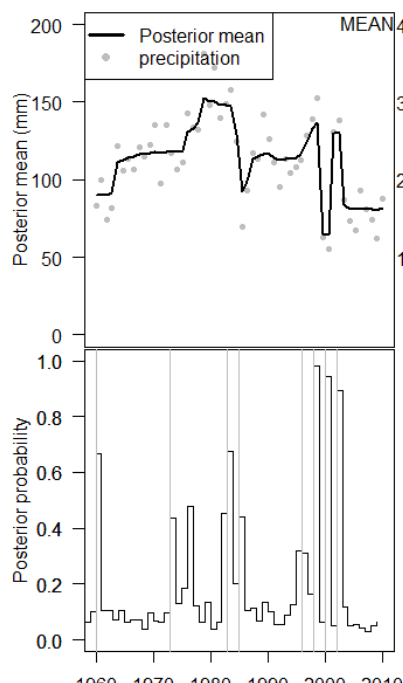

196019701980199020002010

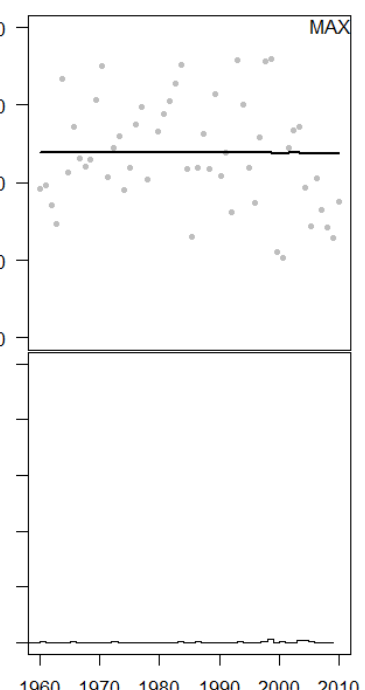

$1960 \quad 197019801990 \quad 2000 \quad 2010$

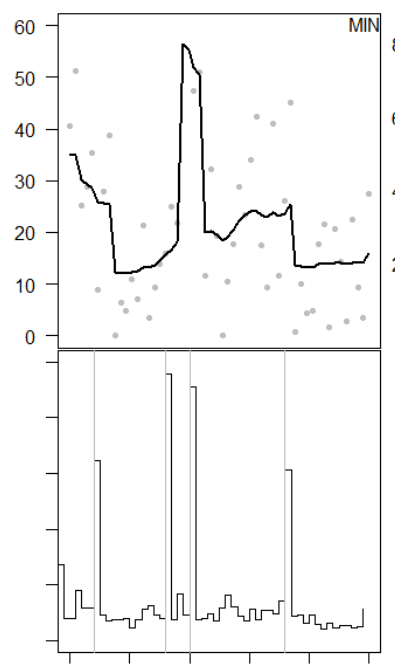

$19601970198019902000 \quad 2010$

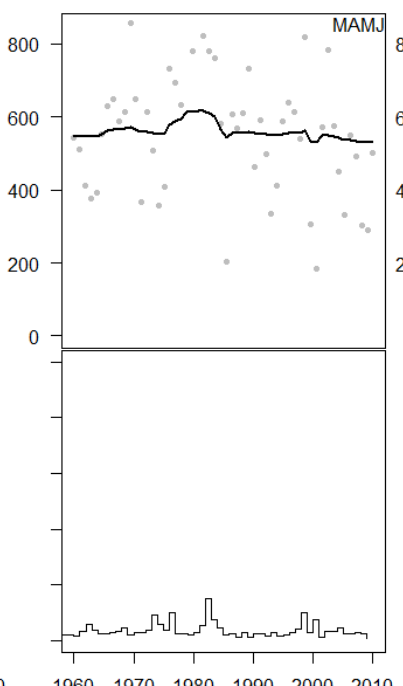

196019701980199020002010

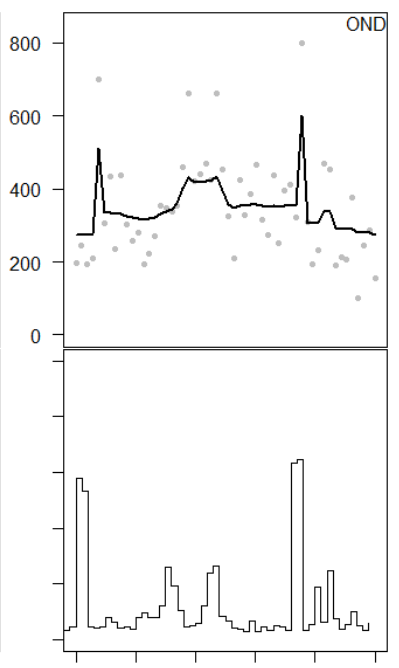

$1960-1970-1900-1990-2000-2010$

Figure 2-8: Abrupt shifts (top) and posterior probability distribution (bottom) of the mean, maximum, and minimum annual precipitation, as well as for the months March/April/May/June and the months October/November/December, respectively, at station 9036272 located at the Turasha subcatchment 
Characterisation of hydroclimatological trends and variability

The analysis of abrupt changes using the Bayesian approach showed that the largest contributor to the lake, the Turasha River, did not exhibit any abrupt shifts upstream of the dam (stations 2GC05 and 2GC07) (Table 2-2). However, flows downstream of the dam, at station 2GC04, did show evidence of shifts in the mean, maximum, minimum, as well as seasonal MAMJ and OND flows.

The Malewa River, the second largest contributor to the lake, showed no shifts in the annual mean, maximum, or seasonal flows at its stations (2GB05 and 2GB08), although the minimum flows experienced several abrupt shifts over the past 50 years (Table 2-2). Seasonal OND flows for station 2GB08, however, showed temporal shifts, which were due to higher than average flows that did not last long enough to significantly affect the posterior mean.

The Gilgil River, the third largest contributor to the lake, showed a nearly doubling of the annual discharge recorded at station 2GA03 between 1987 and 2010. This abrupt change was due to sudden periodic increases in the minimum and seasonal flows, while the peak flows remained unaltered (Figure 2-9).

Abrupt changes in the lake volumes were analyzed as well. The observed annual total lake volume fluctuations experienced high probabilities of abrupt changes in the posterior mean (Figure 2-10). After a significant step change in 1961, the lake volumes remained fairly stable, and experienced two upward and four downward abrupt changes between 1973 and 2001. This pattern was quite different from that of the re-constructed lake volume. Instead of 5, only 2 abrupt changes occurred. Reconstructed lake volumes were stable from 1962 until 2000, after which time a decline in posterior mean was observed. 


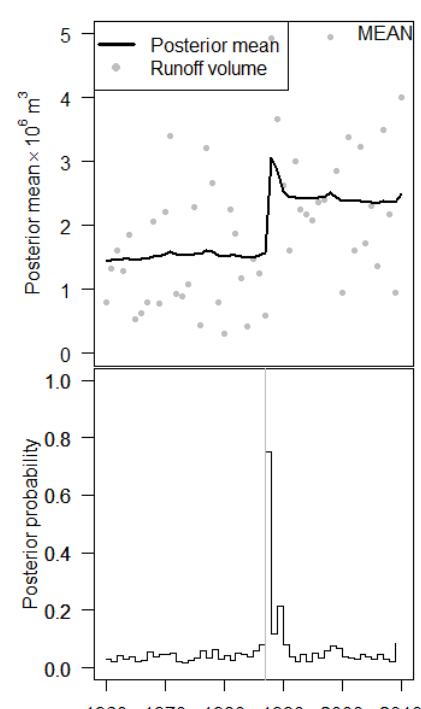

196019701980199020002010

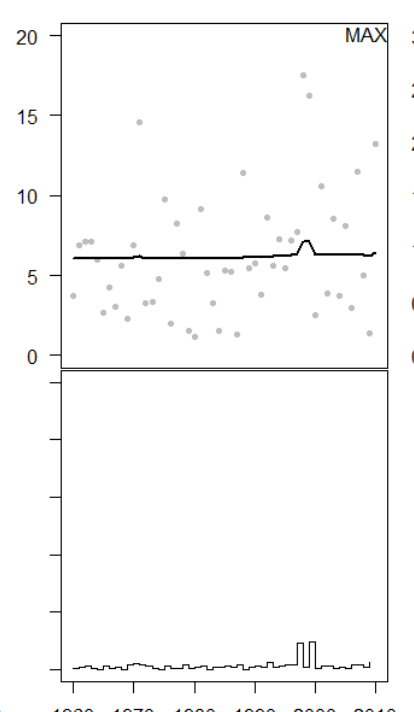

$19601970198019902000 \quad 2010$

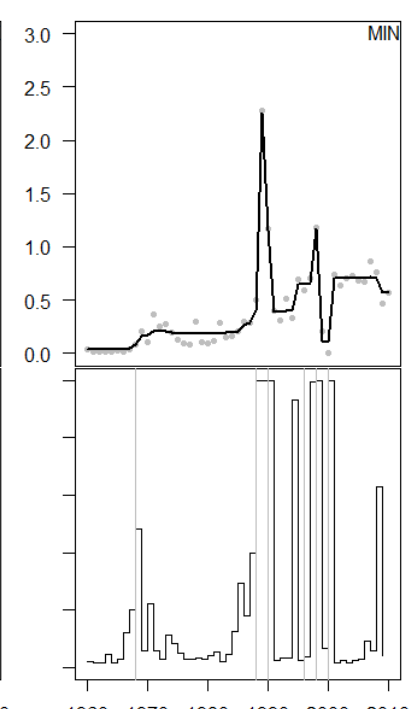

$1960 \quad 19701980199020002010$

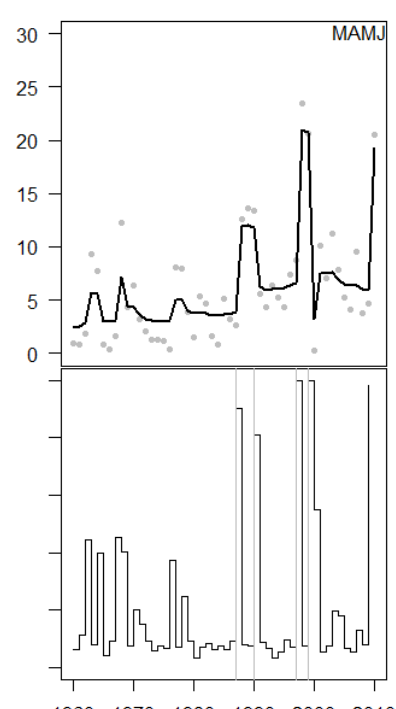

19601980199020002010

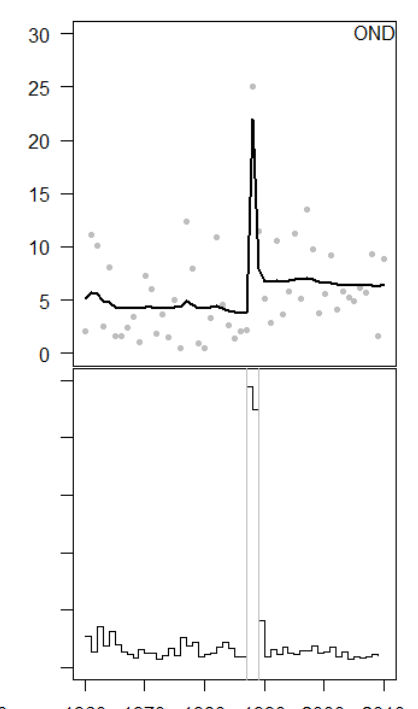

$1960 \quad 1970 \quad 1980 \quad 199020002010$

Figure 2-9: Abrupt shifts (top) and posterior probability distribution (bottom) of the mean, maximum, and minimum annual runoff, as well as the annual runoff in the months March/April/May/June and the months October/November/December, respectively, for the Gilgil River sub-catchment (at station 2GA03) 

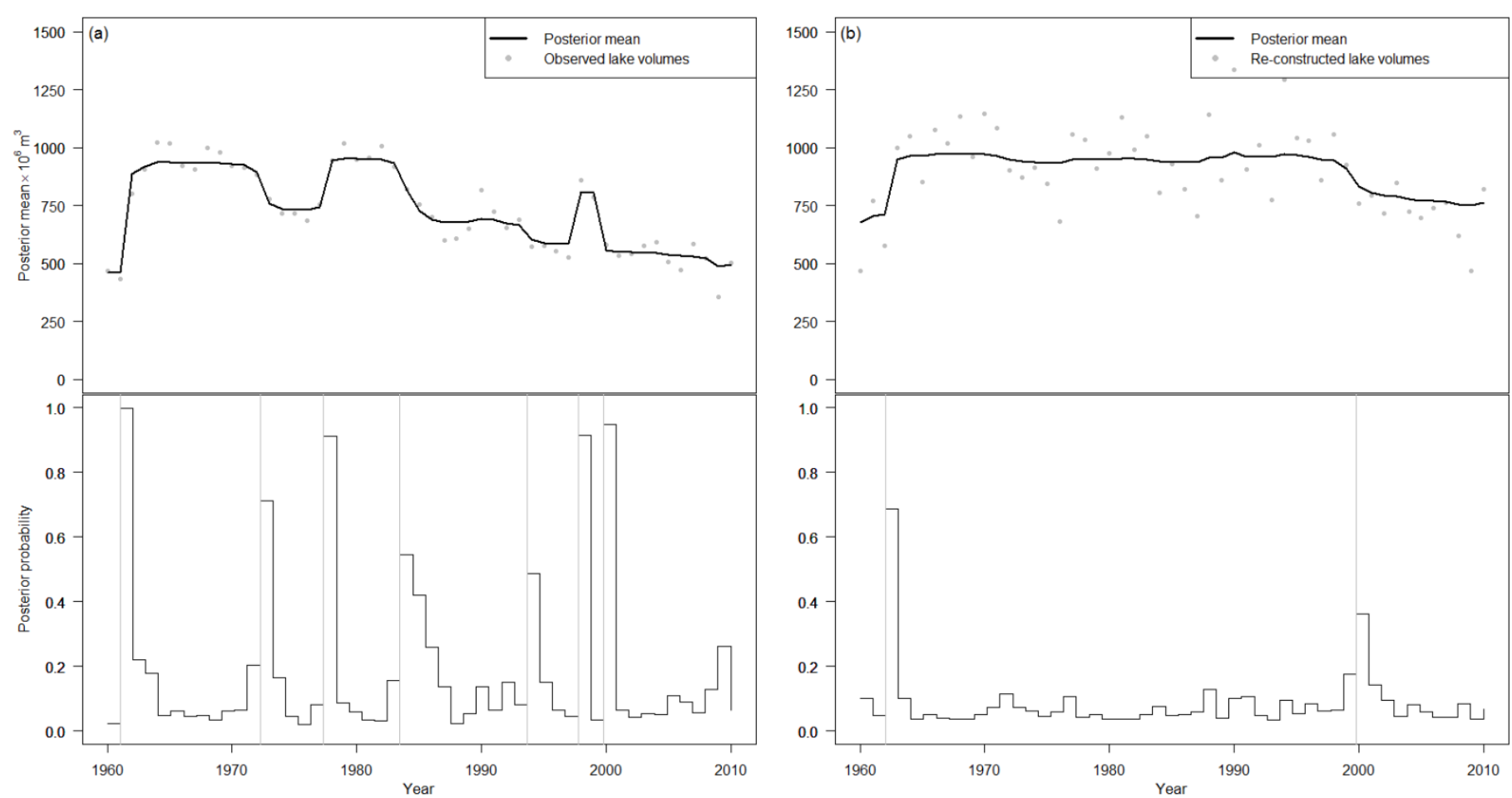

Figure 2-10: Posterior probability distribution of abrupt change points of annual (a) observed mean lake volumes and (b) re-constructed lake volumes 


\subsubsection{Double mass curve analysis}

The double mass curves show that precipitation and total mean outflow from Turasha and Malewa sub-basins were consistently linearly related prior to 1988 (Figure 2-11), as indicated by the slope of the line. After 1988, increased flows were observed, which prevailed until 1998. This shows that precipitation and outflows from the headwaters of the basin varied naturally before 1988. Immediately after 1998, the flows resumed a slope similar to the slope in the period before 1988. The Gilgil subbasin showed an increase in flow of 53\% around 1988, which prevailed until 2010 (Figure 2-12).

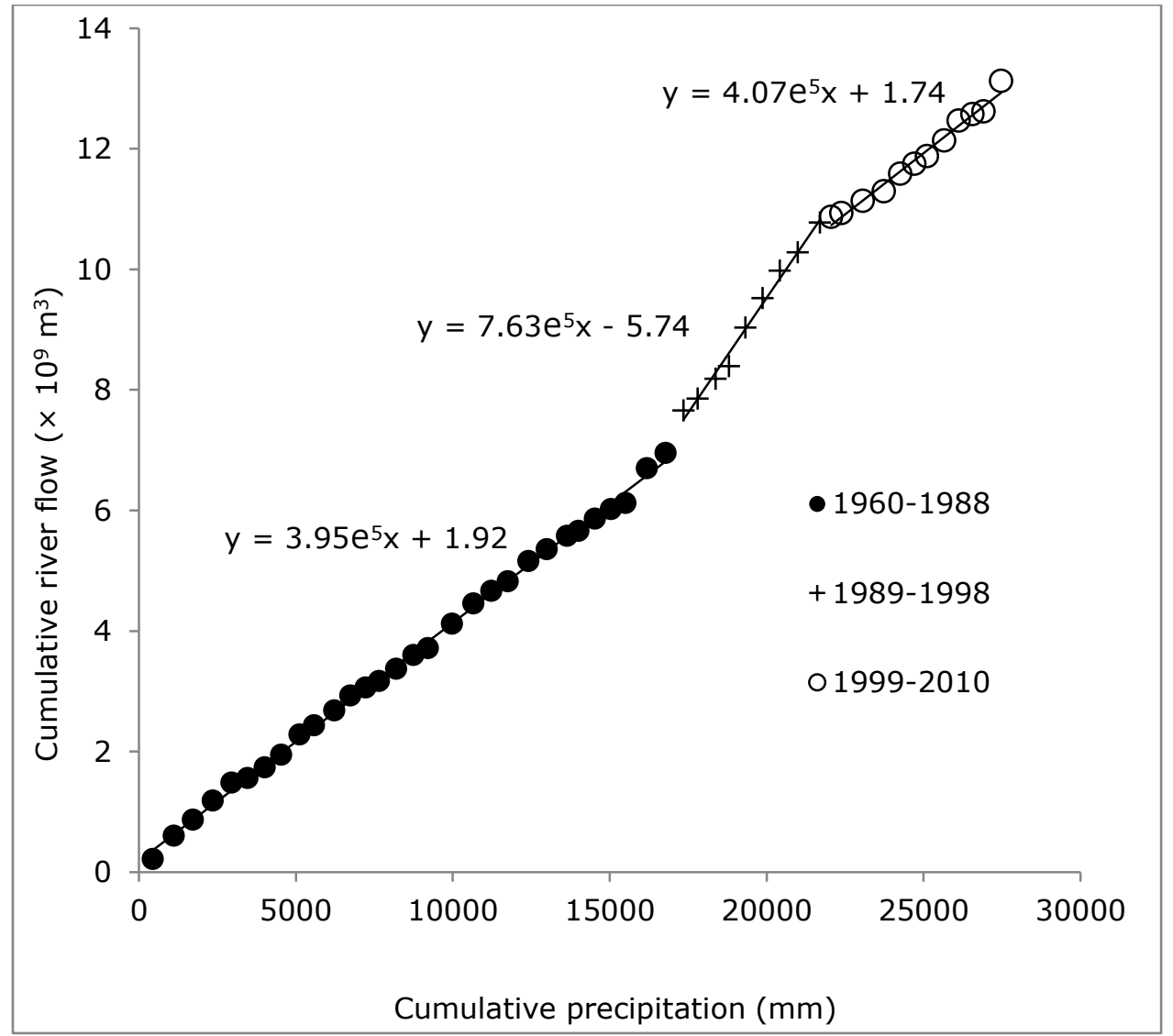

Figure 2-11: Double cumulative curve for annual precipitation and total outflow of the combined Malewa (at 2GB05) and Turasha (at 2GC04) sub-catchments 


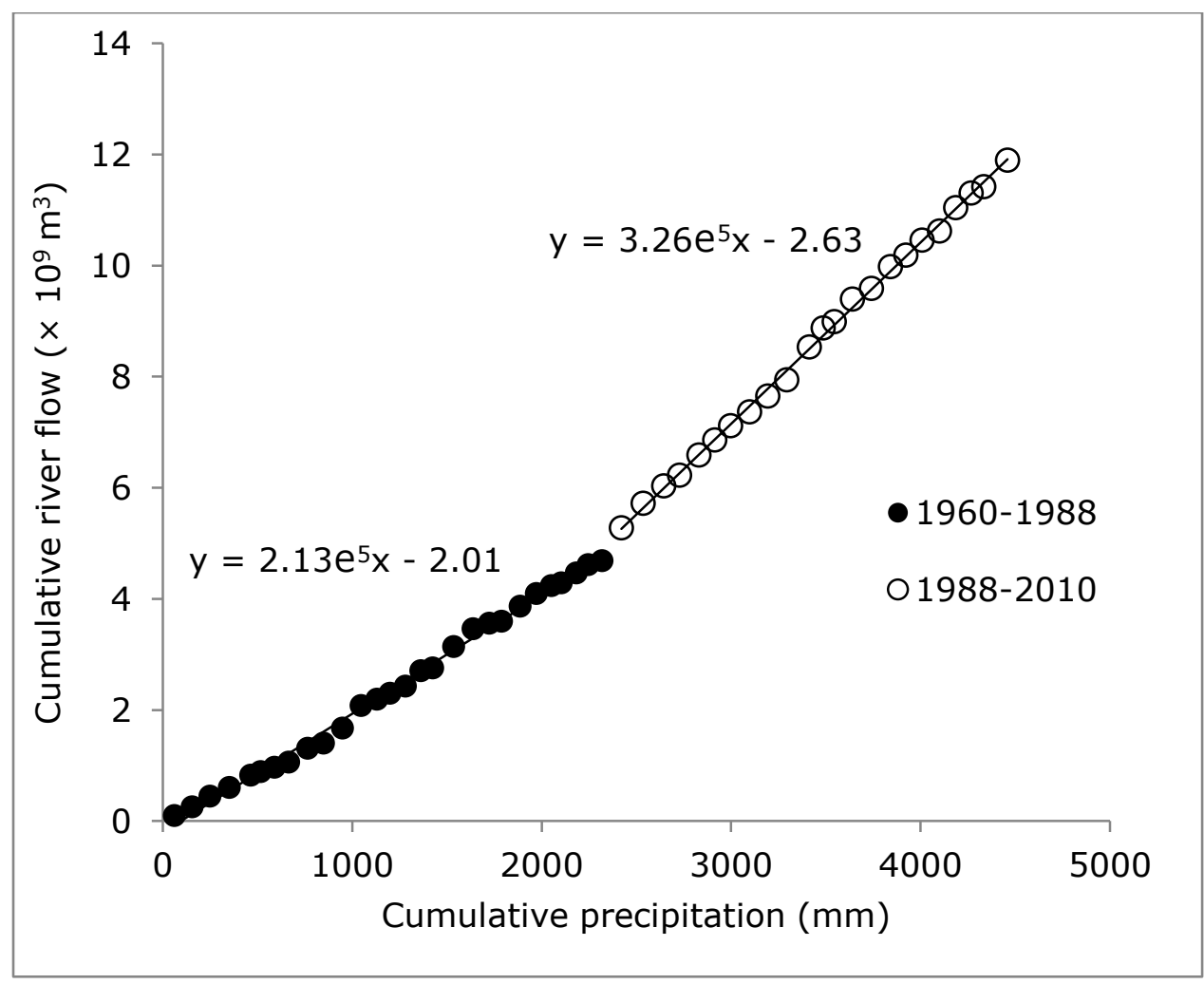

Figure 2-12: Double mass curve for annual precipitation and minimum outflow of Gilgil sub-catchment at station $2 \mathrm{GAO} 3$

Results of the double mass curve analysis used to investigate the influence of water abstraction from the Turasha dam introduced in 1992 showed that, in the absence of abstraction from the system, the minimum flows of the Turasha sub-basin would remain consistent with those in the pre-dam period (Figure 2-13).

Double mass curve analysis of lake volume changes and total flow input to the lake varied linearly until 1987 after which the slope changes (Figure 2-14). After 1988, changes in flow input to the lake resulted in only little change in lake volume. The change in slope between the two periods showed that the lake volume changes were reduced by approximately $46 \%$. Increased difference was observed between the $1: 1$ line and the cumulative curve suggesting that the residual term $(U)$ has increased since 1988. 


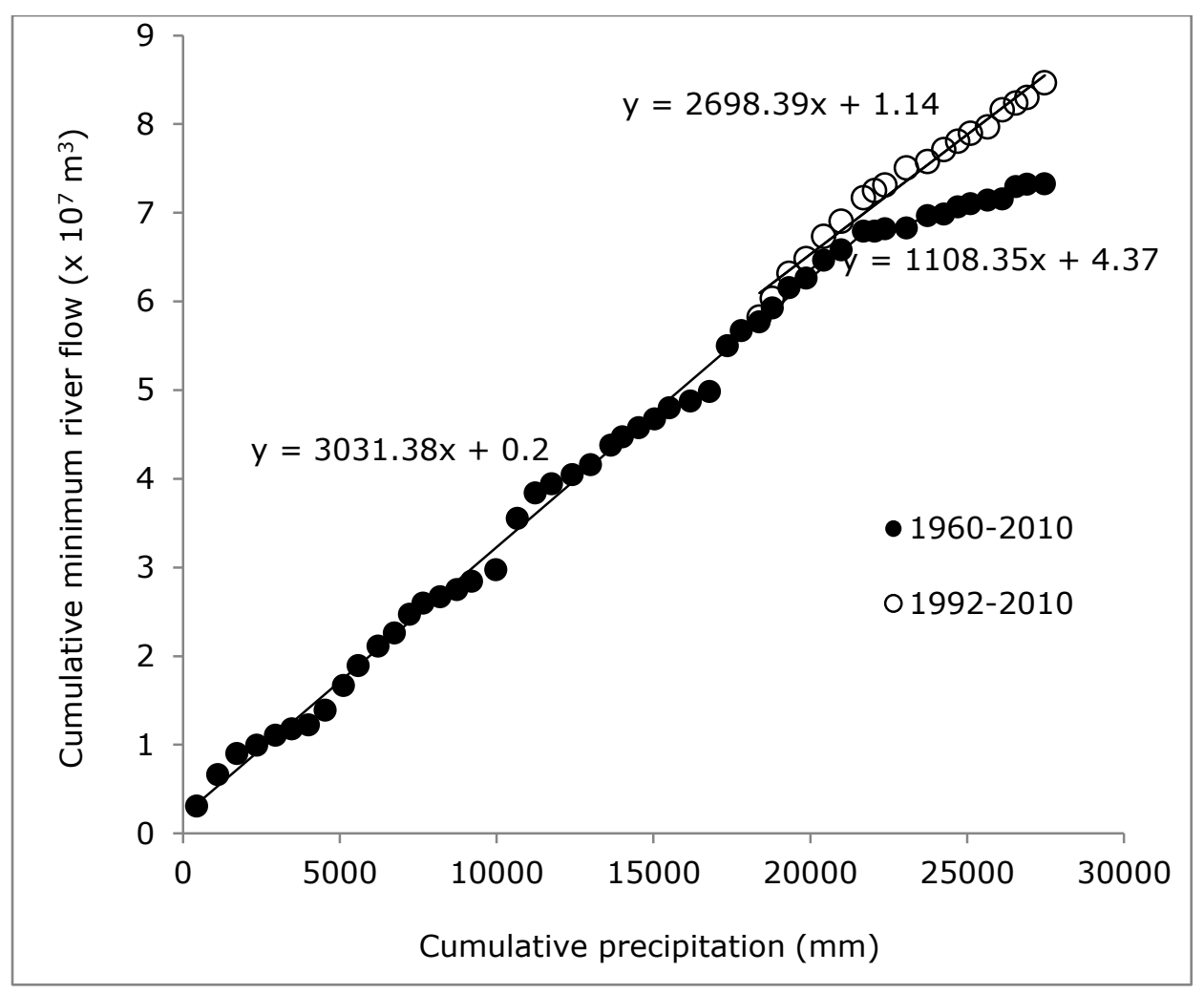

Figure 2-13: Double mass curve for annual precipitation and minimum outflow of Turasha subcatchment at station 2GC04. Open circles represent cumulative minimum river flows with dam abstraction included. Solid circles represent cumulative minimum river flows as observed without abstractions

\subsubsection{Trend analysis}

Trends were detected in the annual mean, maximum, and minimum, as well as the seasonal MAMJ precipitation observed at some stations (Table 2-3) in the Turasha and Malewa sub-catchments. For the Gilgil sub-catchment, however, representative precipitation series data did not exhibit any significant gradual trends. No trends were evident under either the STP or the LTP assumptions.

The MK trend analysis based on STP assumptions for stream flow suggests that mean, maximum, minimum, and seasonal annual flows have experienced an upward trend over the past 50 years for Gilgil River station 2GA03 (Table 2-4). This was further confirmed by subjecting the test to the LTP assumptions, which showed that the Hurst coefficient, which is a measure of LTP, was insignificant in all cases other than the minimum flows. The upward trend was still significant after correcting for LTP in the minimum flows of the Gilgil River at station 2GA03. 


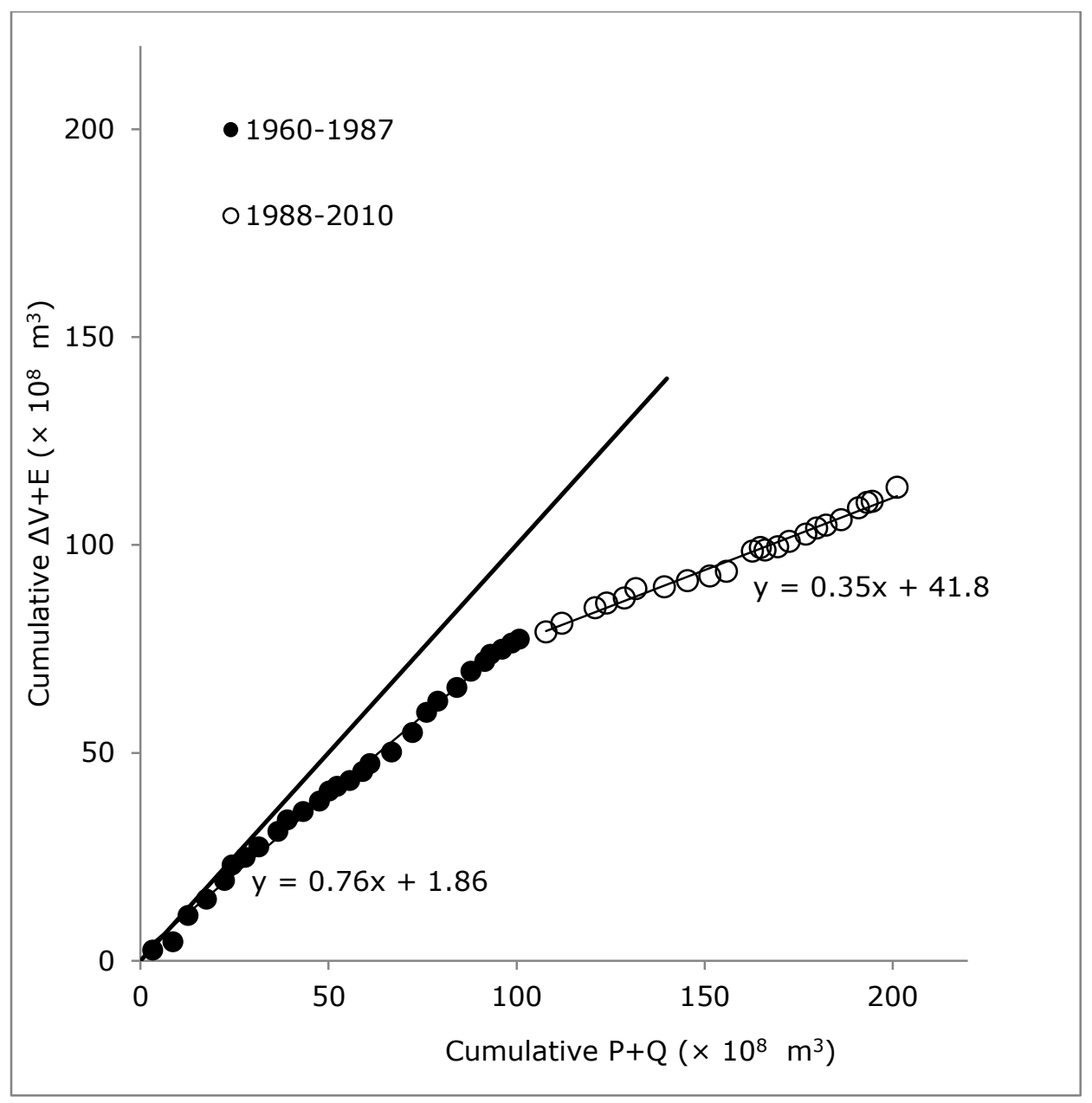

Figure 2-14: Double mass curve of annual lake volume change and total input into the lake. The difference between the $1: 1$ line and the cumulative curve is the cumulative residual term $U$ 
Table 2-3: Modified MK trend results under STP and LTP assumption for precipitation stations.

Significant trends are in bold type and marked with the symbolt

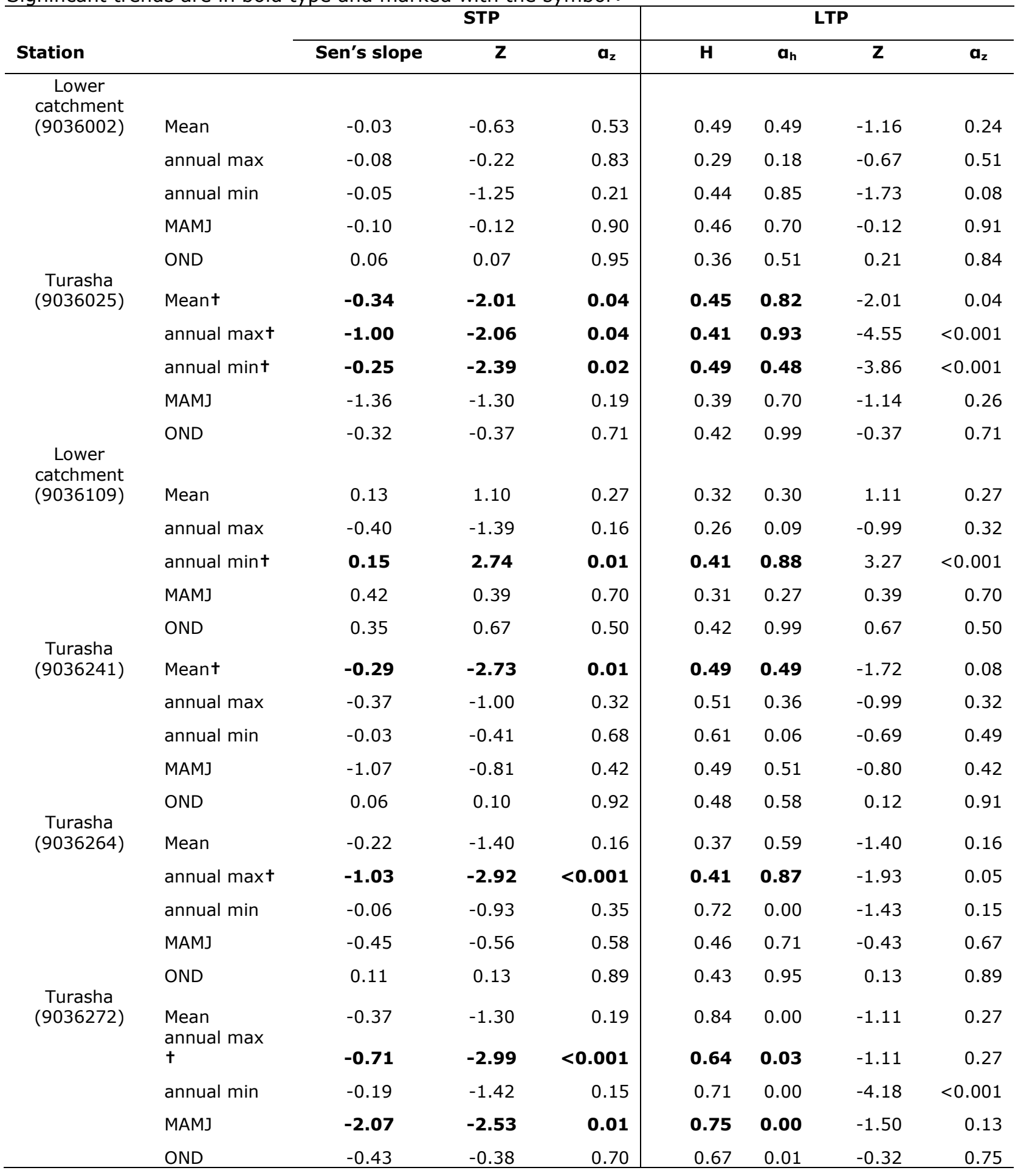


Table 2-3 continued: Modified MK trend results under STP and LTP assumption for precipitation stations. Significant trends are written in bold and marked with the symbol +

\begin{tabular}{|c|c|c|c|c|c|c|c|c|}
\hline \multirow[b]{2}{*}{ Station } & & \multicolumn{3}{|c|}{ STP } & \multicolumn{4}{|c|}{ LTP } \\
\hline & & Sen's slope & $\mathbf{Z}$ & $\mathbf{a}_{\mathbf{z}}$ & $\mathbf{H}$ & $\mathbf{a}_{\mathbf{h}}$ & $\mathbf{Z}$ & $\mathbf{a}_{\mathbf{z}}$ \\
\hline \multirow[t]{5}{*}{$\begin{array}{c}\text { Lower } \\
\text { catchment } \\
(9036281)\end{array}$} & Mean & -0.03 & -0.49 & 0.62 & 0.57 & 0.14 & -0.49 & 0.63 \\
\hline & annual max & -0.19 & -0.58 & 0.56 & 0.39 & 0.74 & -0.58 & 0.56 \\
\hline & annual min & -0.08 & -1.30 & 0.19 & 0.45 & 0.76 & -2.59 & 0.01 \\
\hline & MAMJ & -0.64 & -0.70 & 0.48 & 0.44 & 0.90 & -0.70 & 0.48 \\
\hline & OND & 0.02 & 0.05 & 0.96 & 0.36 & 0.54 & 0.04 & 0.96 \\
\hline \multirow{5}{*}{$\begin{array}{c}\text { Malewa } \\
(9036289)\end{array}$} & Mean & -0.01 & -0.02 & 0.98 & 0.41 & 0.91 & -0.01 & 0.99 \\
\hline & annual max & -0.26 & -1.12 & 0.26 & 0.40 & 0.80 & -0.64 & 0.52 \\
\hline & annual min & -0.04 & -0.41 & 0.69 & 0.70 & 0.01 & -1.04 & 0.30 \\
\hline & MAMJ & 0.11 & 0.13 & 0.89 & 0.39 & 0.72 & 0.13 & 0.89 \\
\hline & OND & 0.29 & 0.86 & 0.39 & 0.51 & 0.39 & 0.47 & 0.63 \\
\hline \multirow{5}{*}{$\begin{array}{c}\text { Malewa } \\
(9036290)\end{array}$} & Mean & 0.19 & 1.09 & 0.27 & 0.56 & 0.18 & 1.26 & 0.21 \\
\hline & annual max & 0.12 & 0.57 & 0.57 & 0.39 & 0.72 & 0.25 & 0.80 \\
\hline & annual min & 0.00 & -0.48 & 0.63 & 0.78 & 0.00 & -0.54 & 0.59 \\
\hline & MAMJ & 0.97 & 0.90 & 0.37 & 0.44 & 0.87 & 0.89 & 0.37 \\
\hline & OND & 1.27 & 1.15 & 0.25 & 0.58 & 0.11 & 1.49 & 0.14 \\
\hline \multirow{5}{*}{$\begin{array}{c}\text { Gilgil } \\
\text { (9036999) }\end{array}$} & Mean & 0.06 & 0.49 & 0.62 & 0.48 & 0.60 & 0.49 & 0.62 \\
\hline & annual max & -0.21 & -0.46 & 0.65 & 0.50 & 0.43 & -1.39 & 0.16 \\
\hline & annual min & -0.05 & -0.90 & 0.37 & 0.57 & 0.13 & -1.15 & 0.25 \\
\hline & MAMJ & 0.29 & 0.34 & 0.73 & 0.37 & 0.59 & 0.34 & 0.73 \\
\hline & OND & 1.31 & 1.58 & 0.11 & 0.51 & 0.37 & 1.57 & 0.12 \\
\hline
\end{tabular}

The MK test revealed that the minimum flows of the Malewa and Turasha River stations experienced significantly declining trends, even after accounting for the LTP behavior. The annual mean, annual maximum, as well as seasonal MAMJ and OND flows did not show any evidence of a trend (Table 2-4). Re-analysis based on the reconstructed minimum flows of the Turasha River, derived by adding the known abstraction from the reservoir, did not show any evidence of a significant trend $(p>0.05)$ either. The minimum flows also exhibited long term persistence behavior, with the Hurst coefficient being significantly greater than 0.5 in all stations. Annual total lake volumes showed a significant, declining trend under STP assumptions, even after accounting for LTP behavior (Table 2-4). The reconstructed lake volumes also showed a significant trend $(p<0.05)$ under STP assumptions; however, this trend was absent after accounting for LTP.

This was further confirmed by subjecting the test to the LTP assumptions, which showed that the Hurst coefficient, which is a measure of LTP, was insignificant in all cases other than the minimum 
flows. The upward trend was still significant after correcting for LTP in the minimum flows of the Gilgil River at station 2GA03.

The MK test revealed that the minimum flows of the Malewa and Turasha River stations experienced significantly declining trends, even after accounting for the LTP behavior. The annual mean, annual maximum, as well as seasonal MAMJ and OND flows did not show any evidence of a trend (Table 2-4). Re-analysis based on the re-constructed minimum flows of the Turasha River, derived from the assumption no water abstraction had taken place at the dam, did not show any evidence of a significant trend either $(p>0.05)$. Minimum flows were found to exhibit long term persistence behavior, with the Hurst coefficient being significantly greater than 0.5 in all stations.

Annual total lake volumes showed a significant, declining trend under STP assumptions, even after accounting for LTP behavior (Table 2-4). The re-constructed lake volumes also showed a significant trend $(p<0.05)$ under STP assumptions; however, this trend was absent after accounting for LTP. 
Table 2-4 : Modified MK trend results under STP and LTP assumption for discharge stations and lake volumes. Significant trends are in bold type and marked with the symbol +

\begin{tabular}{|c|c|c|c|c|c|c|c|c|}
\hline \multirow{2}{*}{ Station } & \multirow{2}{*}{ s } & \multicolumn{3}{|c|}{ STP } & \multicolumn{4}{|c|}{ LTP } \\
\hline & & Sen's slope & $\mathbf{Z}$ & \multirow{2}{*}{$\begin{array}{l}a_{z} \\
0.01\end{array}$} & $\mathbf{H}$ & \multirow{2}{*}{$\begin{array}{l}a_{h} \\
0.66\end{array}$} & $\mathbf{Z}$ & \multirow{2}{*}{$\begin{array}{l}\mathbf{a}_{\mathbf{z}} \\
<0.001\end{array}$} \\
\hline Gilgil (2GA03) & Mean + & 31431.21 & 2.43 & & 0.37 & & 3.07 & \\
\hline & $\begin{array}{l}\text { annual } \\
\text { maxt }\end{array}$ & 47561.42 & 2.14 & 0.03 & 0.36 & 0.55 & 1.32 & 0.19 \\
\hline & annual mint & 14753.61 & 7.70 & $<0.001$ & 0.71 & $<0.001$ & 6.07 & $<0.001$ \\
\hline & MAMJ & 124831.23 & 2.95 & $<0.001$ & 0.53 & 0.26 & 3.06 & $<0.001$ \\
\hline & ONDt & 66852.49 & 1.98 & 0.05 & 0.44 & 0.84 & 1.98 & 0.05 \\
\hline \multirow[t]{5}{*}{ Malewa (2GB05) } & Mean & -46018.72 & -1.07 & 0.28 & 0.34 & 0.42 & -1.07 & 0.28 \\
\hline & annual max & -119674.25 & -1.05 & 0.29 & 0.17 & 0.02 & -0.98 & 0.33 \\
\hline & annual mint & -26480.63 & -4.29 & $<0.001$ & 0.71 & $<0.001$ & -4.09 & $<0.001$ \\
\hline & MAMJ & -24982.13 & -0.15 & 0.88 & 0.43 & 0.92 & -0.15 & 0.88 \\
\hline & OND & -87257.72 & -0.89 & 0.37 & 0.48 & 0.56 & -0.89 & 0.37 \\
\hline \multirow[t]{5}{*}{ Malewa (2GB08) } & Mean & -24135.51 & -0.86 & 0.39 & 0.40 & 0.88 & -0.86 & 0.39 \\
\hline & annual max & -107577.56 & -0.96 & 0.34 & 0.46 & 0.67 & -0.96 & 0.34 \\
\hline & annual min & 9255.42 & 1.17 & 0.24 & 0.83 & $<0.001$ & 1.00 & 0.32 \\
\hline & MAMJ & 24951.46 & 0.21 & 0.83 & 0.55 & 0.18 & 0.23 & 0.82 \\
\hline & OND & -16978.19 & -0.15 & 0.88 & 0.69 & 0.01 & -0.14 & 0.89 \\
\hline \multirow[t]{5}{*}{ Turasha (2GC04) } & Mean & 37881.39 & 0.55 & 0.58 & 0.59 & 0.09 & 0.54 & 0.59 \\
\hline & annual max & 400824.94 & 1.61 & 0.11 & 0.63 & 0.04 & 1.57 & 0.12 \\
\hline & annual mint & -26423.73 & -5.33 & $<0.001$ & 0.72 & $<0.001$ & -2.88 & $<0.001$ \\
\hline & MAMJ & 74400.69 & 0.29 & 0.77 & 0.56 & 0.17 & 0.29 & 0.77 \\
\hline & OND & 132936.23 & 0.83 & 0.41 & 0.37 & 0.63 & 0.86 & 0.39 \\
\hline \multirow[t]{5}{*}{ Turasha (2GC05) } & Mean & 1852.38 & 0.24 & 0.81 & 0.47 & 0.61 & 0.23 & 0.82 \\
\hline & annual max & 18840.72 & 1.06 & 0.29 & 0.65 & 0.02 & 0.71 & 0.48 \\
\hline & annual min & -3232.41 & -1.59 & 0.11 & 0.68 & 0.01 & -1.54 & 0.12 \\
\hline & MAMJ & -41264.91 & -0.71 & 0.47 & 0.46 & 0.70 & -0.71 & 0.48 \\
\hline & OND & 48133.68 & 1.53 & 0.13 & 0.31 & 0.28 & 1.40 & 0.16 \\
\hline \multirow[t]{5}{*}{ Turasha (2GC07) } & Mean & -1515.92 & -0.60 & 0.55 & 0.41 & 0.96 & -0.60 & 0.55 \\
\hline & annual max & -4895.35 & -0.73 & 0.46 & 0.54 & 0.26 & -0.73 & 0.47 \\
\hline & annual min & -467.27 & -0.60 & 0.55 & 0.64 & 0.03 & -0.59 & 0.56 \\
\hline & MAMJ & -10227.83 & -1.48 & 0.14 & 0.40 & 0.89 & -0.76 & 0.45 \\
\hline & OND & 868.51 & 0.15 & 0.88 & 0.28 & 0.17 & 0.15 & 0.88 \\
\hline Lake volumes & Meant & -9354656.35 & -4.25 & $<0.001$ & 0.91 & $<0.001$ & -3.70 & $<0.001$ \\
\hline $\begin{array}{l}\text { Re-constructed Lake } \\
\text { volumes }\end{array}$ & Mean & -4422006.36 & -2.76 & 0.01 & 0.87 & $<0.001$ & -1.86 & 0.063 \\
\hline
\end{tabular}




\subsection{Discussion}

We found no evidence of changes in the mean precipitation in the study area during the last 50 years (Table 2-2) This is agreement with most studies in other parts of the East African region (Seleshi and Zanke, 2004; Shang et al., 2011; Wagesho et al., 2013), which all suggest that there is no evidence of trends in precipitation, although some studies showed a decrease of rainfall in East Africa (Williams and Funk, 2011), while the Inter-governmental Panel for Climate Change (IPCC) in its 4th Assessment Report (AR4) projects an increase in precipitation over Eastern Africa (Boko et al., 2007). A recent hydro-climatological study of the Lake Victoria basin did observe a significant increase in precipitation, while at the same time recording insignificant changes in flows (Nyeko-Ogiramoi et al., 2013). The findings by Nyeko-Ogiramoi et al. (2013) did not report correction for the presence of STP or LTP in their analysis since they used the traditional Mann Kendall statistical method.

As discussed before, trends have to be interpreted with care, and for this reason, the novel approach by Hamed (2008) was adopted here, which takes both STP and LTP into account. This was important because presence of LTP in a stochastic process is known to induce artificial significant trends (Cohn and Lins, 2005).

Despite homogenous observations of precipitation in this study, significant changes were observed in runoff volumes. The fact that precipitation changes are unrelated to changes in river discharge suggests that there must be other underlying causes of the changes in flows, other than precipitation. Two possible explanations: (1) measurement error regarding discharge, (2) changes in surface condition in this part of the basin.

For the Gilgil sub-basin, the steep and confined nature of the upper parts of the sub-catchment coupled with land use and cover changes over the years could have rendered this area vulnerable to increased flows.

For the Malewa and Turasha sub-basins, it was hypothesized that the decline in precipitation observed at a few stations was the cause of the observed significant decline in minimum flow downstream. However, this was not the case as the changes in precipitation were small. It is more likely that a dam for water abstraction caused the decline in minimum flows in that part of the basin, as shown in Figure 2-13. Since 1992 an average of $6.6 \times 10^{6} \mathrm{~m}^{3}$ of water has been abstracted annually from the reservoir and transferred outside the basin (Nakamura et al., 2001). The findings revealed that the water abstraction as a result of the dam did affect the minimum annual flow downstream, while the contribution of gradual changes in precipitation $\left(-0.22 \sim-0.37 \mathrm{~mm} \mathrm{y}^{-1}\right)$ to the decline in minimum flow was much smaller. This was on average one order of magnitude less $\left(1.59 \times 10^{5} \sim 2.68 \times 10^{5} \mathrm{~m}^{3} \mathrm{y}^{-1}\right)$ than the annual dam abstraction. 
The results of the cumulative curve analysis and the fact that the majority of the precipitation stations showed no abrupt changes, suggest that climate change did not affect the hydrological regime of the Lake Naivasha Basin over the past 50 years, but that factors other than precipitation alone were responsible for the changes observed in stream flow. A number of studies (e.g. Cheung et al., 2008; Huo et al., 2008; Siriwardena et al., 2006) that used double mass curve analysis in other regions have shown that human related impacts have caused decline in basin annual total flows. In the case of the Naivasha Basin, however, human impact through abstraction and diversion from the dam was only evident in the annual minimum flows.

Contrary to the observed decline in annual minimum flow due to abstraction, the relation between mean inflow to the lake and precipitation did not change (Figure 2-11). However, increased flows were observed between 1988 and 1998. Immediately after 1998, it can be observed that the flows resumed a trend near similar to the period before 1988. Two possible explanations for the inconsistency in the pattern over this period are proposed here: (1) the construction of the dam, caused sedimentation which changed the cross sectional area of the river, and eventual wash-down during the extreme high flows of El Niño in 1998. or (2) Changes in gauge location, error in the data or changes in the surface condition affecting runoff generation. Unfortunately, we do not have details to confirm either hypothesis.

Double mass curve analysis of the lake water balance components suggested increased residual output $(U)$ in the post 1988 period (Figure 2-14). Increased input to the lake yielded minimal lake volume changes, meaning that the observed gradual decline in lake volume was not due to climatic influences, but mostly due to the increased residual term $U$.

The observed lake volumes declined at a mean rate of $9.35 \times 10^{6} \mathrm{~m}^{3} \mathrm{year}^{-1}$ (Equivalent to $0.06 \mathrm{~m}$ year${ }^{1}$ ) (Table 2-3). This decline was significant under both STP and LTP assumptions. It was further revealed that the lake exhibits long term persistence behavior contrary to the suggestion that the lake is an anti-persistence lake (Tarafdar and Harper, 2008). A re-analysis for evidence of a trend regarding the computed lake volumes was significant $(p<0.05)$ under STP assumption. However, under LTP this trend was found not to be significant. Furthermore, the trend of the re-constructed lake volumes showed a less gradual decline of $4.42 \times 10^{6} \mathrm{~m}^{3}$ year $^{-1}$ (equivalent to $0.03 \mathrm{~m}_{\text {year }}{ }^{-1}$ ) which was insignificant $(p>0.05)$. This rate of decline was about $50 \%$ less than the observed rate of decline. These findings were similar to findings for Lake Victoria reported by Sutcliffe and Petersen (2007), who found that observed lake levels declined but re-constructed lake levels remained unaltered if abstractions from a power plant station were excluded from the water balance.

The absence of a trend in the reconstructed lake volumes and the presence of a trend in the observed lake volumes proves that there has been an increase in the unknown term, $U$ (Figure 2-2). The term $U$ shows considerable interannual variability that is smaller than the variability of $Q_{i}$, but still large 
compared the average $U$. It is unlikely that this variability is caused by interaction with the groundwater, which is expected to depend on lake levels. Abstractions may exhibit some interannual variability. Increased abstractions due to increased population and growth in horticultural industry in the basin have been evidence since the early 1980's (Becht and Harper, 2002). The trend in $U$ may be attributed to abstractions, although we cannot rule out measurement errors. The causes of changes in the residual term $U$ will need to be studied using other methods than our statistical analysis.

It was further observed that the abrupt changes in flows of the Lake Naivasha Basin corresponded with significant gradual trends, making the two changes indistinguishable. Our findings agree with those observed by Xiong and Guo (2004) in the Yangtze Basin where the abrupt and gradual changes in flows were found to be closely related and thus indistinguishable. On the contrary, the two types of changes were distinguishable in the precipitation data for the Lake Naivasha Basin. These observations provide valuable insights into the nature of non-stationarity behavior of the hydro-climatological variables of the Lake Naivasha Basin and contribute useful information to the existing knowledge and future water management plan of the basin. The methodological framework presented in this study provides a means of correcting for anthropogenic influences and testing for trends assuming natural conditions.

\subsection{Conclusions}

Hydro-climatological trends and variability in the Lake Naivasha Basin were explored with the aim of identifying tendencies in precipitation, stream flow and lake volumes that could be attributed to climatic or anthropogenic influences. The findings showed that the precipitation series was fairly homogenous with most stations showing little abrupt or gradual changes. Upstream flows were equally homogenous with few abrupt or gradual changes. However, downstream outflows exhibited a contrast with increasing trends being observed in one part of the basin and declining trends in other parts. These changes were unrelated to the few observed changes in precipitation and have been attributed to dam construction, reservoir abstractions and changes in surface conditions. The combined annual mean total precipitation and inflow into the lake did not correspond with the observed lake decline. Lake volumes were found to experience a significant gradual decline at a mean rate of $9.35 \times 10^{6} \mathrm{~m}^{3}$ year $^{-1}$ (equivalent to $0.06 \mathrm{~m} \mathrm{year}^{-1}$ ). The reconstructed lake volumes; however, showed an insignificant decline that was only half of the decline of the observed lake volumes. The increasing discrepancies between net inflows to the lake volume changes indicate either measurement errors or increased losses through ground water seepage or lake water abstractions. There is no evidence of climate change impacting on the hydrological regime of the Lake Naivasha Basin over the past 50 years, but other factors than precipitation have been responsible for the observed changes in stream flow and lake volume. 


\section{Estimating the evaporative water loss of different land use and land cover in the upper Lake Naivasha Basin*}

\footnotetext{
* This chapter is based on:

Odongo, V. O., van der Tol, C., van Oel, P. R., Becht, R., \& Su, Z. Estimating the evaporative water loss of different land use and land cover in the upper Lake Naivasha Basin (Submitted: Hydrology and Earth System Sciences)
} 


\begin{abstract}
Quantifying evapotranspiration (ET) over heterogeneous land surfaces is important for understanding the interaction between the land surface and the atmosphere and for practical applications in hydrological modelling and integrated water resources management. However, this estimation remains a challenge especially in large heterogeneous and data-sparse environments. This situation is further complicated by land use/cover change which is a critical concern in many places, including the Lake Naivasha Basin in Kenya. Technological advances in the field of remote sensing offer solutions towards more reliable estimates for ET for such cases. This chapter evaluates the spatial and temporal patterns of evapotranspiration in the Lake Naivasha Basin for the period 2003 to 2012 using the Surface Energy Balance System (SEBS) in combination with Moderate-resolution Imaging Spectroradiometer (MODIS) and European Centre for Medium-Range Weather Forecasts (ECMWF) Interim Re-Analysis (ERA-Interim) data. The model was evaluated against 2-year flux measurements from an automatic weather station located at a heterogeneous field. The results indicate that evaporative water use accounted for between $55-86 \%$ of the total water balance in the basin. On average, grasslands, woody savannas and cropland/natural vegetation mosaic accounted for $29 \%, 26 \%$ and $25 \%$ of the total evaporative water in the basin respectively. Closed shrublands, savannas and evergreen forest contributed only $2 \%, 5 \%$ and $7 \%$, respectively. Overall, modelled annual ET over the 10 years suggested a decline from $\sim 724 \mathrm{~mm}$ to $\sim 650 \mathrm{~mm}$. This decline was largely explained by reduction in net radiation jointly with increase in actual vapor pressure and decrease in the air-surface temperature difference. Model validation of SEBS further suggested that the difference between observed and simulated fluxes was likely due to the heterogeneity of the measurement site, the uncertainty in the input data, scale mismatch between input data and measured fluxes at the site and uncertainties inherent in the formulation of the SEBS model. The inclusion of additional local measurements of energy fluxes at different land use/cover landscapes would significantly improve understanding of hydrological processes in the basin and further constrain model simulations.
\end{abstract}




\subsection{Introduction}

Terrestrial evapotranspiration (ET) is a major component in the climate system linking the hydrological, energy and carbon cycles (Jung et al., 2010), since it returns about $60-65 \%$ of the continental precipitation (Brutsaert, 2005) and consumes more than half of the solar radiation absorbed by the land surface (Trenberth et al., 2009). As such, accurate estimation of ET is highly relevant to better understand the climatic and hydrologic processes at appropriate scales for water resources management as well as for climate change impact projections. Continuous direct measurements of ET at large spatial scales over long time periods are limited mostly in Sub-Saharan Africa and there is a profound knowledge gap in understanding climatic and hydrologic processes as influenced by ET in most of this region (Marshall et al., 2012). This challenge is further compounded by complexity of land use and land cover (LULC) changes in the region over the years due to population increases and poor land use planning. At local to regional scales, the impacts of LULC changes on surface radiation budgets, surface hydrology, surface energy balance and surface roughness are not straightforward but rather too complex (Lambin and Geist, 2006) to warrant any generalization. This is because the impacts majorly depend on seasons, climate, and soil conditions (Lambin and Geist, 2006) prevailing at these scales.

Nevertheless, considerable progress in developing algorithms to estimate ET from satellite observations has been made over the last decade. However, large uncertainties in estimation of ET using different methods prevail, majorly due to lack of reference observations at the relevant scales (Mueller et al., 2011). For example in non-humid environment, ET is limited by soil moisture availability. However, soil moisture often varies by an order of magnitude over distances as small as a few meters. Field measurement techniques of soil moisture normally sample less than $1 \mathrm{~m}^{2}$, making it a challenge to gather enough data for meaningful comparisons to be made, for example, with climate or catchment model outputs at scales of $\sim 100 \mathrm{~km}$ (Dolman and de Jeu, 2010). Also, the exact magnitude and spatio-temporal variability of ET are also not fully understood (Miralles et al., 2011; Yin et al., 2013).

Relatively few studies have reported on the evaporative water losses of different land use and land cover classes in Africa (e.g. Farah and Bastiaanssen, 2001; Karimi et al., 2015; Kiptala et al., 2013; Kongo et al., 2011). Understanding the spatial heterogeneity and temporal changes of land use and land cover and its impact on water fluxes is of critical importance towards formulating water allocation plans and water use in river basins (Bastiaanssen et al., 2005). To do so, the relationship between land use, water use and water resources must be described quantitatively (Jewitt, 2006). Natural heterogeneity and the interacting nature of hydrological processes in catchments makes this a complex undertaking (Kongo et al., 2011). However, remote sensing approaches using models like SEBS (Su, 2002), SEBAL (Bastiaanssen et al., 1998), S-SEBI (Roerink et al., 2000), and TSEB (Norman et al., 1995) have shown great potential in estimating ET over large areas using sparse meteorological data with surface heterogeneity being accounted for using remotely sensed data. 
Recent advances in the availability of satellite images at finer to medium spatio-temporal resolutions have further enhanced the potential application of these models (Kiptala et al., 2013) towards understanding hydrological processes at local, regional and global scales. This is especially important in most of Sub-Saharan Africa basins where hydrological processes are less certain due to sparse hydro-meteorological data to draw fundamental conclusions.

An example is Lake Naivasha which has been subject to wide fluctuations of water levels over time and has almost dried in the past years (Abiya, 1996; Gaudet, 1977a; Verschuren et al., 2000). With increased socio-economic activities and population, there have been land use and land cover changes that have impacted on the eco-hydrological processes in the basin (Odongo et al., 2014). Humaninduced land use and land cover changes, ground water withdrawals, and irrigation have been observed to directly alter the quantity and timing of ET by modifying the local water and energy balances (Gedney et al., 2006; Gerten, 2013; Jiafu et al., 2015; Lei et al., 2015; Leng et al., 2013a; Leng et al., 2013b; Lo and Famiglietti, 2013; Sterling et al., 2013). Discriminating these humaninduced perturbations from natural factors is expected to increase in importance as anthropogenic transformations of the earth surface intensify (Gerten, 2013; Jiafu et al., 2015; Seneviratne et al., 2010).

Towards this understanding, Farah and Bastiaanssen (2001) investigated sensitivity of land surface variables on evaporation by delineating heterogeneous land units into homogenous hydrological units in Lake Naivasha basin and observed that evaporation was most sensitive to the surface and air temperature difference as well as surface roughness length for heat transport. Farah et al. (2004) further observed the stability of the evaporative fraction on a diurnal scale at a grassland and woodland site in Lake Naivasha basin. While both of these studies discussed subtly the climatic role on evaporative water losses over different land surfaces, the measurements covered a short term period ( $~ 1$ year) to discern the magnitude, trends and implication of land use and land cover on the evapotranspiration component of basin. On the regional scale however, Marshall et al. (2012) reported decreased evapotranspiration due substantial drying during the growing season over East Africa. The authors also observed a positive correlation between evapotranspiration and precipitation in the region during the growing season. These findings were in agreement with those in Jung et al. (2010) that also reported a general decrease of ET linked to decline in soil moisture supply in the Southern Hemisphere. In this study, we focus on understanding the evaporative losses of different land use and land cover classes, their trends and climatic drivers at the catchment scale using SEBS in combination with MODIS and ECMWF Interim Re-Analysis (ERA-Interim) data to compensate for lack of hydrometeorological observations in Lake Naivasha basin. Whereas long-term human influences on streamflow and lake levels have been studied in the basin (Becht and Harper, 2002; Odongo et al., 2014; Odongo et al., 2015; van Oel et al., 2013), the evaporative losses of different land use and land cover classes, their trends and climatic drivers are largely unknown. 
Therefore the objective of this study was to evaluate the evapotranspiration trend of the different land use/cover classes in the upper Lake Naivasha basin. To accomplish this, the performance of SEBS against observed measurements was also evaluated and discussed. Also, we further investigated the contribution of influencing factors to the seasonal and annual ET between year 2003 and 2012. The estimated ET can further be used to constrain hydrological models towards improved water allocation in the study area.

\subsection{Methods}

\subsubsection{Study area}

The Lake Naivasha basin is situated in the Kenyan Rift Valley at a latitude of $0^{\circ} 09^{\prime}$ to $0^{\circ} 55^{\prime} \mathrm{S}$ and a longitude of $36^{\circ} 09^{\prime}$ to $36^{\circ} 24^{\prime} \mathrm{E}$ (Figure 1-2). The maximum altitude is about $3990 \mathrm{~m}$ above mean sea level (a.m.s.l.) on the eastern side of the Aberdare Mountains and the minimum altitude is about 1980 $\mathrm{m}$ a.m.s.l. near the lake. The basin area is approximately $3500 \mathrm{~km}^{2}$. There are three major subbasins, i.e. Gilgil, Malewa and Turasha. Climatic conditions in the study area vary due to considerable differences in altitude and relief. The daily average temperature ranges from 8 to $30{ }^{\circ} \mathrm{C}$. The rainfall regime within the catchment is influenced by local relief, with the catchment being in the rain shadow of the Aberdare Mountains to the East and the Mau Escarpment to the West. There are two rainy seasons: the 'long rains' occurring between March and June (MAMJ) and the 'short rains' which occur between October and December (OND). Annual lake levels are mostly influenced by these two rainy seasons (Vincent et al., 1979). On average the low land areas towards and near the lake experience an annual total rainfall of $610 \mathrm{~mm}$ and the wettest slopes of the Aberdare Mountains receive up to $1525 \mathrm{~mm}$ of rain a year.

Increasing water demand and land use changes exacerbated by population increase in combination with natural fluctuations have led to occasionally strong decreases of the lake water levels (Olaka et al., 2010; Ondimu and Murase, 2007; Otiang'a-Owiti and Oswe, 2007; Trauth et al., 2010). Low lake levels made the lake ecosystem vulnerable and its fragility is a challenge to conservationists and scientists (Becht and Harper, 2002; Becht et al., 2006; Gherardi et al., 2011; Harper and Mavuti, 2004; Harper et al., 2011). The lake is a RAMSAR wetland (Ramsar, 1996) despite supporting important economic activities including fishing, agriculture, power generation, domestic water supply and tourism (Becht et al., 2005). The catchment population has increased five folds from 250,000 persons in 1980 to over 600,000 persons in 2009 (KNBS, 2009). Demand for water by the horticultural sector and the growing population have recently increased substantially (van Oel et al. 2013), and at the same time land-use changes have affected the water balance and put the ecosystem under pressure (Otiang'a-Owiti \& Oswe, 2007). 


\subsubsection{Ground instrumentation and data processing}

A micrometeorological and flux measurements system was installed by setting up a $5.5 \mathrm{~m}$-high tower in a shrubland wildlife park of the Kenya Wildlife Services Institute (KWSTI) in the Lake Naivasha Basin situated in the Great Rift-Valley in Kenya at $36^{\circ} 27^{\prime} 3.142^{\prime \prime} \mathrm{E}, 0^{\circ} 44^{\prime} 11.748^{\prime \prime} \mathrm{S}$ (Figure 1-2). The elevation at the flux site location is $2000 \mathrm{~m}$ above mean sea level. Wind velocity and virtual temperature fluctuations were measured using a three-dimensional (3D) sonic anemometer (WindMaster (Pro) type 1561, Gill Instruments Limited, Hampshire, UK). The sampling frequency of the sonic anemometer was $10 \mathrm{~Hz}$. Aspirated air temperature and humidity (HFM53, Rotronic Instruments (UK) Limited, West Sussex, UK) were measured at 1.8 and $5.5 \mathrm{~m}$ above ground level. This enabled computation of Bowen ratio. Downward and upward solar and longwave radiation was measured using a NR01 four component radiometer (Hukseflux, Delft, The Netherlands). A tipping bucket rain gauge (0.2MM, Davis Instruments Corp., Hayward, CA, USA) was mounted at $1.5 \mathrm{~m}$ above the ground. Soil temperature profiles were measured using $10 \mathrm{k} \Omega$ NTC (Campbell-107, Campbell Scientific Inc., Logan, UT, USA) installed at 1, 2, 3, 4, 5, 6, 8, 10 and $12.5 \mathrm{~cm}$ depths below the ground. Soil heat flux (HFP01SC, Hukseflux, Delft, The Netherlands) was measured at $0.1 \mathrm{~m}$ below the ground underneath the grass and litter. Correction for heat storage in the upper $10 \mathrm{~cm}$ to obtain the soil heat flux at the surface $\left(G_{o}\right)$ was done using the heat diffusion equation:

$$
G(z, t)=-\lambda \frac{\partial T_{s}}{\partial z}
$$

where $T_{s}$ is the soil temperature $\left({ }^{\circ} \mathrm{C}\right.$ or $\left.\mathrm{K}\right), z$ is the depth into the soil $(\mathrm{m}), \lambda$ is the thermal conductivity of the soil $\left(\mathrm{Wm}^{-1} \mathrm{~K}^{-1}\right) . \lambda$ was solved by linear regression of the measured ground heat flux at $10 \mathrm{~cm}$ depth against modelled vertical temperature gradient at this depth following the procedure by van der Tol (2012). This way, the ground heat flux can then be calculated by extrapolation of the calibrated model to the surface as $G(0, t)$. A detailed description of this analysis technique is described in van der Tol (2012).

Soil water content was measured at 5, 10, 15 and $20 \mathrm{~cm}$ depths using Decagon EM50 5ET soil moisture sensors (Decagon Devices, Inc., Washington, USA). A dielectric leaf wetness sensor (LWS-L Campbell Scientific Inc., Logan, UT, USA) was also set up to monitor presence of dew. Surface temperature was measured using an infra-red remote temperature sensor (IR100, Campbell Scientific, Inc., Logan, UT, USA). Other than the soil moisture sensors which had a separate logger, all other instruments were connected to a CR3000 datalogger (Campbell Scientific, Inc., Logan, UT, USA). Soil water content was recorded at 30-min intervals while the soil heat flux was recorded at 15-min intervals. All other hydrometeorological variables were recorded at 1-min intervals. After a start-up period, the system has been operational since January 2012. A LI-7500 gas analyzer (LI-COR Biosciences, Nebraska, USA) recording at $10 \mathrm{~Hz}$ was introduced for a brief period to monitor fluxes during the transition from dry to wet season ( $21^{\text {st }}$ March 2012 to $9^{\text {th }}$ May 2012). 
The software AltEddy (www.climatexchange.nl/projects/alteddy/) of the Alterra Institute (Wageningen University and Research Center, The Netherlands) was used to process 30-min interval turbulent heat fluxes $(H$ and $L E)$. The flux data processing followed standard protocols that included 2-D axis rotation (Moore, 1986), angle of attack correction (Nakai et al., 2006), Webb correction (Webb et al., 1980), despiking and frequency response correction and Burba's correction for the instrument temperature (Burba et al., 2008). Missing data due to instrument malfunction or power failure were $18 \%$ over the 3 year of measurements. Quality control of the data followed the procedures as developed by Foken et al. (2005) based on statistical stationarity and development of turbulent conditions. For periods when the LI-7500 gas analyzer was not operational an inversion of the Bowen ratio $(\beta)$ formulation $[L E=$ $H / \beta]$ was used to calculate $L E . \beta$ was calculated from vertical gradients of air temperature $[\Delta T / \Delta z]$ and water vapor pressure $[\Delta e / \Delta z]$ as follows:

$$
\beta=\gamma \frac{\Delta T / \Delta z}{\Delta e / \Delta z}
$$

\subsubsection{Remote sensing products and meteorological data}

The Remote sensing products and meteorological data are summarized in the Table 3-1.

Table 3-1: Summary of remote sensing and meteorological data used in the study

\begin{tabular}{|c|c|c|c|c|}
\hline Input data & Source & $\begin{array}{l}\text { Spatial } \\
\text { resolution }\end{array}$ & $\begin{array}{l}\text { Temporal } \\
\text { resolution }\end{array}$ & Coverage \\
\hline \multicolumn{5}{|l|}{ Land surface } \\
\hline temperature & MODIS (MOD11A1) & $1000 \mathrm{~m}$ & Daily & $2003-2013$ \\
\hline Emissivity & MODIS (MOD11A1) & $1000 \mathrm{~m}$ & Daily & $2003-2013$ \\
\hline Albedo & MODIS (MCD43B3) & $500 \mathrm{~m}$ & 16 day & $2003-2013$ \\
\hline NDVI & MODIS (MOD13A2) & $500 \mathrm{~m}$ & 16 day & $2003-2013$ \\
\hline Leaf area index & MODIS (MCD15A2) & $1000 \mathrm{~m}$ & 8 day & $2003-2013$ \\
\hline \multicolumn{5}{|l|}{ Land use/cover (IGBP } \\
\hline classification) & MODIS (MOD12Q1) & $1000 \mathrm{~m}$ & Annual & $2003-2013$ \\
\hline \multicolumn{5}{|l|}{ Shortwave down- } \\
\hline welling radiation & ECMWF & $\sim 12.5 \mathrm{~km}$ & 3 hourly & $2003-2013$ \\
\hline \multicolumn{5}{|l|}{ Longwave down- } \\
\hline welling radiation & ECMWF & $\sim 12.5 \mathrm{~km}$ & 3 hourly & $2003-2013$ \\
\hline Air temperature & ECMWF & $\sim 12.5 \mathrm{~km}$ & 3 hourly & $2003-2013$ \\
\hline Surface pressure & ECMWF & $\sim 12.5 \mathrm{~km}$ & 3 hourly & $2003-2013$ \\
\hline Dew point temperature & ECMWF & $\sim 12.5 \mathrm{~km}$ & 3 hourly & $2003-2013$ \\
\hline Wind & ECMWF & $\sim 12.5 \mathrm{~km}$ & 3 hourly & $2003-2013$ \\
\hline
\end{tabular}


The main meteorological variables influencing the SEBS calculations are soil/surface temperature, air temperature, dew temperature, surface pressure, sea level pressure, radiation components, and wind speed. All these variables, with a temporal resolution of $3 \mathrm{~h}$ and spatial resolution of $0.125 \circ \times 0.125$, were retrieved from the ECMWF website (http://data-portal.ecmwf.int/). The land surface variables (emissivity, land surface temperature, albedo, NDVI, and LAI) used in SEBS were obtained from the MODIS website (http://modis-land.gsfc.nasa.gov/).

\subsubsection{Observed runoff and precipitation data}

Runoff and precipitation data were obtained from the Water Resources Management Authority (WRMA) of the Government of Kenya. Runoff data from 2003 to 2010 of the three outlet stations discharging into the Lake and seven precipitation stations within the upper basin were used in the analysis (Figure 1-2).

\subsubsection{Implementing SEBS}

The SEBS algorithm (Su, 2002) was used to estimate the atmospheric turbulent fluxes. First the model was run using ground measurements and NDVI data obtained from MODIS as input. The simulated turbulent fluxes were then compared to those estimated by Bowen ratio estimate from measurements to evaluate the model performance against observation. Later, the turbulent fluxes and available energy were simulated using satellite earth observation from MODIS and meteorological data from ECMWF shown in and also compared with measurements from the Bowen estimate instrument. The outputs of these were spatial maps of latent heat flux from which evaporative water losses from the catchment was extracted for each land use/cover class in GIS. The land use/cover classes were obtained from MODIS MCD12Q1 product covering the period 2002-2013. The SEBS algorithm makes use of the energy balance equation;

$$
R_{n}=H+L E+G_{o}
$$

where $R_{n}$ is the net radiation, $H$ is the sensible heat flux, $L E$ is the latent heat flux and $G_{o}$ is the ground heat flux. The net radiation $\left(R_{n}\right)$ is calculated using;

$$
R_{n}=(1-\alpha) R_{\text {swd }}+\varepsilon R_{l w d}-\varepsilon \sigma T_{\text {surf }}^{4}
$$

where $\alpha$ is albedo, $R_{s w d}$ and $R_{l w d}$ are the shortwave and longwave down-welling solar radiation $\left(\mathrm{Wm}^{-2}\right.$ ) respectively, $\varepsilon$ is the surface emissivity, $\sigma$ is the Stefan-Boltzmann constant $\left(5.67 \times 10^{-8} \mathrm{Wm}^{-2} \mathrm{~K}^{-4}\right)$ and $T_{\text {surf }}$ is the surface temperature $(\mathrm{K})$. The soil heat flux $\left(G_{o}\right)$ is calculated using the following equation; 


$$
G_{o}=R_{n}\left[\Gamma_{c}+\left(1-f_{c}\right) \cdot\left(\Gamma_{s}-\Gamma_{c}\right)\right]
$$

where the $\Gamma_{c}=0.05$ (Monteith, 1973) and $\Gamma_{S}=0.315$ (Kustas and Daughtry, 1990) are empirical constants representing the ratio of the ground heat flux to net radiation for full canopy limit and bare soil limit respectively. $f_{c}$ is the fractional vegetation cover. The sensible heat flux was estimated using Monin-Obukhov similarity theory (MOST) as follows;

$$
H=k u_{*} \rho C_{p}\left(\theta_{0}-\theta_{a}\right)\left[\ln \left(\frac{z-d}{z_{0 h}}\right)-\Psi_{h}\left(\frac{z-d}{L}\right)+\Psi_{h}\left(\frac{z_{0 h}}{L}\right)\right]^{-1}
$$

where $H$ the sensible heat flux, $k$ is the von Kármán constant $(0.41) . u_{*}$ is the friction velocity $\left[\mathrm{ms}^{-1}\right.$ ], $\rho$ is the density of air $\left[\mathrm{kg} \mathrm{m}^{-3}\right], C_{p}$ is specific heat for moist air $\left[\mathrm{J} \mathrm{kg}^{-1} \mathrm{~K}^{-1}\right], \theta_{0}$ is the potential temperature at the surface $[\mathrm{K}]$ estimated using the Poisson's equation, $\theta_{o}=T_{\text {surf }}\left(\frac{P_{s}}{P}\right)^{0.286}$, where $P_{S}$ and $P$ are the standard sea-level pressure and reference pressure respectively, $\theta_{a}$ is the potential air temperature at height $z[\mathrm{~K}]$ estimated using the Poisson's equations $\theta_{o}=T_{\text {air }}\left(\frac{P_{s}}{P}\right)^{0.286}$ where $T_{\text {air }}$ is the ECMWF air temperature. $d$ is the zero plane displacement height [m] (Equation $7 c$ in Chen et al. (2013)),$\Psi_{h}$ is the stability correction function for sensible heat transfer, $L$ is the Obukhov length [m], $z_{0 h}$ is the roughness height for heat transfer [m] calculated as follows;

$$
z_{0 h}=\frac{z_{0 m}}{\exp \left(k B^{-1}\right)}
$$

where $B^{-1}$ is the inverse Stanton number. $k B^{-1}$ is dependent on the fractional vegetation and soil cover as implemented in Chen et al. (2012). $z_{0 m}$ is the roughness height for momentum transfer [m] estimated as follows;

$$
\frac{z_{0 m}}{h}=\left(1-\frac{d}{h}\right) e^{-k u(h) / u_{*}}
$$

where $h$ is the height of the canopy [m] (Equation 8 in Chen et al. (2013)) and $u(h)$ is the wind speed at the top of the canopy $\left[\mathrm{ms}^{-1}\right]$. The actual sensible heat flux $H$ defined in Equation (3-3) is constrained between $H$ at the dry and wet limits. At the dry limit, $L E$ is considered zero due to lack of moisture and $H$ is at a maximum value. At the wet limit, $H$ is at a minimum value and evaporation is not limited by available moisture but by available energy. As such, relative evaporation $\left(\Lambda_{r}\right)$ can be calculated as follows; 


$$
\Lambda_{r}=1-\frac{H-H_{w e t}}{H_{d r y}-H_{w e t}}
$$

where $H_{d r y}$ and $H_{\text {wet }}$ are the sensible heat fluxes at the dry and wet limit respectively. The evaporative fraction $(\Lambda)$ is then estimated by;

$$
\Lambda=\frac{L E}{R_{n}-G_{o}}=\frac{\Lambda_{r} \cdot L E_{w e t}}{R_{n}-G_{o}}
$$

where $L E_{\text {wet }}$ is the latent heat flux at the wet limit. The latent heat flux $(L E)$ is then calculated by;

$$
L E=\Lambda .\left(R_{n}-G_{o}\right)
$$

Finally the daily actual evapotranspiration $\left(E T_{\text {daily }}\right.$ ) is estimated based on the assumption that $\Lambda$ is approximately equal to instantaneous value.

$$
E T_{\text {daily }}=8.64 \times 10^{7} \times \frac{\Lambda \overline{R_{n}}}{\lambda \rho_{w}}
$$

where $E T_{\text {daily }}$ is actual evapotranspiration $\left(\mathrm{mm} \mathrm{d}^{-1}\right), \lambda$ is the latent heat of vaporization $\left(\mathrm{J} \mathrm{kg}^{-1}\right), \overline{R_{n}}$ is the daily net radiation and $\rho_{w}$ is the density of water $\left(\mathrm{kg} \mathrm{m}^{-3}\right)$.

The SEBS model was simulated on a daily time step. The model simulation results had missing days since it is difficult to retrieve a dataset from remote sensing without gaps due to the temporal resolution, cloud coverage, sensor failures and unreliable data flagged by the quality control of MODIS on the surface variables such as land surface temperature and emissivity. To overcome this, we employ the approach of Gokmen et al. (2013) and Jin et al. (2013) where the sum of available daily $E T$ estimates is divided by the number of days with available $E T$ to be representative of the daily monthly average $E T$. Later this is multiplied by the total number of days for each month to get the monthly total $E T$ and the summation of the monthly $E T$ yields estimates of annual $E T$.

\subsection{Results and discussions}

\subsubsection{SEBS model evaluation}

Results of SEBS performance against flux tower are presented in Figure 3-1. $R_{n}$ was underestimated with an RMSE of 27.43 and $45.97 \mathrm{Wm}^{-2}$ per month for year 2012 and 2013 respectively while $L E$ was overestimated with an RMSE of 28.83 and $35.34 \mathrm{Wm}^{-2}$ per month for year 2012 and 2013 
respectively. Simulated $H$ and $G_{0}$ were fairly comparable to measured fluxes for year 2012 but were overestimated for year 2013. The mismatch between observed and simulated fluxes could partly be attributed to lack of energy balance closure in measurements while SEBS closes the energy balance. Other reasons for mismatch could be heterogeneity of the flux tower site and the low spatial resolution of the remote sensing and meteorological products used as input into the model. Uncertainties of flux simulation using SEBS associated with spatial resolution of input data or cloud/aerosol presence are also known to contribute to the differences between observed data and SEBS results (Pardo et al., 2014).
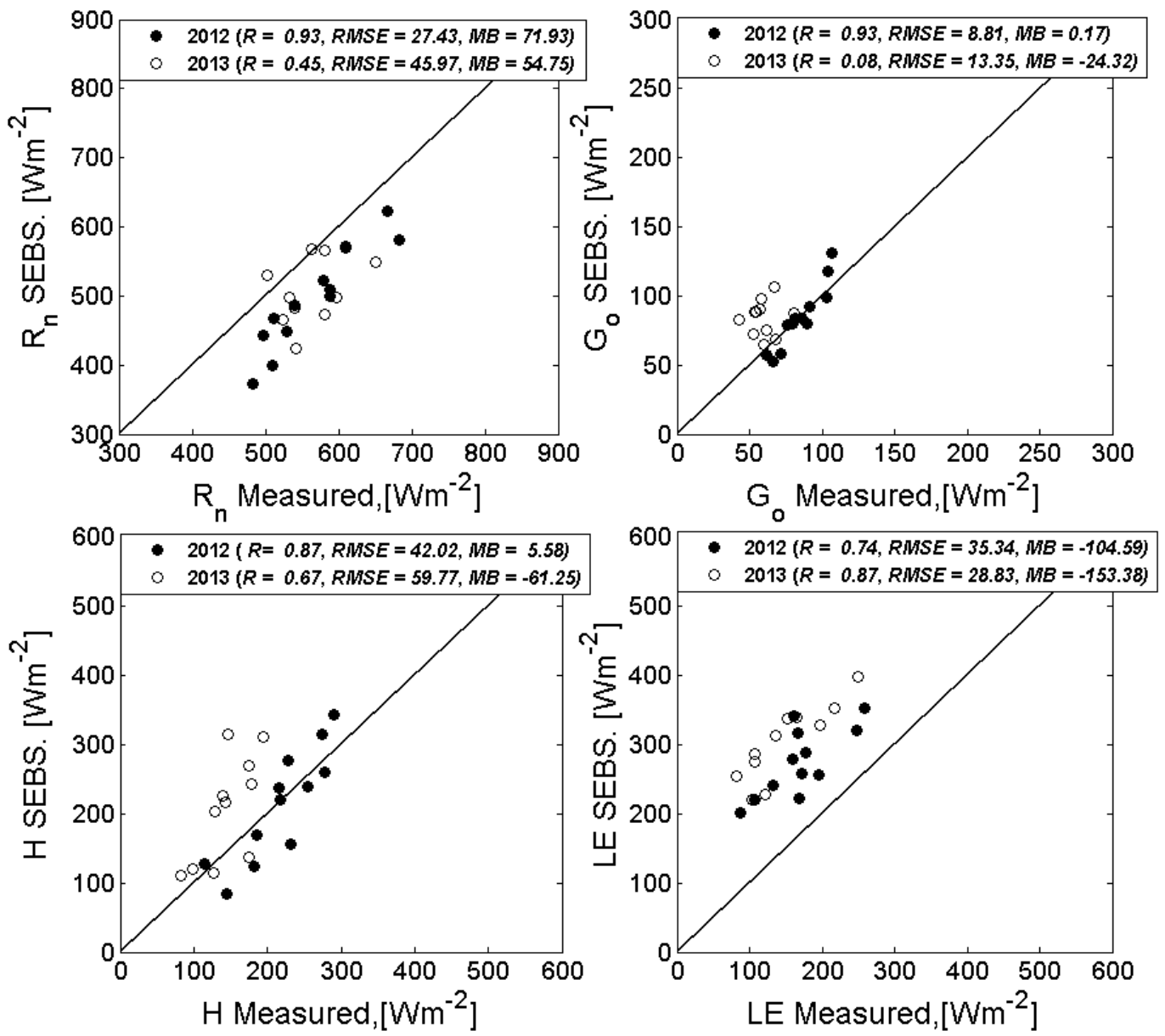

Figure 3-1: Comparison of SEBS performance in simulating monthly fluxes against measured fluxes

Comparison of measured air temperature with ECMWF air temperature suggested that ECMWF underestimated air temperature with a mean bias of $\sim 1^{\circ} \mathrm{C}$ (Figure $3-2$ ). On the contrary, MODIS land surface temperature was overestimated compared to the ground measured surface temperature with a mean bias of $0.93{ }^{\circ} \mathrm{C}$. The estimation of sensible heat flux presents greatest challenge in energy balance studies than the estimation of the available energy flux (Ershadi et al., 2013). Previous studies (e.g. van der Kwast et al., 2009) have estimated deviation of up to $70 \%$ in SEBS simulated $H$ 
due to small changes $\left(\sim 0.5^{\circ} \mathrm{C}\right)$ in surface temperature over an irrigated field. Other surface energy balance models e.g. Two-Source Energy Balance (TSEBS) (Norman et al., 2000) have also been found sensitive to changes in surface temperature causing errors of up to $75 \%$ in the estimated sensible heat flux (Timmermans et al., 2007). Previously, Kustas and Norman (1997), had reported that $\pm 3 \mathrm{~K}$ uncertainty in the difference of surface temperature and air temperature could lead to over $50 \%$ variation in $H$ estimated using the TSEBS model.

The defined pixel size of input data used in SEBS covered a much larger area than that of the flux tower footprint of our study area. A flux footprint analysis following Hsieh et al. (2000) showed that over $80 \%$ of the measured turbulent heat fluxes originated from within $\sim 450 \mathrm{~m}$ and $5000 \mathrm{~m}$ of the tower during unstable and stable conditions respectively (Figure 3-3). The diurnal footprint was about $45 \%$ of the resolution of SEBS output. Moreover, the lack of energy balance closure, partly due to heterogeneity of the landscape at the flux tower site reported as $\sim 0.65$ (Odongo et al., 2016) may contribute to further uncertainty in the validation of SEBS fluxes with the measured fluxes. It has been previously noted that SEBS estimated sensible heat fluxes relate well with measured fluxes over homogenous landscapes but when different land cover types exist within the measurement footprint, errors are introduced by the land surface variables aggregated to the size of image pixels used as input for the model (van der Kwast et al., 2009).

Uncertainty due SEBS model formulation was also evaluated whereby the turbulent fluxes were simulated primarily using measured tower data with NDVI retrieved from MODIS included as the only remotely input. The results of simulated turbulent heat fluxes are presented in Figure 3-4. The results suggest a general underestimation of $H$ for some periods. This is expected of surface energy balance models and has been the subject of on-going studies (Gokmen et al., 2012; Pardo et al., 2014). Specifically, the $\mathrm{kB}^{-1}$ parameter has been known to vary widely in areas with sparse vegetation (Gokmen et al., 2012; van der Tol et al., 2015). For our study site kB-1 ranged between -2.03 to 4.16 within the year. While surface energy balance models like SEBS are able to reproduce the full range of $\mathrm{kB}^{-1}$, its evolution over time is not without uncertainty in the estimation of $H$ (Figure 3-5). Values of $\mathrm{kB}^{-1}<0$ were observed to lead to higher root mean square error, mean bias and reduced slope of simulated $H$ compared to observed $H$. As such the slight over and underestimation of turbulent fluxes by SEBS can be explained by model simplifications, natural variability in system response, and issues of measurement or sampling errors inherent in the input data for both physical and empirical models (Ershadi et al., 2013; Kalma et al., 2008; Samanta et al., 2007; Timmermans et al., 2013). 

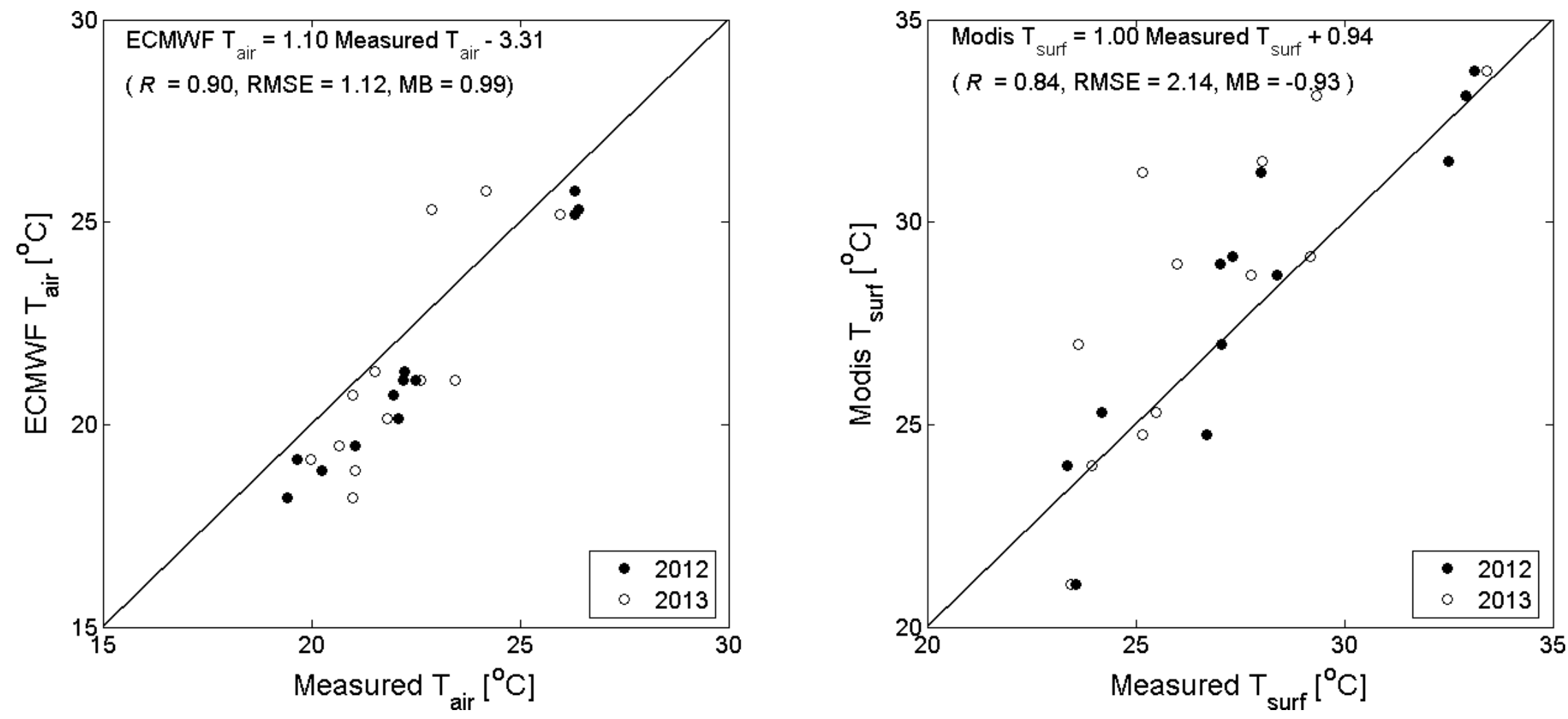

Figure 3-2: Comparison of mean monthly measured air temperature and ECMWF air temperature (left) measured surface temperature and MODIS land surface temperature (right) 
Fetch for Stable Conditions

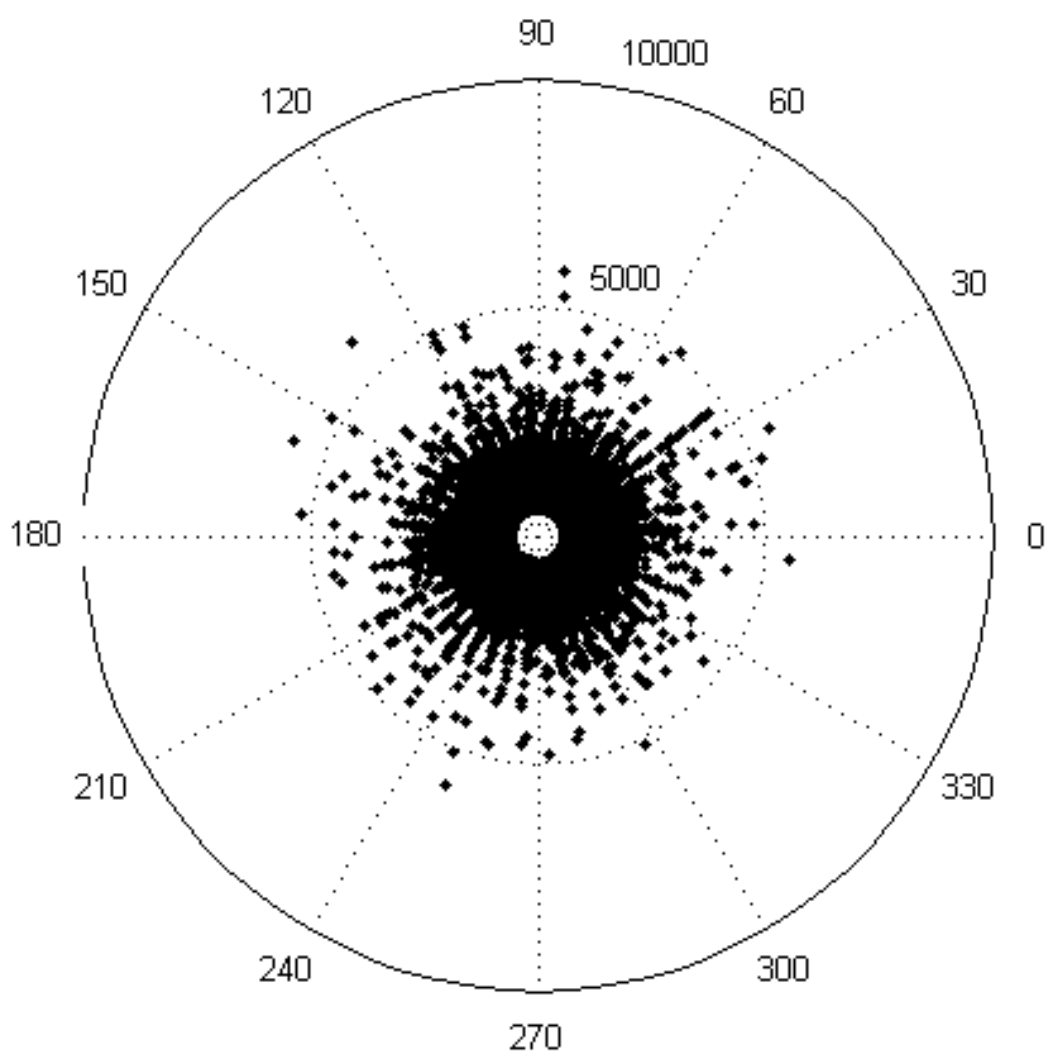

Fetch for Unstable Conditions

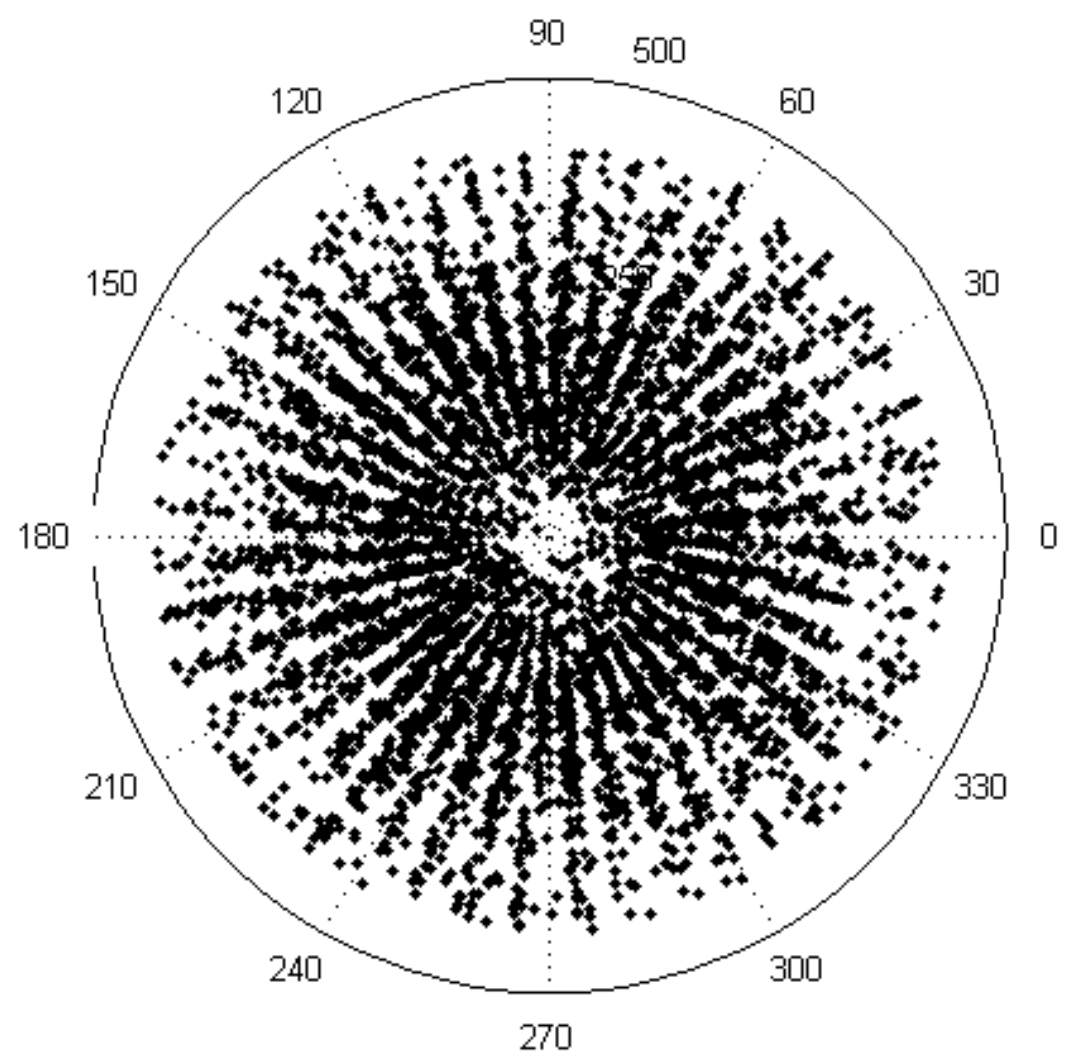

Figure 3-3: Flux footprint analysis following Hsieh et al. (2000) around the flux tower. Under stable conditions the flux footprint was within $5000 \mathrm{~m}$ radius of the tower while during unstable conditions the flux footprint was within $450 \mathrm{~m}$ of the measurement tower 

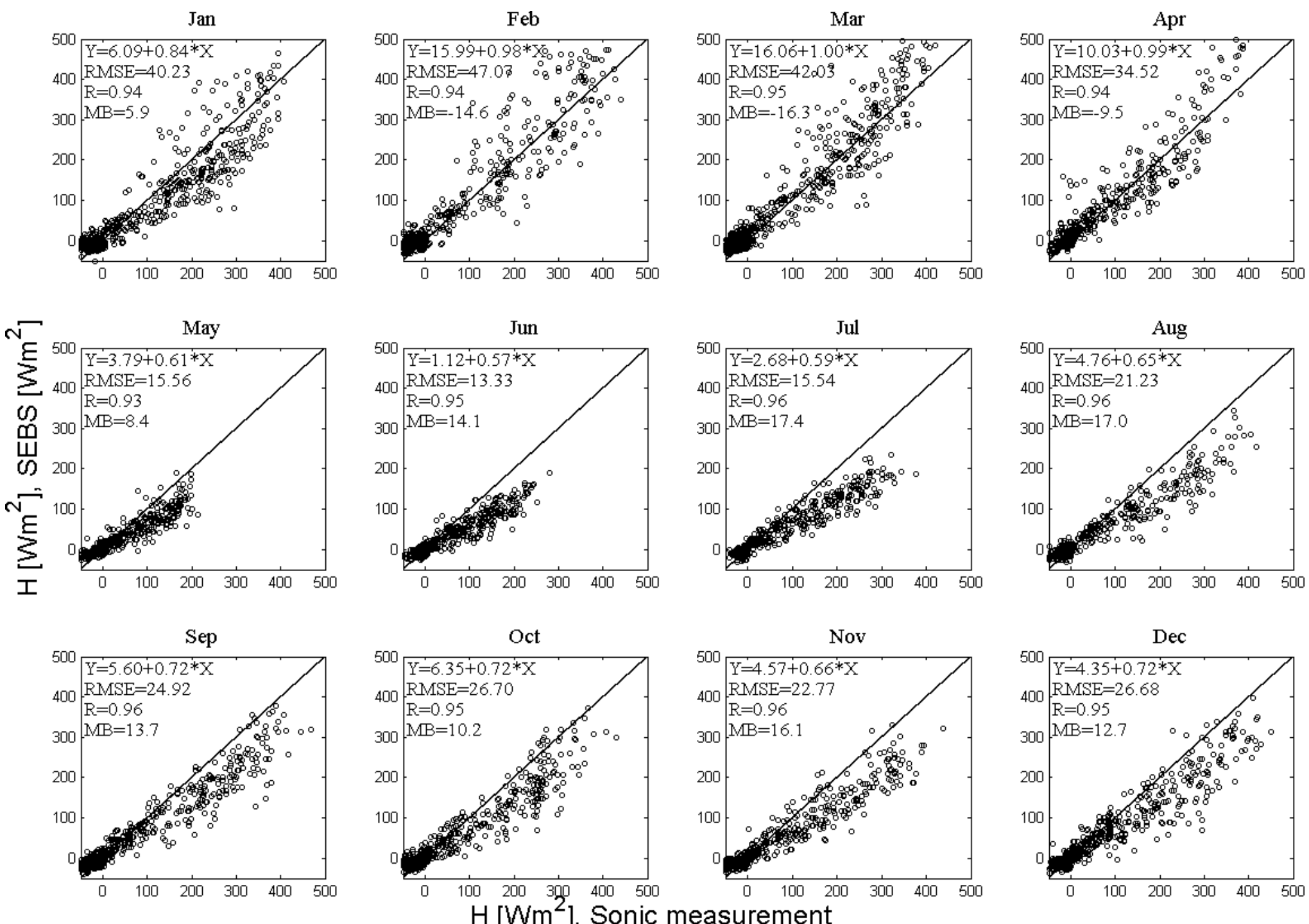

Figure 3-4: Monthly comparison of sensible heat flux between SEBS simulation and sonic anemometer measurement using ground measured data for 2012 


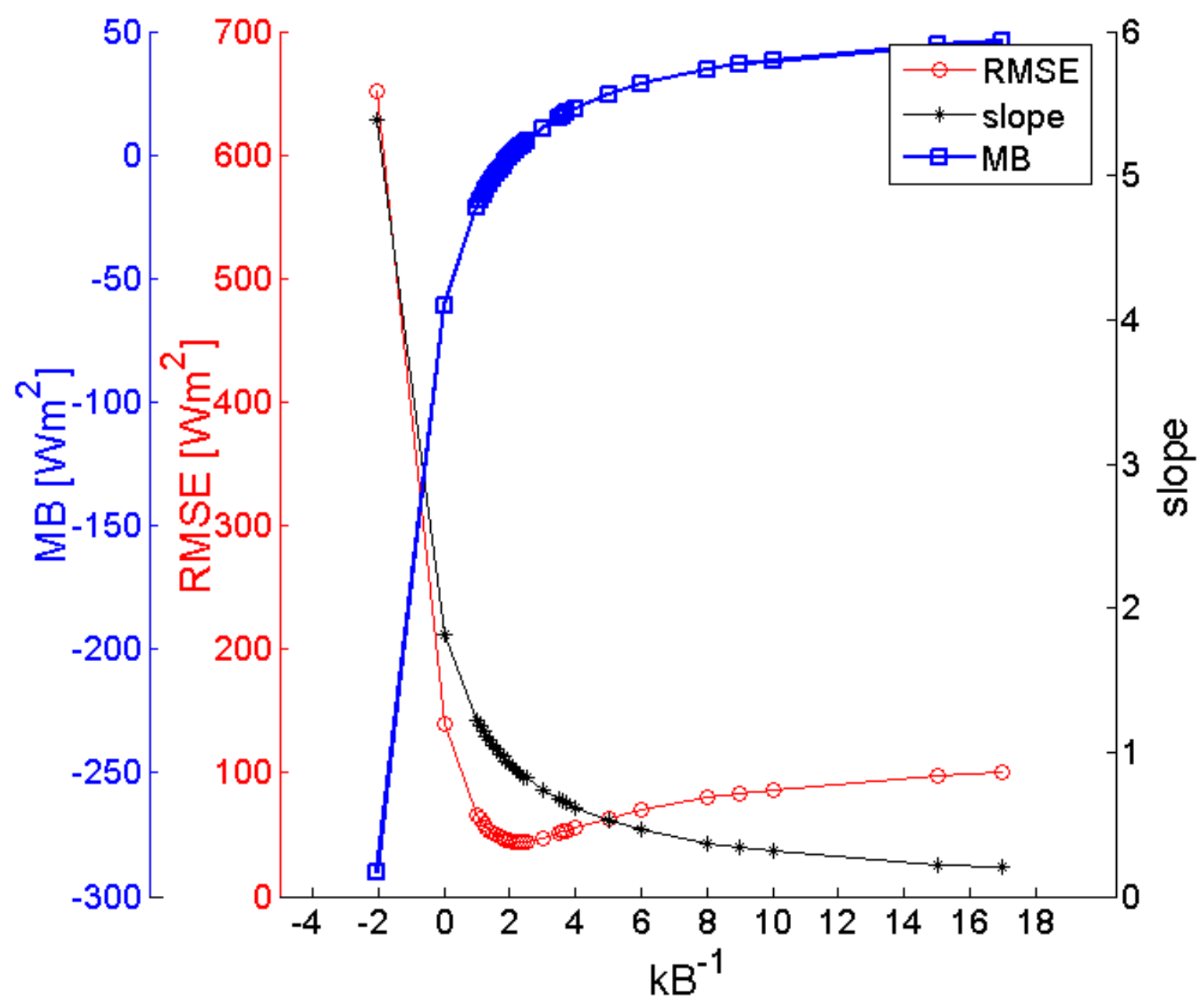

Figure 3-5: Effect of varying $\mathrm{kB}^{-1}$ on simulated sensible heat flux against measured sensible heat flux 


\subsubsection{Estimating evaporative water use of different land uses}

Changes in land use/cover and spatial estimates of ET in the Naivasha basin are shown in Figure 3-6 and Figure 3-7. The MODIS retrieved land use/cover showed that the upper Lake Naivasha basin has undergone significant land use/cover conversions from 2003 to 2012 (Figure 3-8). Specifically, much of the grasslands have been on decline from $\sim 53 \%$ to $\sim 15 \%$ between the period while woody savannas and cropland/natural vegetation mosaic have been on the increase from $\sim 18 \%$ to $\sim 32 \%$ and $\sim 16 \%$ to $\sim 32 \%$ respectively. Evergreen forest and closed shrublands declined from $\sim 6.4 \%$ to $\sim 6 \%$ and $1.7 \%$ to $0.3 \%$ respectively. The cropland/natural vegetation mosaic, however, could be lands that were previously grassland dominated since the population in this part of the basin practices crop rotations and grazing. The consequence of these land use conversions has been suggested to alter the water balance in the basin (Odongo et al., 2014). Although the evergreen forest and closed shrublands cover a small part of the basin, they had the highest annual evapotranspiration compared to the other land uses/cover with grasslands and savannas evaporating the least (Figure 3-9). However, the volume of total water released was less for shrublands $(\sim 0.26-5.24 \%)$ and forests $(\sim 3.96-8.92 \%)$ compared to that released by cropland/natural vegetation $\sim 16.43-25.91 \%)$, grasslands ( $15.48-51.63 \%)$ and woody savannas ( $17.70-32.09 \%$ ) because the former covers a much smaller area compared to cropland/natural vegetation, grasslands or woody savannas. On average, modelled annual ET over the 10 years suggested a decline from $\sim 724 \mathrm{~mm}$ to $\sim 650 \mathrm{~mm}$. Specifically, annual ET reached its lowest in year 2009 before rising to year 2012. In that year, LST reached a peak value of $\sim 300 \mathrm{~K}$ (Figure 3-10) with precipitation observed to decline reaching a minimum of $\sim 735 \mathrm{~mm}$ in 2009 (Figure 3-11). After 2009, ET increased due to moisture availability following improved rains.

The decline in ET from 2003 to 2009 could generally be explained by a combination of factors; reduced moisture supply through precipitation, reduced net radiation and increased actual vapor pressure combined with decrease in the difference between air and surface temperature (Figure 3-11 \& Figure 3-12). These factors accounted for at least $90 \%$ of the decline in ET over the period. This finding was in agreement with that of Jung et al. (2010) who observed that lack of moisture in Southern Hemisphere, particularly in Africa and Australia, decreased from 1998 to 2008. The authors concluded that the decrease in soil moisture in the region led to the recently observed decline in global ET. Similar findings are also reported by Marshall et al. (2012) who observed decreased evapotranspiration due to substantial drying during the growing season (i.e. June, July and August) over East Africa. The authors also observed a positive correlation between evapotranspiration and precipitation in the region during the growing season. Our basin wide annual ET estimates accounted for at least $55-86 \%$ of the total annual precipitation in the basin. 
Over the 10-year period, averaged ET for the respective land uses/covers suggested that grasslands, woody savannas and cropland/natural vegetation mosaic accounted for 28.7\%, 25.9\% and $25 \%$ respectively of the total evaporative water in the basin with closed shrublands, savannas and evergreen forest contributing the least at $2.3 \%, 4.7 \%$ and $6.6 \%$ respectively.

On a monthly basis, ET was observed to be highest in the driest months ( 47- 64 mm) of January through to March before starting a decline in the wettest months and reaching minimum values $\sim 32 \mathrm{~mm}$ in July for most of the land use/cover (Figure 3-13). After July, ET starts to increase again reaching 45-55 $\mathrm{mm}$ in October before taking a small decline in November which coincides with the peak of the short rainy period of October, November and December. Modelled ET appeared to decline with decreasing precipitation during the months of May through to August coinciding with decreasing LST over the same period (Figure 3-14 \& Figure 3-15). This suggested that even though there was plenty of moisture following the rains in April and May, a lack of sufficient energy ensured little ET occurrence between May and August. Later in the months between July and March following increased net radiation, ET appeared to increase. ET scaled well with monthly temperature difference between LST and air temperature ( $\delta T)$ and net radiation indicating the significant control of these variables in determining ET in this part of the basin (Figure 3-16 \& Figure 3-17). However, these results should be interpreted with caution because of lack of ground measurements to validly confirm the degree of influence these surface variables have on the processes in this part of the basin. 

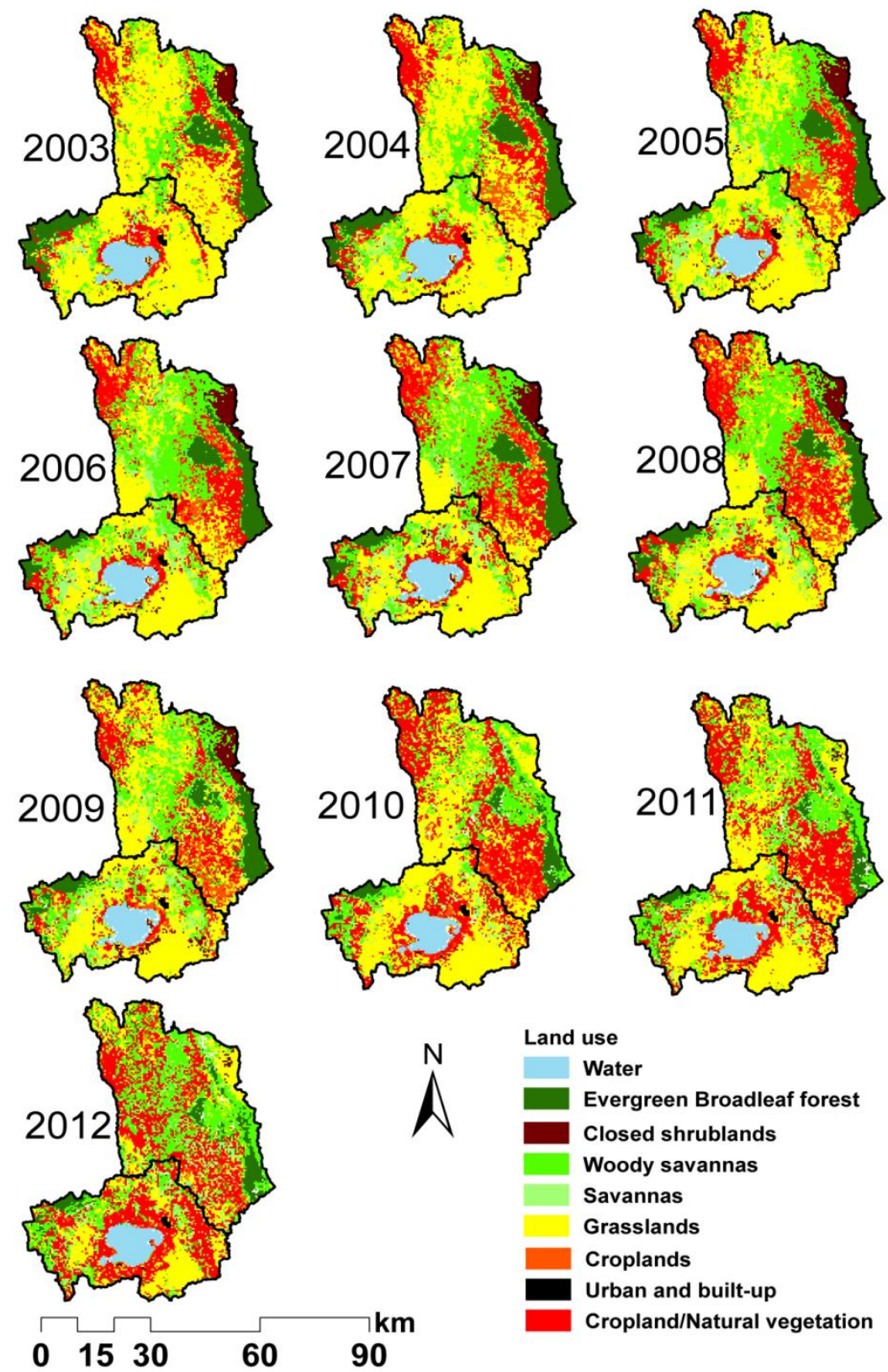

Figure 3-6: Land use/land cover maps in Lake Naivasha Basin 

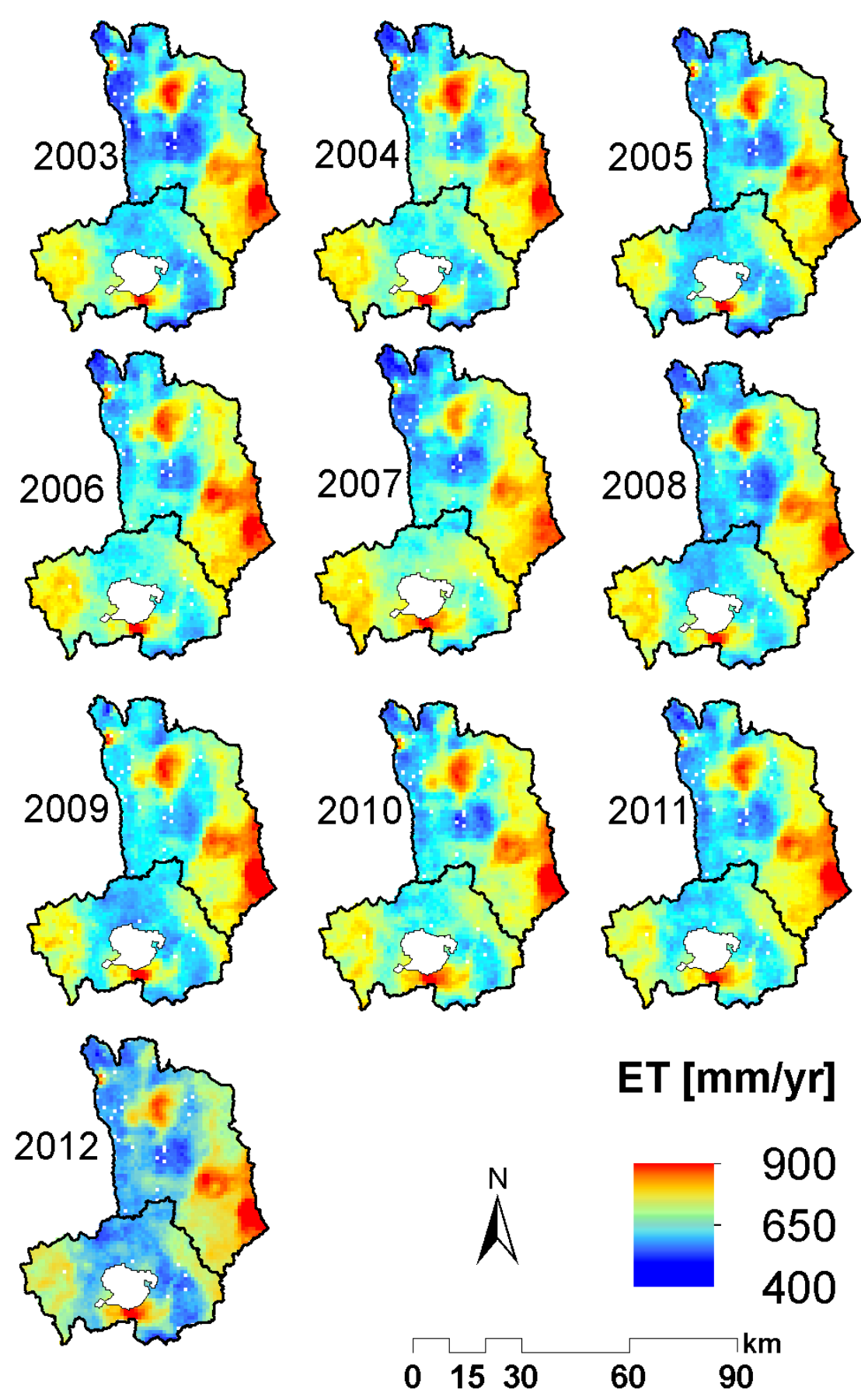

Figure 3-7: Spatial distribution maps of ET in Lake Naivasha Basin 


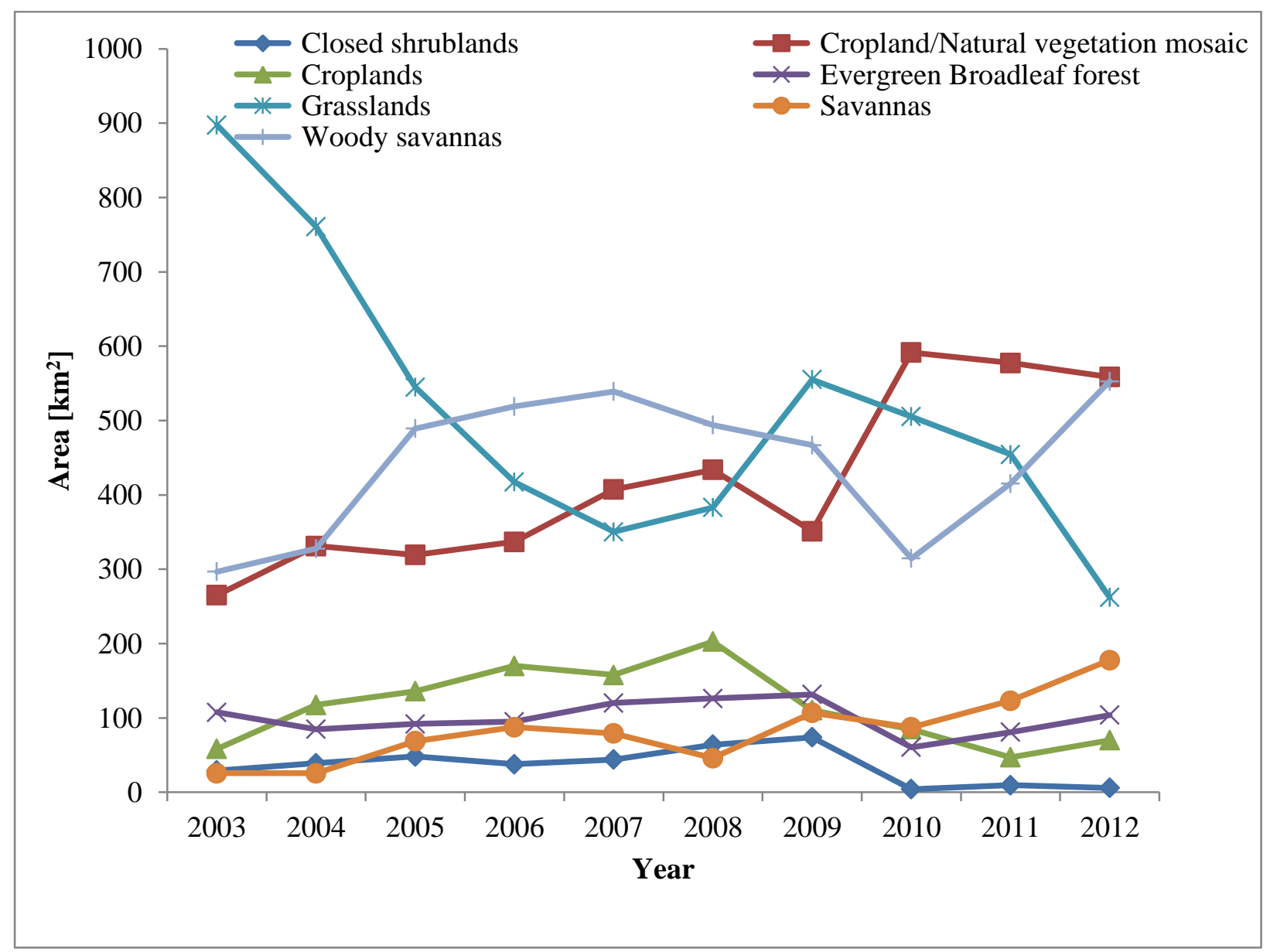

Figure 3-8: Land use/cover changes in the upper Lake Naivasha basin from 2003 to 2012 


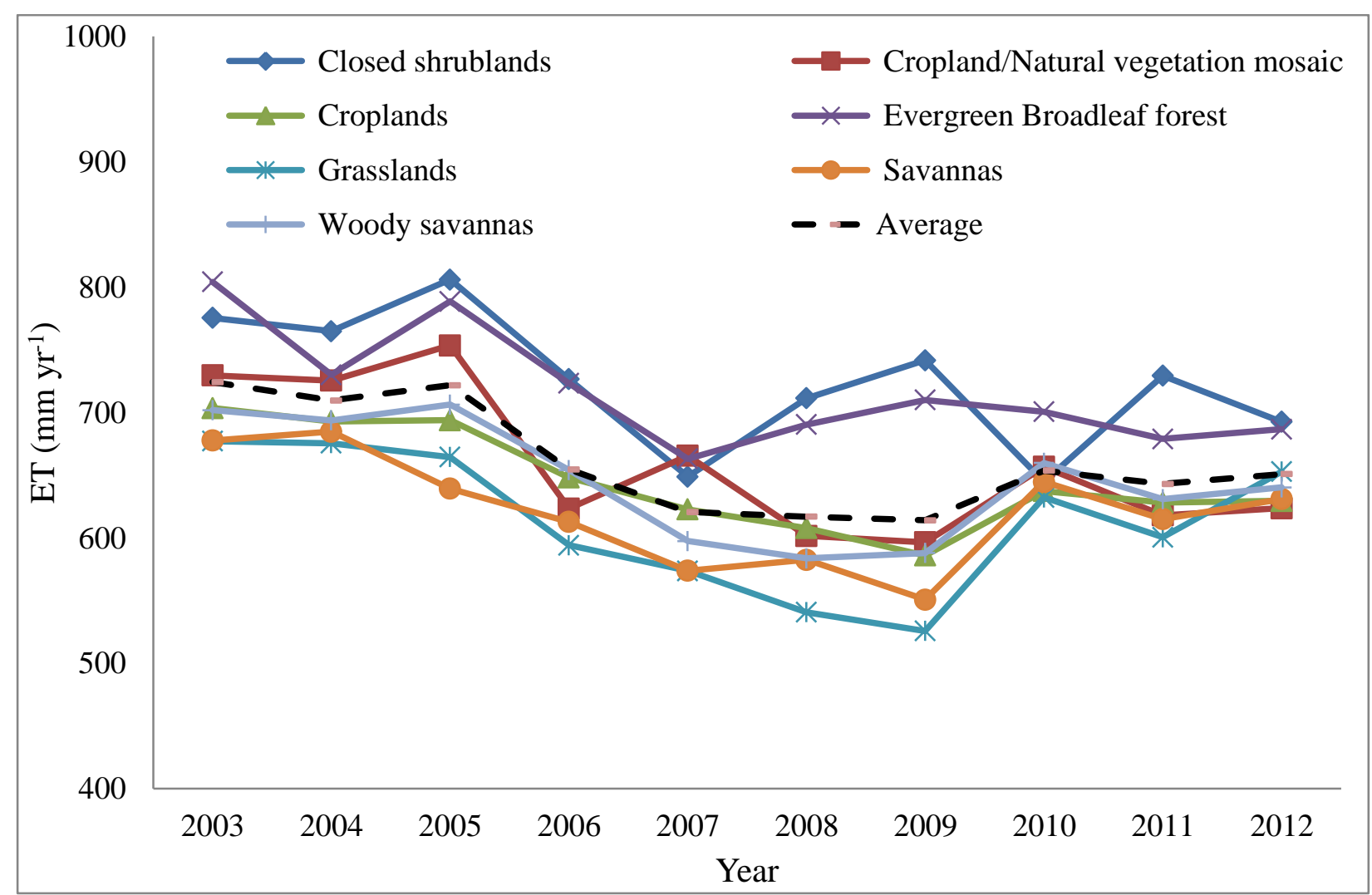

Figure 3-9: Annual trends in evapotranspiration of different land use/cover in upper Lake Naivasha basin 


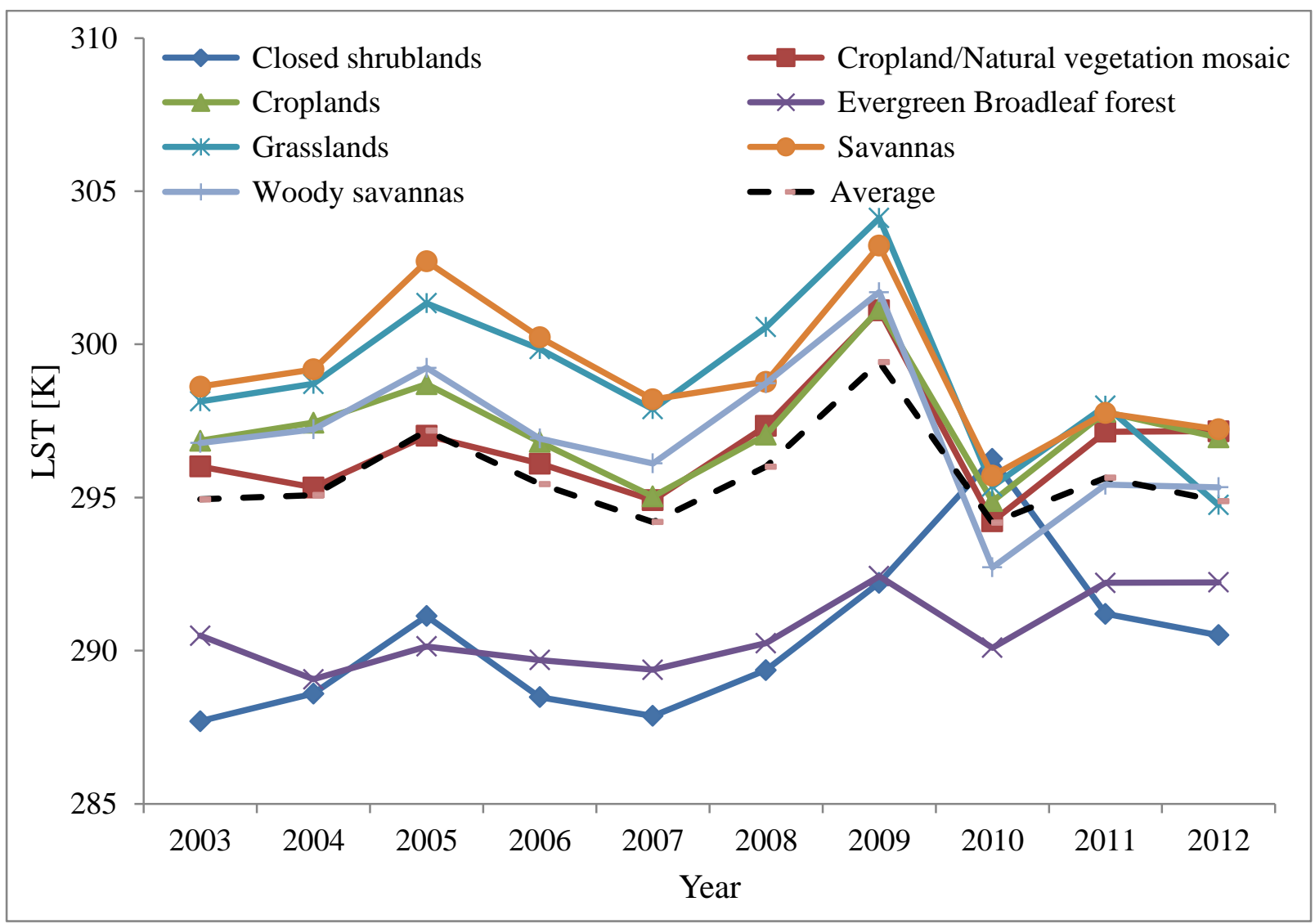

Figure 3-10: Annual trends in LST of the different land use/cover in upper Lake Naivasha basin 


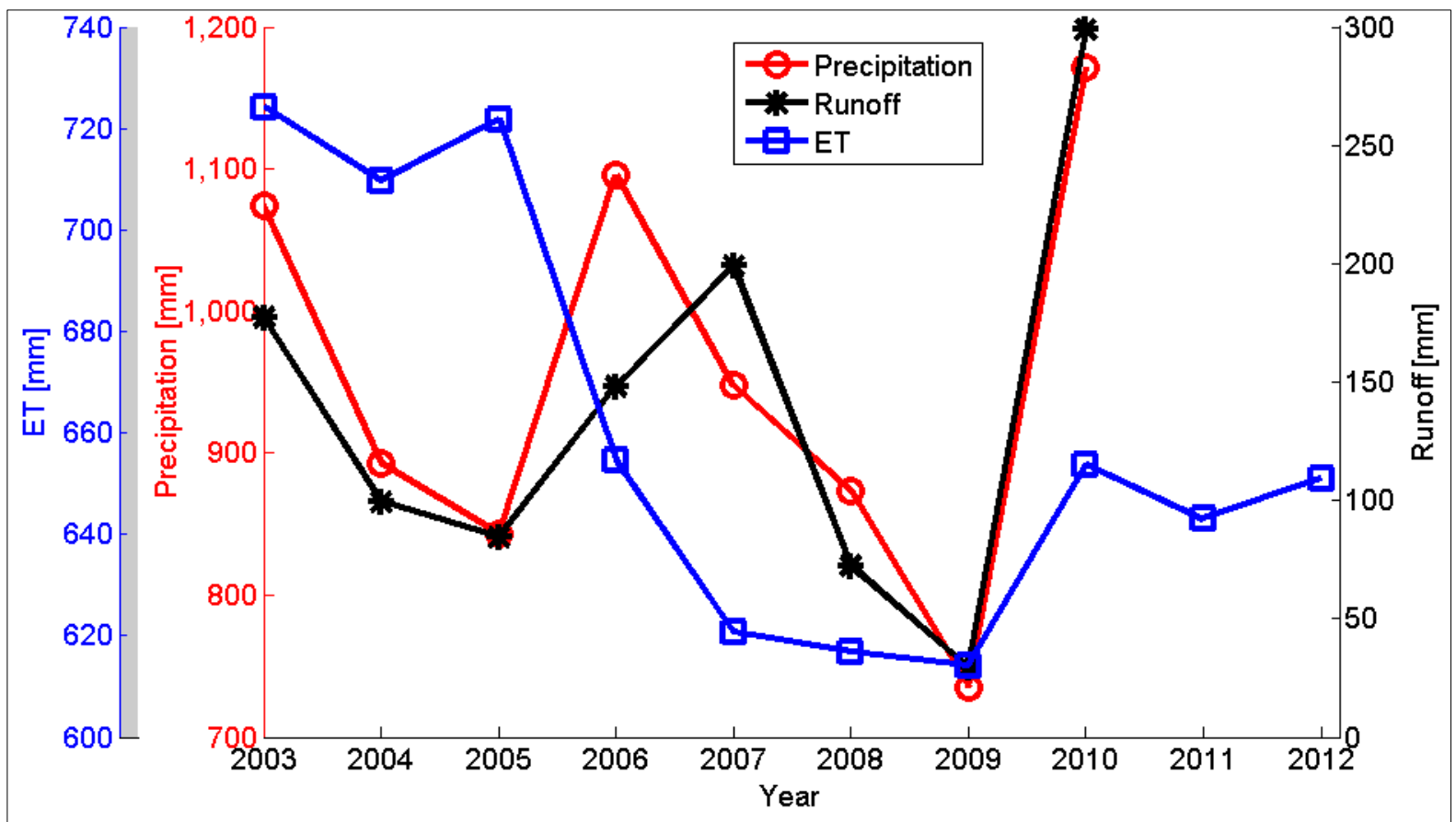

Figure 3-11: Annual trend of precipitation, Discharge and ET 

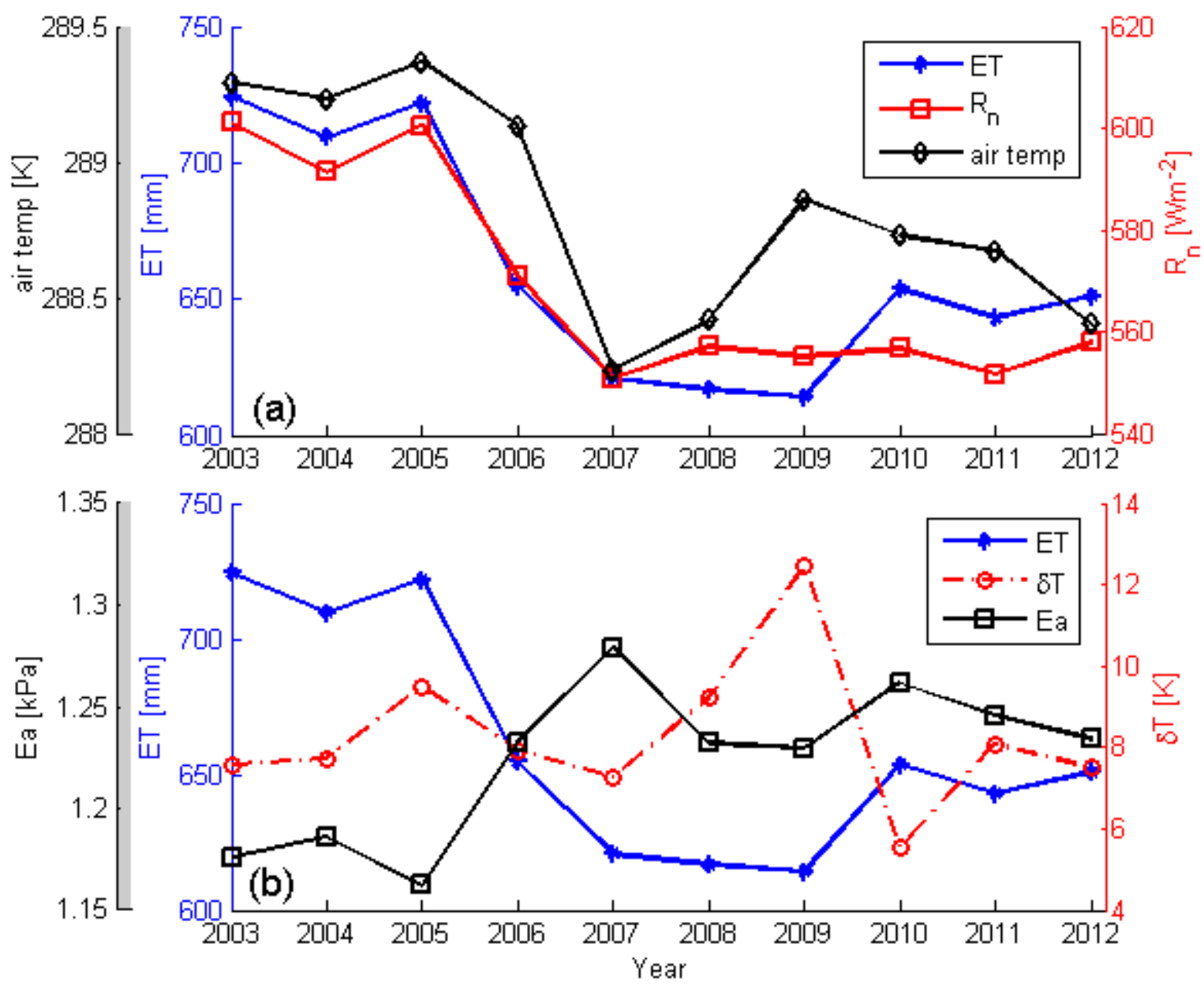

Figure 3-12: Annual trend of ET alongside (a) $R_{n}$ and air temperature (b) difference between air temperature and surface temperature $(\delta T)$ and actual vapor pressure (Ea) between 2003 and 2012 


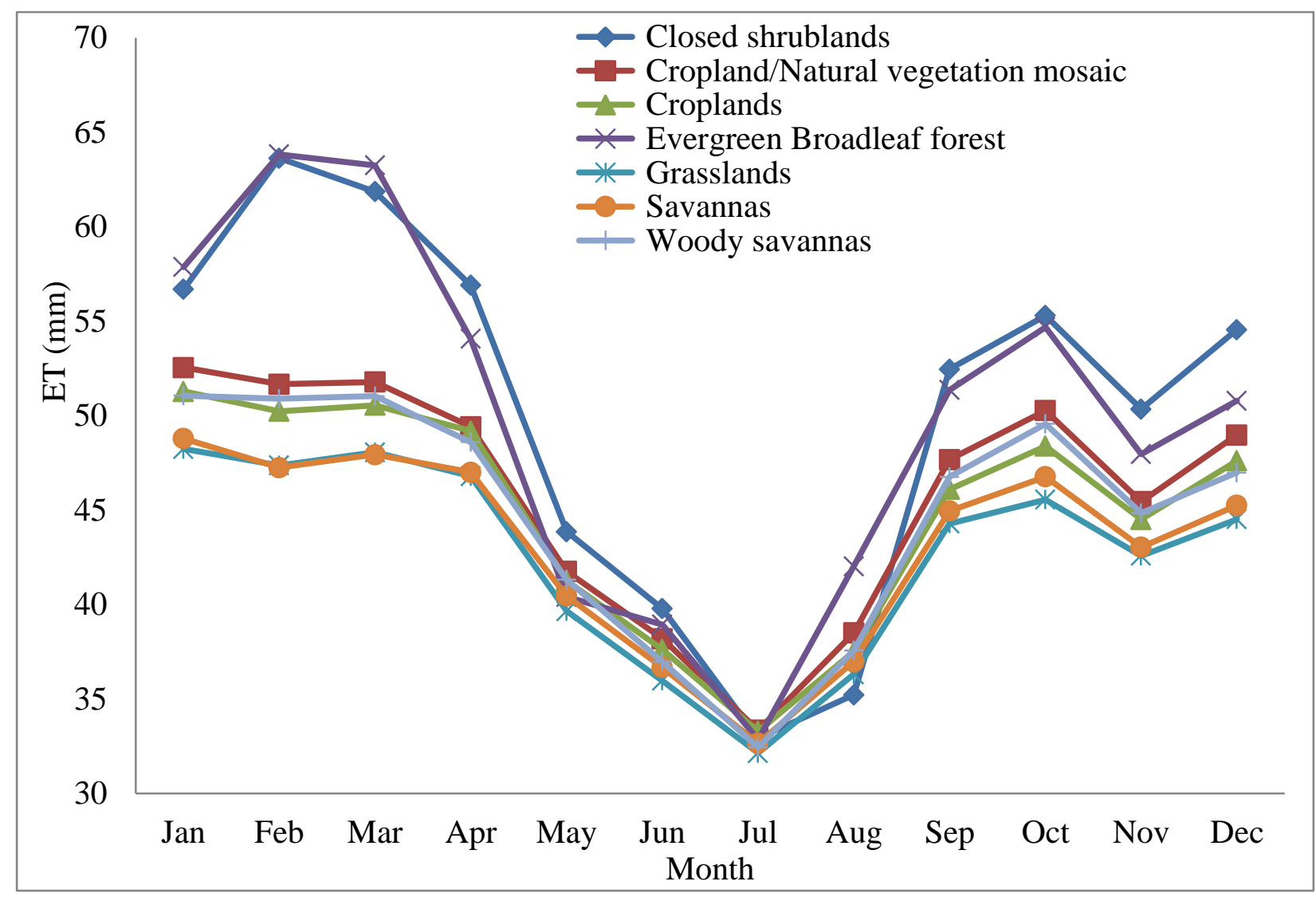

Figure 3-13: Monthly trends of SEBS derived evapotranspiration for dominant land use/cover in upper Lake Naivasha basin 


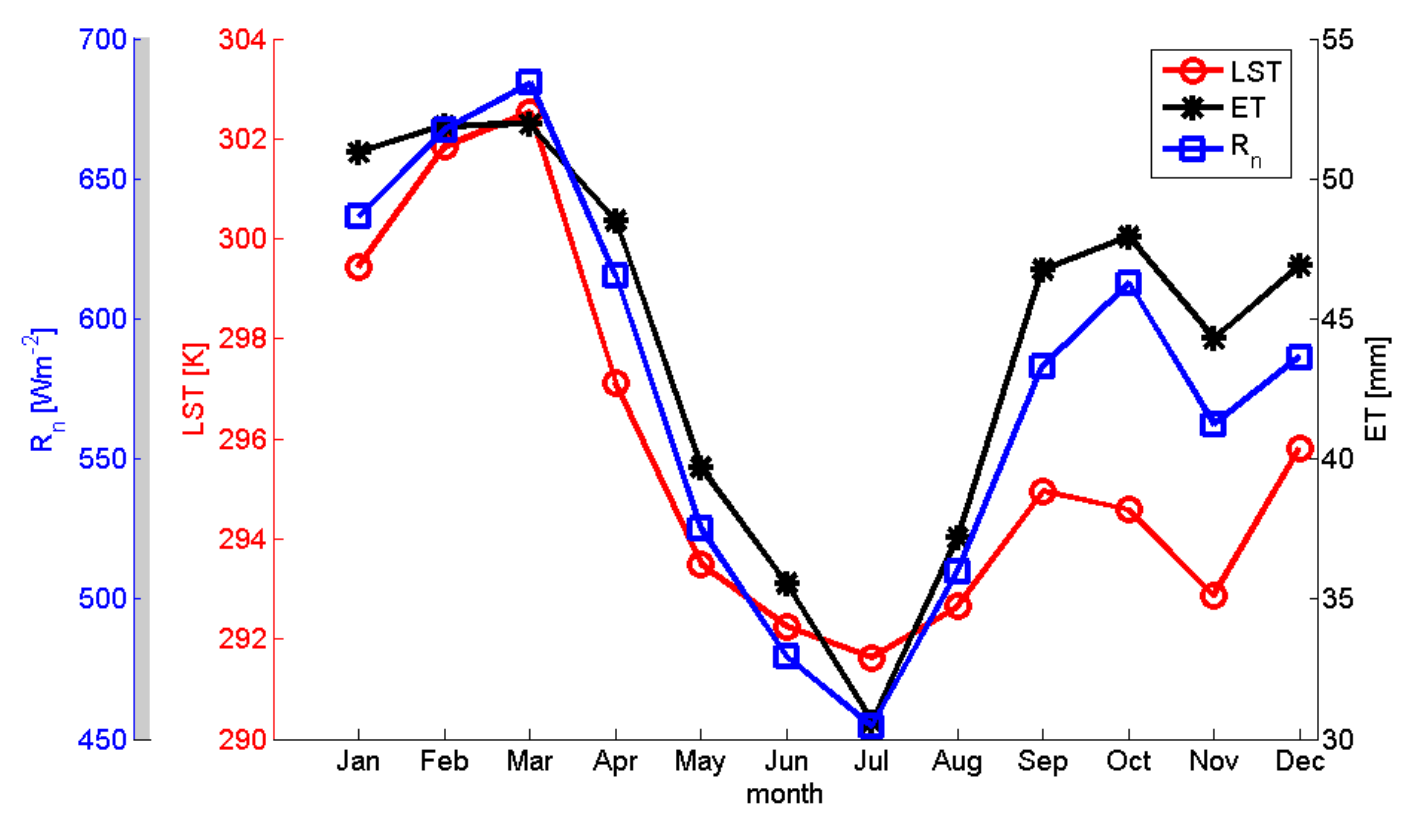

Figure 3-14: Monthly averaged trends of LST, ET and net radiation

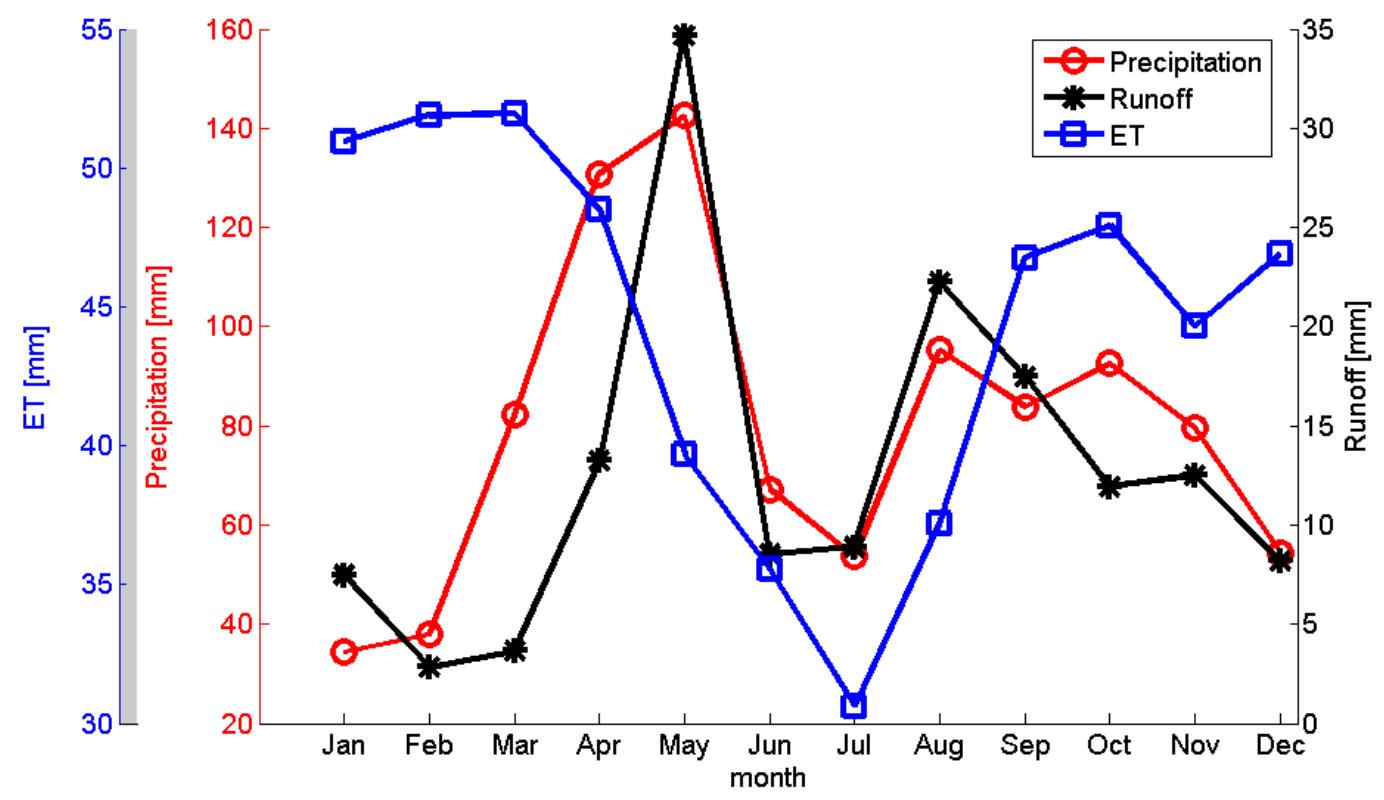

Figure 3-15: Monthly averaged trends of precipitation, discharge and ET 


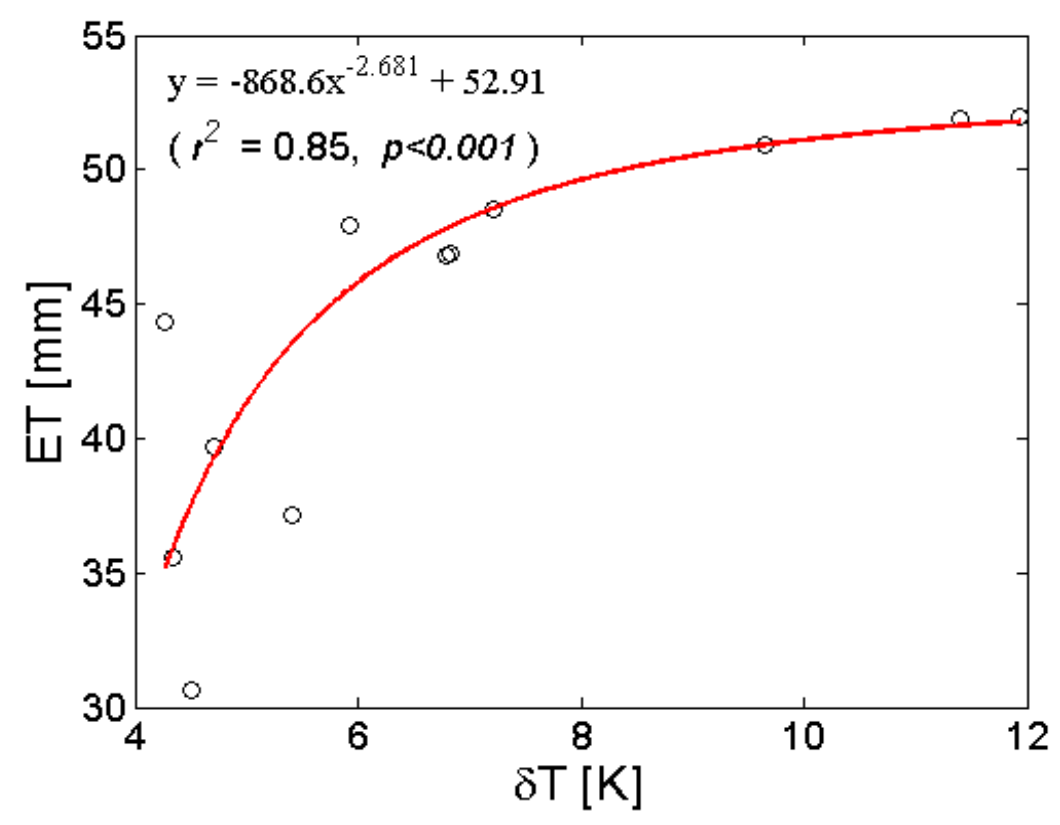

Figure 3-16: Relationship between 10-year monthly averages of $\delta T$ and ET

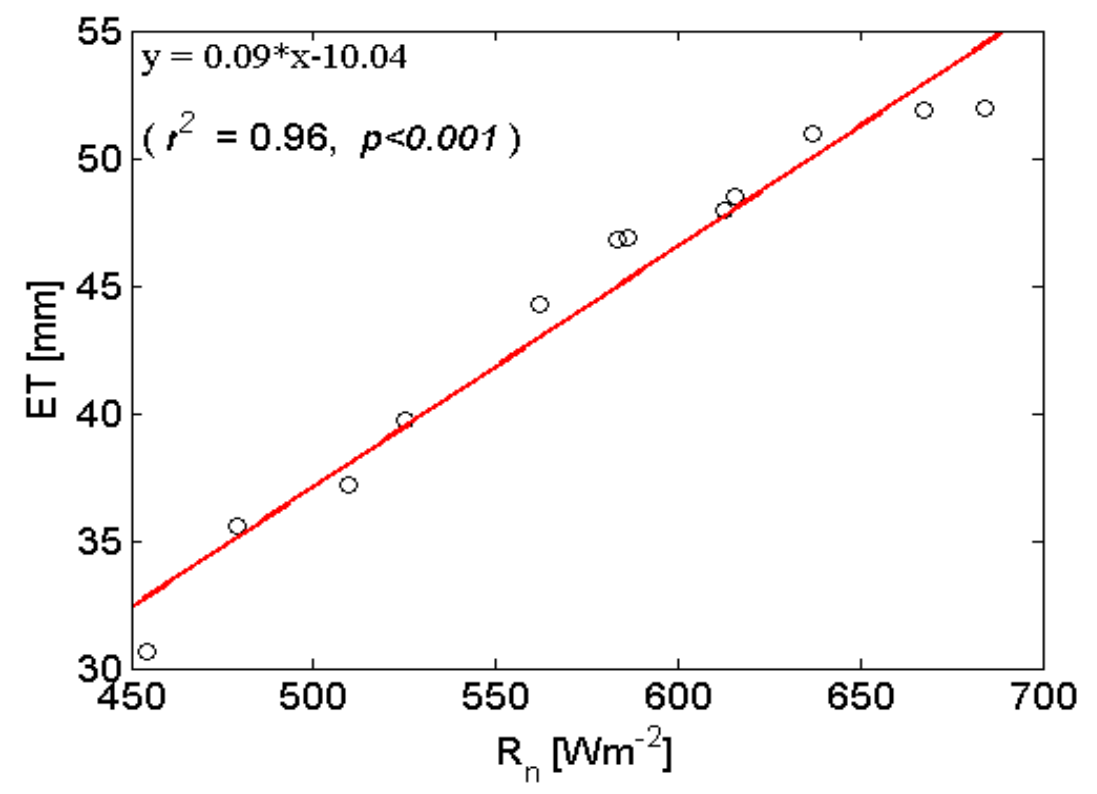

Figure 3-17: Relationship between 10-year monthly averages of net radiation and ET. 


\subsection{Conclusions}

Evapotranspiration accounts for a substantial amount of catchment water use. Understanding the spatial and temporal rates of ET provides a better understanding of the evaporative losses and to establish a link between land use, water allocation, and water use in river basins. However, quantifying ET at the catchment scale remains a challenge especially in large heterogeneous and data sparse environments such as the Lake Naivasha Basin. This situation is further complicated with the dynamics of land use/cover conversions which is a critical concern in the Lake Naivasha Basin. This chapter evaluates 10-year spatial and temporal patterns of evapotranspiration in the Lake Naivasha Basin from 2003 to 2012 using the Surface Energy Balance System (SEBS) in combination with Moderate-resolution Imaging Spectroradiometer (MODIS) and European Centre for Medium-Range Weather Forecasts (ECMWF) Interim Re-Analysis (ERA-Interim) data. The model was evaluated against 2-year flux measurements from an automatic weather station at a heterogeneous landscape site. Our findings show that evergreen forest and closed shrublands had the highest annual evapotranspiration flux (i.e. volume per $\mathrm{m}^{2}$ per year) compared to other land uses/cover, with grasslands and savannas evaporating the least. However, the volume percentage of total water evaporated was less for shrublands ( 0.25-5.24 \%) and forests ( 3.96-8.92\%) compared to that released by cropland/natural vegetation $\sim 16.43-25.91 \%)$, grasslands $(\sim 15.48-$ $51.63 \%)$ and woody savannas $(\sim 17.70-32.09 \%)$ because the former covers a much less area compared to cropland/natural vegetation, grasslands or woody savannas. 10-year average ET for the respective land uses/covers suggested that grasslands, woody savannas and cropland/natural vegetation mosaic accounted for $29 \%, 26 \%$ and $25 \%$ respectively of the total evaporative water in the basin with closed shrublands, savannas and evergreen forest contributing the least at $2.3 \%$, $4.7 \%$ and $6.6 \%$ respectively. Overall, estimated basin wide annual ET over the 10 years suggested a decline from $\sim 724 \mathrm{~mm}$ to $\sim 650 \mathrm{~mm}$. Specifically, annual ET reached its lowest in the year 2009 before rising again until 2012. This decline in modelled ET was due to reduced net radiation and increased actual vapor pressure as well as a marked decrease of the difference between air and surface temperature. These factors accounted for at least $90 \%$ of the decline in ET over the period. Our findings further indicated that evaporative water use accounted for between $55-86 \%$ of the total annual precipitation in the basin. A comparison of SEBS ET to flux tower data suggested that the difference between observed and simulated fluxes was likely due to the heterogeneity of the measurement site, the uncertainty in the input data, scale mismatch between input data and measured fluxes at the site and uncertainties inherent in SEBS model formulation. The inclusion of more local measurements of energy fluxes at different land use/cover landscapes would 
Chapter 3

significantly improve understanding of hydrological processes in the basin and further constrain model simulations. 


\section{Energy partitioning and its controls over a}

heterogeneous semi-arid Shrubland Ecosystem in the Lake Naivasha Basin, Kenya*

* This chapter is based on:

Odongo, V. O., van der Tol, C., Becht, R., Hoedjes, J. C. B., Ghimire, C. P., \& Su, Z. Energy partitioning and its controls over a heterogeneous semi-arid shrubland ecosystem in the Lake Naivasha Basin, Kenya. Ecohydrology:DOI:10.1002/eco.1732 


\begin{abstract}
We report on the energy balance and partitioning analyzed from 3-year micrometeorological flux measurements of energy and water fluxes over a heterogeneous semi-arid shrubland ecosystem in Lake Naivasha basin. The measurements enabled the characterization of the seasonal and interannual variability of the energy and water fluxes of the ecosystem covering two wet years (2012 and 2013) and one drought year (2014). On an annual scale, more than $60 \%$ of net radiation $(R n)$ was partitioned as latent $(L E)$ and sensible $(H)$ energy flux, with the latter being the larger consumer of $R n(\sim 34 \%)$ and dominant for most months. The transition from $H$ to $L E$ dominance occurred from early noon to late afternoon in the wettest months of April and May. The residual energy balance closure term $(C)$ accounted for between $25-40 \%$ of the $R n$ with the imbalance tending to be highest during periods of high insolation. Annual evapotranspiration was estimated at $873 \mathrm{~mm}, 632 \mathrm{~mm}$ and $537 \mathrm{~mm}$ for year 2012, 2013 and 2014 respectively. This accounted for at least $80 \%$ of the annual precipitation received for the respective years. Surface conductance $\left(g_{s}\right)$ scaled significantly with leaf expansion and Priestley-Taylor a coefficient, but was limited during periods of drought due to inadequate soil moisture suggesting that the change in $L E$ was paralleled by changes in green leaf area index. Low values of decoupling coefficient $(\Omega)$ during these periods indicated that evapotranspiration was strongly controlled by $g_{s}$ and vapor pressure deficit (VPD). However, under non-limiting moisture conditions evapotranspiration was decoupled from the atmosphere. This suggested that during the dry seasons and periods of prolonged drought, a lack of moisture in combination with high VPD leads to significant decreases in stomatal conductance that eventually limits partitioning of available energy into $L E$ in the semi-arid ecosystem part of the Lake Naivasha basin. However, during wet season these factors are nonlimiting and radiation is the dominant control of energy partitioning into $L E$ in the ecosystem. The coupling and decoupling pattern provide insights towards formulating models that quantify evapotranspiration for ecosystems that experience seasonal shifts in controlling factors.
\end{abstract}




\subsection{Introduction}

The partitioning of available energy into sensible $(H)$ and latent heat (LE) fluxes plays a critical role in defining the vertical profiles of temperature and water vapor in the atmosphere, cloud cover and precipitation, consequently driving many local, regional and global climatological processes (Dirmeyer, 1994; Seth and Giorgi, 1996; Wilson and Baldocchi, 2000). LE forms a major component of an ecosystem's energy balance and water lost by evapotranspiration (ET) accounts for about $60 \%$ of annual precipitation on the land surface globally (Jung et al., 2010). In semi-arid and arid ecosystems the fraction of precipitation lost as ET accounts for over $90 \%$ of annual precipitation for periods longer than seasons (Huxman et al., 2005; Kurc and Small, 2004). It is important to quantify the variability of $E T$ in these dryland ecosystems because $E T$ affects both plant productivity and energy balance of a region (Lu et al., 2011). Furthermore, hydrological state variables such as soil moisture content and fluxes such as streamflow, and biological processes such as nutrient fluxes and forest productivity are tightly linked via $E T$ in an ecosystem (McNulty et al., 1994; Wagle and Kakani, 2014; Wilson and Baldocchi, 2000).

Long-term measurements are needed to obtain understanding of the variability of $E T$ and energy fluxes and their biophysical controls over a site. Such long-term measurements can reveal patterns of biophysical factors that characterize vegetation types (Wilson and Baldocchi, 2000). Evaluation of these factors is also relevant for parametrization of models of weather and climate at local to regional and global scale (Loescher et al., 2005; Sellers et al., 1997). Moreover, they also allow for testing of new eco-hydrology theories developed for predicting soil water balance (e.g. Laio et al., 2001a; Laio et al., 2001b) and for investigating stability of climates of wet and dry landscapes (Baldocchi et al., 2004; Brubaker and Entekhabi, 1996; Zeng and Neelin, 2000). Energy flux measurements in semi-arid ecosystems are limited (Kurc and Small, 2004; Ramier et al., 2009). Although there have been concerted long-term efforts in parts of Africa such as the African Monsoon Multidisciplinary Analyses (AMMA) dedicated to study the West African Monsoon system (Redelsperger et al., 2006), few flux measurements have been reported for the East African region. A major reason has been a general lack of instrumentation to provide long-term measurements dedicated to studying the energy flux partitioning and its control in this region. Such dedicated long-term measurements are key to supporting comprehensive analyses of the land surface exchange processes and to advancing model development and validation in this region. A number of studies have focused on energy flux partitioning in Africa (for example the Sahel Energy Balance Experiment (SEBEX) (Wallace et al., 1991), the hydrologic and Atmospheric Pilot Experiment in the Sahel (HAPEX-Sahel), Global Change in the Hydrological cycle (GLOWA- 
Volta) project (Schüttemeyer et al., 2006), but most are limited to short-term campaigns of less than a year and only provide partial insights into the dynamics of surface fluxes (Bagayoko et al., 2007). However, the long-term flux measurements of the AMMA project have provided insights on the interannual partitioning of surface energy fluxes over a heterogeneous savanna, in a West African Sudano-Sahelian region and related this variability to changing atmospheric and land surface conditions (Guyot et al., 2012).

A recent flux measurement campaign in East Africa by Mpala Research Center/Princeton University has aimed at providing such long-term flux measurements for understanding land degradation of a semi-arid savanna in Central Kenya (Good et al., 2012). Reported short-term measurements from this campaign during a dry season suggested that meteorological conditions of net radiation and relative humidity are significant in controlling the partitioning of evapotranspiration (ET) into evaporation $(E)$ and transpiration $(T)$ over the diurnal cycle while at the longer time scale, leaf area and soil moisture were the dominant controlling factors (Good et al., 2014). Limitations of soil moisture are believed to be the most important, particularly in arid and semiarid environments. There is need for more field observations in other similar semi-arid ecosystems to test relationships (Kurc and Small, 2004).

The main objectives of this study were, therefore, to evaluate the energy balance and partitioning for a heterogeneous semi-arid shrubland ecosystem; and to identify the biological and environmental factors that control the seasonal and interannual energy partitioning of this ecosystem. In doing so, 3-year flux data were used to characterize the seasonal and interannual variability of energy and water fluxes of the ecosystem covering two wet years (2012 and 2013) and one drought year (2013).. Three biophysical parameters, notably surface conductance, $g_{s}$ (Monteith, 1965), decoupling coefficient, $\Omega$ (Jarvis and McNaughton, 1986) and the PriestleyTaylor a coefficient (Priestley and Taylor, 1972) were quantified and examined their seasonal and intrannual variability for the first time in this part of Africa. Unlike most of the previous work in Africa that has focused on specific components of energy flux partitioning, this study presents a more comprehensive analysis of the physical and biological processes of energy flux partitioning and their coupling dynamics. To our knowledge this is the first set of relatively long-term measurements reported in this part of Africa to investigate the physical and biological processes of energy flux partitioning and their coupling dynamics. 


\subsection{Methods}

\subsubsection{Site description}

The site is located inside a wildlife park of the Kenya Wildlife Services Institute (KWSTI) in the Lake Naivasha Basin situated in the Great Rift-Valley in Kenya at 36 27'3.142" E, $0^{\circ} 44^{\prime} 11.748^{\prime \prime} \mathrm{S}$ (Figure 4-1). The elevation of the flux site is $2000 \mathrm{~m}$ above mean sea level. There are two rainy seasons experienced in this catchment. Long rains occurring in the months of March to May and the short rains experienced between October and November. The Lake Naivasha basin experiences an average annual rainfall of $610 \mathrm{~mm}$ in most of the semi-arid parts of the basin, and the wettest slopes of the Aberdare ranges receive as much as $1525 \mathrm{~mm}$. The rainfall regime is influenced by local relief with the catchment being in the rain shadow of the Aberdare ranges to the East and the Mau Escarpment to the West. The vegetation is predominantly shrub (Psiadia panctulata, Ocimum gratissimum and Lippia kituensis) with about 40-45\% canopy cover with grasses (Digitaria scalarum and Cynodon dactylon) with a few scattered trees (Acacia xanthophloea, Schinus molle, Acacia abyssinica, Tachonanthus camphoratus, Phytolacca dodecandra, Acacia drepanolobium) and litter covering the underneath surfaces. The vegetation height of the shrubland ranged between 0.5 to $1 \mathrm{~m}$. Leaf emergence and expansion coincides with the rainy seasons. During the dry seasons (January to middle of March), leaf senescence is predominant. The soils in the catchment are of volcanic origin. The soils found on the mountain and major escarpments of the catchment are developed from olivine basalts and ashes of older volcanoes (Odongo et al., 2014). The terrain is relatively flat with a slope of less than $2 \%$ on average. 


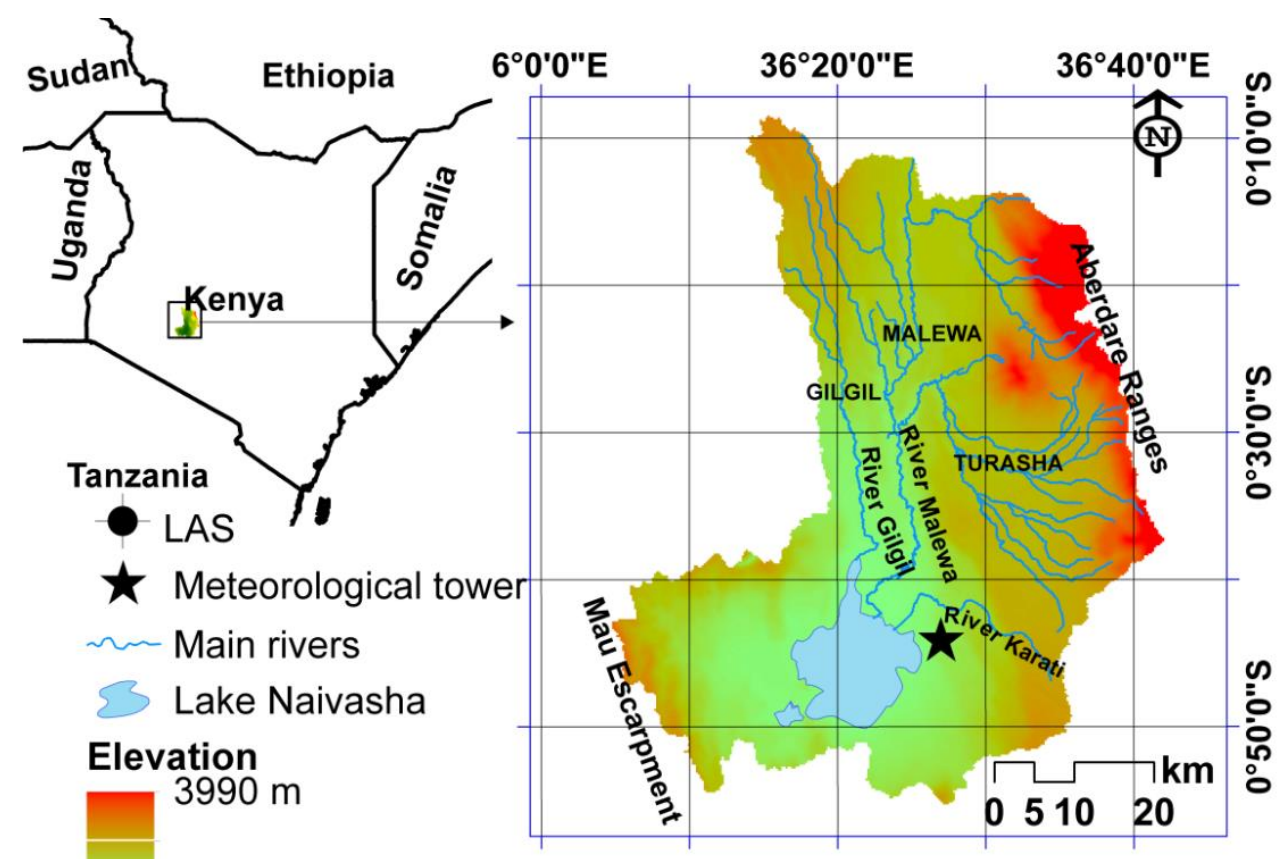

$1980 \mathrm{~m}$

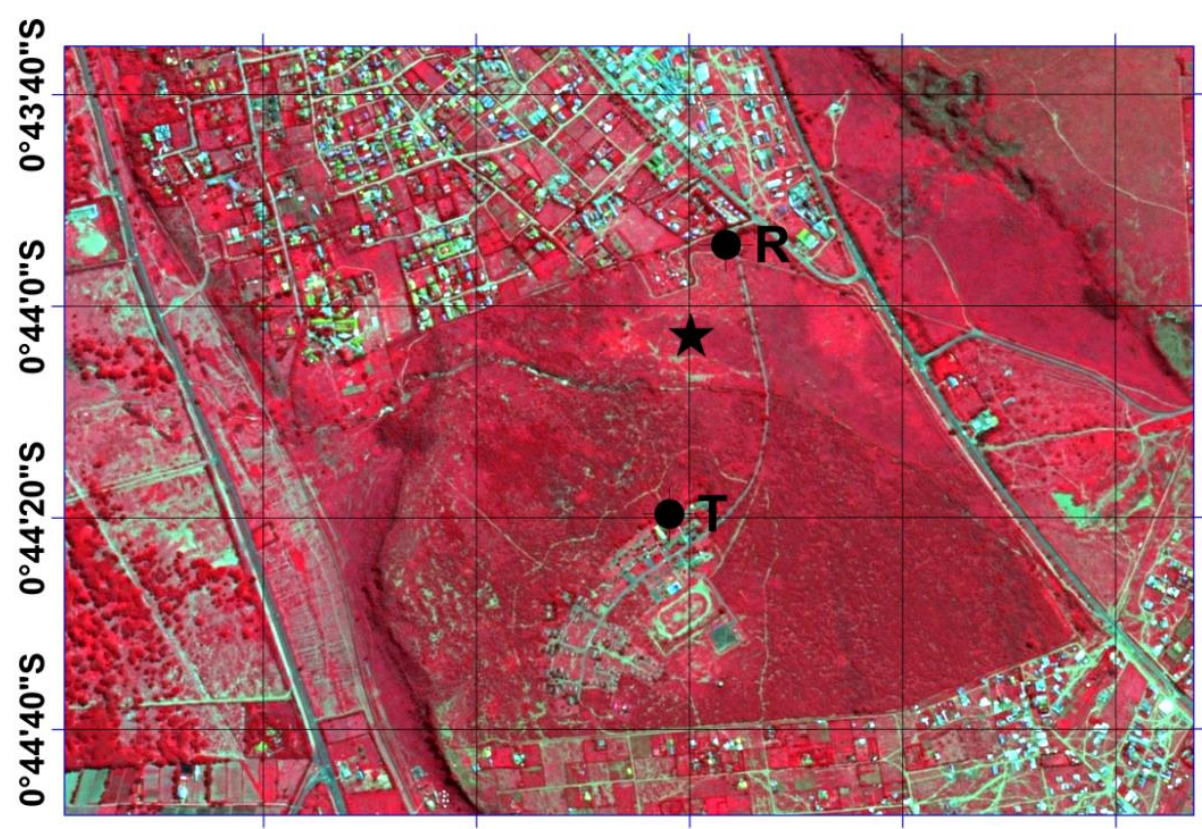

$36^{\circ} 26^{\prime} 20^{\prime \prime E} \quad 36^{\circ} 26^{\prime} 40^{\prime \prime E} \quad 36^{\circ} 27^{\prime} 0^{\prime \prime E} \quad 36^{\circ} 27^{\prime} 20^{\prime \prime E} \quad 36^{\circ} 27^{\prime} 40^{\prime \prime E}$

Figure 4-1: Location of meteorological flux tower in the lake Naivasha Basin 


\subsubsection{Micrometeorological measurements and data acquisition}

A micrometeorological and flux measurement system was installed by setting up a $5.5 \mathrm{~m}$-high tower. Wind velocity and virtual temperature fluctuations were measured using a threedimensional (3D) sonic anemometer (WindMaster (Pro) type 1561, Gill Instruments Limited, Hampshire, UK). The sampling frequency of the sonic anemometer was $10 \mathrm{~Hz}$. Aspirated air temperature and humidity (HFM53, Rotronic Instruments (UK) Limited, West Sussex, UK) were measured at 1.8 and $5.5 \mathrm{~m}$ above ground level. This enabled computation of Bowen ratio. Downward and upward solar and longwave radiation was measured using a NR01 four component radiometer mounted at $2.5 \mathrm{~m}$ above the ground (Hukseflux, Delft, The Netherlands). A tipping bucket rain gauge ( Rain Collector II, Davis Instruments, USA; $0.2 \mathrm{~mm}$ per tip) was mounted at $1.5 \mathrm{~m}$ above the ground to avoid the ground splash effects. Soil temperature profiles were measured using $10 \mathrm{k} \Omega$ NTC (Campbell-107, Campbell Scientific Inc., Logan, UT, USA) installed at 1, 2, 3, 4, 5, 6, 8, 10 and $12.5 \mathrm{~cm}$ depths below the ground. Soil heat flux (HFP01SC, Hukseflux, Delft, The Netherlands) was measured at $0.1 \mathrm{~m}$ below the ground underneath the grass and litter. Soil water content was measured at 5, 10, 15 and $20 \mathrm{~cm}$ depths using Decagon EM50 5ET soil moisture sensors (Decagon Devices, Inc., Washington, USA). A dielectric leaf wetness sensor (LWS-L Campbell Scientific Inc., Logan, UT, USA) was also set up to monitor presence of dew. Surface temperature was measured using an infra-red remote temperature sensor (IR100, Campbell Scientific, Inc., Logan, UT, USA). Other than the soil moisture sensors which had a separate logger, all other instruments were connected to a CR3000 datalogger (Campbell Scientific, Inc., Logan, UT, USA). Soil water content was recorded at 30-min intervals while the soil heat flux was recorded at 15 -min intervals. All other hydrometeorological variables were recorded at 1 -min intervals. After a start-up period, the system has been operational since January 2012. A LI-7500 gas analyzer (LI-COR Biosciences, Nebraska, USA) recording at $10 \mathrm{~Hz}$ at a height of $5.5 \mathrm{~m}$ above the ground was introduced for a brief period to monitor fluxes during the transition from dry to wet season (21 $1^{\text {st }}$ March 2012 to $9^{\text {th }}$ May 2012). A Large Aperture Scintillometer (LAS) (Scintec BLS 450) was also set up at a path height of $6.85 \mathrm{~m}$ above ground, with a propagation length of $810 \mathrm{~m}$. It was operational between $7^{\text {th }}$ February 2012 to $4^{\text {th }}$ December 2012 but intermittent instrument failures hampered continuous measurements. A flux footprint analysis following Hsieh et al. (2000) showed that over $80 \%$ of the turbulent heat fluxes originated from within $\sim 450 \mathrm{~m}$ and $5000 \mathrm{~m}$ of the tower during unstable and stable conditions respectively (Appendix A). 8-day temporal resolution leaf area index (LAI) of the flux site was also extracted from moderate-resolution imaging spectroradiometer (MODIS) product MCD15A from the grid containing the flux station. Due to cloud contaminated anomalies inherent in MODIS LAI product, the Harmonic 
Analysis of Time Series (HANTS) algorithm (Verhoef et al., 1996) was used to remove cloud contaminated observations. The algorithm uses Fourier analyses to remove pronounced outliers in a time series and reconstruct a smooth curve. Measurements from January 2012 to December 2014 are the subject of the present chapter.

\subsection{Data processing}

The software AltEddy (www.climatexchange.nl/projects/alteddy/) of the Alterra Institute (Wageningen University and Research Center, The Netherlands) was used to process 30-min interval turbulent heat fluxes ( $H$ and $L E$ ). The flux data processing followed standard protocols that included 2-D axis rotation (Moore, 1986), angle of attack correction (Nakai et al., 2006), Webb correction (Webb et al., 1980), despiking and frequency response correction and Burba's correction for the instrument temperature (Burba et al., 2008). Missing data due to instrument malfunction or power failure were $18 \%$ over the 3 year of measurements. Quality control of the data followed the procedures as developed by Foken et al. (2005) based on statistical stationarity and development of turbulent conditions. Using this procedure $25 \%$ of the data during the 3 -year study period were filtered out and gap-filled using linear interpolation. These gaps were no more than $2 \mathrm{~h}$ window period. Therefore the gap filling technique followed the strategies put forward by Falge et al. (2001) recommending linear interpolation to fill the gaps that were less than 2 h by calculating an average of the values immediately before and after the data gap.

\subsection{Energy balance partition}

The partitioning of net radiation $\left(R_{\mathrm{n}}\right)$ into sensible $(H)$, latent $(L E)$ and soil heat flux at the surface $\left(G_{0}\right)$ was as follows:

$$
R_{n}-G_{o}=H+L E+C
$$

where $C$ is the closure term or residual, accounting for incomplete balance through measurement error or missing terms. The soil heat flux at the surface was modelled using the heat diffusion equation (3-1). 
The energy balance closure was evaluated for each year using linear regression where dependent turbulent fluxes $(H+L E)$ were plotted against the independent available energy $\left(R_{n}-G_{o}\right)$ after excluding data in rainy days and nocturnal conditions when the frictional velocity $\left(u_{*}\right)$ was $<0.15$ $\mathrm{m} \mathrm{s}^{-1}$ (Chen et al., 2009). The energy balance ratio $\left(E_{B R}\right)$ was also used to assess the degree of energy closure as follows:

$$
E_{B R}=\frac{\sum(H+L E)}{\sum\left(R_{n}-G_{o}\right)}
$$

An inversion of the Bowen ratio $(\beta)$ formulation $[\mathrm{LE}=\mathrm{H} / \beta$ ] was used to calculate LE. $\beta$ was calculated from vertical gradients of air temperature $[\Delta \mathrm{T} / \Delta \mathrm{z}]$ and water vapor pressure $[\Delta \mathrm{e} / \Delta \mathrm{z}]$ as follows:

$$
\beta=\gamma \frac{\Delta T / \Delta z}{\Delta e / \Delta z}
$$

Estimates of $L E$ from the Bowen ratio method were also compared to those of eddy covariance measurements during LI-7500 operational period. The LAS also provided simultaneous measurements of $H$ during its operation for comparing the sonic measured $H$.

\subsection{Biophysical modelling}

To understand the seasonal and interannual variability of evapotranspiration and energy fluxes three model parameters were used: surface conductance, $g_{s}(\mathrm{~mm} / \mathrm{s})$ (Monteith, 1965), decoupling coefficient, $\Omega$ (Jarvis and McNaughton, 1986) and the Priestley-Taylor a coefficient (Priestley and Taylor, 1972). The surface conductance was calculated by inverting the Penman-Monteith equation as follows:

$$
g_{s}=\frac{\gamma L E g_{a}}{\Delta\left(\boldsymbol{R}_{n}-\mathrm{G}_{\mathrm{o}}\right)+\rho \mathrm{C}_{\mathrm{p}} \mathrm{VPDg}_{\mathrm{a}}-\boldsymbol{L E}(\Delta+\gamma)} \times 1000
$$

where $\gamma$ is the psychrometric constant $\left(0.0665 \mathrm{kPa} \mathrm{K}^{-1}\right), C_{p}$ is the specific heat of air at constant pressure $\left(1013 \mathrm{~J} \mathrm{~kg}^{-1} \mathrm{~K}^{-1}\right), \rho$ is the density of air $\left(1.2 \mathrm{~kg} \mathrm{~m}^{-3}\right), V P D$ is the air vapor pressure deficit $(\mathrm{kPa}), \Delta$ is the rate of change of saturation water vapor pressure with temperature $\left(\mathrm{KPa} \mathrm{K}^{-1}\right), g_{a}$ is the aerodynamic conductance of the air layer between the canopy and the flux measurement height $\left(\mathrm{ms}^{-1}\right)$ and is estimated using the Monteith-Unsworth equation (Monteith and Unsworth, 1990) as follows: 


$$
g_{a}=\left(\frac{u}{u_{*}^{2}}+6.2 u_{*}^{-2 / 3}\right)^{-1}
$$

where $u$ is the mean wind velocity $\left(\mathrm{ms}^{-1}\right)$, and $u_{*}$ is the friction velocity estimated from the sonic anemometer. A number of studies have shown that surface conductance as implemented using the inverted Penman-Monteith equation is representative of the canopy integrated surface conductance, provided that the soil evaporation is insignificant (Baldocchi and Meyers, 1998; Wever et al., 2002; Wilson and Baldocchi, 2000). In this study the contribution of soil evaporation was assumed to be low due to vegetation litter and grass cover underneath the shrubs.

The relative importance of $g_{s}$ and $R_{n}$ to changes in evapotranspiration rates was computed using the decoupling coefficient $(\Omega)$. The value of $\Omega$ can vary from 0 to 1 with lower values indicative of evapotranspiration being highly sensitive to $g_{s}$ and $V P D$, while high values of $\Omega$ are indicative of evapotranspiration being sensitive to $R_{n}$ (Jarvis and McNaughton, 1986). The decoupling coefficient was estimated following Jarvis and McNaughton (1986):

$$
\Omega=\frac{\Delta+\gamma}{\Delta+\gamma\left(1+g_{a} / g_{s}\right)}
$$

The Priestley-Taylor a coefficient normalizes the measured evapotranspiration against an equilibrium rate determined primarily by net radiation (Blanken et al., 1997; McNaughton and Jarvis, 1983). This coefficient was used to provide a comparison of measured evapotranspiration to a climatological expectation. It was estimated as the ratio of measured $L E$ and equilibrium $L E$ ( $a=$ $\left.L E / L E_{e q}\right)$. The equilibrium $L E\left(L E_{e q}\right)$ is calculated using the following equation (Priestley and Taylor, 1972):

$$
L E_{e q}=\frac{\Delta}{\Delta+\gamma}\left(R_{n}-G_{o}\right)
$$

$L E_{e q}$ provides a comparison of measured $L E$ to a climatologically expected $L E$ assuming a closed volume with constant net radiation over a wet surface (McNaughton and Spriggs, 1986; Ryu et al., 2008). Potential $L E$ can then be estimated from $1.26 \times L E_{e q}$ (Priestley and Taylor, 1972). 


\subsection{Results}

\subsubsection{Hydrometeorological conditions}

The annual total precipitation observed during the study was $687 \mathrm{~mm}, 816 \mathrm{~mm}$ and $586 \mathrm{~mm}$ per year, for years 2012, 2013 and 2014 respectively. Comparing these totals with the long-term annual average $( \pm S D)$ precipitation $(1960-2010)$ of $674( \pm 136) \mathrm{mm}$ received in the area, the year 2014 received below average precipitation amounts whereas 2012 and 2013, received above average precipitation. More than $60 \%$ of the precipitation was received during the long (March, April, May, June) and short (October, November, December) wet seasons (Figure 4-2a). Seasonal variation in soil moisture followed that of the precipitation pattern (Figure 4-2b). The soil water content increased rapidly with the onset of precipitation during the wet seasons. The annual daily average $( \pm S D)$ temperature over the 3-year measurements was $16.59( \pm 4.60){ }^{\circ} \mathrm{C}(\mathrm{SD}), 16.65( \pm$ 4.28) ${ }^{\circ} \mathrm{C}$ and $17.03( \pm 4.36){ }^{\circ} \mathrm{C}$ for year 2012, 2013 and 2014 respectively. The months of January, February and March recorded the highest daily temperatures up to $\sim 32^{\circ} \mathrm{C}$ (Figure $4-2 \mathrm{C}$ ). The same months also recorded the lowest daily temperatures ranging from $0.90-4.25{ }^{\circ} \mathrm{C}$. The annual daily average vapor pressure deficit (VPD) was highest in year $2014(\sim 0.75 \mathrm{kPa})$ and lowest in 2013 $(\sim 0.68 \mathrm{kPa})$ with the dry season of January and February having higher monthly average $V P D$ $(1.05-1.10 \mathrm{kPa})$ than the wet season of April, May and June (0.48-0.57 kPa). The hourly average of daily maximum VPD was also highest in the dry season (4.06-4.38 kPa) and lowest in the wet season (2.18-2.78 kPa) (Figure 4-2d). 


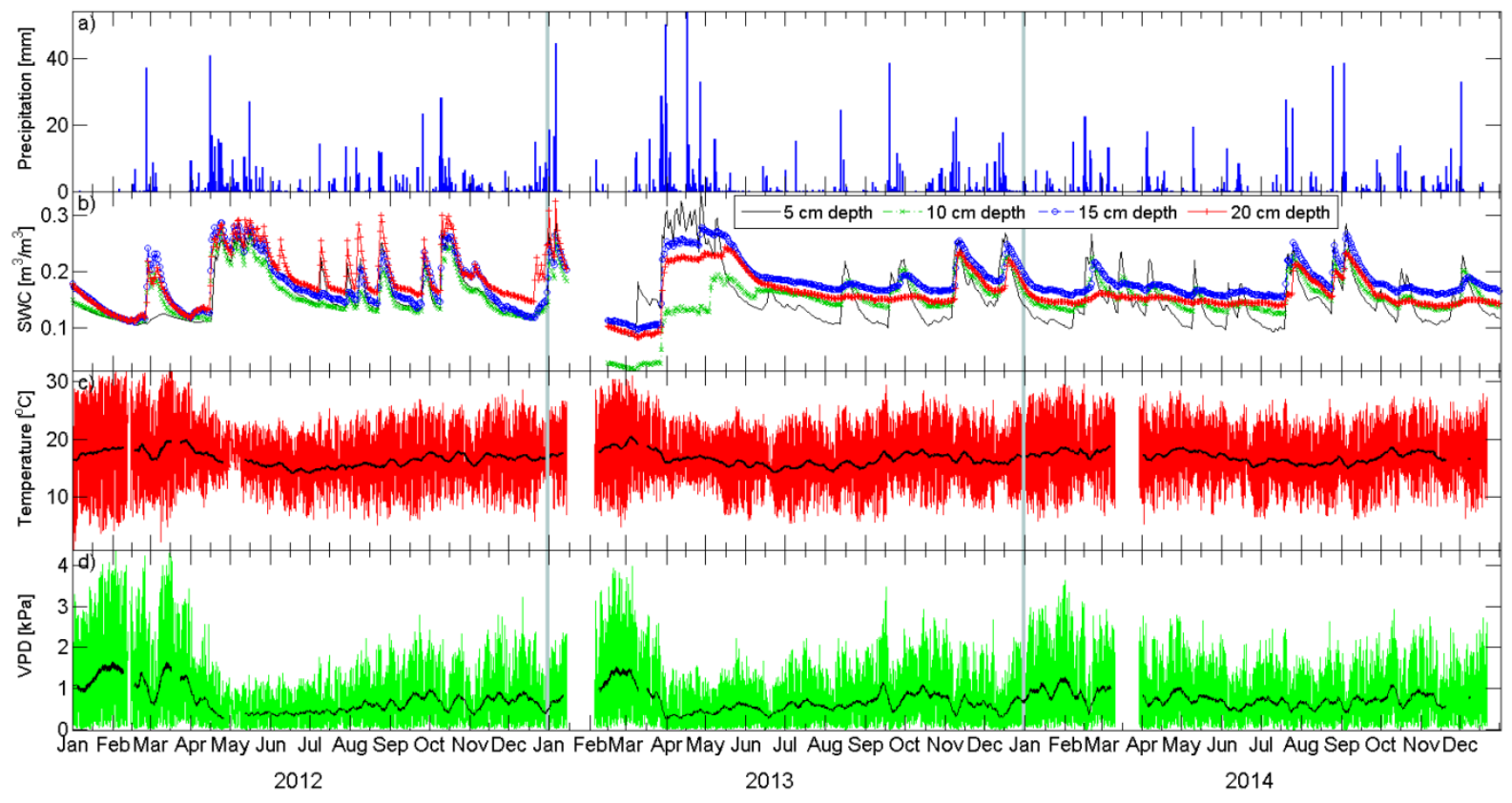

Figure 4-2: Summaries of daily (a) total precipitation $(P)$, (b) Volumetric soil water content (SWC) and hourly (c) air temperature $\left(T_{a}\right)$ and $(\mathrm{d})$ vapor pressure deficit (VPD) at $1.8 \mathrm{~m}$ from $1^{\text {st }}$ January 2012 to $31^{\text {st }}$ December 2014. The black line in $2 \mathrm{c}$ and $2 \mathrm{~d}$ represents the weekly moving average

\subsubsection{Energy balance closure}

The degree of energy balance closure was assessed by regression of the sum of turbulent fluxes ( $H$ $+L E$ ) against available energy $\left(R_{n}-G_{o}\right)$ (Figure 4-3). Using half-hourly data for all the years, the slope between available energy and turbulent fluxes was less than one for all years with a value of 0.66. The intercept was $4.23 \mathrm{Wm}^{-2}$ with interannual range from $-1.77-15.38 \mathrm{Wm}^{-2}$ and a coefficient of determination $\left(R^{2}\right)$ of 0.84 . All the years had almost similar slopes and $R^{2}$. The root mean square error $(R M S E)$ varied from $56.5-90.9 \mathrm{Wm}^{-2}$. The 3-year energy balance ratio $\left(E_{B R}\right)$ was 0.66 with an interannual range of 0.60-0.71. Regression statistics of the energy balance closure are shown in Table 4-1 for each of the 3 years. 
Table 4-1: Slope, intercept, $R^{2}$ and the energy balance ratio $\left(E_{B R}\right)$ of the half-hourly energy balance closure.

\begin{tabular}{cccccc}
\hline Year & slope & Intercept $\left(\mathrm{Wm}^{-2}\right)$ & $R^{2}$ & $R M S E\left(\mathrm{Wm}^{-2}\right)$ & $\mathrm{E}_{\mathrm{BR}}$ \\
\hline 2012 & 0.67 & 15.38 & 0.77 & 90.9 & 0.71 \\
2013 & 0.64 & -0.28 & 0.87 & 61.0 & 0.60 \\
2014 & 0.66 & -1.77 & 0.90 & 56.5 & 0.65 \\
$2012-2014$ & 0.66 & 4.23 & 0.84 & 72.9 & 0.65 \\
\hline
\end{tabular}




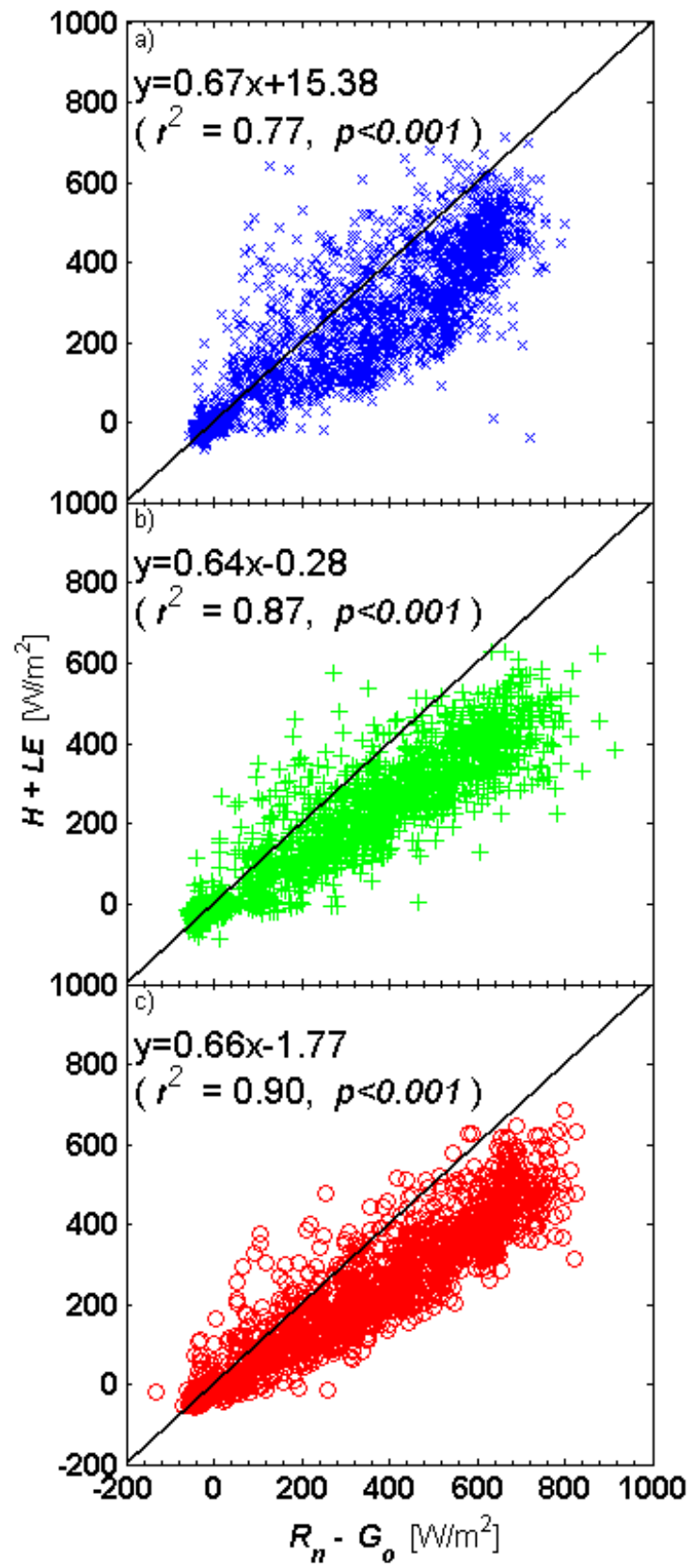

Figure 4-3: Energy balance closure of 30-min sum of turbulent fluxes (H+LE) against available energy $\left(R_{n}-G_{o}\right)$ for year (a) 2012 (b) 2013 and (c) 2014. The solid line indicates 1:1 relationship 
Chapter 4

Comparison between the Bowen ratio estimated $L E$ and that measured when LI-7500 was operational had a coefficient of determination $\left(R^{2}\right)$ of $0.72(p<0.001)$ and an $R M S E$ of $39.1 \mathrm{Wm}^{-2}$ with the energy balance closure slopes being identical for the two cases (EC closure slope $=0.602$, Bowen ratio closure slope $=0.608$ ) (Figure 4-4). The sonic measured $H$ also compared favorably with that measured by the LAS system achieving an $R^{2}=0.83(p<0.001)$ and $R M S E=40.07 \mathrm{Wm}^{-2}$ (Figure 4-5).

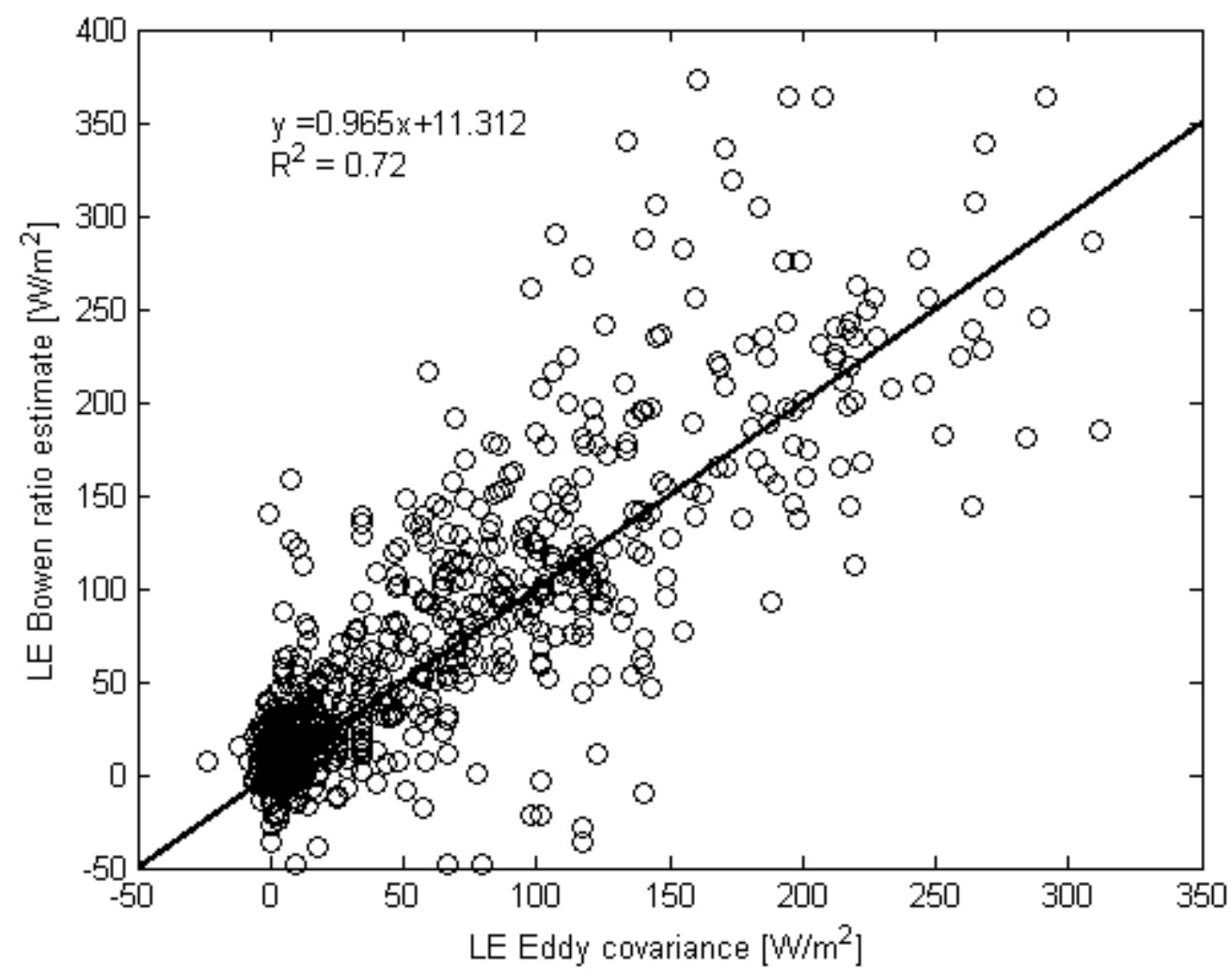

Figure 4-4: Comparison of $L E$ estimated using the Bowen ratio method and that measured using the eddy covariance technique during the period the LI-7500 was operational 


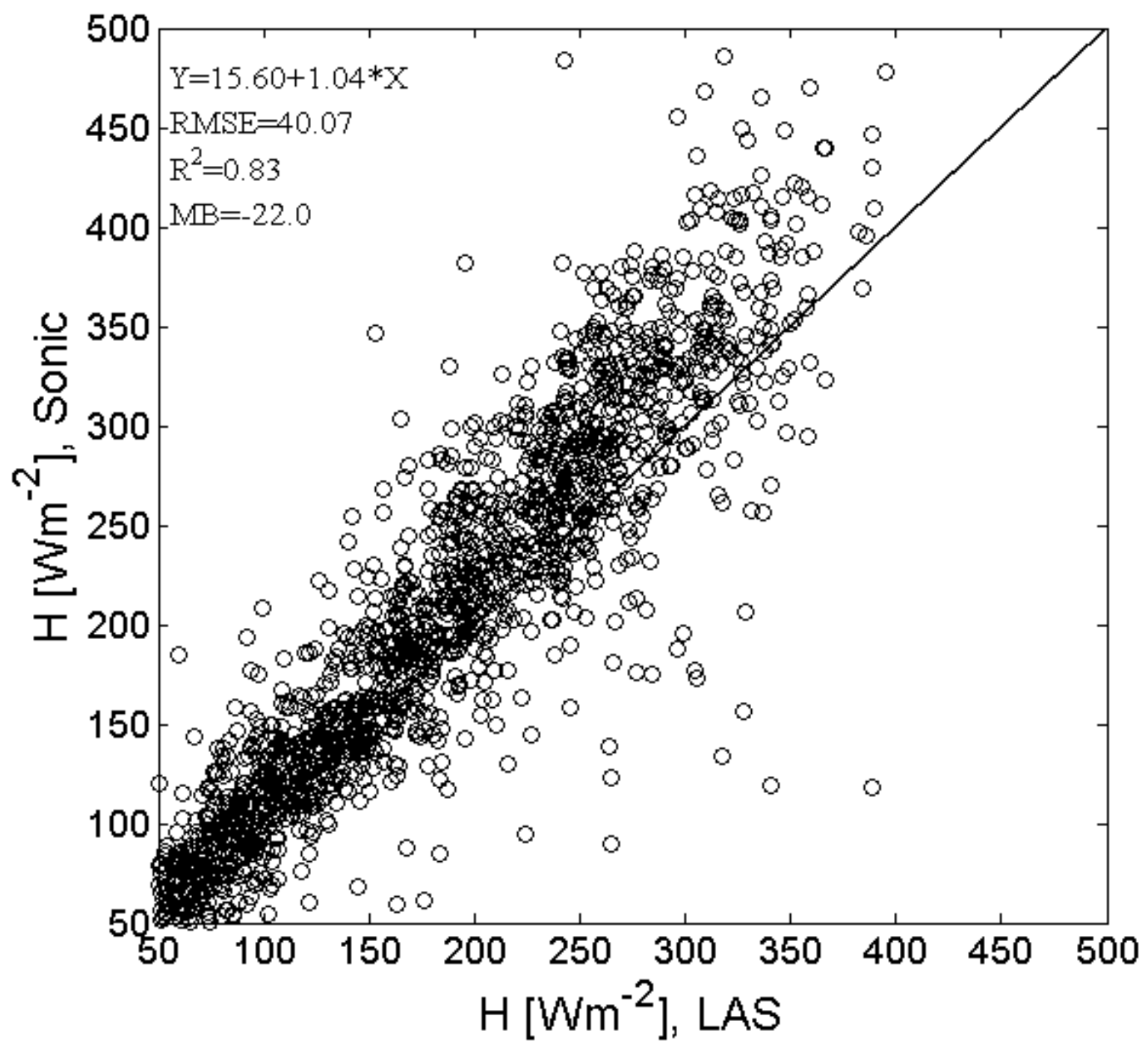

Figure 4-5: Comparison of 30-minute averaged $H$ from LAS and Sonic when LAS was operational in 2012. Plotted values are of $H>50 \mathrm{Wm}^{-2}$

\subsubsection{Seasonal variations in energy partitioning and evapotranspiration}

The seasonal pattern of energy fluxes of $R_{n}, G_{0}, H$ and $L E$ are shown in Figure 4-6 and Table 4-2. Over the entire period of measurements, the monthly diurnal $R_{n}, G_{0}$ and $H$ peaked in January, February and March while $L E$ was lower for the same months. The opposite was observed for the wet months of April, May and June. Monthly diurnal peaks $R_{n}$ also declined from January reaching 
Chapter 4

minimum values in June and July and then gradually increasing until December. The diurnal seasonal $H$ decreased with the decrease in $R_{n}$. The midday (10:00-14:00 hr) $H$ was the highest flux in all months other than April and May when LE was the highest flux from early noon to late afternoon (Figure 4-6).

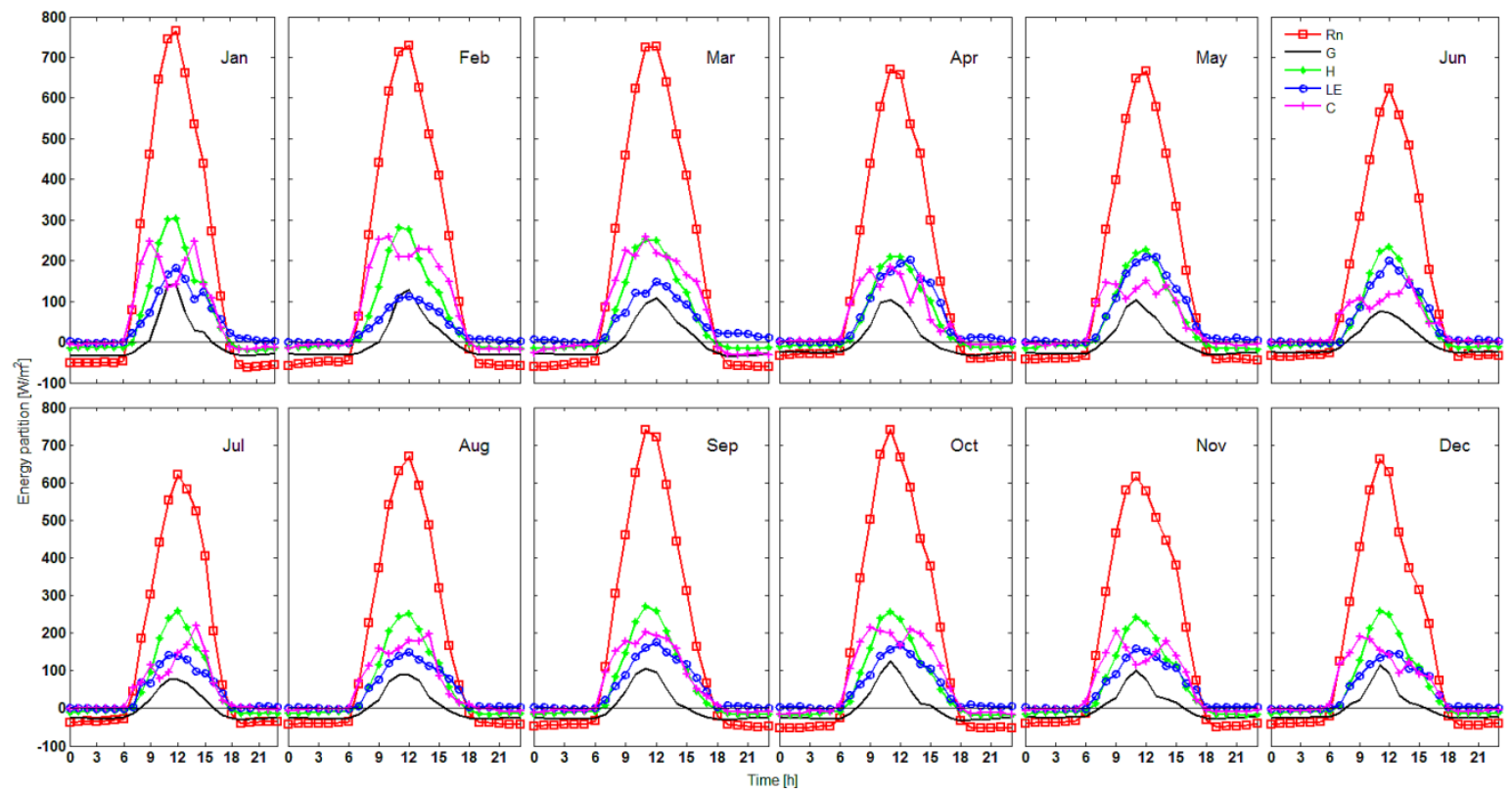

Figure 4-6: Monthly diurnal pattern of energy fluxes of $R_{n}, G_{0}, H, L E$ and $C$ for the period 20122014 
Energy partitioning and its controls

Table 4-2: Table 2: Monthly and annual summaries of energy balance components, equilibrium $L E$ and potential $L E$, and key hydrometeorological factors at the study site

\begin{tabular}{|c|c|c|c|c|c|c|c|c|c|c|c|c|c|}
\hline Year & Period & $\underset{\left[\mathbf{W} / \mathbf{m}^{2}\right]}{\mathbf{R n}}$ & $\begin{array}{c}\text { G0 } \\
{\left[\mathbf{W} / \mathbf{m}^{2}\right]}\end{array}$ & $\underset{\left[\mathbf{W} / \mathbf{m}^{2}\right]}{\mathbf{H}}$ & $\begin{array}{c}\mathbf{L E} \\
{\left[\mathbf{W} / \mathbf{m}^{2}\right]}\end{array}$ & $\begin{array}{c}\mathbf{C} \\
{\left[\mathbf{W} / \mathbf{m}^{2}\right]}\end{array}$ & $\underset{\left[\mathrm{W} / \mathbf{m}^{2}\right]}{\mathbf{L E}_{\mathbf{2}}}$ & $\begin{array}{l}\mathbf{L E}_{\mathrm{pot}} \\
{\left[\mathbf{W} / \mathbf{m}^{2}\right]}\end{array}$ & $\begin{array}{l}\text { Precipitation } \\
{[\mathrm{mm}]}\end{array}$ & $\begin{array}{c}\text { Air } \\
\text { Temperature } \\
{\left[{ }^{\circ} \mathrm{C}\right]} \\
\end{array}$ & $\begin{array}{c}\mathbf{u} \\
{[\mathbf{m} / \mathbf{s}]}\end{array}$ & $\begin{array}{l}\text { VPD } \\
{[\mathrm{kPa}]}\end{array}$ & $\begin{array}{c}\text { Bowen } \\
\text { ratio } \\
{[\beta]}\end{array}$ \\
\hline \multirow[t]{13}{*}{2012} & Jan & 191.91 & 1.68 & 65.55 & 54.35 & 70.34 & 138.73 & 174.80 & 0.40 & 17.50 & 2.63 & 1.24 & 1.85 \\
\hline & Feb & 178.44 & 3.56 & 67.85 & 29.24 & 77.79 & 127.01 & 160.03 & 49.60 & 18.40 & 2.90 & 1.28 & 3.06 \\
\hline & Mar & 178.89 & 2.05 & 70.94 & 51.32 & 54.57 & 128.36 & 161.73 & 17.40 & 18.71 & 3.12 & 1.20 & 1.82 \\
\hline & Apr & 158.32 & 2.39 & 49.99 & 62.36 & 43.57 & 107.67 & 135.66 & 158.40 & 17.07 & 2.14 & 0.53 & 1.25 \\
\hline & May & 175.03 & 2.46 & 52.41 & 120.46 & -0.30 & 116.55 & 146.85 & 90.80 & 16.30 & 2.26 & 0.41 & 0.45 \\
\hline & Jun & 157.62 & 3.36 & 48.99 & 91.30 & 13.98 & 102.87 & 129.62 & 14.80 & 14.96 & 2.23 & 0.39 & 0.64 \\
\hline & Jul & 156.03 & 3.81 & 55.65 & 67.83 & 28.74 & 101.42 & 127.79 & 42.80 & 14.98 & 2.05 & 0.44 & 1.01 \\
\hline & Aug & 178.46 & 3.36 & 62.67 & 64.87 & 47.55 & 118.90 & 149.82 & 67.80 & 15.53 & 2.46 & 0.58 & 1.27 \\
\hline & Sep & 182.82 & 4.73 & 68.78 & 70.30 & 39.00 & 122.79 & 154.72 & 52.20 & 16.35 & 2.93 & 0.71 & 1.35 \\
\hline & Oct & 205.84 & 6.86 & 62.10 & 78.03 & 58.85 & 138.03 & 173.92 & 100.40 & 17.09 & 2.82 & 0.70 & 1.02 \\
\hline & Nov & 176.23 & 3.61 & 60.73 & 72.78 & 39.11 & 119.33 & 150.36 & 34.00 & 16.73 & 2.30 & 0.66 & 1.20 \\
\hline & Dec & 159.01 & 3.02 & 63.99 & 41.60 & 50.40 & 108.31 & 136.47 & 59.00 & 16.70 & 2.18 & 0.68 & 1.99 \\
\hline & Annual & 175.17 & 3.44 & 60.52 & 67.66 & 43.55 & 119.16 & 150.14 & 687.60 & 16.68 & 2.50 & 0.74 & 1.40 \\
\hline \multirow[t]{5}{*}{2013} & Jan & 207.36 & 3.41 & 51.72 & 80.09 & 72.14 & 143.23 & 180.47 & 80.20 & 17.55 & 2.30 & 0.76 & 0.94 \\
\hline & $\mathrm{Feb}$ & 184.25 & 0.48 & 49.42 & 18.86 & 115.49 & 134.62 & 169.62 & 12.60 & 18.45 & - & 1.23 & 2.04 \\
\hline & Mar & 186.56 & 3.33 & 55.00 & 44.75 & 83.49 & 131.73 & 165.98 & 156.20 & 18.68 & 2.92 & 0.95 & 1.95 \\
\hline & Apr & 172.80 & 3.00 & 42.43 & 77.86 & 49.51 & 116.50 & 146.78 & 188.80 & 16.64 & 1.87 & 0.38 & 0.53 \\
\hline & May & 170.06 & 0.87 & 45.64 & 86.97 & 36.58 & 116.08 & 146.26 & 40.00 & 16.08 & 2.51 & 0.51 & 0.63 \\
\hline
\end{tabular}




\begin{tabular}{|c|c|c|c|c|c|c|c|c|c|c|c|c|c|c|}
\hline & & & & & & & & & & & & & & Chapter 4 \\
\hline & Jun & 152.22 & 0.72 & 47.00 & 53.61 & 50.88 & 102.68 & 129.38 & 20.20 & 15.17 & 2.22 & 0.47 & 1.08 & \\
\hline & Jul & 159.64 & -0.28 & 55.51 & 34.33 & 70.08 & 109.87 & 138.43 & 24.00 & 15.52 & 2.28 & 0.62 & 2.19 & \\
\hline & Aug & 146.50 & -0.04 & 50.91 & 28.45 & 67.18 & 99.97 & 125.96 & 38.20 & 15.37 & 2.77 & 0.59 & 2.94 & \\
\hline & Sep & 173.52 & 1.14 & 58.63 & 36.46 & 77.29 & 120.35 & 151.64 & 77.00 & 16.66 & 2.78 & 0.73 & 2.41 & \\
\hline & Oct & 177.58 & -0.41 & 52.97 & 40.43 & 84.59 & 126.21 & 159.03 & 23.00 & 17.47 & 3.43 & 0.88 & 1.80 & \\
\hline & Nov & 162.40 & 0.15 & 43.95 & 49.16 & 69.14 & 112.96 & 142.32 & 81.40 & 16.68 & 2.34 & 0.62 & 1.28 & \\
\hline & Dec & 151.93 & -0.17 & 49.61 & 54.65 & 47.83 & 105.15 & 132.49 & 74.60 & 16.34 & 1.92 & 0.56 & 1.16 & \\
\hline & Annual & 167.81 & 0.84 & 50.27 & 49.10 & 67.60 & 116.41 & 146.68 & 816.20 & 16.65 & 2.47 & 0.68 & 1.61 & \\
\hline 2014 & Jan & 181.16 & 2.24 & 70.81 & 44.37 & 63.73 & 129.37 & 163.01 & 24.00 & 17.63 & 2.51 & 0.98 & 2.07 & \\
\hline & Feb & 170.12 & 2.47 & 67.31 & 47.62 & 52.72 & 120.08 & 151.30 & 78.20 & 17.70 & 2.21 & 0.83 & 1.98 & \\
\hline & Mar & 192.54 & 0.03 & 61.51 & 50.32 & 80.67 & 138.80 & 174.89 & 20.80 & 18.32 & 2.74 & 0.98 & 1.45 & \\
\hline & Apr & 170.71 & 1.02 & 60.01 & 48.66 & 61.01 & 121.14 & 152.64 & 55.40 & 17.40 & 2.78 & 0.78 & 0.87 & \\
\hline & May & 148.26 & 1.16 & 62.91 & 31.13 & 53.05 & 103.80 & 130.79 & 30.40 & 17.67 & 2.84 & 0.76 & 3.47 & \\
\hline & Jun & 145.95 & 1.43 & 62.06 & 27.90 & 54.55 & 99.06 & 124.81 & 38.60 & 16.36 & 2.41 & 0.59 & 2.97 & \\
\hline & Jul & 154.00 & 1.75 & 66.42 & 31.17 & 54.66 & 104.70 & 131.93 & 74.80 & 16.08 & 2.59 & 0.65 & 4.68 & \\
\hline & Aug & 158.58 & 1.46 & 58.45 & 45.61 & 53.06 & 107.86 & 135.90 & 55.60 & 15.88 & 2.73 & 0.63 & 1.67 & \\
\hline & Sep & 176.80 & 1.33 & 56.45 & 56.26 & 62.76 & 121.56 & 153.17 & 73.80 & 16.03 & 2.93 & 0.66 & 1.24 & \\
\hline & Oct & 159.51 & 1.16 & 56.45 & 43.18 & 58.72 & 111.75 & 140.80 & 37.00 & 17.75 & 2.96 & 0.80 & 2.08 & \\
\hline & Nov & 144.07 & 0.85 & 56.91 & 34.87 & 51.44 & 100.55 & 126.69 & 51.60 & 17.36 & 2.44 & 0.73 & 3.36 & \\
\hline & Dec & 175.00 & 1.81 & 61.06 & 48.87 & 63.26 & 120.70 & 152.09 & 45.40 & 16.88 & - & 0.75 & 1.39 & \\
\hline & Annual & 162.69 & 1.44 & 61.66 & 41.71 & 57.88 & 113.36 & 142.83 & 585.60 & 17.03 & 2.68 & 0.75 & 2.36 & \\
\hline
\end{tabular}


Energy partitioning and its controls

The ratio $L E / R_{n}$ was lowest in the drier periods of January, February and March with values ranging $0.10-0.39$, and it increased gradually to maximum values $>0.40$ in the wet season months of April and May (Figure 4-7). Consequently, for the years 2012 and 2013 that recorded above average precipitation, actual evapotranspiration was highest during the wettest months accounting for 46 $82 \%$ of potential evapotranspiration. For year 2014 that recorded below average precipitation, actual evapotranspiration during the wettest months accounted for $24-32 \%$ of potential evapotranspiration. Over the entire period of measurements, actual evapotranspiration hardly ever exceeded the total equilibrium evapotranspiration. The pattern of $H / R_{n}$ was opposite to that of $L E / R_{n}$ (Table 4-3) as one can also observe in the Bowen ratio (Figure 4-7). On annual scale, over $60 \%$ of $R_{n}$ was partitioned as $L E$ and $H$, whereas the contribution of $G_{0}$ was less than $3 \%$ (Table 4-3). The residual energy balance closure term (C) accounted for between $25-40 \%$ of the $R_{n}$. While $C$ tended to peak towards midday on a diurnal scale, it was less pronounced in the wettest months and highest in the driest months (Figure 4-6).

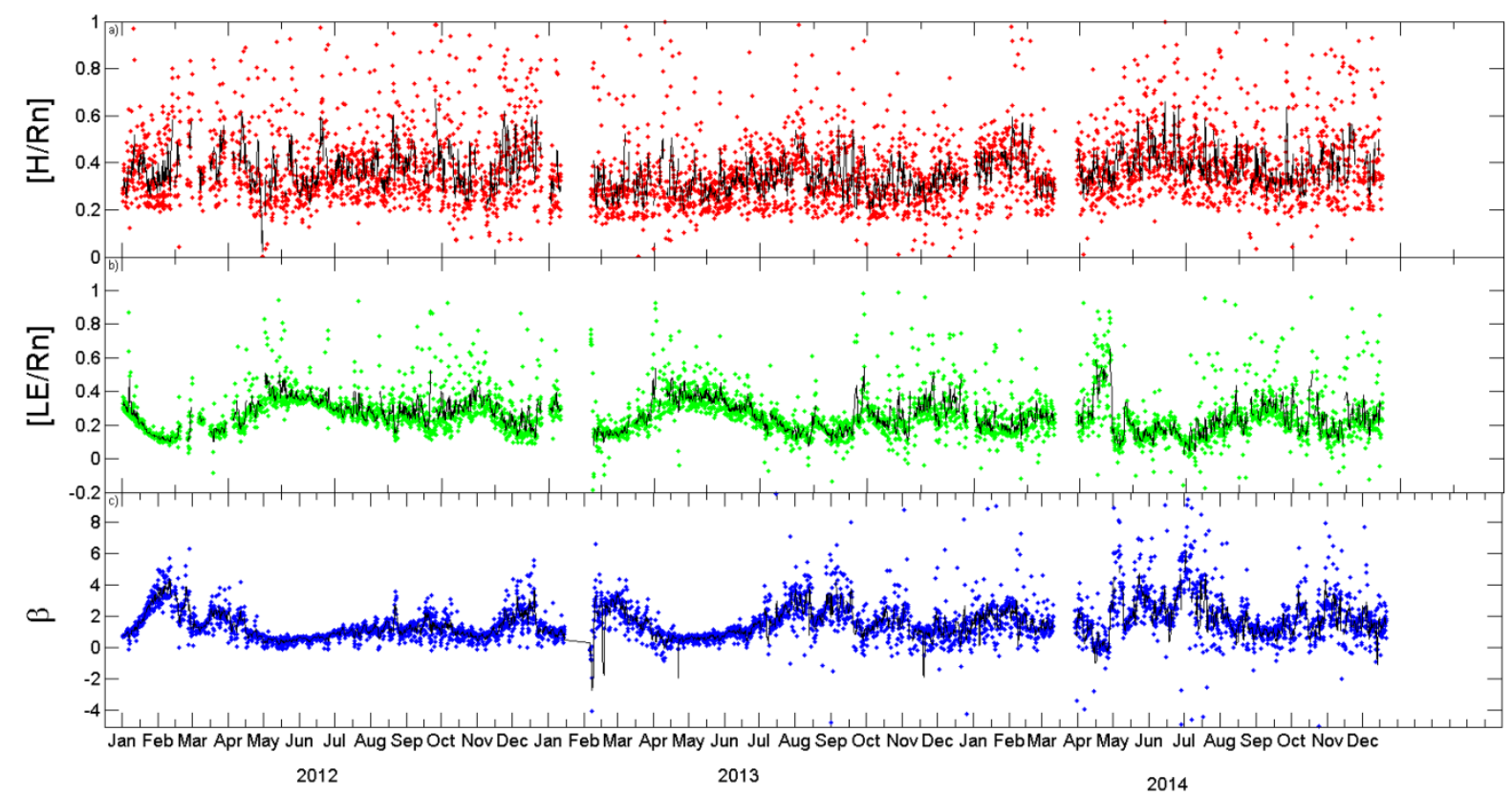

Figure 4-7: Seasonal midday (10:00-14:00 hr) values of the (a) ratio of energy partition of sensible heat flux to net radiation $\left(H / R_{n}\right)$ (b) ratio of energy partition of latent heat flux to net radiation $\left(L E / R_{n}\right)$ (c) Bowen ratio $(\beta)$ from January 2012 to December 2014. The black line is the 4-hr moving average 
Chapter 4 Table 4-3: Monthly and annual summaries of energy balance partition, Priestley-Taylor coefficient (a), actual ET, potential ET, and percent of actual ET to potential ET and average monthly leaf area index

\begin{tabular}{|c|c|c|c|c|c|c|c|c|c|c|}
\hline Year & Period & LE/Rn & H/Rn & G0/Rn & C/Rn & $\alpha$ & ET [mm] & $\mathbf{E} \mathbf{T}_{\text {pot }}[\mathrm{mm}]$ & $\mathbf{E T} \mathbf{E T}_{\text {pot }}[\%]$ & $\mathrm{LAI}\left[\mathrm{m}^{2} / \mathrm{m}^{2}\right]$ \\
\hline \multirow[t]{13}{*}{2012} & Jan & 0.28 & 0.34 & 0.01 & 0.37 & 0.39 & 59.42 & 191.10 & 31.09 & 1.53 \\
\hline & Feb & 0.16 & 0.38 & 0.02 & 0.44 & 0.23 & 29.90 & 163.66 & 18.27 & 0.90 \\
\hline & Mar & 0.29 & 0.40 & 0.01 & 0.31 & 0.40 & 56.10 & 176.81 & 31.73 & 0.93 \\
\hline & Apr & 0.39 & 0.32 & 0.02 & 0.28 & 0.58 & 65.98 & 143.52 & 45.97 & 1.33 \\
\hline & May & 0.69 & 0.30 & 0.01 & 0.00 & 1.03 & 131.69 & 160.54 & 82.03 & 2.50 \\
\hline & Jun & 0.58 & 0.31 & 0.02 & 0.09 & 0.89 & 96.59 & 137.13 & 70.44 & 2.05 \\
\hline & Jul & 0.43 & 0.36 & 0.02 & 0.18 & 0.67 & 74.15 & 139.71 & 53.08 & 1.85 \\
\hline & Aug & 0.36 & 0.35 & 0.02 & 0.27 & 0.55 & 70.92 & 163.79 & 43.30 & 1.50 \\
\hline & Sep & 0.38 & 0.38 & 0.03 & 0.21 & 0.57 & 74.38 & 163.69 & 45.44 & 1.45 \\
\hline & Oct & 0.38 & 0.30 & 0.03 & 0.29 & 0.57 & 85.31 & 190.13 & 44.87 & 1.55 \\
\hline & Nov & 0.41 & 0.34 & 0.02 & 0.22 & 0.61 & 77.00 & 159.07 & 48.41 & 1.60 \\
\hline & Dec & 0.26 & 0.40 & 0.02 & 0.32 & 0.38 & 45.47 & 149.19 & 30.48 & 1.18 \\
\hline & Annual & 0.39 & 0.35 & 0.02 & 0.25 & 0.57 & 866.90 & 1938.34 & 44.72 & 1.51 \\
\hline \multirow[t]{5}{*}{2013} & Jan & 0.39 & 0.25 & 0.02 & 0.35 & 0.56 & 87.56 & 197.30 & 44.38 & 1.58 \\
\hline & $\mathrm{Feb}$ & 0.10 & 0.27 & 0.00 & 0.63 & 0.14 & 18.62 & 167.49 & 11.12 & 1.23 \\
\hline & Mar & 0.24 & 0.29 & 0.02 & 0.45 & 0.34 & 48.92 & 181.45 & 26.96 & 1.10 \\
\hline & Apr & 0.45 & 0.25 & 0.02 & 0.29 & 0.67 & 82.38 & 155.29 & 53.05 & 2.00 \\
\hline & May & 0.51 & 0.27 & 0.01 & 0.22 & 0.75 & 95.08 & 159.90 & 59.46 & 2.33 \\
\hline
\end{tabular}




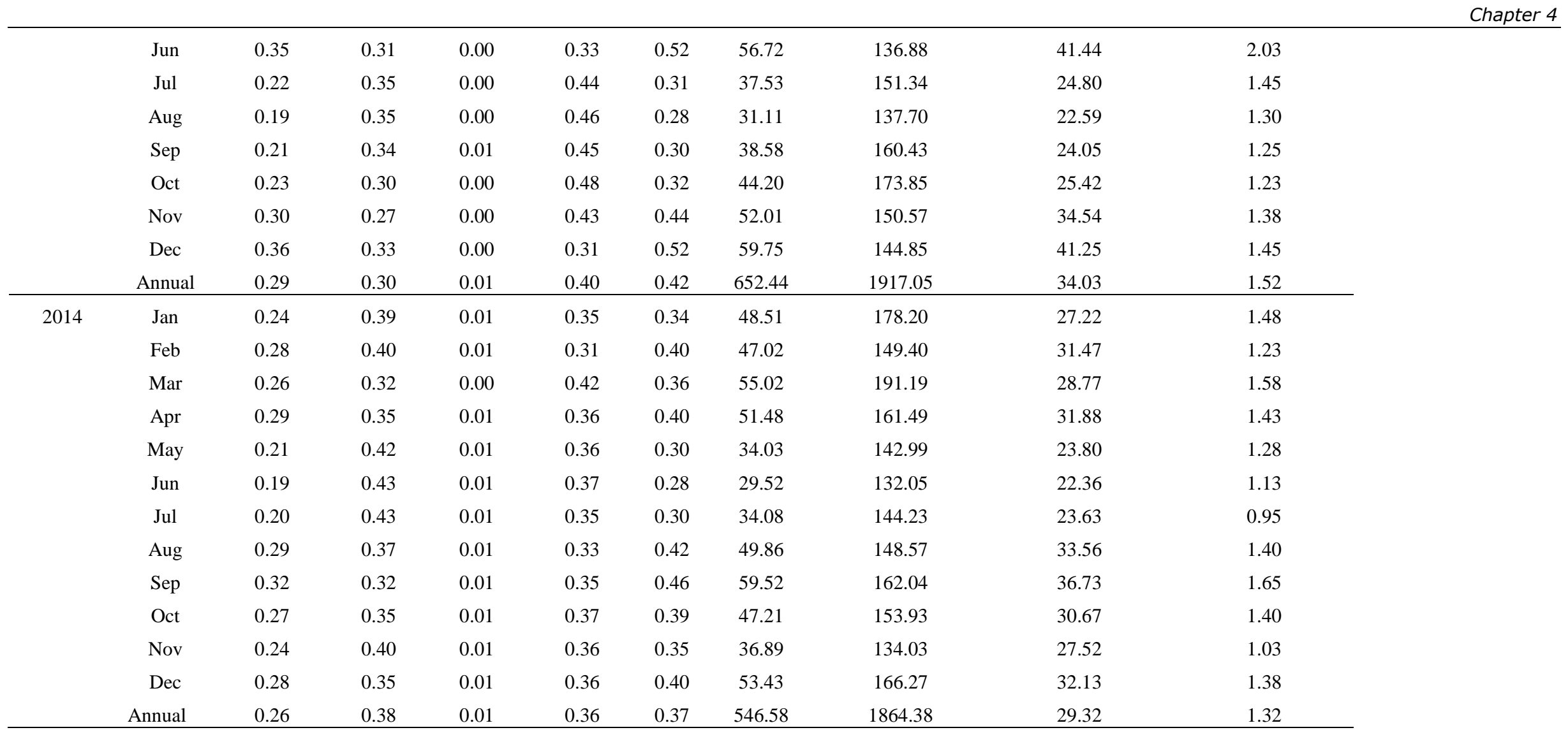




\subsubsection{Climatic and biological control of energy partitioning}

The Priestley-Taylor a coefficient was mostly $<1$ for the entire period of measurements with cases $>1$ occurring mostly during the wet seasons Figure 4-8. The mean monthly Priestley-Taylor a coefficient were lowest ( 0.14-0.23) in February for year 2012 and 2013 while May, June and July recorded lowest Priestley-Taylor a coefficient ( 0.28-0.30) for the year 2014 (Table 4-2). Maximum Priestley-Taylor a coefficient $(>0.6$ ) occurred mostly in April, May and June for year 2012 and 2013. However, during 2014, the maximum Priestley-Taylor a coefficient was observed during the months of August and September, and was much lower ( 0.42-0.46) than during 2012 and 2013. 


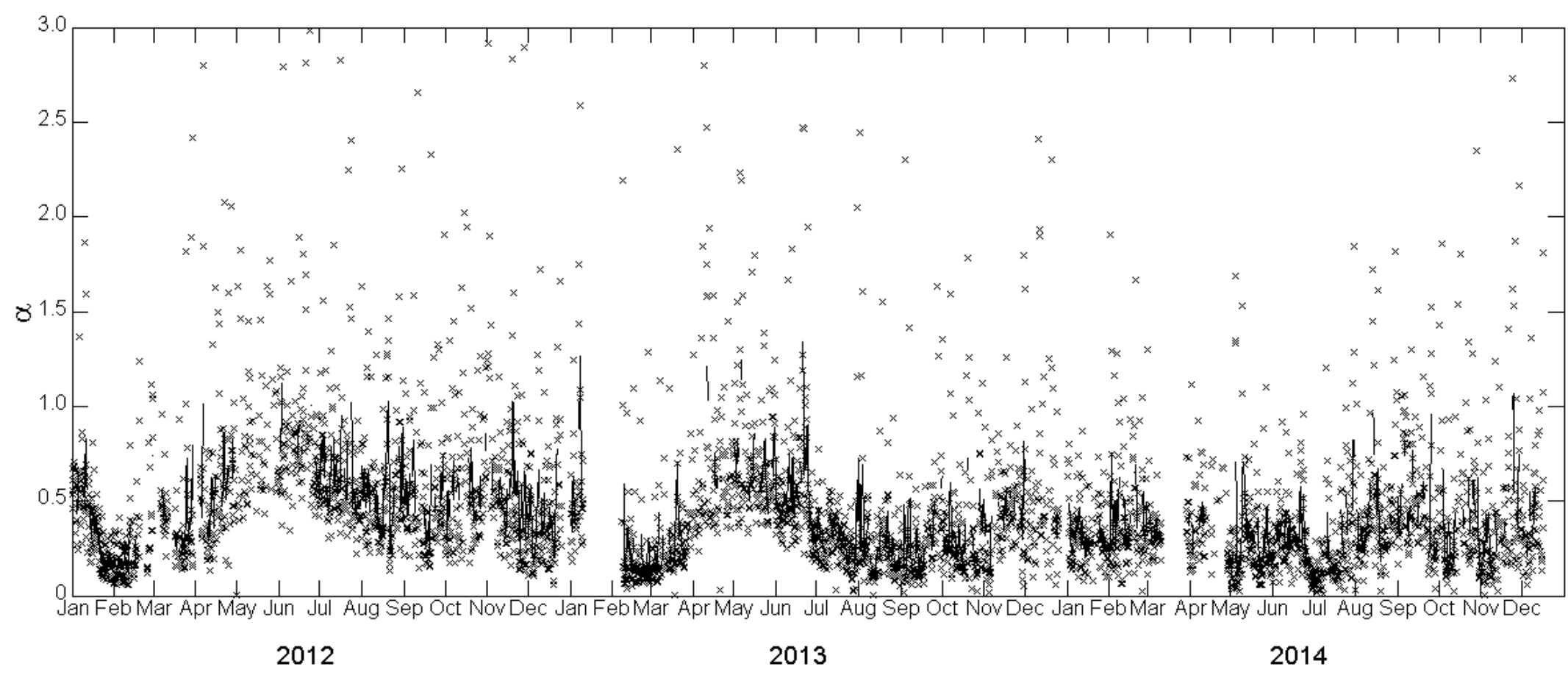

Figure 4-8: Seasonal trend of Priestley-Taylor a coefficient for the period 2012-2014. The black line represents the weekly moving average 102 
Chapter 4

Midday canopy surface conductance $\left(g_{s}\right)$ was positively correlated with Priestley-Taylor a coefficient for the period of measurements (Figure 4-9) with higher values (>5 mm/s) of $g_{s}$ predominantly experienced in the months of April, May and June (Figure 4-10b). On an annual timescale, the average $g_{s}$ was $3.78,2.60$ and $1.86 \mathrm{~mm} / \mathrm{s}$ for the years 2012, 2013 and 2014 respectively. Mean monthly $g_{s}$ was significantly correlated with MODIS extracted leaf area index (Figure 4-12) than with the average soil water content (SWC) measured at the top $20 \mathrm{~cm}$ of the soil surface (Figure 4-12). In the drought year 2014, maximum leaf area index was lowest compared to years 2012 and 2013. Moreover, $g_{s}$ decreased exponentially with VPD (Figure 4-13).

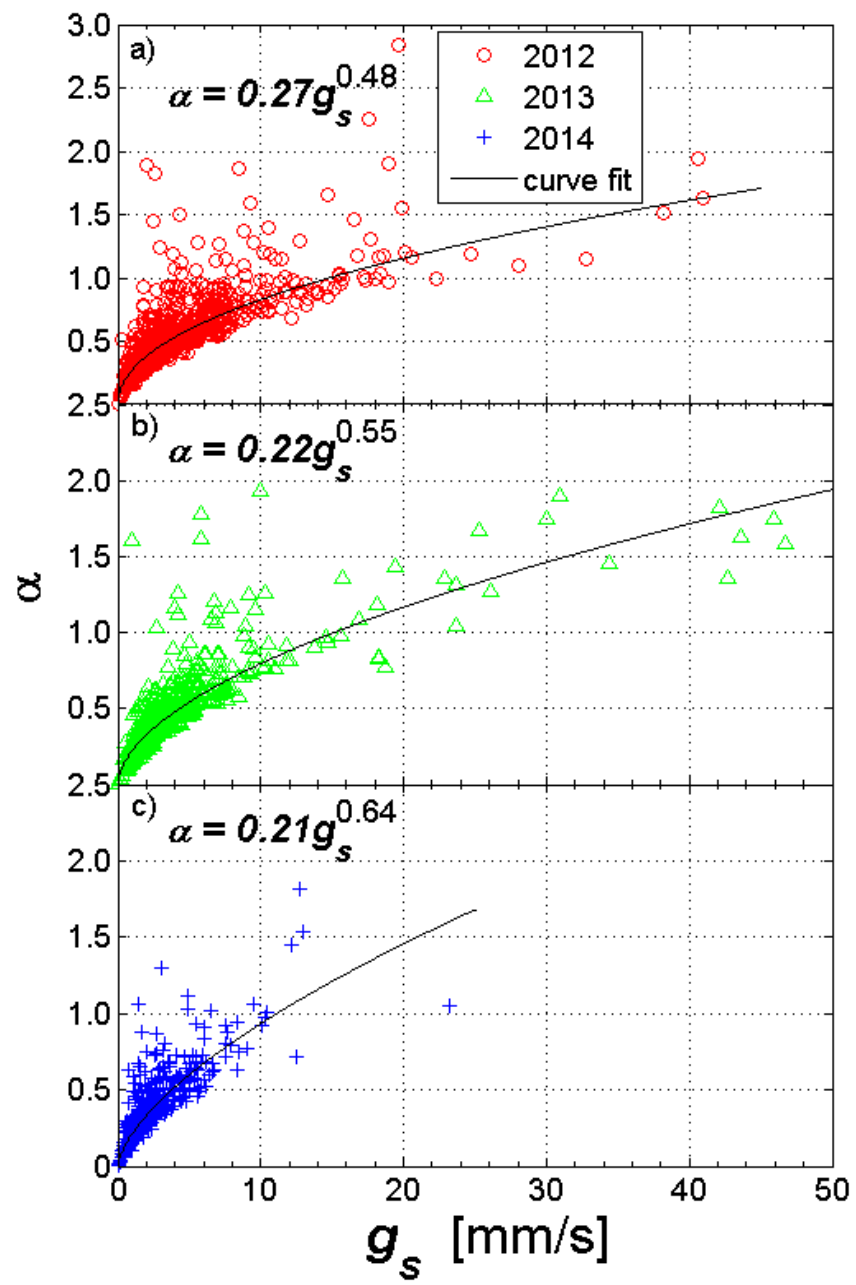

Figure 4-9: Relationship between midday (10:00-14:00 h) Priestley-Taylor a coefficient and midday canopy surface conductance $\left(g_{s}\right)$. 
Dry months (January-March) had high VPD ranging from 1.48-4.22 kPa with $g_{s}$ mostly $<5.0 \mathrm{~mm} / \mathrm{s}$ whereas the wet months (April-June) experienced low VPD ranging from 0.21-2.56 $\mathrm{kPa}$ with $g_{s}$ mostly $>5.0 \mathrm{~mm} / \mathrm{s}$. The decoupling coefficient $(\Omega)$ followed a similar seasonal trend with $g_{s}$ (Figure 4-10c). The $\Omega$ was predominantly $<0.5$ during the dry months but peaked in the wet months reaching values of $\sim 0.8$.

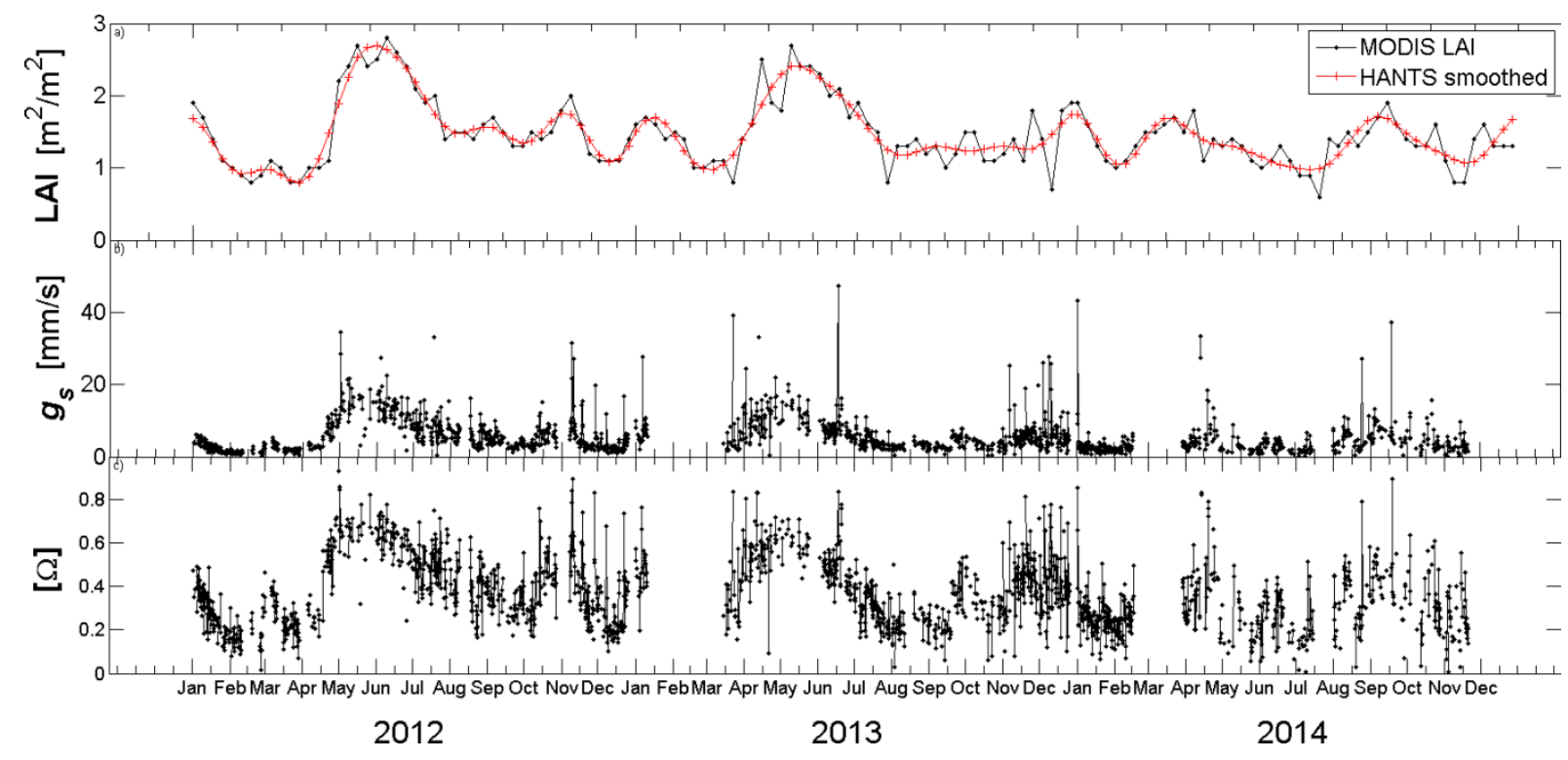

Figure 4-10: Seasonal pattern of (a) MODIS observed and HANTS smoothed LAI trend and midday $(10: 00-14: 00 \mathrm{~h})$ monthly patterns of $(\mathrm{b})$ canopy surface conductance $\left(g_{s}\right)$ (c) decoupling coefficient $(\Omega)$ for the period $2012-2014$.

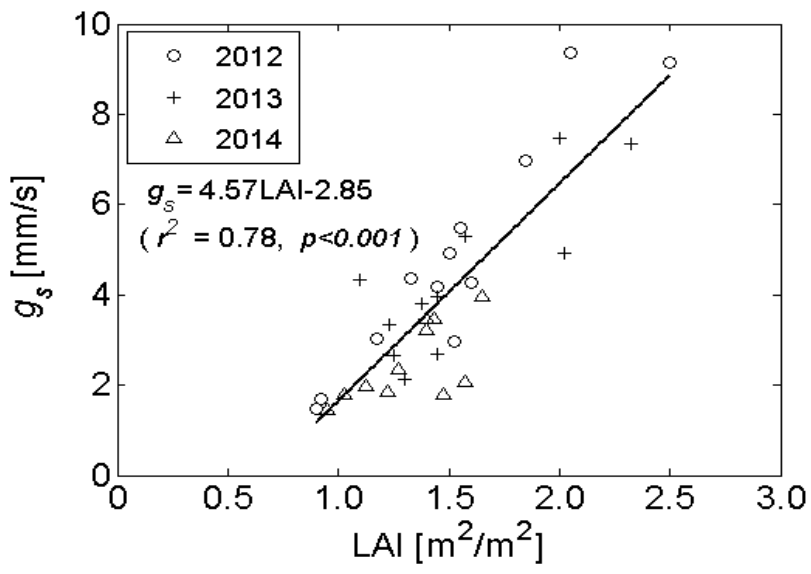

Figure 4-12: The relationship between monthly leaf area index (LAI) and monthly midday surface conductance $\left(g_{\mathrm{s}}\right)$

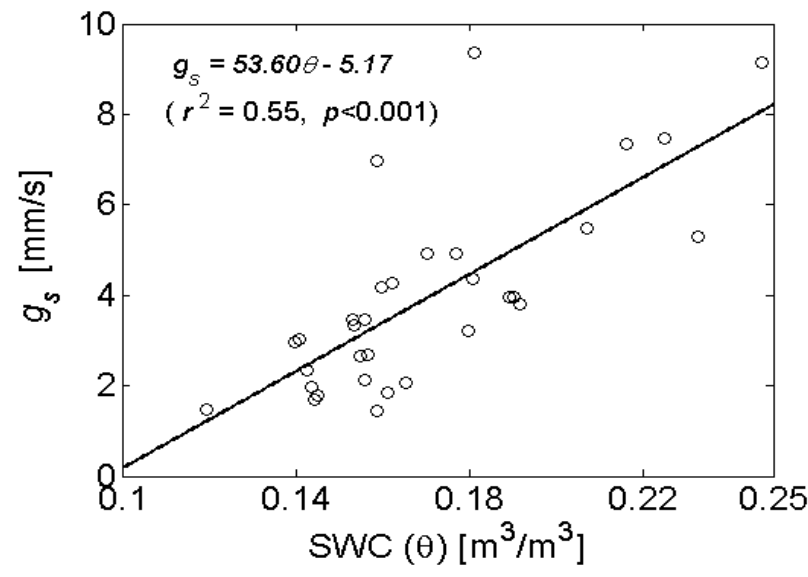

$1 \cap 1$

Figure 4-12: Relationship between monthly mean canopy conductance, $\left(\mathrm{g}_{\mathrm{s}}\right)$ and mean top soil $(0-30 \mathrm{~cm})$ water content (SWC) 


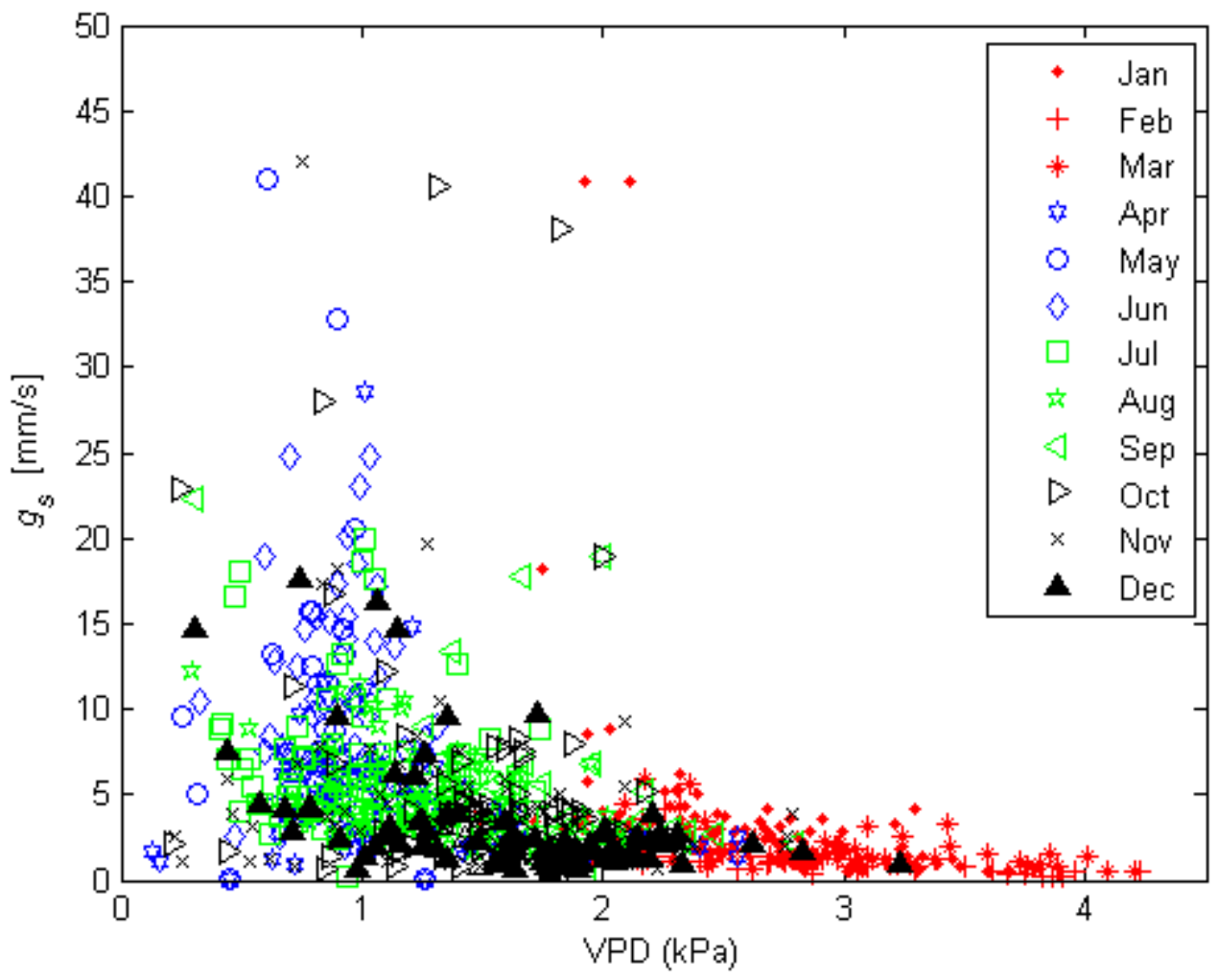

Figure 4-13: The relationship between midday vapor pressure deficit (VPD) and canopy surface conductance $\left(g_{s}\right)$ during the 3-year measurement period

\subsection{Discussion}

\subsubsection{Energy balance closure}

Energy balance closure was used to assess the system performance. Assuming no measurement errors and perfect closure, the slope of regression between available energy $\left(R_{n}-G_{0}\right)$ and the turbulent $(H+L E)$ fluxes measured from meteorological sensors should be unity (Wilson and Baldocchi, 2000). Using 30-min flux data from January 2012 to December 2014, the slope between available energy $\left(R_{n}-G_{0}\right)$ and the turbulent $(H+L E)$ fluxes over the study site was 0.66 with an intercept of $4.23 \mathrm{Wm}^{-2}$ and a coefficient of determination $\left(R^{2}\right)$ of 0.84 . Over the 3-year period of measurements, the slope was less than unity (Table 4-1) indicating that the 
Chapter 4

measurements underestimated the net energy loss at night and net energy gain during the day (Lei and Yang, 2010; Vourlitis et al., 2008).

The lack of energy balance closure has been reported in many studies and remains a subject of much ongoing research (Foken, 2008; Lei and Yang, 2010; Stoy et al., 2013; Veenendaal et al., 2004; Wilson et al., 2002). The 3-year energy balance ratio $\left(E_{B R}\right)$ was 0.65 with an interannual range of 0.60-0.71. While most common reasons for the energy balance closure problem have been attributed to random and/or systematic errors due to inadequacies of the micrometeorological measurement systems (Foken et al., 2010; Vourlitis et al., 2008), the moderate degree of closure for this site could be due to the heterogeneity of the landscape in this area and also, partly due to the small amount of energy stored in the vegetation layer (Moors, 2012). Frequency response analysis of the unstable co-spectra (Appendix B) suggested an overestimation of fluxes at low frequencies (large eddies) and underestimation at peak and higher frequencies (small eddies). While it has been previously suggested (e.g. Foken et al., 2005; Mauder and Foken, 2006; Mauder et al., 2007; Moncrieff, 2004) that large eddies operating at the landscape scale contribute to turbulent fluxes and energy balance closure, the mechanism influencing these processes still remains unclear (Foken, 2008). Also, a mismatch of $R_{n}$ and $G_{0}$ footprints which are close to the measurement tower with those of $H$ and $L E$ that are larger and upwind the tower may increase the energy imbalance (Wever et al., 2002). On an annual basis, the water balance analysis suggested that at least $80 \%$ of the local precipitation evaporates back to the atmosphere. This implies that the lack of energy balance closure may not be due to the latent energy flux but probably due to mismatch of $R_{n}$ and $G_{0}$ footprints. Although the energy balance closure for our site was not perfect, it was within values of FLUXNET (Wilson et al., 2002) and ChinaFLUX ( $\mathrm{Li}$ et al., 2005) sites, whose reported slope values range from 0.58 to 0.99 and 0.49 to 0.81 respectively.

\subsubsection{Seasonal changes in energy fluxes and evapotranspiration}

The partitioning of net radiation into sensible and latent heat flux is usually influenced by changes in vegetation characteristics. The shift of energy partition associated with $L E$ dominance (leaf emergence) and $H$ dominance (leaf senescence) has been observed in many ecosystems (e.g. Lei and Yang, 2010; Valentini et al., 1995; Wever et al., 2002; Wilson and Baldocchi, 2000). For our study site, we observed transition of $H$ dominance to $L E$ dominance in the month of April and this prevailed into the month of May before shifting back to $H$ dominance. Specifically, the dominance in $L E$ during the months of April and May was more apparent from early noon to late afternoon (Figure 46 ). While $L E / R n$ partition was lowest in the drier months of January, February and March 
Chapter 4
following leaf senescence with values $\sim<0.39$, this was observed to increase to $\sim 0.51-0.69$ in the wetter month of May for years with above average precipitation (Table 43 ). On the annual scale, $\sim>60 \%$ of $R_{n}$ was partitioned as $L E$ and $H$ with the latter being the larger consumer of net radiation $(\sim 34 \%)$, whereas the contribution of $G_{0}$ was less than $3 \%$. The residual energy balance closure term (C) accounted for between $25-40 \%$ of the $R_{n}$. This imbalance tended to be greatest in the months when insolation was high, an observation similar to that of semi-arid savanna in Southern Africa (Veenendaal et al., 2004). It is possible that this imbalance is due to increased $H$ during the dry seasons in the region, leading to entrainment of dry air within the flux footprint (McNaughton and Spriggs, 1989).

The partitioning of available energy was mainly controlled by soil moisture, in combination with low VPD effects on $L E$ during the wet months. The opposite was true for the drier months when $H$ dominated. This was evident during 2014, when below average annual and wet season long-term precipitation was experienced (Figure 4 14a). The low precipitation for that year provided little water recharge for soil moisture that limited refill of the dry soil (Figure 4 14b). The consequence of decreased soil moisture coupled with the low net radiation also observed during that year (Figure 4 14c) led to a much lower LE (Figure 4 14d) compared to years 2012 and 2013, which received above long-term average precipitation. Moreover, the higher monthly VPD and air temperature observed during the wet season months of year 2014 (Figure 4 15) further contributed to the reduced $L E$ and higher $H$ in that year. The shift in partitioning of the net radiation between $H$ and $L E$ was characteristic of a typically precipitation sensitive ecosystem whereby limited precipitation causes a decrease in soil moisture, consequently leading to a decrease in the evaporation component of LE (Chen et al., 2009). At the same time higher VPD in combination with high temperatures and net radiation may lead to a reduction in the stomatal conductance of the foliage, leading to a reduction in the transpiration component. 


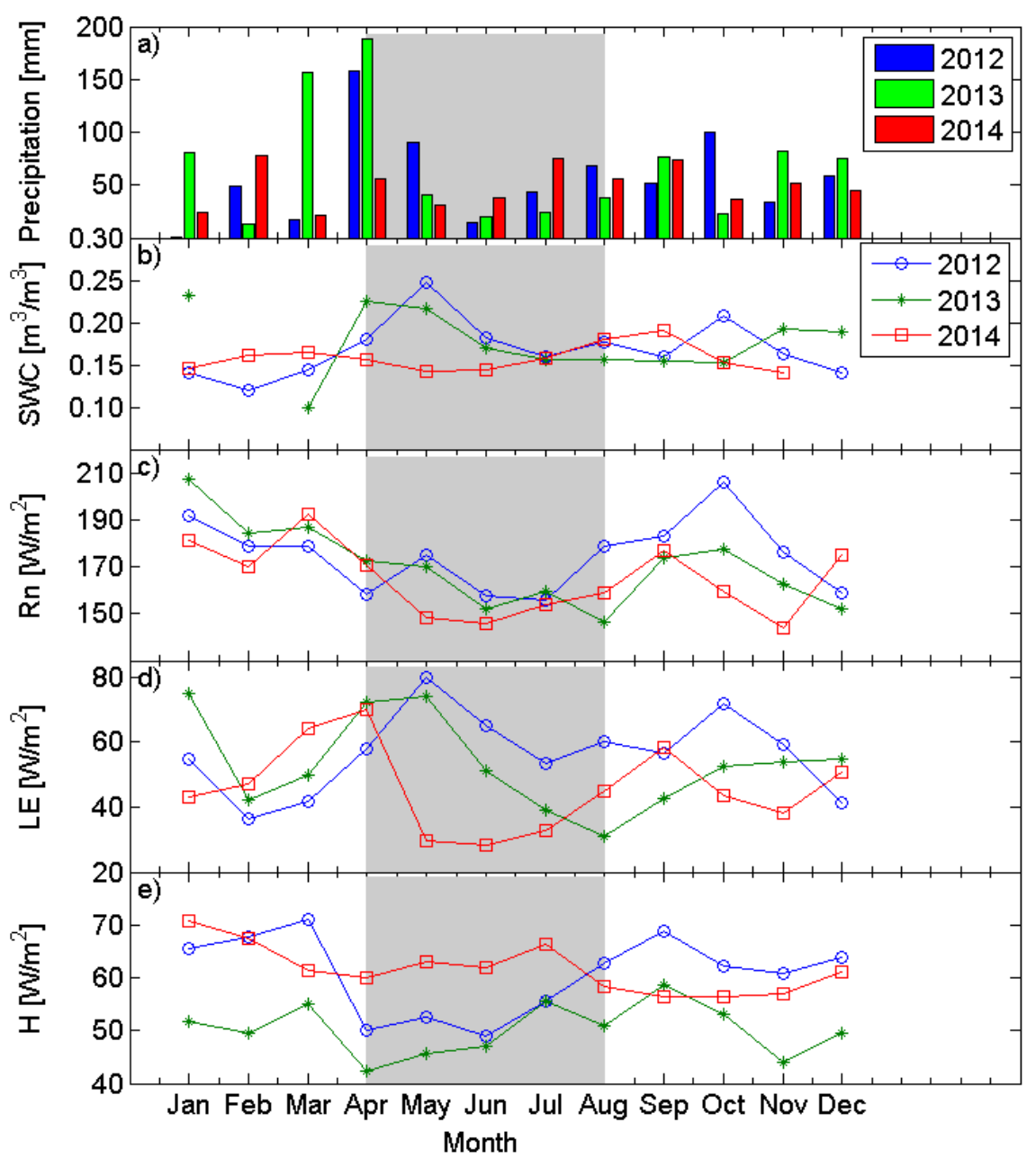

Figure 4-14: Average monthly (a) Precipitation (b) Soil water content (c) Net radiation (d) Latent energy flux and (e) sensible heat flux for the 3-year observation period. For ease of comparison with the data from 2012 and 2013, the 2014 wet season period when precipitation, soil water content, net radiation and latent energy flux were lowest is shaded in grey. 


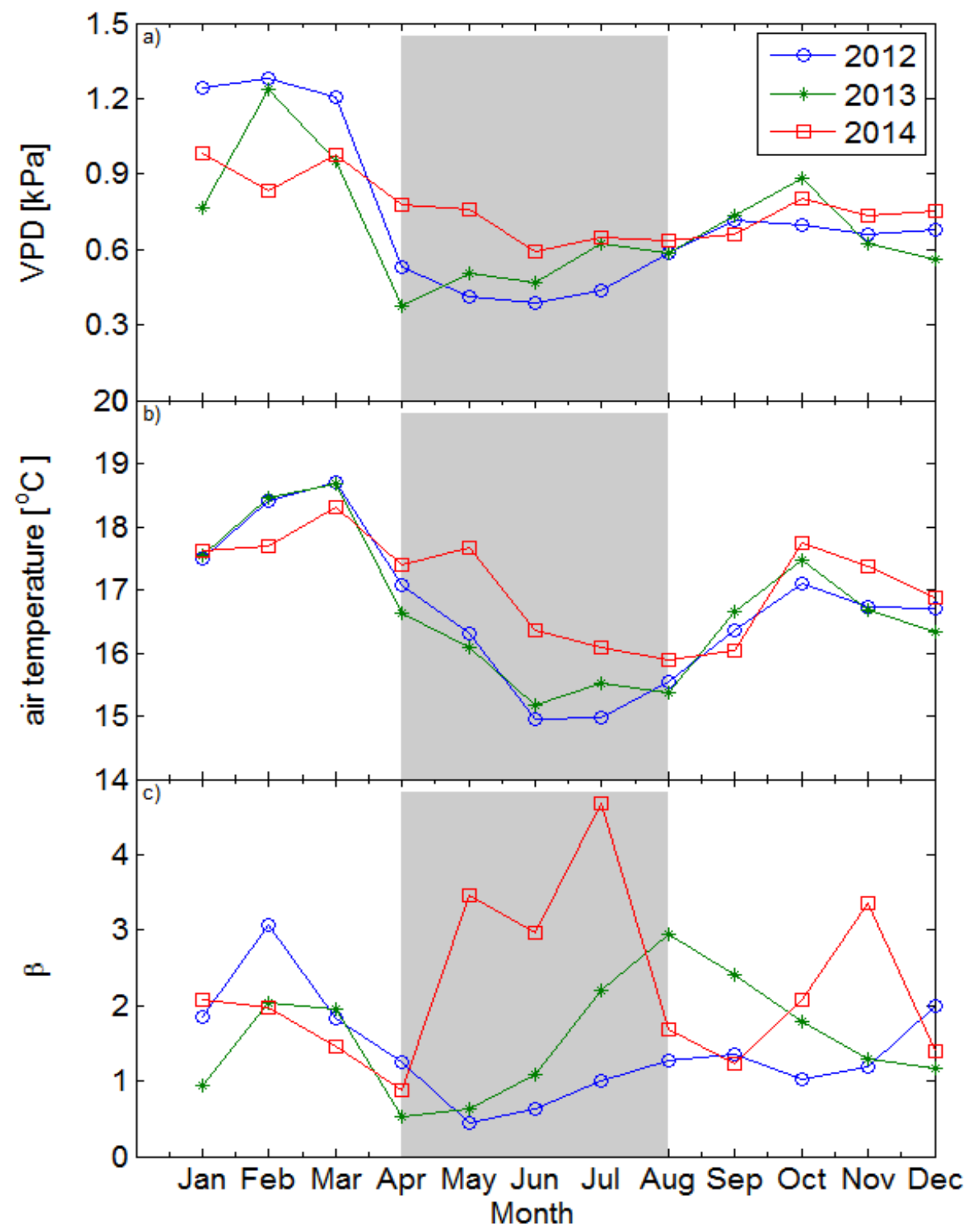

Figure 4-15: Average monthly (a) Vapor pressure deficit (b) air temperature (c) Bowen ratio during the 3-year observation period. The shaded gray regions highlight the wet season period when vapor pressure deficit, air temperature and Bowen ratio were highest for year 2014 in comparison to year 2012 and 2013 
Annual evapotranspiration was $873 \mathrm{~mm}, 632 \mathrm{~mm}$ and $537 \mathrm{~mm}$ for 2012, 2013 and 2014 respectively. For 2012, the annual evapotranspiration was 26\% higher than the annual total precipitation received in that year suggesting vegetation within the flux footprint has access to the moisture in deeper soil layer. Indeed, the lack of response of $g_{\mathrm{s}}$ to change in soil content at the present and many other similar studies (e.g. Ghimire et al., 2014; Giambelluca et al., 2003; Luis et al., 2005; Nieveen et al., 2001; Tanaka et al., 2003; Tanaka et al., 2008) must be largely due to continued access to moisture in the deeper soil layers. For years 2013 and 2014 the annual evapotranspiration was approximately $20 \%$ and $9 \%$ less than the annual precipitation received respectively implying that at least $80 \%$ of annual precipitation returned back to the atmosphere through evapotranspiration. These evapotranspiration values were generally larger than those reported for a dryland sandstone ecosystem (551 $\mathrm{mm} \mathrm{year}^{-1}$ ) in Southern Africa (Dzikiti et al. (2014), a grassland ecosystem (271-517 mm year ${ }^{-1}$ ) in Eastern cape, South Africa (Finca et al., 2015) and a semi-arid savanna (378 mm year ${ }^{-1}$ ) in Kruger National Park, South Africa. Compared with other ecosystems, the evapotranspiration values were also larger than those measured for forest ecosystems (e.g. $493 \mathrm{~mm}$ year $^{-1}$ in a temperate mixed forest (Wu et al., 2007) and $524 \mathrm{~mm}$ year $^{-1}$ in natural forest and $577 \mathrm{~mm}_{\text {year }}{ }^{-1}$ in planted forest (Ghimire et al., 2014)). For the years 2012 and 2013, during which above average precipitation was recorded, actual evapotranspiration was highest during the wettest months accounting for $46-82 \%$ of potential evapotranspiration. For year 2014, during which below average precipitation was recorded, actual evapotranspiration during the wettest months accounted for $24-32 \%$ of potential evapotranspiration. This implied that the variability in evapotranspiration was largely controlled by the changes in seasonal precipitation, unlike in humid environments where actual evapotranspiration is usually controlled by changes in potential evapotranspiration (Yang et al., 2006).

\subsubsection{Climatic and biological control of energy partitioning}

The partitioning of available energy into sensible and latent heat fluxes, and the subsequent effects on boundary layer processes depend on both climatic and biological controls of an ecosystem (Wilson and Baldocchi, 2000). Climatic control refers to the magnitude of atmospheric demand that controls evapotranspiration, i.e. the vapor pressure deficit and net radiation influence on evapotranspiration. Biological control refers to the effect of surface conductance on evapotranspiration. Changes in $L A I$ were observed to correlate positively with $g_{s}$ (Figure 4-10 \& Figure 4-12) suggesting that reduction in green $L A I$ partly causes the reduction in surface conductance and subsequent lower latent heat flux. Similar relationships have been observed in 
Chapter 4 forest (Wilson and Baldocchi, 2000), steppe (Chen et al., 2009) and grassland (Baldocchi et al., 2004; Saigusa et al., 1998) ecosystems. For the drought year 2014 leaf expansion was limited due to inadequate soil moisture, reducing the photosynthetic activity of the vegetation and subsequently limiting $g_{s}$ and $L E$. The lower $L E$ results in a higher $H$. The consequence of a large $H$ is a deep planetary boundary layer, and considerable entrainment of dry air. This has a negative effect on stomatal conductance (McNaughton and Spriggs, 1989). Our finding was in agreement with a study by Granier and Bréda (1996) who found that $g_{s}$ of a French oak forest was a function of leaf expansion. Similar patterns have also been reported for temperate deciduous forests in North America (Wilson and Baldocchi, 2000), temperate grasslands in Canada (Wever et al., 2002) and for a steppe ecosystem in Mongolia (Chen et al., 2009).

On the comparison of measured evapotranspiration against the climatological expectation, it is usually expected that ecosystems with unlimited moisture supply have high a values $(a>1.26)$, while dry ecosystems with lower potential evaporation rates have characteristically low values (a <1) (Arain et al., 2003). Over our experimental site, the Priestley-Taylor a coefficient was often $<1$ for the entire period of measurements with few cases a $>1$ occurring mostly during the wet seasons (Figure 4-8). Non-drought years 2012 and 2013 had much higher a values with weekly maximum values approaching $\sim>0.6$ which dramatically dropped to $<0.46$ during the drought year 2014 ( 0.42-0.46). This finding was comparable to that by Meyers (2001) who reported values of a ranging from $0.59-0.66$ for non-drought years and 0.39 for a drought year over a rangeland site in Oklahoma, US. The low values of a were indicative of restricted soil moisture supply for evapotranspiration. The relationship between $a$ and $g_{s}$ suggested that evapotranspiration in this site was greatly influenced by surface conductance when $g_{s}$ was below approximately $10-15 \mathrm{~mm} \mathrm{~s}^{-}$ ${ }^{1}$ (Figure 4-9). A similar observation was also reported for a West African Savanna (Bagayoko et al., 2007). Occurrence of this $g_{s}$ threshold was well within modelling analysis of McNaughton and Spriggs (1989) and Kim and Entekhabi (1997) who suggested that in a well-mixed boundary layer, evapotranspiration becomes limited at $g_{s}$ threshold value below $16 \mathrm{~mm} \mathrm{~s}^{-1}$. This finding was also consistent with other observations in maize (Lei and Yang, 2010; Steduto and Hsiao, 1998; Suyker and Verma, 2008) alfalfa (Van Bavel, 1967) and grassland (Wever et al., 2002).

Values of $\Omega$ in our site were predominantly $<0.5$ during the dry months but peaked in the wet months reaching values of approximately $\sim 0.8$ (Figure $4-10 \mathrm{c}$ ). These values suggest that during the dry season, evapotranspiration was coupled more with the VPD and $g_{s}$ than with net radiation while during the wet season, evapotranspiration was more sensitive to net radiation. This pattern 
Chapter 4

of coupling during the dry season and decoupling during the wet season was consistent and confirmatory of that observed in a West African Savanna ecosystem (Bagayoko et al., 2007). Since this pattern is consistent for both $g_{s}$ and a as well, we suggest that during dry season and periods of prolonged drought conditions, a lack of moisture in combination with VPD leads to significant decreases in stomatal conductance that eventually limits partitioning of available energy into $L E$ in the semi-arid ecosystem part of the Lake Naivasha basin. However, during the wet season these factors are non-limiting and radiation is the dominant control of energy partitioning into $L E$ in the ecosystem.

\subsection{Conclusion}

A 3-year flux measurements (January 2012-December 2014) over a semi-arid shrubland wildlife site in Lake Naivasha Basin showed that, on annual scale, more than $60 \%$ of net radiation $\left(R_{n}\right)$ was partitioned as latent $(L E)$ and sensible energy $(H)$, with the latter being the larger consumer of net radiation ( $34 \%$ ) and dominating for most months. The transition from $H$ to $L E$ dominance occurred in the month of April and prevailed into May before shifting back to $H$ dominance. This dominance of $L E$ in April and May was apparent from early noon to late afternoon. The residual energy balance closure term $(C)$ accounted for between $25-40 \%$ of the $R_{n}$ with the imbalance tending to be highest during periods of high insolation.

Annual evapotranspiration for year 2012, 2013 and 2014 were estimated as $873 \mathrm{~mm}, 632 \mathrm{~mm}$ and $537 \mathrm{~mm}$ respectively. This accounted for at least $80 \%$ of the annual precipitation received for the respective years. Seasonal evapotranspiration during the wettest months of years 2012 and 2013 accounted for $46-82 \%$ of potential evapotranspiration while evapotranspiration for the wettest months of 2014 which was a drought year, accounted for $24-32 \%$ of potential evapotranspiration. This implied that the variability in evapotranspiration was largely controlled by the changes in seasonal precipitation unlike in humid environments where actual evapotranspiration is usually controlled by changes in potential evapotranspiration.

Values of surface conductance $\left(g_{s}\right)$ were significantly positively correlated with leaf expansion and a suggesting that, change in latent heat flux and surface conductance was paralleled by changes in green LAI. $g_{s}$ was low during periods of low soil moisture. Low values of decoupling coefficient $(\Omega)$ during these periods of drought indicated that evapotranspiration was strongly controlled by $g_{s}$ and $V P D$. During periods of non-limiting moisture conditions, evapotranspiration was decoupled from the atmosphere. This finding suggested that during the dry seasons and during periods of prolonged drought, a lack of moisture in combination with VPD leads to significant decreases in 
Chapter 4 stomatal conductance, which eventually limits partitioning of available energy. However, during the wet season these factors are non-limiting and radiation is the dominant control of energy partitioning into $L E$ in the ecosystem. These coupling and decoupling patterns provide insights towards formulating relatively simplistic models for quantifying evapotranspiration for ecosystems that experience seasonal shifts in controlling factors. Moreover, this finding provides a synoptic predictive tool on changes that maybe expected in such an ecosystem in this region of Africa under climatic changes of increased precipitation. On one hand, with the projected future precipitation increases over East Africa, the energy flux partitioning is likely to be principally enhanced by $R_{n}$. On the other hand, in the event of enhanced drought conditions, the energy flux partitioning in the ecosystem is likely to be coupled to the atmosphere. 


\section{Coupling socio-economic factors and eco-hydrological processes using a cascade-modeling approach*}

\footnotetext{
* This chapter is based on:

Odongo, V. O., D. W. Mulatu, F. K. Muthoni, P. R. van Oel, F. M. Meins, C. van der Tol, A. K. Skidmore, T. A. Groen, R. Becht, J. O. Onyando \& A. van der Veen, 2014. Coupling socio-economic factors and eco-hydrological processes using a cascade-modeling approach. Journal of Hydrology. doi:http://dx.doi.org/10.1016/j.jhydrol.2014.01.012.
} 


\begin{abstract}
Most hydrological studies do not account for the socio-economic influences on eco-hydrological processes. However, socio-economic developments often change the water balance substantially and are highly relevant in understanding changes in hydrological responses. In this study a multidisciplinary approach was used to study the cascading impacts of socio-economic drivers of land use and land cover (LULC) changes on the eco-hydrological regime of the Lake Naivasha basin. The basin has recently experienced substantial LULC changes exacerbated by socio-economic drivers. The simplified cascade models provided insights for an improved understanding of the socioecohydrological system. Results show that the upstream population has transformed LULC such that runoff during the period 1986-2010 was 32\% higher than during the period 1961-1985. Cut-flower export volumes and downstream population growth explain $71 \%$ of the water abstracted from Lake Naivasha. The influence of upstream population on LULC and upstream hydrological processes explained $59 \%$ and $30 \%$ of the variance in lake storage volumes and sediment yield respectively. The downstream LULC changes had significant impact on large wild herbivore mammal species on the fringe zone of the lake. This study shows that, in cases where observed socio-economic developments are substantial, the use of a cascade-modeling approach, that couple socio-economic factors to ecohydrological processes, can greatly improve our understanding of the eco-hydrological processes of a catchment.
\end{abstract}

Key words: Socio-economic; Land use and land cover change; eco-hydrology; cascade modeling; Lake Naivasha 


\subsection{Introduction}

Eco-hydrological systems respond to perturbations of varying magnitude and intensity across space and time (Caylor et al., 2005). And so do socio-ecohydrological systems. Identifying mechanisms that translate these perturbations into structural and functional changes is important towards informing on socio-economic decisions of management and conservation of basins (Burcher et al., 2007). For example land use and land cover (LULC) changes mirror the impacts of human activities (Houghton et al., 1999; Schneider and Eugster, 2005).

With increasing population, human actions and associated LULC are known to increasingly affect the water quality and quantity and may compromise the integrity of eco-hydrological systems through numerous and complex pathways (Allan et al., 1997; Allan, 2004b; Strayer et al., 2003; Townsend et al., 2003). There is a need to understand the main drivers of such systems and how they interact and influence the system. Without knowing how these drivers propagate through a system, we cannot identify the associated trigger mechanisms, thus limiting our ability to understand or manage such a system. However, identifying the driving factors and processes of these influences is complicated by the multitude of potential causalities and time-frames at which the processes take effect.

Pathways define the propagation of influences from an initiation phase which is then conveyed through entities in space and time to a destination (Figure 5-1) where consequences are realized (Reiners and Driese, 2001). Such an organization of links or couples is described in this chapter as a cascade where a series of connected links originate from a trigger that is translated through chains of interdependent elements terminating in a response (Burcher et al., 2007). 


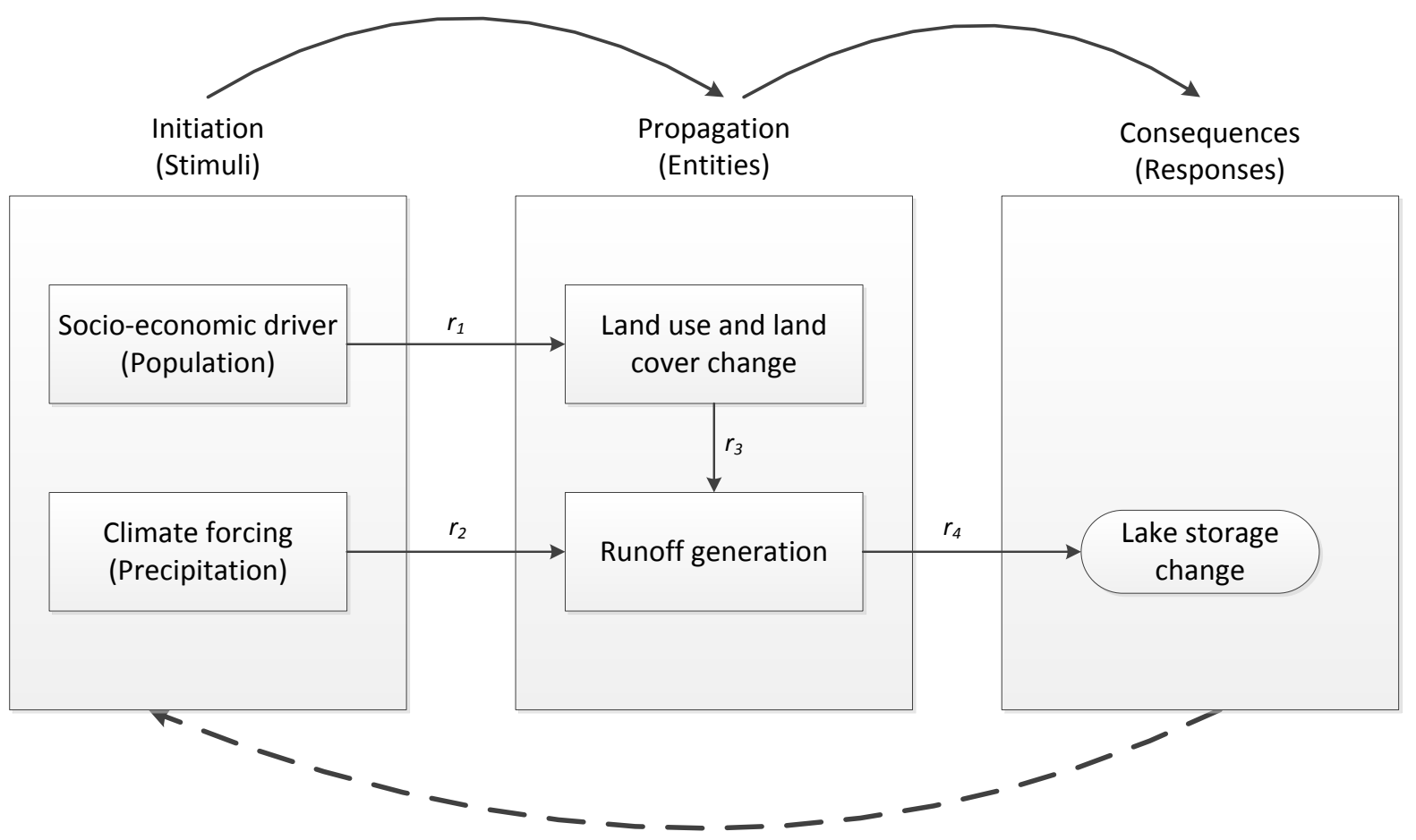

Figure 5-1: A conceptual framework illustrating a path diagram of a hypothesized cascade model that predicts lake storage change. The links, $r_{1}, r_{2}, r_{3}$ and $r_{4}$ represent the pathways through which factor influences are propagated through entities and responses. Adapted from Reiners and Driese (2001)

Hydrological modeling approaches for densely populated areas should factor the socio-economic influences in the hydrological processes (Loucks and Van Beek, 2005; van Oel et al., 2013). However, before we optimize and allocate water we need to know what drives water withdrawals and water diversions. Only then, we are able to formalize a river basin management plan, and design policy instruments either in the physical or in the social realm. As an example, an important factor is the growing human population that exerts increasing pressure on the LULC, as demand multiplies for resources such as food and water. Another example is increase in industrial production requiring water. Socioeconomic factors dictate how land is used regionally as well as locally, and how much water is needed. Therefore, it is vital to assess the major socioeconomic drivers of LULC changes (especially in developing countries) and their impact on the environment. In total, the interaction between physical and social phenomena builds up a system with positive and negative feedbacks in space and time (Kelly et al., 2013). 
In this study, we focus on understanding the historical cause of events in the Lake Naivasha basin socio-ecohydrological system. To realize this, we restrict ourselves to a less demanding model, given that we are in a relatively data poor environment; We apply a cascade model to study the case of Lake Naivasha Basin.

The economy of the basin is highly dependent on natural resources but the response of the environment due to the socio-economic influences is highly uncertain. Despite the increased socioeconomic activities and LULC changes experienced in the Lake Naivasha Basin, there is limited knowledge on the impacts of these changes on the eco-hydrological regime of the basin. The magnitude of these impacts at relevant spatial and temporal scales is uncertain. Much of what is known about these impacts has only been inferred through water balance models (Becht and Harper, 2002) or sediment studies (Odongo et al., 2013; Tarras-Wahlberg et al., 2002). However, these models fail to explain the disturbance pathways involved because they do not integrate multiple scales (Burcher et al., 2007; Downes et al., 2002). No attempt has been made to integrate multiple trigger mechanisms at different scales that include socio-economic factors and LULC changes that trigger the observed responses. Therefore, there is a need to understand the main drivers of the system and how their effect propagates through the system. Without knowing exactly how the influence of these drivers propagates through the system, we cannot identify the associated processes that need to be understood in order to address them.

The cascade modeling approach using path analysis as adopted in this study enhances a holistic understanding of a complex system such as Lake Naivasha Basin amidst the cross-cutting disciplines of socio-economy and eco-hydrological processes. It might not be the best method to apply in multi-disciplinary research that involves feedback mechanisms; however, it is a better method to apply in a data scarce environment for an African country. Alternatives to cascade modeling would be process-based models (e.g. agent-based modeling (ABM) or system-dynamics (SD)) that account for relevant feedback mechanisms, explore impacts of future scenarios or compare effects of alternative measures. However, these alternatives are data intensive and complex compared to path analysis. The advantage of using path analysis is that it mirrors theories of causation and inform on which hypothesized causal models best fits the observed pattern of correlations among datasets (Burcher et al., 2007). Also the approach allows one to decompose various factors affecting an outcome into direct and indirect components. This way the method is a first step in developing clear and logical theories about processes influencing a particular response in a system (Lleras, 2005). 
Chapter 5

To our knowledge this is the first time that a basin scale integration using hypothesized cascades of events is used to asses eco-hydrological impacts by coupling socio-economic factors in a subSaharan tropical basin. The combined effect of these cascades has put the lake ecosystem services under pressure (Becht and Nyaoro, 2005; Becht et al., 2006; Harper and Mavuti, 2004; Otiang'aOwiti and Oswe, 2007). This study aimed at quantifying the impacts of socio-economic factors on eco-hydrological regime of Lake Naivasha Basin using a conceptual framework based on cascade modeling.

\subsection{Methods}

\subsubsection{Study area}

The Lake Naivasha basin is situated in the Great Rift-Valley at a latitude of $0^{\circ} 09^{\prime}$ to $0^{\circ} 55^{\prime} \mathrm{S}$ and longitude of $36^{\circ} 09^{\prime}$ to $36^{\circ} 24^{\prime} \mathrm{E}$. The altitude ranges from $1980 \mathrm{~m}$ to about $3990 \mathrm{~m}$ above mean sea level (a.m.s.l) on the eastern side of the Aberdare Ranges. The catchment area is approximately $3400 \mathrm{~km}^{2}$ (Figure 5-2).

Climatic conditions in the study area are diverse due to considerable differences in altitude and relief. Figure 1-3 summarizes the monthly average precipitation and temperature variations in the Lake Naivasha basin. The daily mean temperature ranges from $8^{\circ} \mathrm{C}$ to $30^{\circ} \mathrm{C}$. The rainfall regime within the basin is influenced by local relief with the catchment being in the rain shadow of the Aberdare ranges to the East and the Mau Escarpment to the West. There are two rainy seasons experienced in this catchment. Long rains occurring in the months of March to May and the short rains experienced between October and November. The Lake Naivasha basin experiences an average annual rainfall of $610 \mathrm{~mm}$, and the wettest slopes of the Aberdare ranges receive as much as $1525 \mathrm{~mm}$. The major soils in the study area are of volcanic origin. The soils found on the mountain and major escarpments of the catchment are developed from olivine basalts and ashes of major older volcanoes.

Lake Naivasha has been subject to wide fluctuations of water levels over time and has almost dried in the past years (Abiya, 1996; Gaudet, 1977a; Verschuren et al., 2000). This natural fluctuation, combined with increasing water demand and land use change have led to occasionally strong decreases of the lake water levels (Becht and Harper, 2002; Olaka et al., 2010; Ondimu and Murase, 2007; Otiang'a-Owiti and Oswe, 2007; Trauth et al., 2010). Low lake levels made the lake ecosystem vulnerable and its fragility is a challenge to conservationists and scientists (Becht et al., 2006; Gherardi et al., 2011; Harper and Mavuti, 2004; Harper et al., 2011). The lake is a 
Chapter 5

RAMSAR wetland (Ramsar, 1996) despite supporting important economic activities including fishing, agriculture, power generation, domestic water supply and tourism (Becht et al., 2005).

Moreover, the basin has experienced increasing pressures on its land and water resources due to an increase in population majorly attracted with the rise in the horticultural industry since early 1980s (van Oel et al. 2013). The industry has supported and sustained the economy of the basin through production and export of flowers. The agriculture has encroached on previously communal grazing with significant effect on large herbivore species (Harper and Mavuti, 2004). Consequently conflicts have risen because of misunderstandings of the socio-hydro-ecological system (Becht et al., 2006).

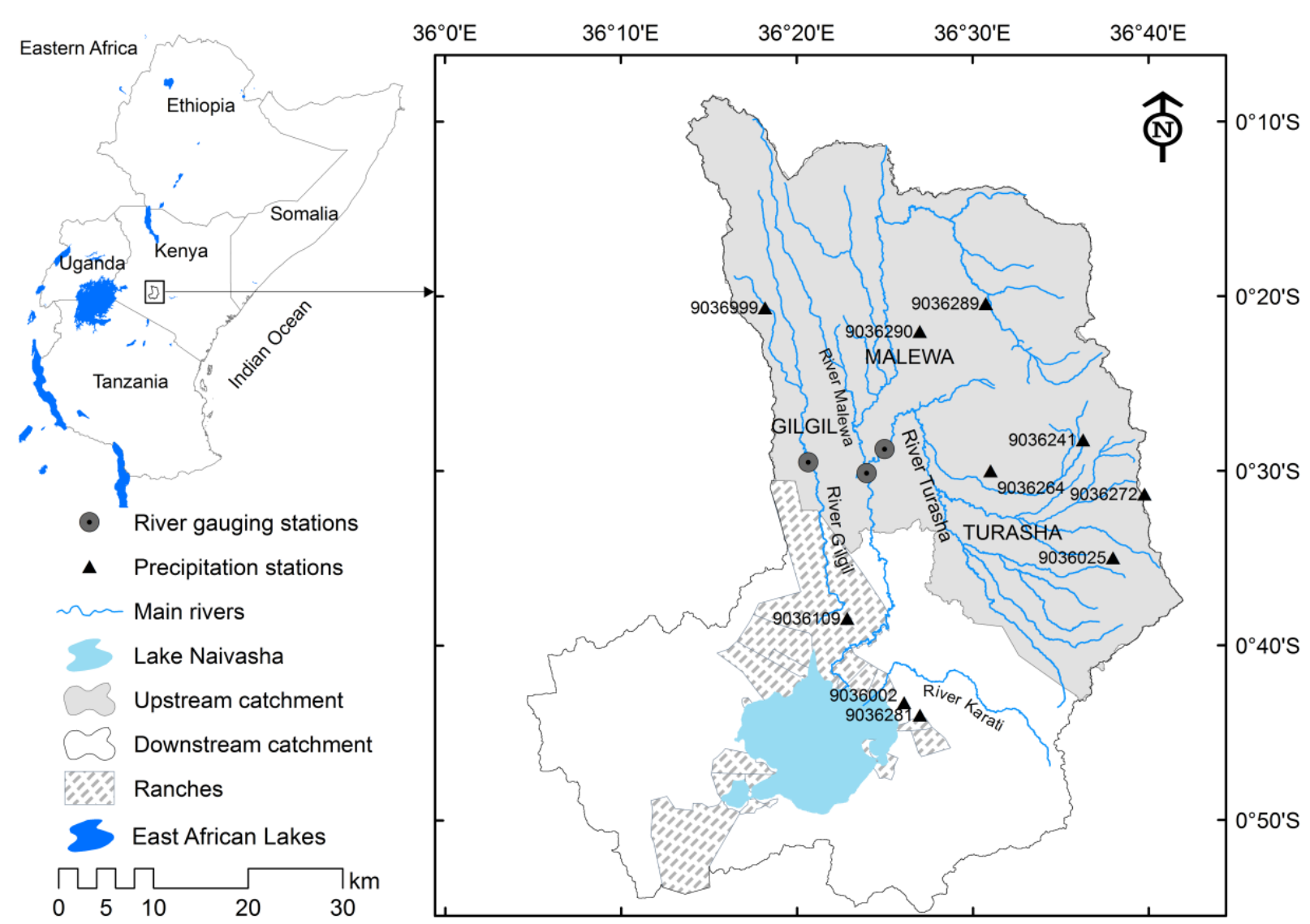

Figure 5-2: Lake Naivasha Basin showing its main rivers and tributaries. The upstream area forms part of the hydrologically active area contributing majority of the flows downstream 


\subsubsection{Methods}

Land use/cover was extracted from time series satellite imagery using remote sensing techniques, and consequently changes between scenes were identified in a change detection exercise. Correlation analysis was used to explore the relationship between socio-economic drivers and LULC. Path analysis (Shipley, 2000) was used to investigate the cascading impact of changes in LULC on hydrological and ecological responses. To understand the effect of the changes, these analyses were investigated using two cascade models.

The first cascade (Cascade 1) in our basin is that change from the upper catchment propagating through multiple systems, where population pressure changed the LULC, modifying the hydroecological system (Figure 5-3). In the downstream area, around Lake Naivasha, another cascade (Cascade 2) prevails that is mostly driven by extensive horticultural production, increase in downstream population on LULC changes and changes in downstream hydrology on biodiversity (Figure 5-4). The associated employment opportunities have induced rapid population growth in and around the town of Naivasha (KNBS 1979; 1989; 1999; 2009). The reason for evaluating two separate cascades is because of differences between the drivers in both parts of the Lake Naivasha basin.

\subsubsection{Development of the cascade model}

Path analysis (Shipley, 2000) was used to test whether changes in socio-economic stimuli variables significantly affect hydrological behavior downstream. The analysis is a methodological tool that use relationships which are defined a priori and follow a specific causal hypothesis guided by a conceptual framework to estimate the magnitude and strength of effects (Maloney and Weller, 2011). The conceptual framework is normally represented using graphical path diagrams that infer causality as predetermined by a researcher's knowledge of the system. The requirement of a priori hypothesis in path analysis makes it an appropriate tool to predict important interactions in a system. The paths are then evaluated either by path coefficients or by regression coefficients. Regression coefficients provide information about the functional relationships between pairs of variables, predicting how much the dependent variable changes with a given change in any of the different causal variables (Wootton, 1994). Path coefficients indicate the strengths of association, providing a relative measure of the amount of variance explained by different causal variables, and the sign of the interaction or effect from the causal variable (Grace et al., 2010; Wootton, 1994). The analysis follows a general form of structural equation modeling (SEM) approach expressed as 
where $Y$ is a vector of endogenous observed variables (dependent variables) which could be response or intermediate entity variables, $X$ is a vector of exogenous observed variables (independent variables with no causal assumptions), $\beta$ is a coefficient matrix defining relationships among the endogenous variables and $\Gamma$ is a coefficient matrix defining the relationship of exogenous and endogenous variables and $\zeta$ is vector of errors for the equation. In this study the cascade models illustrating relationships between stimuli, entities and responses were developed and tested using AMOS $^{\mathrm{TM}}$ (Arbuckle, 2006). The estimated path coefficients and regression coefficients were standardized by the ratio of the standard deviations of the independent and dependent variables to allow relative comparison of magnitudes of effects on the different dependent and response variables (Lleras, 2005). Following Kozak et al. (2007) and adopting their notation, a standardized regression model is given by

$$
y=\sum_{i=1}^{k} p_{i y} x_{i}+\varepsilon \quad \text { for } i=1, \ldots, k
$$

where $y$ is the standardized response or dependent variable, $x_{i}$ represents the standardized independent variables, $p_{i y}$ are the partial regression coefficients for the model $\mathrm{E}\left(y \mid x_{i}, \ldots, x_{k}\right)$ and $\varepsilon$ is the residual error term of the model. Interpretation of the path analysis is then based on decomposition of the correlation coefficients between response and independent variables as follows:

$$
r_{y x_{i}}=p_{i y}+\sum_{j=1}^{k} p_{j y} r_{i j} \text { for } j=1, \ldots, k \text { and } j \neq i
$$

where $r_{y x_{i}}$ are the correlation coefficient between the $i^{\text {th }}$ independent variable and the response variable $y$ and $r_{i j}$ is the correlation coefficient between the $i^{\text {th }}$ and $j^{\text {th }}$ independent variable. Details on the complete formulation and procedure of path analysis have been described in Shipley (2000).

We focused on the interpretation of the standardized partial regression coefficients to quantify the amount of variance in entities/dependent and response variables as depicted over an entire pathway or section explained by the preceding cascade model. Assessment of the cascade model fit was based on Chi-square analysis where $p$ values $>0.05$ indicate no significant difference 
Chapter 5

between model and the data. Values of $p \sim 1$ are indicative of good model fit (Burcher et al., 2007).

Possible causal paths that linked socio-economic indicators to land use/cover and hydrological indicators were established. Figure 5-3 and Figure 5-4 illustrate the upstream and the downstream cascades respectively. In the upstream parts of the basin (Cascade 1), upstream population was identified as the key socio-economic driver of land use/cover changes. The effect of these LULC changes propagate to direct runoff and sediment yield generation downstream following precipitation events since direct runoff and sediment yield generation are a function of land use/cover. Direct runoff contributes to total runoff which again contributes to lake storage volume downstream. Potential paths that fitted the sample data were then identified. This led to three sub-cascades that fitted the sample data forming the upstream catchment (Cascade 1) and two sub-cascades for the downstream catchment (Cascade 2). The potential paths that fitted the sample data from Cascade (1) were Cascade (1A) describing the effect of upstream population on land use/cover change and the relationship of the direct runoff and precipitation, Cascade (1B) describing the relationship of land use/cover change and direct runoff on sediment deposited into the lake. Cascade (1C) describing the effect of direct runoff on total runoff volume and lake volume changes.

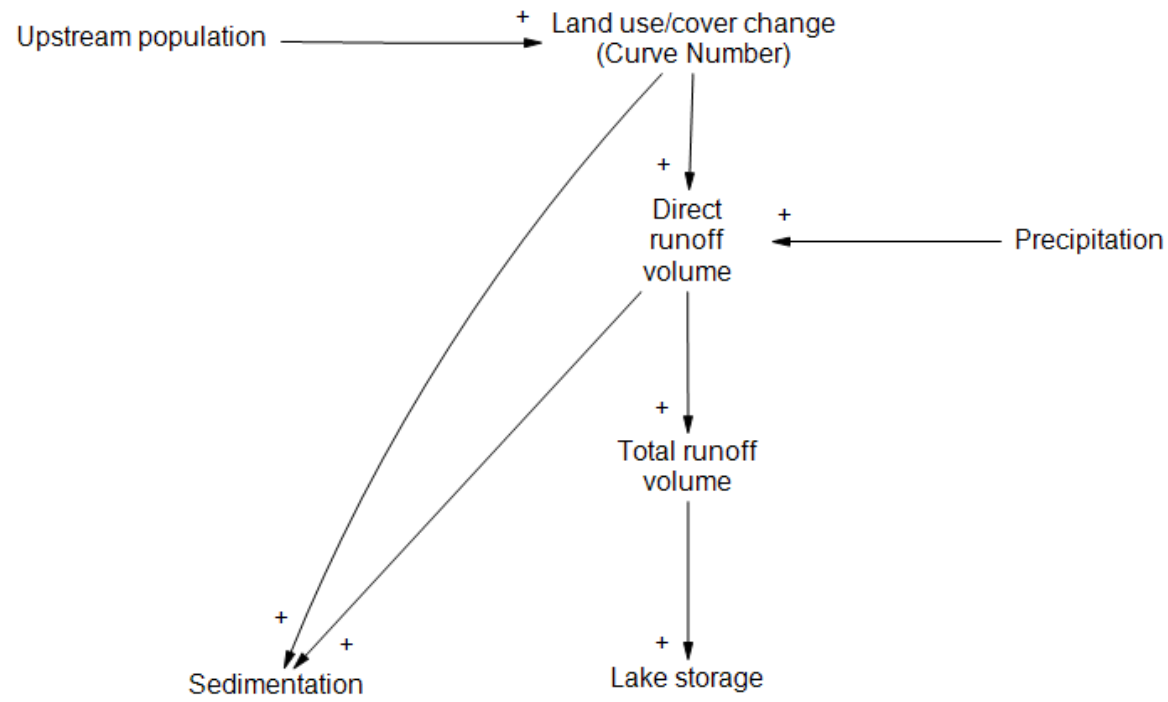

Figure 5-3: Upstream population-land use/cover driven cascade impacting the hydrological system of the basin. Upstream population is the main trigger of land use/cover activities that transform the surface for hydrological changes. Precipitation is the exogenous variable that provides water to 
the transformed surface as runoff. Sedimentation and lake storage are the response of the system due to upstream effects. +/- sign indicate direction of change of the variable or effect

The potential paths that fitted the sample data for the downstream cascades were Cascade $(2 A)$, which described the lake as a source of freshwater for irrigation, commercial and domestic consumption and sustains a variety of flora and fauna. The developments associated with the horticultural farms have seen an increase in flower export volumes. This has led to increased downstream population attracted by employment opportunities in the horticultural farms. As a consequence water removal from the lake and its conjunctive aquifer has increased over the last two decades (Becht and Harper, 2002). Cascade (2B) explores the impact of the downstream LULC conversions and hydrological changes (lake levels and precipitation) on the biomass of large herbivorous mammals. The next sections titled "Land use/cover variables", "image classification and accuracy assessment", "socio-economic variables and Pearson correlation", "Assessment of runoff", "sediment yield" and "Biodiversity in the fringe zone of the lake" describe data and methods used for development of the cascade models.

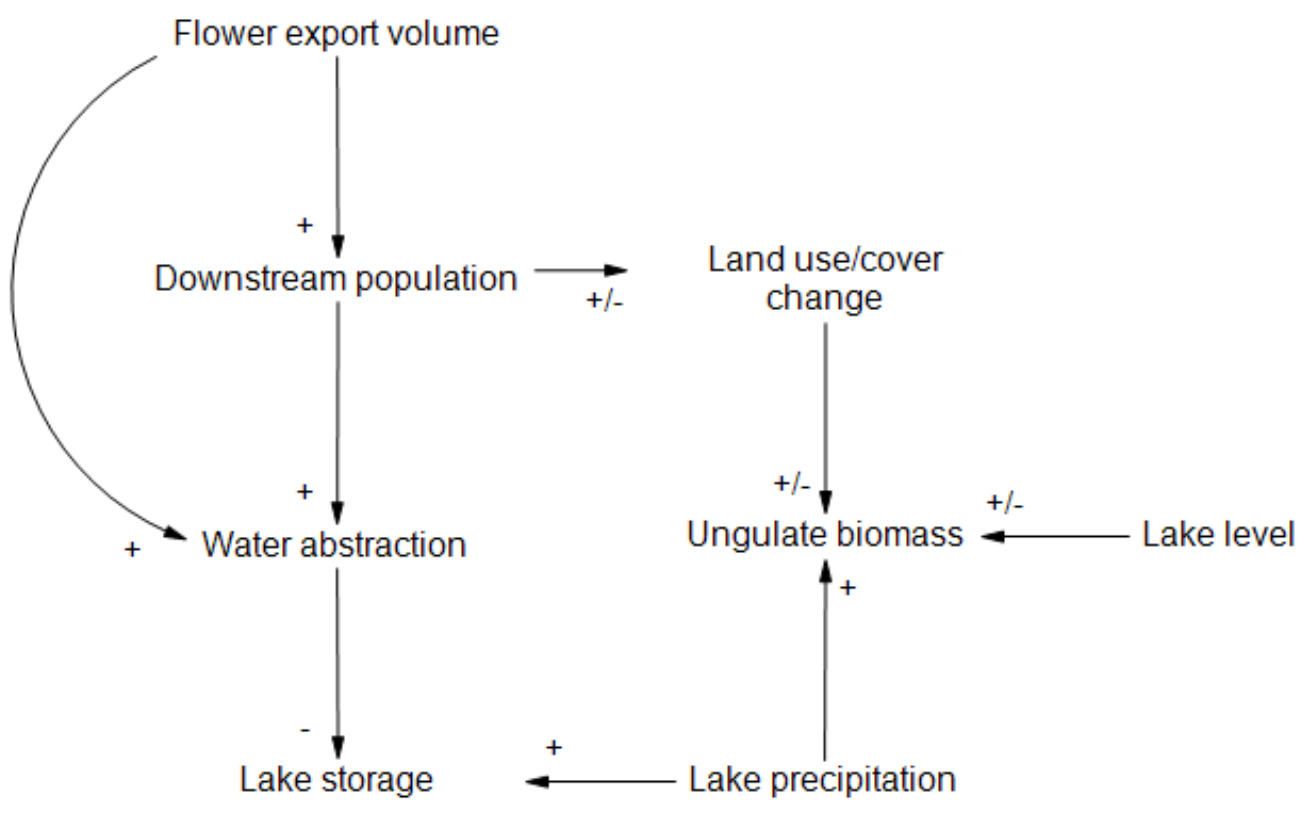

Figure 5-4: Downstream cascade driven mainly by horticultural sector and population increase impacting the eco-hydrological system of the basin. Lake precipitation is an exogenous variable that contributes to the lake storage changes and ungulate biomass downstream. Lake levels are exogenous variable that influence Ungulate biomass. Lake storage is the response with flower 
Chapter 5

export volume being the trigger of the system. +/- sign indicate direction of change of the variable or effect

\subsubsection{Land Use/Cover variables}

Data used for image classification were Landsat MSS of $31^{\text {st }}$ January 1973 , Landsat TM $1^{\text {st }}$ January 1986, Landsat TM $2^{\text {nd }}$ February1987, Landsat TM $17^{\text {th }}$ January 2011, ASTER of $14^{\text {th }}$ March 2011, Worldview 2 of December 2010. A stratified random sample of 302 ground reference points of major LULC spaced at a minimum distance of $1 \mathrm{~km}$ were collected using a GPS. Ground photos taken with a handheld camera and aerial photos of August 2010 acquired from Department of Remote Sensing and Resource Survey (DRSRS) of Kenya were also used to support interpretation and extraction of extra ground reference data.

\subsubsection{Image classification and accuracy assessment}

Unsupervised classification was conducted on all the images using the ISODATA algorithm with an initial set of 50 classes. The 50 unsupervised classes allowed for identification of contiguous homogenous classes. Overlaying ground reference points on the contiguous homogenous classes enabled defining of regions of interest (ROIs) for use in supervised classification. For each ground reference point an ROI where the point falls were extracted. The Jeffries-Matusita (J-M) class separability test was also performed to distinguish different classes based on their spectral profiles (Thomas et al., 1987).

Ground reference points collected during the study (January to March 2012) and aerial photos of August 2010 were used to distinguish classes for supervised classification of the Landsat TM, ASTER and World View 2 images representative of the year 2011. Half of the ROIs extracted ( $n=$ 151 ROIs) were then used in training the maximum likelihood classifier to develop 12 main dominant land use/cover classes of Lake Naivasha Basin for the year 2011. For the 1976 Landsat MSS image, ROIs were developed by unsupervised classification using ISODATA algorithm together with vegetation map of 1976 published by the British Ordnance Survey. Forthwith, a maximum likelihood classification was conducted using the ROIs that led to 8 dominant land use/cover classes of the Lake Naivasha Basin representative for the year 1973.

The other half of the reference data $(n=151)$ were used to conduct the accuracy assessment of the classified image of 2011The true map accuracy for 1973 could not be easily established due to a lack of field observations at that time, but a 1976 vegetation map published by the British Ordnance Survey was considered a reasonably accurate rendition of map accuracy because it was 
prepared from ground observations and aerial photographic interpretation. There being no ground truth data to match with the 1986 images, the LULC map of 1986 was produced using unsupervised classification in combination with known land use/cover spectral signatures derived from the 2011 LULC map.

\subsubsection{Socio Economic variables and Pearson correlation}

Socio-economic variables of the basin used in this study were obtained from various government agencies in Kenya. Decadal census population data from 1969 to 2009 was provided by the Kenya National Bureau of Statistics (KNBS). Annual flower export volume from 1994 to 2010 was provided by the Kenya Horticultural Crops Development Authority (KHCDA).

Pearson correlation was used to describe the relationship between socio-economic variables and LULC. In the upstream part only population data was available for inclusion in cascade model 1 . In the downstream cascade, the extent of irrigated and horticultural areas, population size and flower export volumes were identified as the main drivers for inclusion in the cascade model. Single LULC change dynamic degree (Equation5-4) was employed to quantify the rate of LULC change between two periods. This provided estimates of annual LULC for years that had no representative LULC maps.

$$
K_{i}=\left[\frac{L U_{b i}-L U_{a i}}{L U_{a i}}\right] \times \frac{1}{T} \times 100 \%
$$

where $K$ is the annual rate of change of a specific LULC type $i$, in a fixed time period. $L U_{a i}$ and $L U_{b i}$ is the area of the LULC type $i$ at the beginning and the end of the time period, respectively; and $T$ is the time period.

\subsubsection{Assessment of runoff}

To evaluate the impact of changes in surface conditions on the runoff of Lake Naivasha basin, runoff coefficient (Equation 5-6) was calculated to assess the evolution of surface conditions. The Soil Conservation Service Curve Number (SCS-CN) method (SCS, 1985) was used to estimate direct runoff volumes for given rainfall events (Equation 5-7).

$$
C=\frac{Q}{P}
$$


where $C$ is the annual runoff coefficient, $Q$ is the total runoff volume $(\mathrm{mm})$, and $P$ is the total annual precipitation $(\mathrm{mm})$ received in the upper basin.

$$
Q_{d}=\frac{\left(P_{d}-I_{a}\right)^{2}}{\left(P_{d}-I_{a}\right)+S}
$$

Where $Q_{d}$ is the direct runoff $(\mathrm{mm})$ following a precipitation event, $P_{d}$ is the daily precipitation $(\mathrm{mm}), S$ is the potential maximum retention after the start of runoff generation $(\mathrm{mm})$ which is estimated as function of curve number as follows,

$$
S=\frac{25400}{C N}-254
$$

where $\mathrm{CN}$ is the area weighted basin curve number obtained by aggregating the individual curve number of each individual land use/cover obtained from look-up table following procedures described in SCS (1985), $I_{a}$ is the initial abstraction of all losses before runoff generation and includes water retained in surface depressions, evaporation, infiltration and that which is intercepted by vegetation. Through experimental studies $I_{a}(\mathrm{SCS}, 1985)$ is approximated as

$$
I_{a}=0.2 S
$$

A low $C N$ value is suggestive of low direct runoff generation from the basin while a higher $C N$ would suggest the opposite assuming that other determinant parameters of flow remain the same. Runoff and precipitation data were obtained from the Water Resources Management Authority (WRMA) of the Government of Kenya. Runoff data from 1960 to 2010 of the three outlet stations discharging into the Lake and seven precipitation stations within the upper basin were used for this analysis.

\subsubsection{Sediment yield}

In this study it was postulated that the sedimentation rate of the lake is influenced by the upstream LULC changes. Data of lake sedimentation rate from Stoof-Leichsenring et al. (2011) was used as response proxy indicator of water quality downstream arising from LULC changes upstream. Rate of change for years with no sedimentation rate were estimated using a similar approach as Equation (5-12) with sediment for known years as input. 
Chapter 5

\subsubsection{Biodiversity in the fringe zone of the lake}

Downstream LULC and hydrological regimes can impact on biomass density of large herbivore mammals. The trend in large herbivore mammal's population was obtained from biennial (April and October) wildlife census conducted by Nakuru Wildlife Conservancy (NWC) from 1999 to 2010.

The data was collected using a total count of large mammal species on all ranches between Lake Naivasha and Lake Nakuru. We selected data for the 12 most common large herbivore species on 16 ranches that are immediately adjacent to Lake Naivasha (Table 5-1). During the census, the ranches were divided into fixed counting blocks in each ranch divided by physical barriers such as hills, escarpments and the lake. Each block was assigned a counting team consisting of experienced Kenya Wildlife Service scientists, ranch staff and trained volunteer scouts. Counting was carried out between 0600 to $1000 \mathrm{hr}$ when most of species are active. This was done using vehicles or walking in some inaccessible sections. Detailed information on the survey method is outlined in Ogutu et al. (2012).

Table 5-1: Detail on the surveyed mammal species and the ranches/blocks

\begin{tabular}{|c|c|c|c|c|}
\hline \multicolumn{2}{|l|}{ Ranches/Sampling Blocks } & \multicolumn{3}{|l|}{ Mammal species } \\
\hline Name & $\begin{array}{l}\text { Area } \\
\text { (Acres) }\end{array}$ & $\begin{array}{l}\text { Common } \\
\text { name }\end{array}$ & $\begin{array}{l}\text { Scientific } \\
\text { name }\end{array}$ & $\begin{array}{l}\text { Unit } \\
\text { weight } \\
(\mathrm{Kg})\end{array}$ \\
\hline Crater Lake/ Indu / Lentolia & 1000 & $\begin{array}{l}\text { Common Zebra } \\
\text { Thomsons }\end{array}$ & Equus burchelli & 200 \\
\hline Mundui & 1145 & Gazelle & Gazella thomsoni & 15 \\
\hline Hippo Point/ Nderit & 500 & Impala & Aepyceros melampus & 40 \\
\hline OLERAI & 500 & Eland & Taurotragus oryx & 340 \\
\hline Oserian Wildlife Sanctuary & 18000 & Buffalo & Syncerus caffer & 450 \\
\hline Oserian Game Corridor & 3000 & Grants Gazelle & Gazella granti & 40 \\
\hline $\begin{array}{l}\text { Cresent Island } \\
\text { Bushy-Island/Flay/Yatch- }\end{array}$ & 190 & $\begin{array}{l}\text { Kongoni } \\
\text { Defassa }\end{array}$ & Alcelaphus lichtensteinii & 125 \\
\hline Club/D'Olier/Higgins/Sanctuary & 100 & Waterbuck & Kobus ellipsiprymnus & 160 \\
\hline Marula & 25000 & $\begin{array}{l}\text { Wildebeast } \\
\text { Common }\end{array}$ & Connochaetes taurinus & 123 \\
\hline KARI \& OI Magogo & 9000 & warthog & Phacochoerus africanus & 45 \\
\hline Loldia & 6000 & Giraffe & Giraffa camelopardalis & 1402 \\
\hline
\end{tabular}




\begin{tabular}{|c|c|c|c|c|}
\hline & & \multicolumn{3}{|c|}{ Hippopotamus } \\
\hline Manera & 1600 & Hippo & amphibious & 1160 \\
\hline DDD ROCCO FARM & 200 & & & \\
\hline KWSTI ANNEX/Institute/Mirera & 200 & & & \\
\hline Green Park \& Brixia & 1500 & & & \\
\hline Morendat & 100 & & & \\
\hline
\end{tabular}

The herbivore numbers were converted to biomass density $\left(\mathrm{kg} \mathrm{km}^{-2}\right)$ using units weights in (Coe et al., 1976) and the total area $\left(275 \mathrm{~km}^{2}\right)$ of the 16 selected ranches (Table 5-1). A principle components analysis (PCA) (Legendre and Legendre, 2012) was carried-out on the land cover data to obtain an orthogonal linear combination of land cover values for each year. The first PCA axis explained $99 \%$ of variance and was thus selected in the subsequent analysis to represent the LULC for each year. Path analysis was used to explore the significant of downstream population, LULC, annual downstream precipitation and lake levels changes to the total ungulates density.

\subsection{Results}

\subsubsection{Socio-economic drivers}

Pearson correlation analysis (Table 5-2) of the upstream sections of the basin identified population as having negative correlation with forest cover, bushland and shrubland and a positive correlation with farmland, woodland, grassland and built-up.

Table 5-2: Correlation of upstream population and land use/cover

\begin{tabular}{l|lllllll}
\hline & Forest & Bushland & Farmland & Woodland & Grassland & Shrubland & Built-up \\
\hline Population & -0.43 & -0.85 & 0.8 & 0.97 & 0.94 & -0.03 & 0.96 \\
\hline
\end{tabular}

In the downstream parts of the basin, Pearson correlation analysis (Table 5-3) of socio-economic variables identified downstream population, flower export volumes and irrigation land to be positively and strongly correlated.

Table 5-3: Table 3: Correlation of downstream population and land use/cover

\begin{tabular}{l|llll}
\hline & Irrigation & Horticulture & Population & Flower export volume \\
\hline Irrigation & 1 & & & \\
Horticulture & 0.77 & 1 &
\end{tabular}




\begin{tabular}{l|llll}
\hline Population & 0.78 & 0.99 & 1 & \\
Flower export volume & 0.69 & 0.96 & 0.98 & 1 \\
\hline
\end{tabular}

\subsubsection{Cascade models}

All the cascade models had chi-square $p$-values greater than 0.5 (Table 5-4) suggesting that the model outputs matched those of the sample data. Cascade $(1 \mathrm{~A})$ indicated that $63 \%$ of upstream land use/cover changes could be explained by population growth. This explained only $40 \%$ of the observed variance in changes of land use/cover suggesting that other exogenous variables accounted for $60 \%$ of the variance. Land use/cover changes had direct effect of $36 \%$ on direct runoff generation, while upstream precipitation had $95 \%$ effect on direct runoff. The combined influence of upstream population, land use/cover changes and precipitation explained $95 \%$ of the variance in direct runoff generated from the basin (Figure 5-5).

Table 5-4: Chi-square measures of model fit for the significant cascades

\begin{tabular}{lllll}
\hline Model & & & & \\
& & & df & $\mathrm{p}$ \\
\hline Upstream Cascade (1) & A & 0.022 & 2 & 0.989 \\
& B & 0.071 & 1 & 0.790 \\
& C & 0.233 & 1 & 0.629 \\
Downstream Cascade (2) & A & 4.632 & 6 & 0.592 \\
& B & 7.159 & 3 & 0.067 \\
\hline
\end{tabular}




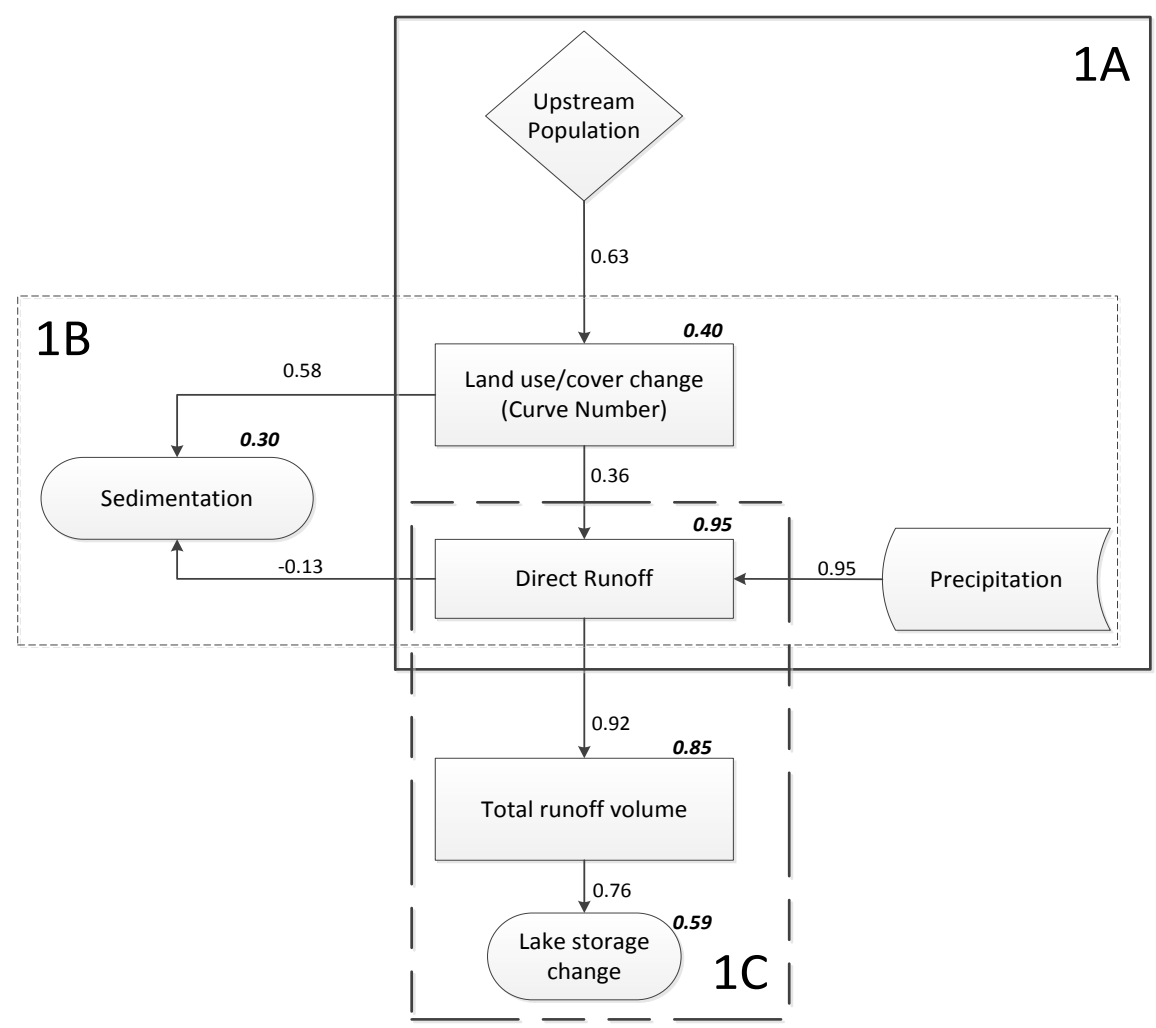

Figure 5-5: Upstream path diagram quantifying the cascade effects of upstream population on hydrological variables. Numbers along the arrows are standardized path correlation coefficients and represent the direct bivariate effect of the two linked variables. Bold and italicized numbers on the edges of effect and response variables represent the multiple correlation coefficients that describe the multivariate strength of the preceding model. Bounding boxes labeled $1 \mathrm{~A}-1 \mathrm{C}$ are the significant cascade models.

The second sub-cascade (1B) had precipitation being the main impulse triggering runoff generation. Land use/cover changes had a direct effect of $58 \%$ on sediment yield while direct runoff had a negative influence on sediment yield. The overall influence of both could only explain $30 \%$ of sediment yield deposited to the lake.

Sub-cascade model three (1C), showed direct runoff as the main trigger contributing to total runoff volume generated in the upstream parts and contributing to lake volume storage downstream. $57 \%$ of variation in lake volume storage changes could be explained by direct effects contribution of upstream total runoff (76\%) and direct runoff $(92 \%)$. 
The downstream sub-cascade model (2A) majorly driven by the horticultural sector explained $71 \%$ of the variation in water abstracted, with flower export contributing $58 \%$ as direct effect to the overall water abstraction volumes ( Figure 5-6). Water abstraction had a negative direct effect of $15 \%$ on lake storage changes. Overall influence of the triggers and effects of this cascade explained $34 \%$ of the lake storage changes with precipitation falling over the lake contributing $59 \%$ to the changes.

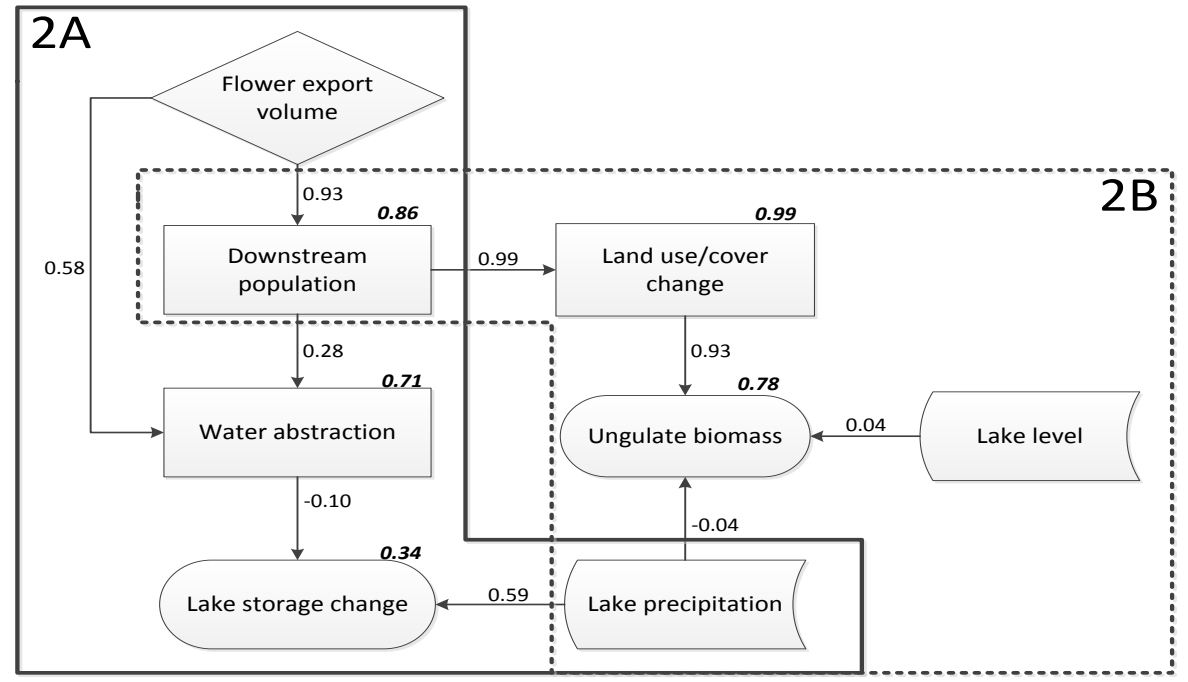

Figure 5-6: Downstream horticultural/irrigation driven cascade impacting the lake storage change. The horticultural and irrigation commercial agriculture activities are the main triggers of hydrological changes. Numbers along the arrows are standardized path correlation coefficients and represent the direct bivariate effect of the two linked variables. Bold and italicized numbers on the edges of effect and response variables represent the multiple correlation coefficients that describe the multivariate strength of the preceding model. Bounding boxes labeled $2 \mathrm{~A}-2 \mathrm{~B}$ are the significant cascade models

Cascade (2B), showed that the downstream population had a strong significant positive effect (99\%) on downstream LULC changes (Figure 5-6). The total herbivore biomass density on the fringe zone had almost tripled over the study period (Figure 5-7). This was related to a $93 \%$ positive direct effect of downstream LULC changes. Lake levels had a $4 \%$ direct effect on ungulate biomass production while precipitation over the lake had a $4 \%$ negative direct effect. The four variables in this cascade explained $78 \%$ multivariate effect of total ungulate density. 


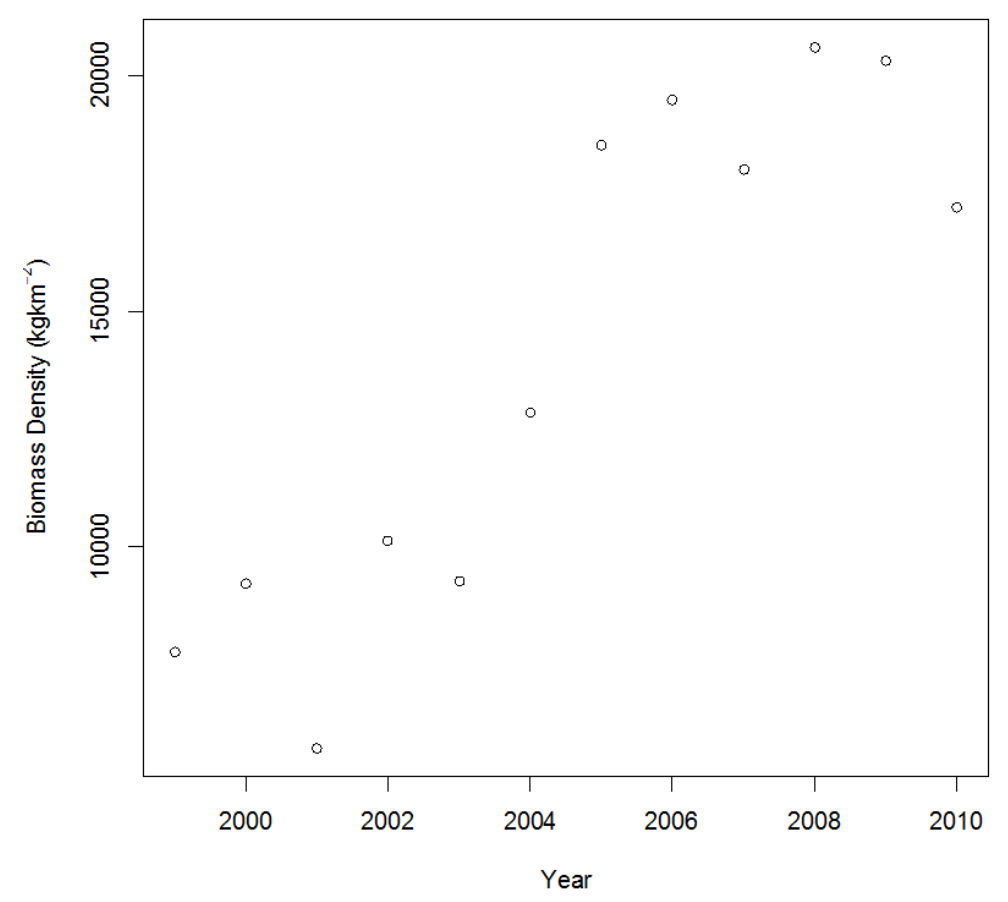

Figure 5-7: Total herbivore biomass density for 12 years on ranches adjacent to Lake Naivasha

\subsubsection{Hydrological effects}

The results of basin runoff generation indicate that the runoff conditions have undulated over time with minima and maxima runoff coefficient cycles occurring between 2 to 4 years (Figure 5-8). Increased total runoff flows were observed during the period of 1986-2010 suggesting that surface changes due to LULC changes are responsible for the changed hydrological regime. The runoff coefficient for the period of 1961-1985 significantly $(p<0.05)$ differs from the one of the period 1986-2010. Over the entire period precipitation has remained fairly unchanged with a monthly average reduction of $5 \%$ (Figure $5-9$ ) while total runoff volume has significantly $(p<0.05)$ increased by $32 \%$ (Figure $5-10$ ). Direct runoff generation estimated using SCS-CN method remained fairly unchanged over the two periods even though the basin curve number showed an increase from 55 to 61 for 1973 and 2010 respectively. 


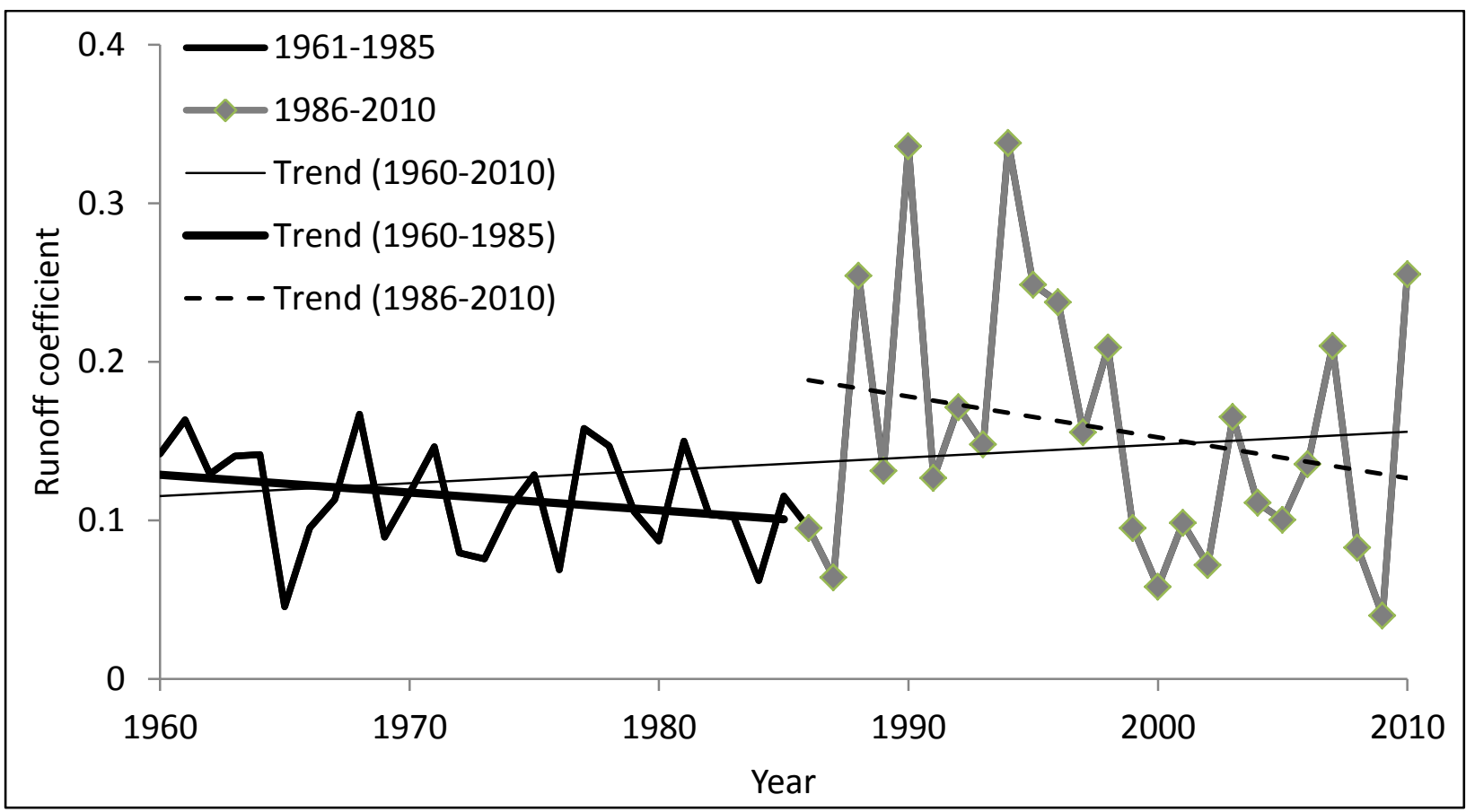

Figure 5-8: Evolution of annual runoff coefficient for Lake Naivasha Basin between 1960 and 2010 

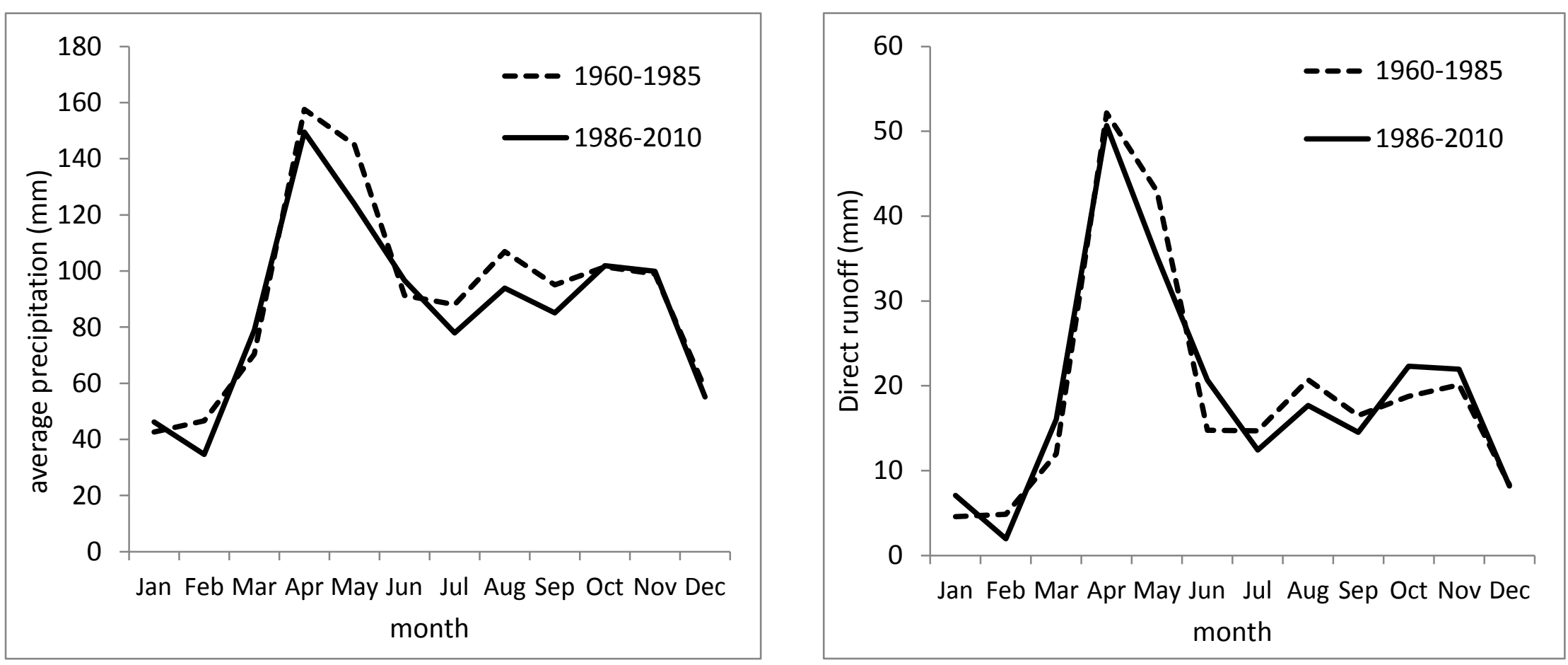

Figure 5-9: Variation of monthly precipitation (left) and direct runoff (right) generation from upstream of Lake Naivasha Basin 

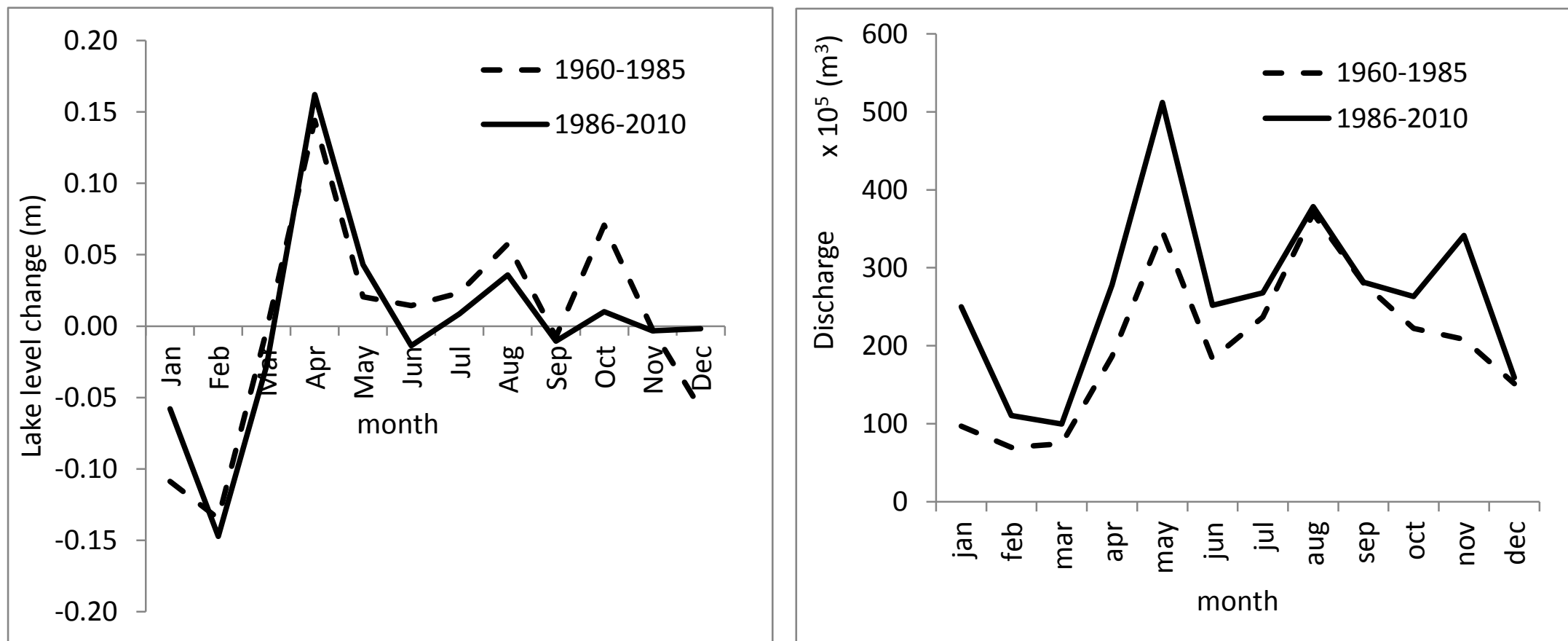

Figure 5-10: Monthly total runoff (left) and lake level change (right) for periods 1 (1960-1985) and 2 (1985-2010) for Lake Naivasha Basin 
Although total runoff volumes into the lake between the two periods of change have been distinct, the lake storage changes have been marginally lower (Figure 5-10).

\subsection{Discussion}

\subsubsection{Hydrological effects}

Cascade models indicate that the rural population in the upstream part of the Lake Naivasha Basin determined much of the land use/cover changes impacting on the hydrology, whereas the cutflower production and downstream population are identified as the main drivers influencing the hydro-ecological system in the lower basin. The total runoff volumes from the upstream part of the basin explain the variation of the lake volume rather than water abstractions from the lake and its conjunctive aquifer.

Our findings show that upstream land use/cover changes exacerbated by population increase over the last 25 years have increased total runoff generation even though precipitation has not changed over the same period. Runoff analysis in this study confirmed these observations since monthly total runoff volumes increased significantly $(p<0.01)$ by up to $32 \%$ even though the precipitation amount between the two periods remained significantly unchanged. The downstream effect of these upstream changes has seen a positive response in the lake storage change over the same period. The lake storage changes have been lower on average than was in the period 1961-1985.

Considering that precipitation conditions in the basin have remained constant over the last four decades, intuitively, this would suggest that precipitation being an external climatic forcing was unlikely to be the cause of the observed changes in total runoff in the last 25 years. However, this could be explained by changes in land use/cover exacerbated by upstream human population increase. Our land use and land cover classification results for the upstream part of the basin (Figure 5-11) suggest that the decline in forest $(-5.4 \%)$ and bush land $(-26.4 \%)$ between the period 1973 and 2011, have been at the expense of substantial increases in grassland (20.3\%) and farm lands (5\%). The grasslands may be transitional lands that might have been previously under cultivation. The grassland and farm lands typically have low leaf area that intercepts less rainfall, shallow rooting depths and even higher surface albedo compared to forests and bush land (Costa et al., 2003; Costa and Foley, 1997; Zhang et al., 2001). Moreover, pastoralism is an activity that prevails in this part of the basin with livestock overgrazing having left the surfaced 
exposed. Considering that the precipitation changes are insignificant, the above LULC change may have caused a reduction in the evapotranspiration (ET) and infiltration rates and subsequent increment in discharge in this part of the basin. The LULC changes may have caused the observed significant changes in runoff coefficients and land cover curve numbers between the periods 19611985 and 1986-2010 that resulted to the increased runoff.

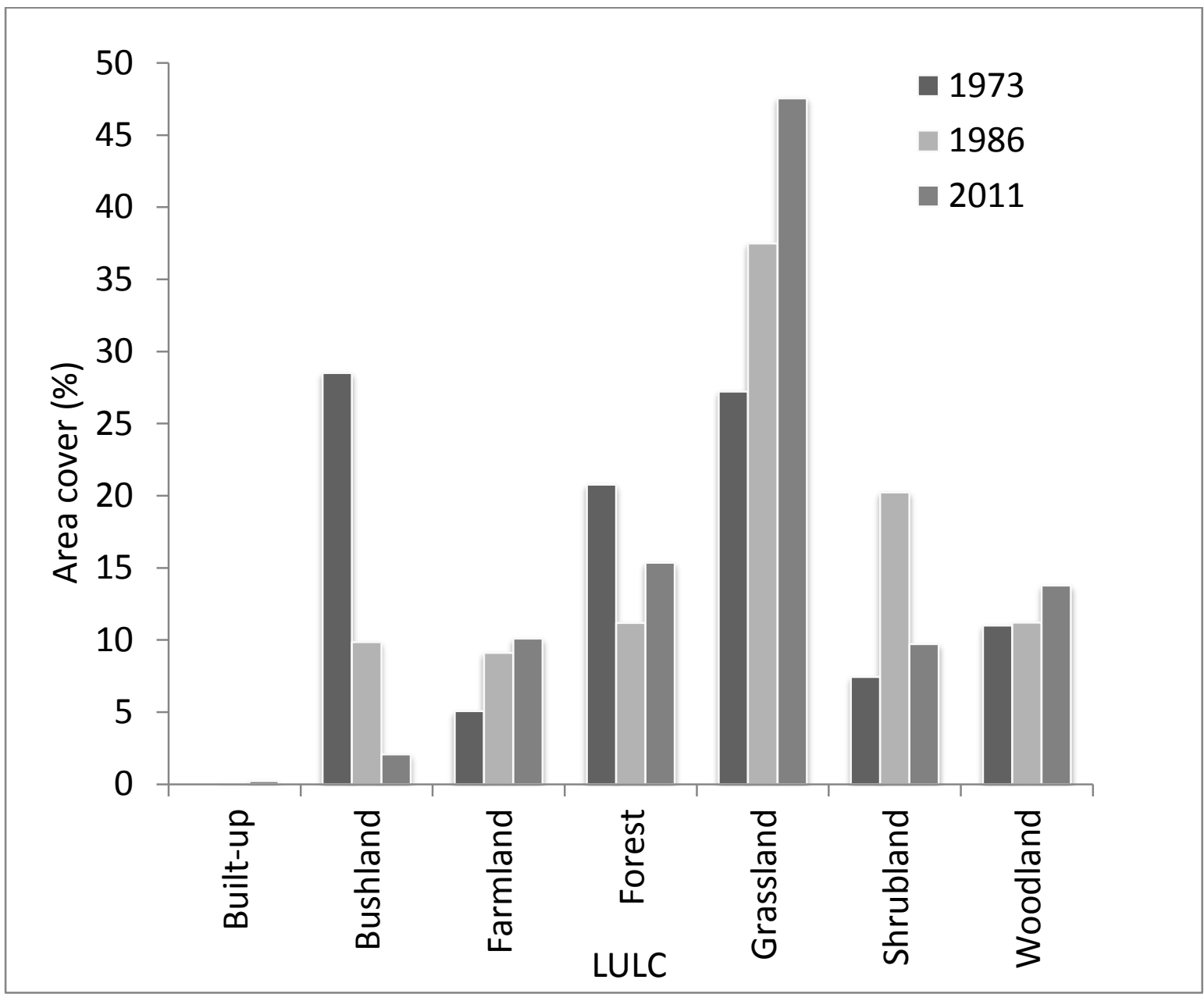

Figure 5-11: Temporal changes of land use and land cover in upstream parts of the Lake Naivasha Basin

Observable impacts of land use/cover changes on basin hydrology at larger catchment scales $\left(>100 \mathrm{~km}^{2}\right)$ have been relatively few (e.g. Costa et al., 2003; Siriwardena et al., 2006; Zhang and Schilling, 2006). This is particularly because as the scale of the basin increases so have been the 
Chapter 5

increased mixed effects of climatology and land cover changes at these scales making it difficult to discriminate the influence of land use/cover changes from that of climate (van Dijk et al., 2012). For the case of Lake Naivasha basin which has a hydrological active contributing area of approximately $1800 \mathrm{~km}^{2}$, our findings agree with those from large-scale studies (Cognard-Plancq et al., 2001; Costa et al., 2003; Gentry and Lopez-Parodi, 1980; Siriwardena et al., 2006; Zhang and Schilling, 2006) and from small-scale deforestation experiments (Bruijnzeel, 1990; Sahin and Hall, 1996). Much of the changes in those catchments were due to large scale land use and land cover changes despite experiencing insignificant changes in precipitation. Most previous studies including those of the Murray-Darling basin in South Eastern Australia, however, have observed decline in flows attributed to decreased rainfall, increased temperatures, increased evapotranspiration and increased water abstractions (Potter et al., 2010; van Dijk et al., 2007). Other research findings (Bruijnzeel, 1990; Wilk et al., 2001) from large scale basins that have experienced deforestation disagrees with results observed at small-scale deforestation experiments. This has been attributed to simultaneous regrowth of land cover in some parts of the basin while other parts are being deforested or cleared proportionally such that changes in runoff volumes cannot be observed.

The consequence of the increased runoff volumes from the upper catchment of Lake Naivasha caused deep channelization at the lower reaches of River Malewa that hindered the dendritic redistribution of water on the former aquatic North swamp, leading to its eventual drying (Harper and Mavuti, 2004). The impact of drying of the swamp was that the lake water quality was compromised due an excess of sediment and nutrients transported by upstream runoff. Before the drying of the swamp, the swamp acted as filter that improved the water quality of the lake by trapping sediments and nutrients (Gaudet, 1977b; Kitaka et al., 2002). The cascade model in this study explained $30 \%$ of the variation in sediment yield from the upper basin. Most important was the impact of upstream land use/cover changes which contributed $57 \%$ of the total variation in sediment yield.

\subsubsection{Biodiversity effects: total biomass density of large herbivores mammals}

The downstream LULC explained the highest variation on herbivore biomass density on ranches adjacent to Lake Naivasha. The observed LULC on formerly communal grazing lands surrounding Lake Naivasha resulted to loss of habitats and grazing land eventually leading to aggregation of high ungulate biomass along a riparian zone. The LULC progressively converted the riparian zone into a high ungulate biomass island. This contrast with earlier studies that observed that increased LULC caused a decline in herbivore biomass density (Mundia and Murayama, 2009; Western et al., 
Chapter 5 2009). However our results concur with (Harper and Mavuti, 2004), who observed that the ungulates biomass especially the buffaloes in the riparian zone had tripled compared to mid-1990's. This increase was attributed to land cover conversions especially in the deforestation of Eburru forest, to the west of the Lake. The increased ungulates density can induce continuous intense grazing that can alter plant composition and productivity (Morrison and Harper, 2009; Muthoni et al., 2014).

Moreover the low variance explained by the annual precipitation on the herbivores biomass contradicts earlier observations that ungulates density is dependent on annual precipitation (Coe et al., 1976; East, 1984; Georgiadis et al., 2003; Ogutu and Owen-Smith, 2003). The changes in lake levels was also expected to have significant impact on ungulate biomass since decline in levels increase the area of the highly productive riparian grazing land. However these riparian grasslands experience frequent and prolonged flooding even in the dry seasons in response to upstream precipitation regime. However prolonged flooding especially during the dry seasons reduces grazing area during the scarcity when it is supposed to subsidize the forage. Prolonged flooding due to increased lake levels has been observed to reduce herbivores population in the nearby Lake Nakuru as it reduces the foraging area (Ogutu et al., 2012). Since the lake levels are largely dependent on streamflow from upper catchment (see discussion section "Hydrological effects"), the results therefore highlight the impact of the upper catchment rainfall on the ecological integrity of downstream ecosystem.

Overall, our cascade modeling approach offered insight on the contribution of socio-economic factors on the eco-hydrological regime of the Lake Naivasha Basin. Thus, our method could potentially be used to show the influence of eco-hydrological variables on socio-economic developments.

\subsection{Conclusions}

This study shows that, in cases where observed socio-economic developments are substantial, the use of a statistical cascade-modeling approach, coupling socio-economic factors to ecohydrological processes can greatly improve our understanding of the eco-hydrological system. Lake Naivasha basin has experienced substantial land use and land cover (LULC) transformations predominantly caused by socio-economic drivers. Accounting for the implications of socioeconomic drivers of LULC is vital to the understanding of hydrological and ecological functioning of a river basin. This study investigated the cascading impacts of socio-economic drivers of LULC 
Chapter 5

changes on the hydro-ecological regime of Lake Naivasha basin. The findings show that socioeconomic factors have exacerbated LULC transformations leading to increased flow regimes over the last 25 years. The upstream cascade model revealed that population has contributed about $63 \%$ to the land use/cover transformations in that part of the basin. Water abstractions from the lake and its conjunctive aquifer influenced the lake storage changes less than the contribution from upstream runoff volume. Upstream runoff volumes directly affected the lake storage change by up to $76 \%$ whereas water abstractions had $10 \%$ negative effect. The lower cascade further showed that downstream population and the flower export volume accounted for $71 \%$ of water abstraction. The downstream LULC conversions explained the large aggregation of high biomass density of large herbivore mammal species. 
Chapter 6

6 Synthesis 


\subsection{Synthesis}

The aim of this thesis was to quantify the impacts of climate and land use on the hydrological response of Lake Naivasha Basin and identify factors that determine the responses prevailing at different observable scales. Trends in the water balance components, evapotranspiration and its climatic controls were investigated and a modelling framework integrating socio-economic factors of land use change to basin wide eco-hydrological processes were presented.

A major concern in environmental change studies is that ecosystems presumably move from stationary behaviour to unpredictable, nonstationary states. Analysis of past hydrological records may provide insights whether such changes are indeed happening since hydrological records carry signals of climate and land use change (Renner, 2013). In this work, it was found (Chapter 2) that over the past 50 years studied, observed changes in steam flows and lake volumes were unlikely to be attributed to climatic influences but anthropogenic factors such dam constructions, abstractions and changes in surface conditions (land use and soil surface). The precipitation over the basin remained fairly unchanged with no observed significant changes in the basin. The water balance from measured annual total precipitation and inflow into the lake could not explain the significant decline in lake volumes. However, reconstructed lake volumes indicated an insignificant lake decline with the lake volumes expected to be at least 50\% higher than has been (Figure 2-4). These observed differences between reconstructed and observed lake volumes were attributed to uncertainties in measurements and ground water seepages combined with lake abstractions. Overall, the findings showed that there was no evidence of climate change impact on the hydrological regime of Lake Naivasha, and that human induced factors outweighed those of climate change in determining the hydrological regime of Lake Naivasha basin between 1960 and 2010. However, a rapid rise in lake levels, equivalent to those last experienced in early 1980's, was observed in the period between 2010 and 2015 (Figure 1-4). Therefore, lake volume trends shown in Figure 2-4 are likely to change from negative to positive suggesting that much of the observed trend before 2010 could be realizations of a wider window in which observations occur (Koutsoyiannis, 2006). This simply indicates that one has to be extremely cautious in studying such systems showing very low frequencies with wavelength of decades; pointing concern of statistical meaninglessness when discussing poorly understood systems (Cohn and Lins, 2005; von Storch and Zwiers, 1999).

To understand such a system, this study developed a framework that demonstrated how socioeconomic factors influence eco-hydrological processes in Lake Naivasha Basin (Chapter 5). Socioeconomic developments are key drivers of land use change triggering changes of the eco- 
Chapter 6 hydrological regime of basins. Identifying mechanisms that initiate such changes, and how those mechanisms interact to influence the ecosystem, improves systems understanding since they mirror theories of causation (Burcher et al., 2007). Since different socio-economic factors and ecohydrological processes prevail at both the upper and lower parts of the catchment, the framework used hypothesized cascades which were defined a priori and follow specific causal hypothesis to estimate the magnitude and strength of effects. This was a first step in developing clear and logical theories about processes influencing eco-hydrological responses in the Lake Naivasha system. The findings showed that population increase contributed substantially ( $60 \%)$ to land use changes in the upper parts of the catchment. The consequence of these changes was higher monthly total stream flows between 1986 and 2010 than during the period 1960 and 1985 even though precipitation did not change significantly between the two periods. The stream flows explained at least $70 \%$ of the lake storage changes with abstractions only accounting for about $10 \%$. The cascade model could not account for the remaining $20 \%$ and this could be attributed to groundwater outflow from the lake system which remains largely unknown and an uncertain term (Chapter 2). Lower catchment population and cut-flower exports explained at least $70 \%$ of total water abstractions. One possible explanation presented for the increased monthly stream flows between the two periods, was the substantial increases in grassland and cultivated lands at the expense of forest and bush lands. These conversions of forest and bush lands; which have high leaf area, compared to grasslands and cultivated lands which have low leaf area, combined with their shallow roots have been known to intercept less rainfall (Costa et al., 2003; Costa and Foley, 1997; Zhang et al., 2001). With increased human population and activities such as livestock grazing within the hydrologically active parts of the basin, the land surface is also likely to be more compacted and subsequently leading to a reduction of the soil hydraulic conductivity. The cumulative hydrologic effect of these activities is that more rainfall is partitioned into surface runoff with little infiltrating into the ground. Extensive land use conversions such as overgrazing in the sub-tropics and deforestation of rain forests have been known to express their effect on climate through the light-reflecting capacity of the surface (i.e. albedo) (Loarie et al., 2011).

Besides expected reduced leaf area index (LAI) land use conversions from forest to grasslands and cultivated lands would result in increased surface albedo and land surface temperature. These are key surface variables that determine the amount of net radiation available for energy partitioning into latent and sensible heat fluxes. Therefore, the hydrologic consequence of increased surface albedo and land surface temperature as a result of such land use conversions would lead to reduced net radiation and subsequently reduced evapotranspiration (Chapter 3). Increased amount of clouds and aerosols in the atmosphere have also been known to cause reduction of incoming radiation and eventually reduced evapotranspiration. Analysis of the Modern ERA- 
Chapter 6

Retrospective Analysis for Research and Applications (MERRA-2 Model) dataset suggests that both cloud fraction and aerosol scattering over Lake Naivasha basin has been on the increase over the period 2000 to 2015 (Figure 6-1). Moisture availability through precipitation on the other hand also plays a crucial role in determining the amount of evapotranspiration taking place (Figure 3-11). It was evident that evapotranspiration trend was matched by precipitation, discharge and lake level trends.

In Chapter 3 spatial and temporal patterns of evapotranspiration were investigated for the period 2003-2012 using the Surface Energy Balance System (SEBS) with input data from Moderateresolution Imaging Spectroradiometer (MODIS) and European Centre for Medium-Range Weather Forecasts (ECMWF) Interim Re-Analysis (ERA-Interim). These input data were used to compensate for lack of measurements in the basin and together with SEBS model simulations, were validated against 2-year flux measurements from an automatic weather station located at a single site within the basin (Chapter 4).

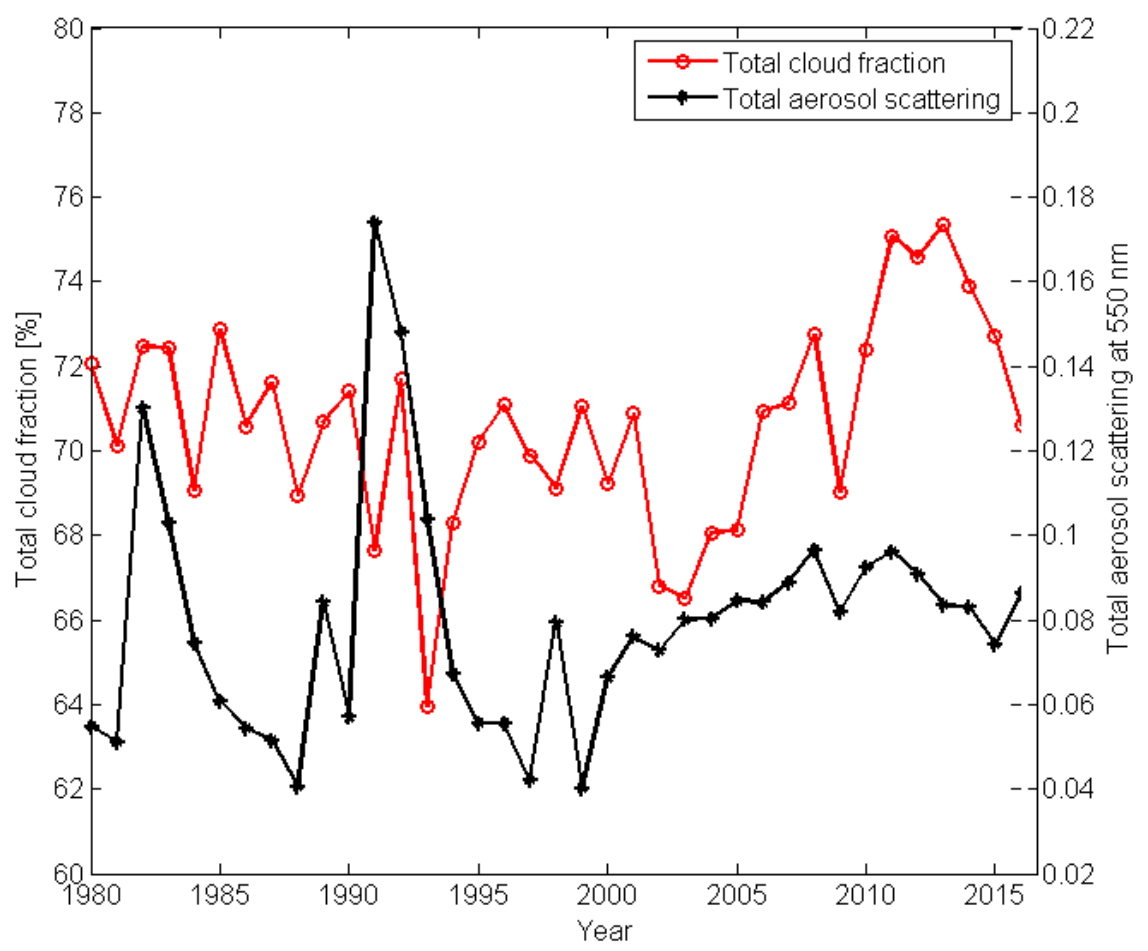

Figure 6-1: Total cloud fraction and aerosol scattering index over Lake Naivasha basin between 1980 and 2016. The two high peaks in 1982 and 1991 of the aerosol scattering index are an influence of the volcanic eruptions of El Chichón and Mt. Pinatubo respectively which released 
volumes of volcanic dust into the atmosphere that circled the globe weeks after the eruption took place

Land use and land cover over the 10 years was obtained from MODIS MOD12Q1 product. The findings showed that in the 10 years studied, annual evapotranspiration in the basin had been on the decline. This decline was due to interannual precipitation decline in combination with reduced net radiation over the period studied but also increased vapor pressure and reduced difference between air and surface temperature were observed. Overall, these factors accounted for at least $90 \%$ of the observed decline in the evapotranspiration. Moreover, evapotranspiration accounted for between $55 \%$ to $86 \%$ of the annual precipitation in the basin with grasslands, woody savanna and cropland/vegetation mosaic being the dominant land use/covers contributing up to 80\% of the total ET.

Evaporative demand as measured directly by the pan evaporation however, showed a declining trend (Figure 2-2) over the period 1960 to 2010 which was similar to other observations reported in many parts of the world including the USA (Hobbins et al., 2004), Australia (Roderick and Farquhar, 2004), the Tibetian Plateau (Zhang et al., 2007), India (Jaswal et al., 2008) and South Africa (Hoffman et al., 2011). These declines have been attributed primarily to declines in radiation (i.e. dimming) associated with increased aerosols and/or clouds and also due to a decline in wind speed (Roderick et al., 2009). Understanding the key factors determining the evaporative demand and associated hydrological processes is crucial because the rate and direction of change of terrestrial water and energy balance has significant consequences for the growth and survival of plants (Hoffman et al., 2011). However, the effect of declining pan evaporation on vegetation especially in water limited environments such as the Lake Naivasha basin where changing evaporative demand and moisture supply through precipitation have a strong influence on terrestrial water balance is not straightforward. This is because increasing air and land surface temperatures on the one hand is expected to accelerate evaporation and the effect of declining wind speed and evaporation on the other hand will lessen the effect of increasing temperatures on soil and plant water balance. Over the period between 1980 to 2010, wind speed over Lake Naivasha basin as analysed from MERRA-2 model suggest a continuous decline at the rate $\sim 1 \%$ per year (Figure 6-2). This observation is similar to those reported in South Africa (Hoffman et al., 2011), Canada (Burn and Hesch, 2007) and Australia (Roderick and Farquhar, 2004) attributing decline in evaporative demand to reduced wind speeds over the regions. Although Brutsaert (2006) argued that suppression of pan evaporation was indicative of increasing actual evapotranspiration, it is unlikely that this would be the case for the decline in pan evaporation for Lake Naivasha basin. This is because increased moisture supply through precipitation would be required for evidence of increased actual evapotranspiration in the study area. Apparently, 
moisture supply through precipitation in the study area has not changed significantly over the studied period.

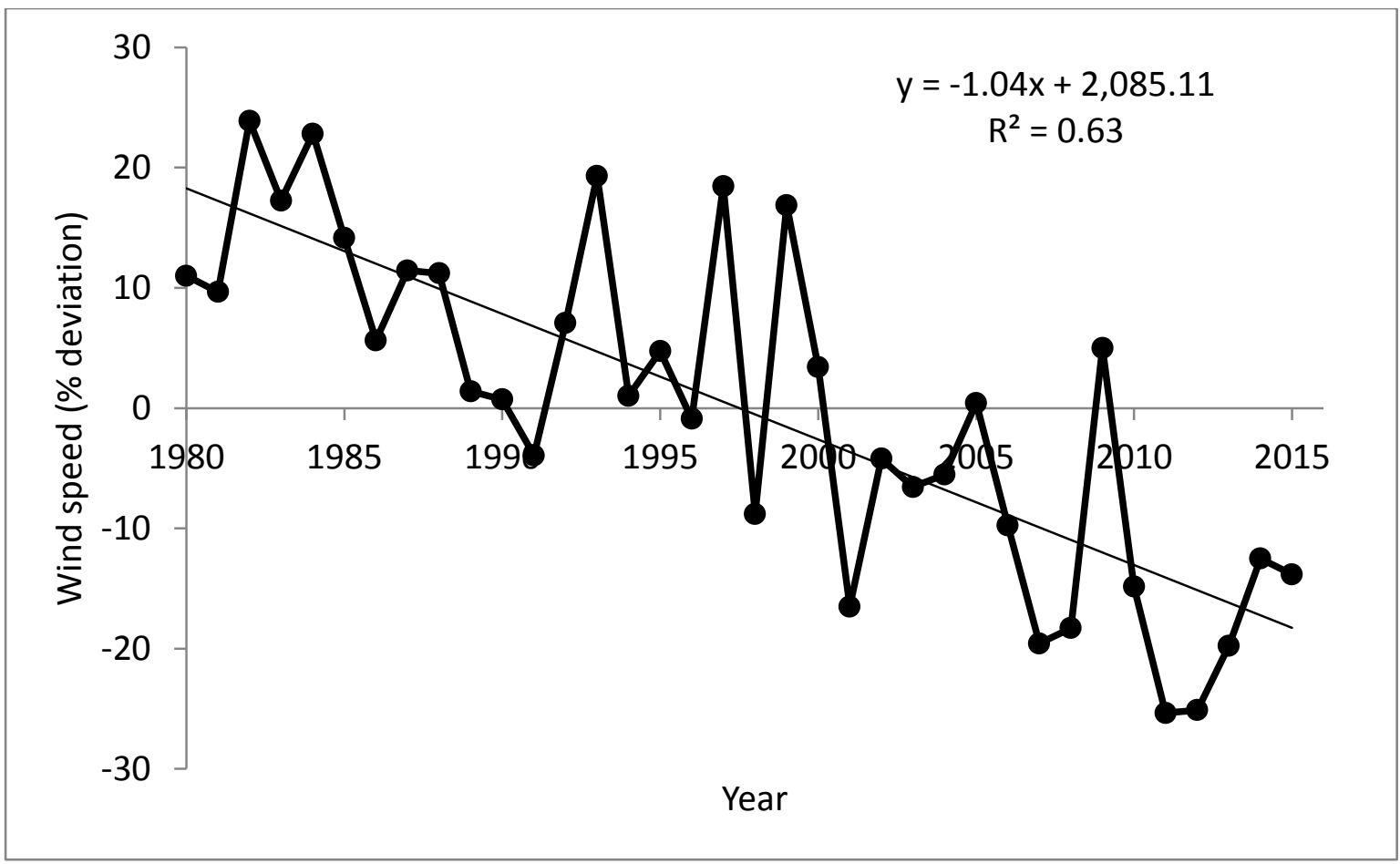

Figure 6-2: Overall trend in the \% deviation of wind speed over Lake Naivasha basin from 1980 to 2015 (relative to the mean value for the period 1980-2015)

The measurements that were used to validate the SEBS model and ECMWF data in chapter 3 were used to investigate the energy partition and its biophysical controls at a heterogeneous landscape site in the basin. The findings are presented and discussed in chapter 4. It was concluded that, variability in evapotranspiration was largely controlled by the changes in seasonal precipitation unlike in humid environments where evapotranspiration is usually controlled by changes in potential evapotranspiration. During periods of limiting moisture, evapotranspiration was observed to be strongly coupled to the atmosphere with surface conductance and vapor pressure deficit being the dominant controlling factors. The converse was true during periods of non-limiting moisture with the vegetation decoupling from the atmosphere and radiation becoming the dominant control of evapotranspiration. Unlike the lower semi-arid part of the catchment where the measurements were conducted, the upstream part of the catchment is wet and humid. It is expected that much of the vegetation there will likely be coupled to the atmosphere with surface 
Chapter 6

conductance and vapor pressure deficit being the dominant controlling factors. This finding provides insights on changes that maybe expected for such an ecosystem in this region of Africa under climatic changes of increased precipitation. With projections of climate change predicting increased precipitation over East Africa, the energy flux partitioning is likely to be controlled more by net radiation. In the case of enhanced drought over the region as predicted in other studies (e.g. Williams and Funk, 2011), the energy flux partitioning in the ecosystem is likely to be coupled to the atmosphere.

Effects of climate change projections have had important influence on policy, governance and social preparedness (Hoffman et al., 2011). Therefore, the implications of the drivers of energy partitioning and evaporation on the water balance and vegetation responses is that there is need to adjust the climate projections for vegetation response in this region and other regions experiencing similar eco-hydrological processes to accommodate the possibility of evaporative demand declining and trends in vegetation dynamics coupling with the changing climatic regimes. Also, declining evaporative demand as inferred from the pan data would suggest that more water has probably become available for infiltration and runoff over the period covering 1960 to 2010 .

The period between 2000 and 2010, however, observed an increase in pan evaporation. This was indicative of increased lake evaporation which when combined with lake abstraction and the sustained precipitation decline between years 2003 and 2005 and years 2006-2009 (Figure 3-11), led to the decline in lake levels that was observed in that period. Terrestrial evapotranspiration matched the sustained decline in precipitation over the same period while the changes in land cover over the period had little effect on decline of evapotranspiration. This suggested that climatic influence outweighed land cover changes in controlling the hydrological processes of the basin within the decadal scale. The probable reason for this is the time scale and spatial scale at which the changes in hydrological events occur and are analyzed. For example, interannual fluctuations of precipitation are more important in determining the year to year lake level changes of Lake Naivasha. These interannual fluctuations are usually within the natural variability which may not prevail over longer time scales. Over longer windows of observations, patterns of hydrological changes may begin to emerge that were otherwise not possible to detect at shorter windows of observations. For the case of Lake Naivasha basin changes in land use were discernible in the longer time scales ( $\sim 50$ year) (Chapter 2 and 5 ) while climate had stronger influence in the shorter time scales ( $\sim 10$ years) (Chapter 3 and 4 ). Moreover sustained drier conditions of $\sim 4$ years and consistent abstraction is enough to significantly reduce the lake levels. The converse is also true. This was the scenario towards the low lake levels experienced towards 2009 (sustained dry conditions) and lake level increase after 2009 (sustained wet conditions). Therefore, the large 
fluctuations of lake levels are predominantly driven by the prevailing long-term dry and wet conditions, and less by land use changes whose effects are nonetheless observable at the longer time scale. This complicates the detection of hydrological changes due to land use in the shorter time scales because their effect maybe part of the inherent natural variability.

\subsection{Recommendations}

This research presented different approaches quantifying the impacts of climate and land use on the hydrological response of Lake Naivasha Basin and identified the controlling factors prevailing at different observable scales. The study provided the first long-term comprehensive analysis of hydrological trends ( $\sim 50$ years) and first long-term flux measurements ( 3 years) that are important for modellers in advancing future understanding and assessment of land surface interactions. However, logistical and financial constraints limited the extension of parts of the study. The following section discusses some of the limitations and proposes recommendations for future work.

The study investigated the long-term trends of annual and seasonal averages of water balance components (Chapter 2). The study did not investigate presence of temporal shifts in onset, length and cessation dates of rainfall distribution. There is need to investigate the presence of temporal shifts, onset, cessation and length of growing season in the basin. This is especially relevant in understanding whether there are seasonal climatic shifts in rainfall patterns that could potentially affect agricultural productivity in the basin that is rainfall depended.

In Chapter 4 it was observed that, during the wet season, evapotranspiration was majorly controlled by net radiation, while during the dry season it was strongly coupled to the atmosphere with vapor pressure deficit and surface conductance controlling the evapotranspiration process. This conclusion was arrived at after three years of flux measurements at a single heterogeneous site. However, it is inconclusive whether this behaviour is representative for the whole catchment or only applicable for the semi-arid part of the basin. Also, the energy balance closure of the site was $\sim 66 \%$ suggesting that there are uncertainties prevalent in the flux measurements at the site.

Increased ground flux measurements at different heterogeneous and homogenous land use/cover types are recommended to further validate the cyclic pattern of biophysical control of evapotranspiration observed in Chapter 4. These measurements would also go a long way in understanding the energy balance closure problem at different land use/cover types in the Lake Naivasha basin. Moreover such measurements are also essential in validating remotely sensed and 
Chapter 6 re-analysis data necessary for upscaling spatial estimates of energy balance components. Specifically, this would improve the assessment of evapotranspiration estimates from SEBS model (Chapter 3) that can then be assimilated in hydrological models. Also increased flux measurements could potentially be used to study eco-hydrological changes that maybe expected under climatic changes of increased precipitation or enhanced drought in parts of Africa with similar ecosystem to Lake Naivasha basin. Under increased projected future precipitation over East Africa (Boko et al., 2007), the energy flux partitioning is likely to be principally enhanced by $R_{n}$. In the event of enhanced drought conditions (Williams and Funk, 2011), the energy flux partitioning in the ecosystem is likely to be coupled to the atmosphere. Isotopic flux partition is also recommended as potential research niche to determine the amount of transpiration flux, $F_{T}\left[\mathrm{~g} \mathrm{~m}^{-2} \mathrm{~s}^{-1}\right]$, in the bulk evapotranspiration flux, $F_{E T}\left[\mathrm{~g} \mathrm{~m}^{-2} \mathrm{~s}^{-1}\right]$. Such methods are able to identify stomatal control of transpiration over the course of the diurnal cycle and also during critical wilting point of plants (Good et al., 2014).

Results at the heterogeneous site (Chapter 4) showed that use of $L E=\left(R_{n}-G_{o}\right) /(1+\beta)$ yielded higher evapotranspiration rates than would be expected for such an ecosystem. Instead, using $L E=H / \beta$, the estimates of evapotranspiration were reasonably close to what would be expected for such an ecosystem. This raises a critical concern on the validity and choice of formulation that is realistic in spite of the fact that they are mathematically identical by derivation. A probable cause of the difference in results was discussed as over and underestimation of measured fluxes at mismatched footprints within the heterogeneous landscape. Further investigation on this mismatch is recommended for future research.

The results also suggested potential of deep layer water abstraction by plants. Therefore, isotopic flux partitioning in combination with ground water monitoring, measurements of interception losses and throughfall are a necessary future undertaking towards advancing the understanding of the eco-hydrological processes in the basin would be realized.

Integrated water resources management at the catchment scale is known to struggle with implementation (Cook and Spray, 2012). However, technological advances in remote sensing and geographical information systems coupled with integrated assessment modelling are making progress towards closing this gap (McDonnell, 2008). Chapter 5 of this thesis provided a conceptual framework towards such a systems understanding relevant for use in an integrated catchment assessment. Therefore, there is need to promote the use and further improvement of such integrated tools for logical and systems analysis to support catchment managers in dealing with complexities of natural ecosystems with substantial human developments especially in Sub- 
Chapter 6

Saharan African. There is also need for improvement of the conceptual models by including feedback mechanisms. The cascade approach used in this study was certainly not the best method to apply for the multi-disciplinary integrated assessment of socio-economic impacts on ecohydrological processes that involve feedback mechanisms; however it was better for the data scarce situation of Lake Naivasha basin. Other alternatives to cascade modelling such as processbased models (e.g. agent-based modelling (ABM) or system-dynamics (SD)) that account for relevant feedback mechanisms, explore impacts of future scenarios or compare effects of alternative measures are recommended for future applications as relevant data become available since these alternatives are data intensive and much complex compared to path analysis. 


\section{Bibliography}

Abiya, I.O., 1996. Towards sustainable utilization of Lake Naivasha, Kenya. Lakes \& Reservoirs: Research \& Management, 2(3-4): 231-242. DOI:10.1111/j.14401770.1996.tb00067.x

Allan, D., Erickson, D., Fay, J., 1997. The influence of catchment land use on stream integrity across multiple spatial scales. Freshwater Biology, 37(1): 149-161. DOI: $10.1046 / j .1365-2427.1997 . d 01-546 . x$

Allan, J.D., 2004a. Influence of land use and landscape setting on the ecological status of rivers. Limnetica, 23( 3-4): 187-198.

Allan, J.D., 2004b. Landscapes and Riverscapes: The Influence of Land Use on Stream Ecosystems. Annual Review of Ecology, Evolution, and Systematics, 35(ArticleType: research-article / Full publication date: 2004 / Copyright (c) 2004 Annual Reviews): 257-284. DOI:10.2307/30034117

Andreassian, V., 2004. Waters and forests; from historical controversy to scientific debate. Journal of Hydrology, 291(1-2): 1-27.

Arain, M.A. et al., 2003. Year-round observations of the energy and water vapour fluxes above a boreal black spruce forest. Hydrological Processes, 17(18): 3581-3600. DOI: $10.1002 /$ hyp. 1348

Arbuckle, J.L., 2006. Amos (Version 5.0) [Computer Program] : SPSS, Chicago.

Archer, D., 2003. Scale effects on the hydrological impact of upland afforestation and drainage using indices of flow variability: The River Irthing, England. Hydrology and earth system sciences, 7(GEOBASE): 325-338.

Ase, L.E., Sernbo, K., Syrdn, P., 1986. Studies of Lake Naivasha, Kenya, and its drainage area. Forskningsrapport fran Naturgeografiska Institutionen Stockholms Universitet 63: 1-75.

Bagayoko, F., Yonkeu, S., Elbers, J., van de Giesen, N., 2007. Energy partitioning over the West African savanna: Multi-year evaporation and surface conductance measurements in Eastern Burkina Faso. Journal of Hydrology, 334(3-4): 545559. DOI:http://dx.doi.org/10.1016/j.jhydrol.2006.10.035

Baldocchi, D., Meyers, T., 1998. On using eco-physiological, micrometeorological and biogeochemical theory to evaluate carbon dioxide, water vapor and trace gas fluxes over vegetation: A perspective. Agricultural and Forest Meteorology, 90(12): 1-25. DOI:10.1016/s0168-1923(97)00072-5

Baldocchi, D.D., Xu, L., Kiang, N., 2004. How plant functional-type, weather, seasonal drought, and soil physical properties alter water and energy fluxes of an oakgrass savanna and an annual grassland. Agricultural and Forest Meteorology, 123(1-2): 13-39. DOI:http://dx.doi.org/10.1016/j.agrformet.2003.11.006

Barry, D., Hartigan, J.A., 1993. A Bayesian Analysis for Change Point Problems. Journal of the American Statistical Association, 88(421): 309-319. DOI:10.2307/2290726

Bastiaanssen, W.G.M., Menenti, M., Feddes, R.A., Holtslag, A.A.M., 1998. A remote sensing surface energy balance algorithm for land (SEBAL). 1. Formulation. Journal of Hydrology, 212-213: 198-212. DOI:http://dx.doi.org/10.1016/S00221694(98)00253-4

Bastiaanssen, W.G.M. et al., 2005. SEBAL Model with Remotely Sensed Data to Improve Water-Resources Management under Actual Field Conditions. Journal of Irrigation 
Bibliography

and Drainage Engineering, 131(1): 85-93. DOI:doi:10.1061/(ASCE)0733-

9437(2005)131:1(85)

Bates, C.G., 1921. First Results in the Streamflow Experiment, Wagon Wheel Gap, Colorado. Journal of Forestry, 19: 402-408.

Becht, R., Harper, D.M., 2002. Towards an understanding of human impact upon the hydrology of Lake Naivasha, Kenya. Hydrobiologia, 488(1-3): 1-11. DOI: $10.1023 / a: 1023318007715$

Becht, R., Nyaoro, J.R., 2005. Groundwater links between Kenyan Rift Valley lakes. In: Odada, E.O. et al. (Eds.), Proceedings of the 11th world lakes conference. Ministry of Water and Irrigation and International Lake Environment Committee (ILEC), Nairobi, Kenya, pp. 384-388.

Becht, R., Odada, E.O., Higgins, S., 2006. Lake Naivasha: Experience and Lessons Learned Brief.

Best, A., Zhang, L., McMahon, T., Western, A., Vertessy, R., 2003. A critical review of paired catchment studies with reference to seasonal flows and climate variability.

Blanken, P.D. et al., 1997. Energy balance and canopy conductance of a boreal aspen forest: Partitioning overstory and understory components. Journal of Geophysical Research: Atmospheres, 102(D24): 28915-28927. DOI:10.1029/97jd00193

Boko, M. et al., 2007. Africa. Climate Change 2007: Impacts, Adaptation and Vulnerability. Contribution of Working Group II to the Fourth Assessment Report of the Intergovernmental Panel on Climate Change, Cambridge, Cambridge, UK.

Bosch, J.M., Hewlett, J.D., 1982. A review of catchment experiments to determine the effect of vegetation changes on water yield and evapotranspiration. Journal of Hydrology, 55(1-4): 3-23.

Brown, A.E., Zhang, L., McMahon, T.A., Western, A.W., Vertessy, R.A., 2005. A review of paired catchment studies for determining changes in water yield resulting from alterations in vegetation. Journal of Hydrology, 310(Compendex): 28-61.

Brubaker, K.L., Entekhabi, D., 1996. Asymmetric Recovery from Wet versus Dry Soil Moisture Anomalies. Journal of Applied Meteorology, 35(1): 94-109. DOI: 10.1175/1520-0450(1996)035<0094:arfwvd>2.0.co;2

Bruijnzeel, L.A., 1990. Hydrology of Moist Forests and the Effects of Conversion: A State of Knowledge Review. Free University, Amsterdam, 224 pp.

Bruijnzeel, L.A., 2004. Hydrological functions of tropical forests: not seeing the soil for the trees? Agriculture, Ecosystems \& Environment, 104(1): 185-228.

Brutsaert, W., 2005. Hydrology: An Introduction. Cambridge University Press. DOI: http://dx.doi.org/10.1017/CB09780511808470

Brutsaert, W., 2006. Indications of increasing land surface evaporation during the second half of the 20th century. Geophysical Research Letters, 33(20). DOI: $10.1029 / 2006$ GL027532

Burba, G.G., McDermitt, D.K., Grelle, A., Anderson, D.J., Xu, L., 2008. Addressing the influence of instrument surface heat exchange on the measurements of $\mathrm{CO} 2$ flux from open-path gas analyzers. Global Change Biology, 14(8): 1854-1876. DOI: $10.1111 / \mathrm{j} .1365-2486.2008 .01606 . x$

Burcher, C.L., Valett, H.M., Benfield, E.F., 2007. The land-cover cascade: Relationships coupling land and water. Ecology, 88(1): 228-242. DOI:10.1890/00129658(2007)88[228:tlcrcl]2.0.co;2 
Bibliography

Burn, D.H., 1994. Hydrologic effects of climatic change in west-central Canada. Journal of Hydrology, 160(1-4): 53-70. DOI:http://dx.doi.org/10.1016/00221694(94)90033-7

Burn, D.H., Hesch, N.M., 2007. Trends in evaporation for the Canadian Prairies. Journal of Hydrology, 336(1-2): 61-73. DOI:10.1016/j.jhydrol.2006.12.011

Caylor, K.K., Manfreda, S., Rodriguez-Iturbe, I., 2005. On the coupled geomorphological and ecohydrological organization of river basins. Advances in Water Resources, 28(1): 69-86. DOI:http://dx.doi.org/10.1016/j.advwatres.2004.08.013

Chen, S. et al., 2009. Energy balance and partition in Inner Mongolia steppe ecosystems with different land use types. Agricultural and Forest Meteorology, 149(11): 1800-1809. DOI:http://dx.doi.org/10.1016/j.agrformet.2009.06.009

Chen, X. et al., 2012. An Improvement of Roughness Height Parameterization of the Surface Energy Balance System (SEBS) over the Tibetan Plateau. Journal of Applied Meteorology and Climatology, 52(3): 607-622. DOI:10.1175/JAMC-D-12056.1

Chen, X., Su, Z., Ma, Y., Yang, K., Wen, J., Zhang, Y., 2013. An Improvement of Roughness Height Parameterization of the Surface Energy Balance System (SEBS) over the Tibetan Plateau. Journal of Applied Meteorology and Climatology, 52(3): 607-622. DOI:doi:10.1175/JAMC-D-12-056.1

Cheung, W.H., Senay, G.B., Singh, A., 2008. Trends and spatial distribution of annual and seasonal rainfall in Ethiopia. International Journal of Climatology, 28(13): 1723-1734. DOI: $10.1002 /$ joc. 1623

Coe, M.J., Cumming, D.H., Phillipson, J., 1976. Biomass and production of large African herbivores in relation to rainfall and primary production. Oecologia, 22(4): 341354.

Cognard-Plancq, A.-L., Marc, V., Didon-Lescot, J.-F., Normand, M., 2001. The role of forest cover on streamflow down sub-Mediterranean mountain watersheds: a modelling approach. Journal of Hydrology, 254(1-4): 229-243. DOI:http://dx.doi.org/10.1016/S0022-1694(01)00494-2

Cohn, T.A., Lins, H.F., 2005. Nature's style: Naturally trendy. Geophysical Research Letters, 32(23): L23402. DOI:10.1029/2005gl024476

Cook, B.R., Spray, C.J., 2012. Ecosystem services and integrated water resource management: Different paths to the same end? Journal of Environmental Management, 109: 93-100. DOI:http://dx.doi.org/10.1016/j.jenvman.2012.05.016

Costa, M.H., Botta, A., Cardille, J.A., 2003. Effects of large-scale changes in land cover on the discharge of the Tocantins River, Southeastern Amazonia. Journal of Hydrology, 283(1-4): 206-217.

Costa, M.H., Foley, J.A., 1997. Water balance of the Amazon Basin: Dependence on vegetation cover and canopy conductance. Journal of Geophysical Research D: Atmospheres, 102(20): 23973-23989.

DeFries, R., Eshleman, K.N., 2004. Land-use change and hydrologic processes: a major focus for the future. Hydrological Processes, 18(11): 2183-2186.

Dirmeyer, P.A., 1994. Vegetation Stress as a Feedback Mechanism in Midlatitude Drought. Journal of Climate, 7(10): 1463-1483. DOI:10.1175/15200442(1994)007<1463:vsaafm>2.0.co;2

Dolman, A.J., de Jeu, R.A.M., 2010. Evaporation in focus. Nature Geosci, 3(5): 296-296. 
Bibliography

Downes, B.J. et al., 2002. Monitoring ecological impacts: Concepts and practice in flowing water. Cambridge University Press, , New York, USA.

Dzikiti, S., Jovanovic, N.Z., Bugan, R., Israel, S., Le Maitre, D.C., 2014. Measurement and modelling of evapotranspiration in three fynbos vegetation types. Water SA, 40(2): 189-198. DOI:10.4314/wsa.v40i2.1

East, R., 1984. Rainfall, soil nutrient status and biomass of large African savanna mammals. African Journal of Ecology, 22(4): 245-270. DOI:10.1111/j.13652028.1984.tb00700.x

Ehsanzadeh, E., Adamowski, K., 2010. Trends in timing of low stream flows in Canada: impact of autocorrelation and long-term persistence. Hydrological Processes, 24(8): 970-980. DOI:10.1002/hyp.7533

Ehsanzadeh, E., Ouarda, T.B.M.J., Saley, H.M., 2011. A simultaneous analysis of gradual and abrupt changes in Canadian low streamflows. Hydrological Processes, 25(5): 727-739. DOI:10.1002/hyp.7861

Ehsanzadeh, E., van der Kamp, G., Spence, C., 2012. The impact of climatic variability and change in the hydroclimatology of Lake Winnipeg watershed. Hydrological Processes, 26(18): 2802-2813. DOI:10.1002/hyp.8327

Erdman, C., Emerson, J.W., 2008. A fast Bayesian change point analysis for the segmentation of microarray data. Bioinformatics, 24(19): 2143-2148. DOI: 10.1093/bioinformatics/btn404

Ershadi, A., McCabe, M.F., Evans, J.P., Mariethoz, G., Kavetski, D., 2013. A Bayesian analysis of sensible heat flux estimation: Quantifying uncertainty in meteorological forcing to improve model prediction. Water Resources Research, 49(5): 2343-2358. DOI: $10.1002 /$ wrcr.20231

Falge, E. et al., 2001. Gap filling strategies for long term energy flux data sets. Agricultural and Forest Meteorology, 107(1): 71-77. DOI:http://dx.doi.org/10.1016/S0168-1923(00)00235-5

Farah, H.O., Bastiaanssen, W.G.M., 2001. Impact of spatial variations of land surface parameters on regional evaporation: a case study with remote sensing data. Hydrological Processes, 15(9): 1585-1607. DOI:10.1002/hyp.159

Farah, H.O., Bastiaanssen, W.G.M., Feddes, R.A., 2004. Evaluation of the temporal variability of the evaporative fraction in a tropical watershed. International Journal of Applied Earth Observation and Geoinformation, 5(2): 129-140. DOI:http://dx.doi.org/10.1016/j.jag.2004.01.003

Fearnhead, P., 2006. Exact and efficient Bayesian inference for multiple changepoint problems. Statistics and Computing, 16(2): 203-213. DOI:10.1007/s11222-0068450-8

Finca, A., Palmer, A.R., Kakembo, V., 2015. Exploring ground-based methods for the validation of remotely sensed evapotranspiration. African Journal of Range \& Forage Science, 32(1): 41-50. DOI:10.2989/10220119.2014.908953

Foken, T., 2008. The energy balance closure problem: An overview. Ecological Applications, 18(6): 1351-1367. DOI:10.1890/06-0922.1

Foken, T. et al., 2005. Post-Field Data Quality Control. In: Lee, X., Massman, W., Law, B. (Eds.), Handbook of Micrometeorology. Atmospheric and Oceanographic Sciences Library. Springer Netherlands, pp. 181-208. DOI:10.1007/1-4020-22654_9

Foken, T. et al., 2010. Energy balance closure for the LITFASS-2003 experiment. Theor Appl Climatol, 101(1-2): 149-160. DOI:10.1007/s00704-009-0216-8 
Bibliography

Gaudet, J.J., 1977a. Natural drawdown on Lake Naivasha, Kenya, and the formation of papyrus swamps. Aquatic Botany, 3: 1-47.

Gaudet, J.J., 1977b. Uptake, Accumulation, and Loss of Nutrients by Papyrus in Tropical Swamps. Ecology 58, : 415-422.

Gedney, N. et al., 2006. Detection of a direct carbon dioxide effect in continental river runoff records. Nature, 439(7078): 835-838.

DOI:http://www.nature.com/nature/journal/v439/n7078/suppinfo/nature04504_ S1.html

Gentry, A.H., Lopez-Parodi, J., 1980. Deforestation and increased flooding of the upper amazon. Science, 210(4476): 1354-1356.

Georgiadis, N., Hack, M., Turpin, K., 2003. The influence of rainfall on zebra population dynamics: Implications for management. Journal of Applied Ecology, 40(GEOBASE): 125-136.

Gerten, D., 2013. A vital link: water and vegetation in the Anthropocene. Hydrol. Earth Syst. Sci., 17(10): 3841-3852. DOI:10.5194/hess-17-3841-2013

Gherardi, F. et al., 2011. A review of allodiversity in Lake Naivasha, Kenya: Developing conservation actions to protect East African lakes from the negative impacts of alien species. Biol. Conserv., 144(11): 2585-2596. DOI: $10.1016 /$ j. biocon.2011.07.020

Ghimire, C.P., Lubczynski, M.W., Bruijnzeel, L.A., Chavarro-Rincón, D., 2014. Transpiration and canopy conductance of two contrasting forest types in the Lesser Himalaya of Central Nepal. Agricultural and Forest Meteorology, 197(0): 76-90. DOI: http://dx.doi.org/10.1016/j.agrformet.2014.05.012

Giambelluca, T.W., Ziegler, A.D., Nullet, M.A., Truong, D.M., Tran, L.T., 2003. Transpiration in a small tropical forest patch. Agricultural and Forest Meteorology, 117(1-2): 1-22. DOI:http://dx.doi.org/10.1016/S0168-1923(03)00041-8

Gokmen, M. et al., 2013. Assessing groundwater storage changes using remote sensingbased evapotranspiration and precipitation at a large semiarid basin scale. Journal of Hydrometeorology, 14(6): 1733-1753. DOI:10.1175/JHM-D-12-0156.1

Gokmen, M. et al., 2012. Integration of soil moisture in SEBS for improving evapotranspiration estimation under water stress conditions. Remote Sensing of Environment, 121: 261-274. DOI:10.1016/j.rse.2012.02.003

Good, S.P. et al., 2014. $\delta 2 \mathrm{H}$ isotopic flux partitioning of evapotranspiration over a grass field following a water pulse and subsequent dry down. Water Resources Research, 50(2): 1410-1432. DOI:10.1002/2013WR014333

Good, S.P., Soderberg, K., Wang, L., Caylor, K.K., 2012. Uncertainties in the assessment of the isotopic composition of surface fluxes: A direct comparison of techniques using laser-based water vapor isotope analyzers. Journal of Geophysical Research: Atmospheres, 117(D15): n/a-n/a. DOI:10.1029/2011jd017168

Grace, J.B., Anderson, T.M., Olff, H., Scheiner, S.M., 2010. On the specification of structural equation models for ecological systems. Ecological Monographs, 80(1): 67-87. DOI: $10.1890 / 09-0464.1$

Granier, A., Bréda, N., 1996. Modelling canopy conductance and stand transpiration of an oak forest from sap flow measurements. Ann. For. Sci., 53(2-3): 537-546.

Guyot, A., Cohard, J.-M., Anquetin, S., Galle, S., 2012. Long-term observations of turbulent fluxes over heterogeneous vegetation using scintillometry and additional observations: A contribution to AMMA under Sudano-Sahelian climate. 
Agricultural and Forest Meteorology, 154-155(0): 84-98.

DOI:http://dx.doi.org/10.1016/j.agrformet.2011.10.008

Hamed, K.H., 2008. Trend detection in hydrologic data: The Mann-Kendall trend test under the scaling hypothesis. Journal of Hydrology, 349(3-4): 350-363. DOI: $10.1016 /$ j.jhydrol.2007.11.009

Hamed, K.H., Rao, A.R., 1998. A modified Mann-Kendall trend test for autocorrelated data. Journal of Hydrology, 204(1-4): 182-196. DOI:10.1016/s00221694(97)00125-x

Harper, D., Mavuti, K., 2004. Lake Naivasha, Kenya: Ecohydrology to guide the management of a tropical protected area. Ecohydrology and Hydrobiology, 4: 287-305.

Harper, D.M., Mavuti, K.M., Muchiri, S.M., 1990. Ecology and Management of Lake Naivasha, Kenya, in Relation to Climatic Change, Alien Species' Introductions, and Agricultural Development. Environmental Conservation, 17(04): 328-336. DOI:doi: $10.1017 /$ S037689290003277X

Harper, D.M., Morrison, H.J., Macharia, M.M., Upton, C., 2011. Lake Naivasha, Kenya: Ecology, society and future. Freshwater Reviews, 4: 98-114.

Hibbert, A.R., 1967. Forest treatment effects on water yield. In: W.E. Sopper, H.W.L.E. (Ed.), International Symposium on Forest Hydrology, Pergamon, Oxford, pp. 813.

Hobbins, M.T., Ramírez, J.A., Brown, T.C., 2004. Trends in pan evaporation and actual evapotranspiration across the conterminous U.S.: Paradoxical or complementary? Geophysical Research Letters, 31(13): L13503 1-5. DOI:10.1029/2004GL019846

Hoffman, M.T., Cramer, M.D., Gillson, L., Wallace, M., 2011. Pan evaporation and wind run decline in the Cape Floristic Region of South Africa (1974-2005): Implications for vegetation responses to climate change. Climatic Change, 109(3-4): 437-452. DOI: $10.1007 / \mathrm{s} 10584-011-0030-\mathrm{z}$

Houghton, R.A., Hackler, J.L., Lawrence, K.T., 1999. The US carbon budget: Contributions from land-use change. Science, 285(5427): 574-578. DOI: $10.1126 /$ science.285.5427.574

Hsieh, C.-I., Katul, G., Chi, T.-W., 2000. An approximate analytical model for footprint estimation of scalar fluxes in thermally stratified atmospheric flows. Advances in Water Resources, 23(7): 765-772. DOI:http://dx.doi.org/10.1016/S03091708(99)00042-1

Hughes, D.A., Smakhtin, V., 1996. Daily flow time series patching or extension: a spatial interpolation approach based on flow duration curves. Hydrological Sciences Journal, 41(6): 851-871. DOI:10.1080/02626669609491555

Huo, Z., Feng, S., Kang, S., Li, W., Chen, S., 2008. Effect of climate changes and waterrelated human activities on annual stream flows of the Shiyang river basin in arid north-west China. Hydrological Processes, 22(16): 3155-3167. DOI: $10.1002 /$ hyp. 6900

Hurst, H., 1951. Long Term Storage Capacity of Reservoirs. Transactions of the American Society of Civil Engineers(116): 770-799.

Huxman, T.E. et al., 2005. ECOHYDROLOGICAL IMPLICATIONS OF WOODY PLANT ENCROACHMENT. Ecology, 86(2): 308-319. DOI:10.1890/03-0583

Jackson, R.B., Jobbágy, E.G., Nosetto, M.D., 2009. Ecohydrology Bearings-Invited Commentary. Ecohydrology in a human-dominated landscape. Ecohydrology, 2(3): 383-389. DOI: $10.1002 /$ eco.81 
Bibliography

Jarvis, P.G., McNaughton, K.G., 1986. Stomatal Control of Transpiration: Scaling Up from Leaf to Region, Advances in Ecological Research, pp. 1-49.

Jaswal, A.K., Rao, G.S.P., De, U.S., 2008. Spatial and temporal characteristics of evaporation trends over India during 1971-2000. Mausam, 59(2): 149-158.

Jewitt, G., 2006. Integrating blue and green water flows for water resources management and planning. Physics and Chemistry of the Earth, Parts $A / B / C$, 31(15-16): 753-762. DOI:http://dx.doi.org/10.1016/j.pce.2006.08.033

Jiafu, M. et al., 2015. Disentangling climatic and anthropogenic controls on global terrestrial evapotranspiration trends. Environmental Research Letters, 10(9): 094008.

Jin, X., Guo, R., Xia, W., 2013. Distribution of actual evapotranspiration over Qaidam basin, an Arid area in China. Remote Sensing, 5(12): 6976-6996. DOI: $10.3390 /$ rs5126976

Jin, X., Schaepman, M.E., Clevers, J.G.P.W., Bob Su, Z., 2009. Impact and consequences of evapotranspiration changes on water resources availability in the arid Zhangye Basin, China. International Journal of Remote Sensing, 30(12): 3223-3238.

Jothityangkoon, C., Sivapalan, M., Farmer, D.L., 2001. Process controls of water balance variability in a large semi-arid catchment: Downward approach to hydrological model development. Journal of Hydrology, 254(1-4): 174-198. DOI: 10.1016/S0022-1694(01)00496-6

Jung, M. et al., 2010. Recent decline in the global land evapotranspiration trend due to limited moisture supply. Nature, 467(7318): 951-954.

DOI:http://www.nature.com/nature/journal/v467/n7318/abs/nature09396.html\# supplementary-information

Kalma, J., McVicar, T., McCabe, M., 2008. Estimating Land Surface Evaporation: A Review of Methods Using Remotely Sensed Surface Temperature Data. Surv Geophys, 29(4-5): 421-469. DOI:10.1007/s10712-008-9037-z

Karimi, P. et al., 2015. Spatial evapotranspiration, rainfall and land use data in water accounting \&ndash; Part 2: Reliability of water acounting results for policy decisions in the Awash Basin. Hydrol. Earth Syst. Sci., 19(1): 533-550. DOI: $10.5194 /$ hess-19-533-2015

Kelly, R.A. et al., 2013. Selecting among five common modelling approaches for integrated environmental assessment and management. Environmental Modelling \& Software, 47(0): 159-181. DOI:http://dx.doi.org/10.1016/j.envsoft.2013.05.005

Kendall, M.G., 1975. Rank Correlation Methods, Griffin: London, UK.

Khaliq, M.N., Ouarda, T.B.M.J., Gachon, P., 2009. Identification of temporal trends in annual and seasonal low flows occurring in Canadian rivers: The effect of shortand long-term persistence. Journal of Hydrology, 369(1-2): 183-197. DOI: $10.1016 / j$.jhydrol.2009.02.045

Kiersch, B., 2001. Land use impacts on water resources: A literature review. Land-water linkages in rural watersheds. Electronic Workshop (Discussion Paper 1), Food and Agriculture Organization of the United Nations, Rome.

Kim, C.P., Entekhabi, D., 1997. Examination of two methods for estimating regional evaporation using a coupled mixed layer and land surface model. Water Resources Research, 33(9): 2109-2116. 
Bibliography

Kiptala, J.K., Mohamed, Y., Mul, M.L., Van der Zaag, P., 2013. Mapping evapotranspiration trends using MODIS and SEBAL model in a data scarce and heterogeneous landscape in Eastern Africa. Water Resources Research, 49(12): 8495-8510. DOI: $10.1002 / 2013$ WR014240

Kitaka, N., Harper, D.M., Mavuti, K.M., 2002. Phosphorus inputs to Lake Naivasha, Kenya, from its catchment and the trophic state of the lake. Hydrobiologia. Kluwer Academic Publishers, pp. 73-80.

Kongo, M.V., Jewitt, G.W.P., Lorentz, S.A., 2011. Evaporative water use of different land uses in the upper-Thukela river basin assessed from satellite imagery.

Agricultural Water Management, 98(11): 1727-1739.

DOI:http://dx.doi.org/10.1016/j.agwat.2010.06.005

Koutsoyiannis, D., 2002. The Hurst phenomenon and fractional Gaussian noise made easy. Hydrological Sciences Journal, 47(4): 573-595.

DOI: $10.1080 / 02626660209492961$

Koutsoyiannis, D., 2003. Climate change, the Hurst phenomenon, and hydrological statistics. Hydrological Sciences Journal, 48(1): 3-24.

DOI: $10.1623 /$ hysj.48.1.3.43481

Koutsoyiannis, D., 2005. Hydrologic Persistence and The Hurst Phenomenon, Water Encyclopedia. John Wiley \& Sons, Inc. DOI:10.1002/047147844X.sw434

Koutsoyiannis, D., 2006. Nonstationarity versus scaling in hydrology. Journal of Hydrology, 324(1-4): 239-254. DOI:http://dx.doi.org/10.1016/j.jhydrol.2005.09.022

Koutsoyiannis, D., 2010. HESS Opinions "A random walk on water". Hydrology and Earth System Sciences, 14(3): 585-601.

Kozak, M., Kang, M.S., Stępień, M., 2007. Causal pathways when independent variables are co-related: New interpretational possibilities. Plant, Soil and Environment, 53(6): 267-275.

Kumar, S., Merwade, V., Kam, J., Thurner, K., 2009. Streamflow trends in Indiana: Effects of long term persistence, precipitation and subsurface drains. Journal of Hydrology, 374(1-2): 171-183.

DOI:http://dx.doi.org/10.1016/j.jhydrol.2009.06.012

Kundzewicz, Z.W., 2004. Editorial. Hydrological Sciences Journal, 49(1): 1 - 6.

Kundzewicz, Z.W., Robson, A.J., 2004. Change detection in hydrological records-a review of the methodology / Revue méthodologique de la détection de changements dans les chroniques hydrologiques. Hydrological Sciences Journal, 49(1): 1 - 19.

Kurc, S.A., Small, E.E., 2004. Dynamics of evapotranspiration in semiarid grassland and shrubland ecosystems during the summer monsoon season, central New Mexico. Water Resources Research, 40(9): W0930501-W0930515. DOI: $10.1029 / 2004 w r 003068$

Kustas, W.P., Daughtry, C.S.T., 1990. Estimation of the soil heat flux/net radiation ratio from spectral data. Agricultural and Forest Meteorology, 49(3): 205-223. DOI: $10.1016 / 0168-1923(90) 90033-3$

Kustas, W.P., Norman, J.M., 1997. A two-source approach for estimating turbulent fluxes using multiple angle thermal infrared observations. Water Resources Research, 33(6): 1495-1508. DOI: 10.1029/97WR00704

Lahmer, W., Pfützner, B., Becker, A., 2001. Assessment of land use and climate change impacts on the mesoscale. Physics and Chemistry of the Earth, Part B: Hydrology, 
Bibliography

Oceans and Atmosphere, 26(7-8): 565-575. DOI:10.1016/S1464-

1909(01)00051-X

Laio, F., Porporato, A., Fernandez-Illescas, C.P., Rodriguez-Iturbe, I., 2001a. Plants in water-controlled ecosystems: active role in hydrologic processes and response to water stress: IV. Discussion of real cases. Advances in Water Resources, 24(7): 745-762. DOI:http://dx.doi.org/10.1016/S0309-1708(01)00007-0

Laio, F., Porporato, A., Ridolfi, L., Rodriguez-Iturbe, I., 2001b. Plants in water-controlled ecosystems: active role in hydrologic processes and response to water stress: II. Probabilistic soil moisture dynamics. Advances in Water Resources, 24(7): 707723. DOI:http://dx.doi.org/10.1016/S0309-1708(01)00005-7

Lambin, E.F., Geist, H. (Eds.), 2006. Land-Use and Land-Cover Change. Global ChangeThe IGPB Series, XVIII. Springer, New York.

Leavesley, G.H., 1994. Modeling the effects of climate change on water resources - a review. Climatic Change, 28(1-2): 159-177. DOI:10.1007/BF01094105

Legendre, P., Legendre, L., 2012. Numerical Ecology, $3^{\text {rd }}$ Ed. Elsevier Science, Amsterdam.

Legesse, D., Vallet-Coulomb, C., Gasse, F., 2003. Hydrological response of a catchment to climate and land use changes in Tropical Africa: Case study south central Ethiopia. Journal of Hydrology, 275(1-2): 67-85. DOI:10.1016/S00221694(03)00019-2

Lei, H., Yang, D., 2010. Interannual and seasonal variability in evapotranspiration and energy partitioning over an irrigated cropland in the North China Plain.

Agricultural and Forest Meteorology, 150(4): 581-589.

DOI:10.1016/j.agrformet.2010.01.022

Lei, H., Yang, D., Yang, H., Yuan, Z., Lv, H., 2015. Simulated impacts of irrigation on evapotranspiration in a strongly exploited region: a case study of the Haihe River basin, China. Hydrological Processes, 29(12): 2704-2719.

DOI: $10.1002 /$ hyp. 10402

Leng, G., Huang, M., Tang, Q., Gao, H., Leung, L.R., 2013a. Modeling the Effects of Groundwater-Fed Irrigation on Terrestrial Hydrology over the Conterminous United States. Journal of Hydrometeorology, 15(3): 957-972. DOI:10.1175/JHMD-13-049.1

Leng, G. et al., 2013b. Modeling the effects of irrigation on land surface fluxes and states over the conterminous United States: Sensitivity to input data and model parameters. Journal of Geophysical Research: Atmospheres, 118(17): 97899803. DOI: $10.1002 /$ jgrd.50792

Li, Z., Liu, W.-Z., Zhang, X.-c., Zheng, F.-I., 2009. Impacts of land use change and climate variability on hydrology in an agricultural catchment on the Loess Plateau of China. Journal of Hydrology, 377(1-2): 35-42.

$\mathrm{Li}$, Z. et al., 2005. Energy balance closure at ChinaFLUX sites. SCIENCE CHINA Earth Sciences, 48(S1): 51-62. DOI:10.1360/05zd0005

Lins, H.F., Cohn, T.A., 2011. Stationarity: Wanted Dead or Alive?1. JAWRA Journal of the American Water Resources Association, 47(3): 475-480. DOI:10.1111/j.17521688.2011.00542.x

Lioubimtseva, E., Cole, R., Adams, J.M., Kapustin, G., 2005. Impacts of climate and land-cover changes in arid lands of Central Asia. Journal of Arid Environments, 62(GEOBASE): 285-308. 
Bibliography

Lleras, C., 2005. Path Analysis. In: Kempf-Leonard, K. (Ed.), Encyclopedia of Social Measurement. Elsevier, New York, pp. 25-30. DOI:http://dx.doi.org/10.1016/B012-369398-5/00483-7

Lo, M.-H., Famiglietti, J.S., 2013. Irrigation in California's Central Valley strengthens the southwestern U.S. water cycle. Geophysical Research Letters, 40(2): 301-306. DOI: $10.1002 / \mathrm{grl} .50108$

Loarie, S.R., Lobell, D.B., Asner, G.P., Field, C.B., 2011. Land-Cover and surface water change drive large albedo increases in south america. Earth Interactions, 15(7): 1-16. DOI: $10.1175 / 2010 \mathrm{EI} 342.1$

Loescher, H.W., Gholz, H.L., Jacobs, J.M., Oberbauer, S.F., 2005. Energy dynamics and modeled evapotranspiration from a wet tropical forest in Costa Rica. Journal of Hydrology, 315(1-4): 274-294. DOI:http://dx.doi.org/10.1016/j.jhydrol.2005.03.040

Lørup, J.K., Refsgaard, J.C., Mazvimavi, D., 1998. Assessing the effect of land use change on catchment runoff by combined use of statistical tests and hydrological modelling: Case studies from Zimbabwe. Journal of Hydrology, 205(3-4): 147163.

Loschi, R.H., Cruz, F.R.B., 2002. An analysis of the influence of some prior specifications in the identification of change points via product partition model. Computational Statistics \& Data Analysis, 39(4): 477-501. DOI:http://dx.doi.org/10.1016/S0167-9473(01)00095-0

Loucks, D.P., Van Beek, E., 2005. Water Resources Systems Planning and Management. In: Organization, U.N.E.S.a.C. (Ed.).

Lu, N., Chen, S., Wilske, B., Sun, G., Chen, J., 2011. Evapotranspiration and soil water relationships in a range of disturbed and undisturbed ecosystems in the semi-arid Inner Mongolia, China. Journal of Plant Ecology, 4(1-2): 49-60. DOI: $10.1093 / \mathrm{jpe} / \mathrm{rtq035}$

Luis, V.C., Jiménez, M.S., Morales, D., Kucera, J., Wieser, G., 2005. Canopy transpiration of a Canary Islands pine forest. Agricultural and Forest Meteorology, 135(1-4): 117-123. DOI:http://dx.doi.org/10.1016/j.agrformet.2005.11.009

Maloney, K.O., Weller, D.E., 2011. Anthropogenic disturbance and streams: land use and land-use change affect stream ecosystems via multiple pathways. Freshwater Biology, 56(3): 611-626. DOI:10.1111/j.1365-2427.2010.02522.x

Mann, H.B., 1945. Nonparametric Tests Against Trend. Econometrica, 13(3): 245-259.

Markovic, D., Koch, M., 2013. Long-term variations and temporal scaling of hydroclimatic time series with focus on the German part of the Elbe River Basin. Hydrological Processes: in press.

Marshall, M., Funk, C., Michaelsen, J., 2012. Examining evapotranspiration trends in Africa. Clim Dyn, 38(9-10): 1849-1865. DOI:10.1007/s00382-012-1299-y

Mauder, M., Foken, T., 2006. Impact of post-field data processing on eddy covariance flux estimates and energy balance closure. Meteorologische Zeitschrift, 15(6): 597-609. DOI: $10.1127 / 0941-2948 / 2006 / 0167$

Mauder, M. et al., 2007. The energy balance experiment EBEX-2000. Part II: Intercomparison of eddy-covariance sensors and post-field data processing methods. Boundary-Layer Meteorol, 123(1): 29-54. DOI:10.1007/s10546-0069139-4

McDonnell, R.A., 2008. Challenges for Integrated Water Resources Management: How Do We Provide the Knowledge to Support Truly Integrated Thinking? International 
Journal of Water Resources Development, 24(1): 131-143.

DOI: $10.1080 / 07900620701723240$

McLeod, A.I., Hipel, K.W., 1978. Preservation of the rescaled adjusted range: 1. A reassessment of the Hurst Phenomenon. Water Resour. Res., 14(3): 491-508. DOI: 10.1029/WR014i003p00491

McNaughton, K.G., Jarvis, P.G., 1983. CHAPTER 1 - Predicting effects of vegetation changes on transpiration and evaporation In: Kozlowski, T.T. (Ed.), Additional Woody Crop Plants. Academic Press, pp. 1-47. DOI:http://dx.doi.org/10.1016/B978-0-12-424157-2.50007-0

McNaughton, K.G., Spriggs, T.W., 1986. A mixed-layer model for regional evaporation. Boundary-Layer Meteorol, 34(3): 243-262. DOI:10.1007/bf00122381

McNaughton, K.G., Spriggs, T.W., 1989. An evaluation of the Priestley and Taylor equation and the complementary relationship using results from a mixed-layer model of the convective boundary layer IAHS Publication 177.

McNulty, S.G., Vose, J.M., Swank, W.T., Aber, J.D., Federer, C.A., 1994. Regional-scale forest ecosystem modeling: database development, model predictions and validation using a geographic information system. Climate Research, 4(3): 223231.

Meyers, T.P., 2001. A comparison of summertime water and $\mathrm{CO} 2$ fluxes over rangeland for well watered and drought conditions. Agricultural and Forest Meteorology, 106(3): 205-214. DOI:http://dx.doi.org/10.1016/S0168-1923(00)00213-6

Miralles, D.G. et al., 2011. Global land-surface evaporation estimated from satellitebased observations. Hydrology and Earth System Sciences, 15(2): 453-469. DOI: $10.5194 /$ hess-15-453-2011

Moncrieff, J., 2004. Surface Turbulent Fluxes. In: Kabat, P. et al. (Eds.), Vegetation, Water, Humans and the Climate. Global Change - The IGBP Series. Springer Berlin Heidelberg, pp. 173-182. DOI:10.1007/978-3-642-18948-7_15

Montanari, A., Rosso, R., Taqqu, M.S., 1997. Fractionally differenced ARIMA models applied to hydrologic time series: Identification, estimation, and simulation. Water Resources Research, 33(5): 1035-1044. DOI:10.1029/97wr00043

Monteith, J.L., 1965. Evaporation and environment. Symposia of the Society for Experimental Biology, 19: 205-34.

Monteith, J.L., 1973. Principles of Environmental Physics, Principles of Environmental Physics (2nd. Edition). Elsevier, Chapman \& Hall, New York, USA., pp. 241.

Monteith, J.L., Unsworth, M.H., 1990. Principles of Environmental Physics, Principles of Environmental Physics (2nd. Edition), Chapman \& Hall, New York, USA.

Moors, E.J., 2012. Water Use of Forests in the Netherlands. PhD Thesis, VU University Amsterdam.

Morrison, E., Harper, D., 2009. Ecohydrological principles to underpin the restoration of Cyperus papyrus at Lake Naivasha, Kenya. Ecohydrology and Hydrobiology, 9(GEOBASE): 83-97.

Mueller, B. et al., 2011. Evaluation of global observations-based evapotranspiration datasets and IPCC AR4 simulations. Geophysical Research Letters, 38(6): n/an/a. DOI:10.1029/2010GL046230

Mundia, C.N., Murayama, Y., 2009. Analysis of land use/cover changes and animal population dynamics in a wildlife sanctuary in East Africa. Remote Sensing, 1(4): 952-970. 
Bibliography

Muthoni, F.K., Groen, T.A., Skidmore, A.K., van Oel, P., 2014. Ungulate herbivory overrides rainfall impacts on herbaceous regrowth and residual biomass in a key resource area. Journal of Arid Environments, 100-101(0): 9-17. DOI:http://dx.doi.org/10.1016/j.jaridenv.2013.09.007

Nakai, T., van der Molen, M.K., Gash, J.H.C., Kodama, Y., 2006. Correction of sonic anemometer angle of attack errors. Agricultural and Forest Meteorology, 136(12): 19-30. DOI:http://dx.doi.org/10.1016/j.agrformet.2006.01.006

Nakamura, M., Tsujimura, S., Kakizawa, R., 2001. Joint Evaluation for Water Supply and Sewerage Projects in Nakuru, Japan International Cooperation Agency.

Nieveen, J.P., El-Kilani, R.M.M., Jacobs, A.F.G., 2001. Behaviour of the static pressure around a tussock grassland-forest interface. Agricultural and Forest Meteorology, 106(4): 253-259. DOI:http://dx.doi.org/10.1016/S0168-1923(00)00234-3

Norman, J.M., Kustas, W.P., Humes, K.S., 1995. A two source approach for estimating soil and vegetation energy fluxes in observations of directional radiometric surface temperature. Agricultural and Forest Meteorology, 77(3-4): 263-293. DOI:http://dx.doi.org/10.1016/0168-1923(95)02265-Y

Norman, J.M., Kustas, W.P., Prueger, J.H., Diak, G.R., 2000. A two-Surface flux estimation using radiometric temperature: A dual-temperature-difference method to minimize measurement errors. Water Resources Research, 36(8): 2263-2274. DOI: $10.1029 / 2000$ WR900033

Nyeko-Ogiramoi, P., Willems, P., Ngirane-Katashaya, G., 2013. Trend and variability in observed hydrometeorological extremes in the Lake Victoria basin. Journal of Hydrology, 489(0): 56-73. DOI:http://dx.doi.org/10.1016/j.jhydrol.2013.02.039

Odongo, V.O., Mulatu, D.W., Muthoni, F.K., van Oel, P.R., Meins, F.M., van der Tol, C., Skidmore, A.K., Groen, T.A., Becht, R., Onyando, J.O., van der Veen, A., 2014. Coupling socio-economic factors and eco-hydrological processes using a cascademodeling approach. Journal of Hydrology, 518, Part A(0): 49-59. DOI:http://dx.doi.org/10.1016/j.jhydrol.2014.01.012

Odongo, V.O., Onyando, J.O., Mutua, B.M., van Oel, P.R., Becht, R., 2013. Sensitivity analysis and calibration of the Modified Universal Soil Loss Equation (MUSLE) for the upper Malewa Catchment, Kenya. International Journal of Sediment Research, 28(3): 368-383. DOI:http://dx.doi.org/10.1016/S1001-6279(13)60047-5

Odongo, V.O., van der Tol, C., Becht, R., Hoedjes, J.C.B., Ghimire, C.P., Su, Z., 2016. Energy partitioning and its controls over a heterogeneous semi-arid shrubland ecosystem in the Lake Naivasha Basin, Kenya. Ecohydrology: n/a-n/a. DOI: $10.1002 /$ eco.1732

Odongo, V.O., van der Tol, C., van Oel, P.R., Meins, F.M., Becht, R., Onyando, J., Su, Z., 2015. Characterisation of hydroclimatological trends and variability in the Lake Naivasha basin, Kenya. Hydrological Processes, 29(15): 3276-3293. DOI: $10.1002 /$ hyp. 10443

Ogutu, J.O., Owen-Smith, N., 2003. ENSO, rainfall and temperature influences on extreme population declines among African savanna ungulates. Ecology Letters, 6(GEOBASE): 412-419.

Ogutu, J.O., Owen-Smith, N., Piepho, H.-P., Kuloba, B., Edebe, J., 2012. Dynamics of ungulates in relation to climatic and land use changes in an insularized African savanna ecosystem. Biodiversity and Conservation, 21(4): 1033-1053. DOI: $10.1007 / \mathrm{s} 10531-012-0239-9$ 
Bibliography

Olaka, L.A., Odada, E.O., Trauth, M.H., Olago, D.O., 2010. The sensitivity of East African rift lakes to climate fluctuations. Journal of Paleolimnology, 44(2): 629-644. DOI: $10.1007 / \mathrm{s} 10933-010-9442-4$

Ondimu, S., Murase, H., 2007. Reservoir Level Forecasting using Neural Networks: Lake Naivasha. Biosystems Engineering, 96(1): 135-138.

Otiang'a-Owiti, G.E., Oswe, I.A., 2007. Human impact on lake ecosystems: the case of Lake Naivasha, Kenya. African Journal of Aquatic Science, 32(1): 79 - 88.

Pardo, N. et al., 2014. SEBS validation in a Spanish rotating crop. Agricultural and Forest Meteorology, 195-196: 132-142. DOI:10.1016/j.agrformet.2014.05.007

Potter, N.J., Chiew, F.H.S., Frost, A.J., 2010. An assessment of the severity of recent reductions in rainfall and runoff in the Murray-Darling Basin. Journal of Hydrology, 381(1-2): 52-64. DOI:http://dx.doi.org/10.1016/j.jhydrol.2009.11.025

Priestley, C.H.B., Taylor, R.J., 1972. On the Assessment of Surface Heat Flux and Evaporation Using Large-Scale Parameters. Monthly Weather Review, 100(2): 8192. DOI: $10.1175 / 1520-0493(1972) 100<0081$ : otaosh $>2.3 . c 0 ; 2$

Ramier, D. et al., 2009. Towards an understanding of coupled physical and biological processes in the cultivated Sahel - 1. Energy and water. Journal of Hydrology, 375(1-2): 204-216. DOI:http://dx.doi.org/10.1016/j.jhydrol.2008.12.002

Ramsar, 1996. The Annotated Ramsar List: Kenya.

Redelsperger, J.-L. et al., 2006. African Monsoon Multidisciplinary Analysis: An International Research Project and Field Campaign. Bulletin of the American Meteorological Society, 87(12): 1739-1746. DOI:10.1175/bams-87-12-1739

Reiners, W.A., Driese, K.L., 2001. The Propagation of Ecological Influences through Heterogeneous Environmental Space. BioScience, 51(11): 939-950. DOI:10.1641/0006-3568(2001)051[0939:tpoeit]2.0.co;2

Renner, M., 2013. Land use effects and climate impacts on evapotranspiration and catchment water balance. PhD Thesis, Technischen Universität Dresden, Dresden

Roderick, M.L., Farquhar, G.D., 2004. Changes in Australian pan evaporation from 1970 to 2002. International Journal of Climatology, 24(9): 1077-1090. DOI: $10.1002 /$ joc. 1061

Roderick, M.L., Hobbins, M.T., Farquhar, G.D., 2009. Pan evaporation trends and the terrestrial water balance. II. Energy balance and interpretation. Geography Compass, 3(2): 761-780. DOI:10.1111/j.1749-8198.2008.00214.x

Roerink, G.J., Su, Z., Menenti, M., 2000. S-SEBI: A simple remote sensing algorithm to estimate the surface energy balance. Physics and Chemistry of the Earth, Part B: Hydrology, Oceans and Atmosphere, 25(2): 147-157. DOI:http://dx.doi.org/10.1016/S1464-1909(99)00128-8

Ryu, Y., Baldocchi, D.D., Ma, S., Hehn, T., 2008. Interannual variability of evapotranspiration and energy exchange over an annual grassland in California. Journal of Geophysical Research: Atmospheres, 113(D9): D09104. DOI: $10.1029 / 2007 j d 009263$

Sahin, V., Hall, M.J., 1996. The effects of afforestation and deforestation on water yields. Journal of Hydrology, 178(1-4): 293-309. DOI:http://dx.doi.org/10.1016/00221694(95)02825-0

Saigusa, N., Oikawa, T., Liu, S., 1998. Seasonal variations of the exchange of CO2 and $\mathrm{H} 2 \mathrm{O}$ between a grassland and the atmosphere: An experimental study. 
Bibliography

Agricultural and Forest Meteorology, 89(2): 131-139. DOI:10.1016/s01681923(97)00060-9

Samanta, S., Mackay, D.S., Clayton, M.K., Kruger, E.L., Ewers, B.E., 2007. Bayesian analysis for uncertainty estimation of a canopy transpiration model. Water Resources Research, 43(4): n/a-n/a. DOI:10.1029/2006WR005028

Schneider, N., Eugster, W., 2005. Historical land use changes and mesoscale summer climate on the Swiss Plateau. Journal of Geophysical Research-Atmospheres, 110(D19). DOI:10.1029/2004jd005215

Schüttemeyer, D., Moene, A.F., Holtslag, A.A.M., de. Bruin, H.A.R., de. Giesen, N.v., 2006. Surface Fluxes and Characteristics of Drying Semi-Arid Terrain in West Africa. Boundary-Layer Meteorol, 118(3): 583-612. DOI:10.1007/s10546-0059028-2

SCS, 1985. National Engineering Handbook, Section 4: Hydrology, Soil Conservation Service. USDA (U.S. Department of Agriculture), Washington, D.C.

Seleshi, Y., Zanke, U., 2004. Recent changes in rainfall and rainy days in Ethiopia. International Journal of Climatology, 24(8): 973-983. DOI:10.1002/joc.1052

Sellers, P.J. et al., 1997. Modeling the exchanges of energy, water, and carbon between continents and the atmosphere. Science, 275(5299): 502-509. DOI: $10.1126 /$ science.275.5299.502

Sen, P.K., 1968. Estimates of the Regression Coefficient Based on Kendall's Tau. Journal of the American Statistical Association, 63(324): 1379-1389.

Seneviratne, S.I. et al., 2010. Investigating soil moisture-climate interactions in a changing climate: A review. Earth-Science Reviews, 99(3-4): 125-161. DOI:http://dx.doi.org/10.1016/j.earscirev.2010.02.004

Seth, A., Giorgi, F., 1996. Three-dimensional model study of organized mesoscale circulations induced by vegetation. Journal of Geophysical Research: Atmospheres, 101(D3): 7371-7391.

Shang, H., Yan, J., Gebremichael, M., Ayalew, S.M., 2011. Trend analysis of extreme precipitation in the Northwestern Highlands of Ethiopia with a case study of Debre Markos. Hydrology and Earth System Sciences, 15(6): 1937-1944. DOI: $10.5194 /$ hess-15-1937-2011

Shipley, B., 2000. Cause and correlation in biology. A user's guide to path analysis, structural equations, and causal inference. Cambridge University Press, Cambridge, UK.

Siriwardena, L., Finlayson, B.L., McMahon, T.A., 2006. The impact of land use change on catchment hydrology in large catchments: The Comet River, Central Queensland, Australia. Journal of Hydrology, 326(1-4): 199-214.

Sivapalan, M., Kalma, J.D., 1995. Scale problems in hydrology: Contributions of the robertson workshop. Hydrological Processes, 9(3-4): 243-250. DOI: $10.1002 /$ hyp.3360090304

Stednick, J.D., 1996. Monitoring the effects of timber harvest on annual water yield. Journal of Hydrology, 176(1-4): 79-95.

Steduto, P., Hsiao, T.C., 1998. Maize canopies under two soil water regimes III. Variation in coupling with the atmosphere and the role of leaf area index. Agricultural and Forest Meteorology, 89(3-4): 201-213. DOI:10.1016/s01681923(97)00083-x

Sterling, S.M., Ducharne, A., Polcher, J., 2013. The impact of global land-cover change on the terrestrial water cycle. Nature Clim. Change, 3(4): 385-390. 
Bibliography

DOI:http://www.nature.com/nclimate/journal/v3/n4/abs/nclimate1690.html\#sup plementary-information

Stoof-Leichsenring, K., Junginger, A., Olaka, L., Tiedemann, R., Trauth, M., 2011. Environmental variability in Lake Naivasha, Kenya, over the last two centuries. Journal of Paleolimnology, 45(3): 353-367. DOI:10.1007/s10933-011-9502-4

Stoy, P.C. et al., 2013. A data-driven analysis of energy balance closure across FLUXNET research sites: The role of landscape scale heterogeneity. Agricultural and Forest Meteorology, 171-172(0): 137-152.

DOI:http://dx.doi.org/10.1016/j.agrformet.2012.11.004

Strayer, D.L. et al., 2003. Effects of Land Cover on Stream Ecosystems: Roles of Empirical Models and Scaling Issues. Ecosystems, 6(5): 407-423. DOI: $10.1007 / \mathrm{pl} 00021506$

Su, Z., 2002. The Surface Energy Balance System (SEBS) for estimation of turbulent heat fluxes. Hydrology and Earth System Sciences, 6(1): 85-99.

Sutcliffe, J.V., Petersen, G., 2007. Lake Victoria: derivation of a corrected natural water level series / Lac Victoria: dérivation d'une série naturelle corrigée des niveaux d'eau. Hydrological Sciences Journal, 52(6): 1316-1321. DOI: $10.1623 /$ hysj.52.6.1316

Suyker, A.E., Verma, S.B., 2008. Interannual water vapor and energy exchange in an irrigated maize-based agroecosystem. Agricultural and Forest Meteorology, 148(3): 417-427. DOI:http://dx.doi.org/10.1016/j.agrformet.2007.10.005

Tanaka, K. et al., 2003. Transpiration peak over a hill evergreen forest in northern Thailand in the late dry season: Assessing the seasonal changes in evapotranspiration using a multilayer model. Journal of Geophysical Research: Atmospheres, 108(D17): n/a-n/a. DOI:10.1029/2002JD003028

Tanaka, N. et al., 2008. A review of evapotranspiration estimates from tropical forests in Thailand and adjacent regions. Agricultural and Forest Meteorology, 148(5): 807819. DOI:http://dx.doi.org/10.1016/j.agrformet.2008.01.011

Tarafdar, S., Harper, D., 2008. Anti-persistence in levels of Lake Naivasha: Assessing effect of human intervention through time-series analysis. Physica A: Statistical Mechanics and its Applications, 387(1): 296-302. DOI:http://dx.doi.org/10.1016/j.physa.2007.08.050

Tarras-Wahlberg, H., Everard, M., Harper, D.M., 2002. Geochemical and physical characteristics of river and lake sediments at Naivasha, Kenya. Hydrobiologia, 488: 27-41.

Thomas, I.L., Ching, N.P., Benning, V.M., D'Aguanno, J.A., 1987. Review Article A review of multi-channel indices of class separability. International Journal of Remote Sensing, 8(3): 331-350. DOI:10.1080/01431168708948645

Timmermans, J., Su, Z., Van Der Tol, C., Verhoef, A., Verhoef, W., 2013. Quantifying the uncertainty in estimates of surface-atmosphere fluxes through joint evaluation of the SEBS and SCOPE models. Hydrology and Earth System Sciences, 17(4): 1561-1573. DOI: $10.5194 /$ hess-17-1561-2013

Timmermans, W.J., Kustas, W.P., Anderson, M.C., French, A.N., 2007. An intercomparison of the Surface Energy Balance Algorithm for Land (SEBAL) and the Two-Source Energy Balance (TSEB) modeling schemes. Remote Sensing of Environment, 108(4): 369-384. DOI:http://dx.doi.org/10.1016/j.rse.2006.11.028

Tollan, A., 2002. Land-use change and floods: What do we need most, research or management? Water Science and Technology. IWA Publishing, pp. 183-190. 
Bibliography

Townsend, C.R., Dolédec, S., Norris, R., Peacock, K., Arbuckle, C., 2003. The influence of scale and geography on relationships between stream community composition and landscape variables: description and prediction. Freshwater Biology, 48(5): 768-785. DOI: $10.1046 / j .1365-2427.2003 .01043 . x$

Trauth, M.H. et al., 2010. Human evolution in a variable environment: the amplifier lakes of Eastern Africa. Quaternary Science Reviews, 29(23-24): 2981-2988. DOI: $10.1016 / j$.quascirev.2010.07.007

Trenberth, K.E., Fasullo, J.T., Kiehl, J., 2009. Earth's Global Energy Budget. Bulletin of the American Meteorological Society, 90(3): 311-323.

DOI: $10.1175 / 2008$ BAMS2634.1

Van Bavel, C.H.M., 1967. Changes in canopy resistance to water loss from alfalfa induced by soil water depletion. Agricultural Meteorology, 4(3): 165-176.

van der Kwast, J. et al., 2009. Evaluation of the Surface Energy Balance System (SEBS) applied to ASTER imagery with flux-measurements at the SPARC 2004 site (Barrax, Spain). Hydrol. Earth Syst. Sci., 13(7): 1337-1347. DOI:10.5194/hess13-1337-2009

van der Tol, C., 2012. Validation of remote sensing of bare soil ground heat flux. Remote Sensing of Environment, 121: 275-286.

van der Tol, C. et al., 2015. An analysis of turbulent heat fluxes and the energy balance during the REFLEX campaign. Acta Geophysica, 63. DOI:10.1515/acgeo-20150061

van Dijk, A.I.J.M., Hairsine, P.B., Arancibia, J.P., Dowling, T.I., 2007. Reforestation, water availability and stream salinity: A multi-scale analysis in the Murray-Darling Basin, Australia. Forest Ecology and Management, 251(1-2): 94-109. DOI:http://dx.doi.org/10.1016/j.foreco.2007.06.012

van Dijk, A.I.J.M., Peña-Arancibia, J.L., Bruijnzeel, L.A., 2012. Land cover and water yield: inference problems when comparing catchments with mixed land cover. Hydrol. Earth Syst. Sci., 16(9): 3461-3473. DOI:10.5194/hess-16-3461-2012

van Oel, P. et al., 2013. The Effects of Groundwater and Surface Water Use on Total Water Availability and Implications for Water Management: The Case of Lake Naivasha, Kenya. Water Resour Manage, 27(9): 3477-3492. DOI: $10.1007 / \mathrm{s} 11269-013-0359-3$

van Oel, P.R. et al., 2014. Supporting IWRM through spatial integrated assessment in the Lake Naivasha basin, Kenya. International Journal of Water Resources Development, 30(3): 605-618. DOI:10.1080/07900627.2014.920248

Veenendaal, E.M., Kolle, O., Lloyd, J., 2004. Seasonal variation in energy fluxes and carbon dioxide exchange for a broad-leaved semi-arid savanna (Mopane woodland) in Southern Africa. Global Change Biology, 10(3): 318-328. DOI: $10.1111 / \mathrm{j} .1365-2486.2003 .00699 . x$

Verhoef, W., Menenti, M., Azzali, S., 1996. Cover A colour composite of NOAA-AVHRRNDVI based on time series analysis (1981-1992). International Journal of Remote Sensing, 17(2): 231-235. DOI:10.1080/01431169608949001

Verschuren, D., Laird, K.R., Cumming, B.F., 2000. Rainfall and drought in equatorial east Africa during the past 1,100 years. Nature, 403(6768): 410-414. DOI: $10.1038 / 35000179$

Vincent, C.E., Davies, T.D., Beresford, A.K.C., 1979. Recent changes in the level of Lake Naivasha, Kenya, as an indicator of equatorial westerlies over East Africa. Climatic Change, 2(2): 175-189. DOI:10.1007/bf00133223 
Bibliography

von Storch, H., Zwiers, F.W., 1999. Statistical analysis in climate research International Journal of Climatology, 20. John Wiley \& Sons, Ltd., Cambridge 484 pp. DOI:10.1002/1097-0088(20000615)20:7<811::aid-joc510>3.0.co;2-p

Vourlitis, G.L. et al., 2008. Energy balance and canopy conductance of a tropical semideciduous forest of the southern Amazon Basin. Water Resources Research, 44(3): n/a-n/a. DOI:10.1029/2006wr005526

Wagesho, N., Goel, N.K., Jain, M.K., 2013. Temporal and spatial variability of annual and seasonal rainfall over Ethiopia. Hydrological Sciences Journal, 58(2): 354-373. DOI: $10.1080 / 02626667.2012 .754543$

Wagle, P., Kakani, V.G., 2014. Growing season variability in evapotranspiration, ecosystem water use efficiency, and energy partitioning in switchgrass. Ecohydrology, 7(1): 64-72. DOI:10.1002/eco.1322

Wallace, J.S., Wright, I.R., Stewart, J.B., Holwill, C.J., 1991. The Sahelian Energy Balance Experiment (SEBEX): Ground based measurements and their potential for spatial extrapolation using satellite data. Advances in Space Research, 11(3): 131-141. DOI:http://dx.doi.org/10.1016/0273-1177(91)90413-E

Wang, S., Zhang, Z., Sun, G., McNulty, S.G., Zhang, M., 2009. Detecting water yield variability due to the small proportional land use and land cover changes in a watershed on the Loess Plateau, China. Hydrological Processes, 23(21): 30833092.

Webb, E.K., Pearman, G.I., Leuning, R., 1980. Correction of flux measurements for density effects due to heat and water vapour transfer. Quarterly Journal of the Royal Meteorological Society, 106(447): 85-100. DOI:10.1002/qj.49710644707

Western, D., Groom, R., Worden, J., 2009. The impact of subdivision and sedentarization of pastoral lands on wildlife in an African savanna ecosystem. Biol. Conserv., 142(11): 2538-2546.

Wever, L.A., Flanagan, L.B., Carlson, P.J., 2002. Seasonal and interannual variation in evapotranspiration, energy balance and surface conductance in a northern temperate grassland. Agricultural and Forest Meteorology, 112(1): 31-49. DOI:http://dx.doi.org/10.1016/S0168-1923(02)00041-2

Wilk, J., Andersson, L., Plermkamon, V., 2001. Hydrological impacts of forest conversion to agriculture in a large river basin in northeast Thailand. Hydrological Processes, 15(14): 2729-2748. DOI: 10.1002/hyp.229

Williams, A.P., Funk, C., 2011. A westward extension of the warm pool leads to a westward extension of the Walker circulation, drying eastern Africa. Clim Dyn, 37(11-12): 2417-2435. DOI:10.1007/s00382-010-0984-y

Wilson, K. et al., 2002. Energy balance closure at FLUXNET sites. Agricultural and Forest Meteorology, 113(1-4): 223-243. DOI:http://dx.doi.org/10.1016/S01681923(02)00109-0

Wilson, K.B., Baldocchi, D.D., 2000. Seasonal and interannual variability of energy fluxes over a broadleaved temperate deciduous forest in North America. Agricultural and Forest Meteorology, 100(1): 1-18. DOI:http://dx.doi.org/10.1016/S01681923(99)00088-X

Wootton, J.T., 1994. Predicting Direct and Indirect Effects: An Integrated Approach Using Experiments and Path Analysis. Ecology, 75(1): 151-165. DOI: $10.2307 / 1939391$

Wu, J. et al., 2007. Energy budget above a temperate mixed forest in northeastern China. Hydrological Processes, 21(18): 2425-2434. DOI:10.1002/hyp.6395 
Bibliography

Xiong, L., Guo, S., 2004. Trend test and change-point detection for the annual discharge series of the Yangtze River at the Yichang hydrological station / Test de tendance et détection de rupture appliqués aux séries de débit annuel du fleuve Yangtze à la station hydrologique de Yichang. Hydrological Sciences Journal, 49(1): 99-112. DOI: 10.1623/hysj.49.1.99.53998

Yang, D., Sun, F., Liu, Z., Cong, Z., Lei, Z., 2006. Interpreting the complementary relationship in non-humid environments based on the Budyko and Penman hypotheses. Geophysical Research Letters, 33(18). DOI:10.1029/2006gl027657

Yao, Y.-C., 1984. Estimation of a Noisy Discrete-Time Step Function: Bayes and Empirical Bayes Approaches. The Annals of Statistics, 12(4): 1434-1447. DOI: $10.2307 / 2241012$

Yin, Y., Wu, S., Zhao, D., 2013. Past and future spatiotemporal changes in evapotranspiration and effective moisture on the Tibetan Plateau. Journal of Geophysical Research: Atmospheres, 118(19): 10,850-10,860. DOI: $10.1002 /$ jgrd. 50858

Zeng, N., Neelin, J.D., 2000. The role of vegetation-climate interaction and interannual variability in shaping the African Savanna. Journal of Climate, 13(15): 26652670.

Zetterqvist, L., 1991. Statistical estimation and Interpretation of trends in water quality time-series Water Resources Research, 27(7): 1637-1648. DOI: $10.1029 / 91 w r 00478$

Zhang, L., Dawes, W.R., Walker, G.R., 1999. Predicting the Effect of Vegetation Changes on Catchment Average Water Balance, Cooperative Research Centre for Catchment Hydrology.

Zhang, L., Dawes, W.R., Walker, G.R., 2001. Response of mean annual evapotranspiration to vegetation changes at catchment scale. Water Resources Research, 37(3): 701-708. DOI:10.1029/2000wr900325

Zhang, Y., Liu, C., Tang, Y., Yang, Y., 2007. Trends in pan evaporation and reference and actual evapotranspiration across the Tibetan Plateau. Journal of Geophysical Research Atmospheres, 112(12). DOI:10.1029/2006JD008161

Zhang, Y.K., Schilling, K.E., 2006. Increasing streamflow and baseflow in Mississippi River since the 1940's: Effect of land use change. Journal of Hydrology, 324(14): 412-422. DOI:http://dx.doi.org/10.1016/j.jhydrol.2005.09.033 


\section{Summary}

Recent theoretical advances recognize the importance of stochastic processes and probabilistic representations that couple vegetation, climate and hydrology (Jackson et al., 2009). Vegetation exerts strong controls over key hydrologic variables and therefore changes in land cover affect the water balance, quantity and quality of water resources. As a consequence, growing human population exacerbates changes in land cover and land use leading to increased pressure on water resources and hydrologic regulation.

It is important to understand the hydrological processes occurring at a catchment scale and the controlling factors within the catchment. Understanding the hydrological response to changes in land use and land cover as well as climate variability give valuable insights on prediction of water yields and quality across landscapes and forecasting consequences of land use conversations on stream flows and lake levels. The main objective of this study was to quantify the impacts of climate and land use on the hydrological response of Lake Naivasha Basin. The study focused on identifying climatic and human-induced factors that determine the responses prevailing at different observable scales.

In Chapter 2, a comprehensive analysis of hydro-climatological trends and variability characteristics were investigated for the Lake Naivasha basin with the aim of understanding changes in water balance components and their evolution over the past 50 years. The results showed that upstream flows and precipitation in the basin were fairly homogenous with most stations showing little abrupt or gradual changes. Downstream flows however, experienced increasing trends in one part of the basin and decreasing trends in other parts. The lake experienced a significant decline over the period at a mean rate of $0.06 \mathrm{~m}_{\text {year }}{ }^{-1}$. This decline was about $50 \%$ lower than reconstructed lake volumes, thereby suggesting net losses attributable to measurement errors, ground water seepage or lake water abstractions. Homogeneity of precipitation in the basin over the period of study was indicative of no evidence of climatic change impacting the hydrological regime of the basin but other factors than precipitation were the likely cause of the observed changes.

In chapter 3 the SEBS model was applied to quantify evapotranspiration of the different land uses/cover in the basin for the period 2003 to 2012. Using MODIS and ECMWF ERA-Interim as input data to compensate for lack of data in the basin, Evergreen forest and closed shrublands, released the least amount of water back to the atmosphere because they covered the smallest 
area in the basin compared to grasslands, cropland/natural vegetation mosaic and savannas. Overall, annual evapotranspiration over the 10 years showed a declining trend $(\sim 10 \%)$ which was likely due to reduced net radiation combined with increases in both actual vapor pressure and decreases in the air-surface temperature difference. These factors accounted for at least $90 \%$ of the estimated decline. Validation of SEBS results against 2-year flux measurements at a heterogeneous site (See chapter 4) further indicated that, heterogeneity of the measurement site, uncertainty in the input data, scale mismatch between input and measured data at the site and uncertainties inherent in the formulation of the SEBS model were the likely causes of mismatch between measured and modelled fluxes. It was recommended that inclusion of additional local flux measurements at different land use/cover types would significantly improve understanding of the hydrological fluxes in the basin and constrain model simulations.

The flux measurements at the heterogeneous site also allowed for the characterization of the seasonal and interannual variability of the energy and water fluxes of the ecosystem covering two wet years (2012 and 2013) and one drought year (2014). On an annual scale, more than 60\% of $R_{n}$ was partitioned as $L E$ and $H$, with the latter being the largest consumer of $R_{n}(\sim 34 \%)$ and dominant for most months. The transition from $H$ to $L E$ dominance occurred from early noon to late afternoon in the wettest months of April and May. The residual energy balance closure term (C) accounted for between $25-40 \%$ of the $R_{n}$ with the imbalance tending to be highest during periods of high insolation. Annual evapotranspiration accounted for at least $80 \%$ of the annual precipitation received at the site. The measurements showed that, during wet seasons, the $R_{n}$ was the dominant control of energy partition into $L E$ while during the dry seasons, VPD and $g_{s}$ strongly dominated the energy partitioning into LE. This cyclic pattern in dominance of controlling factors between wet and dry seasons provide insights towards formulating models that quantify evapotranspiration for ecosystems that experience seasonal shifts in controlling factors.

While land use and climatic controls on eco-hydrological processes are well understood and easily quantified using physical models in hydrological sciences, socio-economic controls on ecohydrological processes have received little attention. Socio-economic developments often change the water balance substantially and are highly relevant in understanding changes in hydrological responses. Lake Naivasha basin has experienced substantial land use and land cover changes predominantly caused by socio-economic drivers. Accounting for the implications of these socioeconomic drivers is vital to the understanding of hydrological and ecological functioning of the basin. Using a statistical cascade-modeling approach, coupling socio-economic factors to ecohydrological processes it was shown that socio-economic factors have intensified land use changes leading to increased flow regimes over the last 25 years. The population in the upstream part of 
Summary the basin contributed over $60 \%$ to the land use/cover transformations in that part of the basin. Water abstractions from the lake and its conjunctive aquifer influenced the lake storage changes less than the contribution from upstream runoff volume. Upstream runoff volumes directly affected the lake storage changes by over $70 \%$ whereas water abstractions affected the lake storage changes by only $10 \%$. The downstream population and cut-flower export volume accounted for at least $70 \%$ of water abstraction. Finally, the large aggregation of high biomass density of large herbivore mammal species in the lake fringe was largely due to land use changes than precipitation. The low variance explained by the annual precipitation on the herbivores biomass contradicts earlier observations that ungulates density is dependent on annual precipitation (Coe et al., 1976; East, 1984; Georgiadis et al., 2003; Ogutu and Owen-Smith, 2003).

Overall, the cascade modeling approach offered insight on the contribution of socio-economic factors on the eco-hydrological regime of the Lake Naivasha basin. Thus, our method could potentially be used to show the influence of eco-hydrological processes on socio-economic developments.

Trends in the water balance components, evapotranspiration and its climatic controls were investigated and a modelling framework integrating socio-economic factors of land use change to basin wide eco-hydrological processes were presented. 


\section{Samenvatting}

Uit theoretisch onderzoek blijkt dat de koppelingen tussen vegetatie, klimaat en hydrologie, vooral stochastische processen zijn (Jackson et al., 2009). Vegetatie oefent een sterke invloed uit op basale hydrologische variabelen. Daardoor hebben veranderingen in landgebruik invloed op de kwaliteit en de kwantiteit van watervoorraden. De groeiende wereldbevolking versterkt veranderingen in landgebruik. Dit leidt tot een toenemende druk op watervoorraden en tot regulering.

Begrip van de hydrologische processen op stroomgebiedsschaal en van de factoren die deze processen beïnvloeden, zijn noodzakelijk om een goede verwachting te kunnen geven van wateropbrengst en -kwaliteit. De hydrologie van een stroomgebied reageert op zowel veranderingen in het landgebruik als op variabiliteit van het klimaat. Inzicht in deze verbanden is waardevol voor het voorspellen van de effecten van veranderingen in landgebruik op rivierafvoer en het waterpeil in meren. Het hoofddoel van dit onderzoek is om de invloeden van klimaat en landgebruik op de hydrologische reacties van het stroomgebied van het Naivashameer te kwantificeren. De studie richt zich op het identificeren van menselijke en klimatologische factoren die de hydrologische reacties op verschillende tijdsschalen bepalen.

In Hoofdstuk 2 worden trends en variabiliteit van de waterbalans van het Naivashameer geanalyseerd, met het doel om tot inzicht te krijgen in de veranderingen van de afgelopen 50 jaar. De afvoer en neerslag bleken bovenstrooms vrij constant te zijn, met weinig abrupte of geleidelijke veranderingen. Benedenstrooms was er op sommige plaatsen een trend van toename, en op andere plaatsen een trend van afname. Het waterpeil in het meer nam significant af met een gemiddelde snelheid van $0.06 \mathrm{~m}$ per jaar. Deze afname was ongeveer $50 \%$ lager dan die verwacht op basis van berekende volumes. Dit suggereert ofwel meetfouten, ofwel een netto verlies aan water door grondwater of onttrekking van water uit het meer. Er is geen bewijs voor een effect van klimaatverandering op het peil in het meer. Het ontbreken van een trend in de neerslag suggereert dat andere factoren dan neerslag verantwoordelijk waren voor de waargenomen veranderingen.

In hoofdstuk 3 wordt het model SEBS toegepast om de verdamping van het oppervlak te kwantificeren voor categorieën van landgebruik en bodembedekking in de periode van 2003 tot 2012. MODIS en ECMWF ERAInterim producten zijn gebruikt als invoer. Daarmee kon het gebrek aan gegevens voor het stroomgebied worden gecompenseerd. Groenblijvend bos en gesloten 

struikgewas verdampten het kleinste volume, omdat ze minder oppervlakte hadden dan grasland, akkerland en savanne. Voor het hele stroomgebied vertoonde de verdamping een neerwaartse trend (ong. 10\%). De oorzaken zijn waarschijnlijk een verminderde netto straling, een toegenomen luchtvochtigheid, en een afgenomen verschil in temperatuur tussen de lucht en het aardoppervlak. Deze factoren verklaarden minimaal $90 \%$ van de berekende afname. De validatie van de gesimuleerde waardes van SEBS tegen 2 jaar gegevens van een fluxstation op een heterogene locatie (zie hoofdstuk 4) lieten verder zien dat de heterogeniteit van de meetlocatie, de onzekerheid in de invoer van het model, de verschillen in ruimtelijke schaal van invoer en gemeten data op de grond en onzekerheid van de modelrepresentatie allemaal mogelijke oorzaken zijn van het grote verschil tussen gemeten en gesimuleerde fluxen. Een aanbeveling van deze studie is om op meer plaatsen de verdamping te meten; plaatsen met verschillend landgebruik. Zo kan het begrip van de hydrologische fluxen in het stroomgebied verbeterd worden en de vrijheid van het model worden ingeperkt.

De metingen van de fluxen op de heterogene locatie gedurende twee natte jaren (2012 en 2013) en een droog jaar (2014) maakte het ook mogelijk om de seizoenmatige en jaarlijkse variabiliteit van de fluxen van energie en water van het ecosysteem te leren kennen. Meer dan $60 \%$ van de jaarlijkse netto straling $\left(R_{n}\right)$ wordt verdeeld over verdamping $(L E)$ en voelbare warmte $(H)$. De voelbare warmte is de grootste consument van netto straling tijdens de meeste maanden (ong. $34 \%$ op jaarbasis). Een overgang van dominantie van $H$ naar $L E$ vond plaats in de vroege namiddag tot late namiddag in de april en mei: de natste maanden. Het restant van de energiebalans, de zogenaamde sluitingsterm C, bedroeg 25 tot $40 \%$ van $R_{n}$. De onbalans was het hoogste tijdens zonnige periodes. De jaarlijkse verdamping was ongeveer $80 \%$ van de jaarlijkse neerslag op de meetlocatie. De metingen laten zien dat $R_{n}$ de dominante factor voor $L E$ was tijdens het natte seizoen, terwijl tijdens het droge seizoen de luchtvochtigheid en de geleidbaarheid van bodem en vegetatie voor water $L E$ bepaalden. Het ontdekken van dit terugkerende patroon van dominantie van verschillende factoren kan helpen om modellen voor de verdamping voor de savanne te ontwikkelen.

De effecten van landgebruik en klimaat op ecohydrologische processen zijn goed begrepen, en gemakkelijk te kwantificeren met fysische modellen. In het vakgebied is veel minder aandacht besteed aan sociaaleconomische effecten op ecohydrologische processen. Sociaaleconomische ontwikkelingen veranderen vaak de waterbalans substantieel, en ze zijn relevant voor het begrip van de hydrologie. Het landgebruik in het stroomgebied van het Naivashameer heeft een substantiële verandering ondergaan, en deze verandering van landgebruik is veroorzaakt door sociaaleconomische ontwikkelingen. Het berekenen van de implicaties van deze 
Summary sociaaleconomische factoren is van groot belang. Uit een statistisch cascademodel blijkt dat sociaaleconomische factoren de veranderingen in landgebruik hebben geïntensifieerd, wat heeft geleid tot toenemende afvoeren gedurende de afgelopen 25 jaar. De bevolking bovenstrooms is verantwoordelijk voor $60 \%$ van de landgebruiksveranderingen. Onttrekking uit het meer en het daaraan verbonden watervoerend pakket hadden minder invloed op het volume van het meer dan de bijdrage van de afvoer van bovenstrooms. Bovenstroomse afvoervolumes hadden een direct effect van $70 \%$ op de veranderingen in het volume van het meer, terwijl onttrekkingen slechts $10 \%$ bijdroegen. De benedenstroomse bevolking en de productie van snijbloemen waren verantwoordelijk voor $70 \%$ van de onttrekkingen. De aggregatie van biomassa en de dichtheid van grote herbivoren rondom het meer was vooral veroorzaakt door veranderingen in landgebruik. Het geringe effect van de jaarlijkse neerslag op de aantallen herbivoren is in tegenspraak met eerdere waarnemingen dat de dichtheid van hoefdieren afhangt van de jaarlijkse neerslag (Coe et al., 1976; East, 1984; Georgiadis et al., 2003; Ogutu and Owen-Smith, 2003).

Het cascademodel heeft inzicht verschaft in de bijdrage van sociaaleconomische factoren op de ecohydrologie van het Naivashameer. Onze methode kan ook elders worden toegepast om het effect van sociaaleconomische ontwikkelingen op de hydrologie aan te tonen.

In deze studie zijn trends in de componenten van de waterbalans, de verdamping en het klimaat zijn onderzocht en is een raamwerk gepresenteerd om sociaaleconomische effecten van landgebruik op een stoomgebied te kwantificeren. 


\section{ITC Dissertation List}

http://www.itc.nl/research/phd/phd_graduates.aspx 


\section{Biography}

Vincent Omondi Odongo completed his Bachelor of Science in Agricultural Engineering (with specialization in Soil and Water Engineering) in 2004 and MSc. Agricultural Engineering (with specialization in Soil and Water Engineering) in 2008 from Egerton University, Kenya. In 2006, he received a postgraduate diploma in Remote Sensing and GIS at the African Regional Centre for Space Science and Technology Education (ARCSSTEE) in Nigeria. In 2008 he was admitted to study for an MSc. in Geoinformation Science and Earth Observation for Environmental Modeling and Management (GEM) which was undertaken in four European Universities namely University of Southampton, Lund University, Warsaw University and the University of Twente (ITC). In April 2010, he joined University of Twente to pursue his PhD in Water Resources Management as part of a larger NWO/WOTRO funded program on Earth Observation and Integrated Assessment (EOIA) for the Governance of Lake Naivasha. His PhD research focused on understanding hydrological changes as determined by climate and land use in the lake Naivasha Basin. As part of his PhD research, he had the opportunity to work and collaborate with other members of the project in multidisciplinary environment towards achieving the research project initiatives. His research interests span across field hydrology and use of remote sensing to compensate for sparse hydrometeorological observations.

\section{ISI Publication}

Odongo, V. O., van der Tol, C., Becht, R., Hoedjes, J.C.B., Ghimire, C.P., Su, Z. (2016). Energy partitioning and its controls over a heterogeneous semi-arid shrubland ecosystem in the Lake Naivasha Basin, Kenya. Ecohydrology. 2016. 02/2016. DOI:10.1002/eco.1732

Odongo, V. O., van der Tol, C., van Oel, P. R., Meins, F. M., Becht, R., Onyando, J. O. and Su, Z. (2015). Characterization of hydroclimatological trends and variability in the Lake Naivasha Basin, Kenya. Hydrological Processes. 2015, 29, 15, 3276-3293.

Odongo, V. O., Mulatu, D. W., Muthoni, F. K., van Oel, P. R., Meins, F. M., van der Tol, C., Skidmore, A. K., Groen, T. A., Becht, R., Onyando, J. O. and van der Veen, A. (2014). Coupling socio-economic factors and eco-hydrological processes using a cascade-modeling approach. Journal of Hydrology. 2014, 518 (PA), pp. 49-59

Odongo, V. O., Hamm, N.A.S. and Milton, E. J. (2014). Spatio-temporal assessment of Tuz Gölü, Turkey as a potential radiometric vicarious calibration site. Remote Sensing. 2014, 6, 2494-2513.

Van Oel, P., Odongo, V. O., Mulatu, D. W., Muthoni, F. K., Ndungu, J.N, Ogada, J, and Van der Veen, A. (2014). Supporting IWRM through Spatial Integrated Assessment for the Lake Naivasha basin, Kenya. International Journal of Water Resources Development. 2014, 30 (3), pp. 605-618.

Odongo, V. O., Onyando, J., Mutua, B. M., Van Oel, P.R., Becht, R. (2013). Sensitivity Analysis and Calibration of the Modified Universal Soil Loss Equation (MUSLE) for the Upper Malewa Catchment, Kenya. International Journal of Sediment Research. 2013, 28, 368-383. 
Van Oel, P. R., Mulatu, D. W., Odongo V. O., Meins, F., Hogeboom, R, Becht, R., Stein, A., Onyando, J and Van der Veen, A (2013). The Effects of Groundwater and Surface Water Use on Total Water Availability and Implications for Water Management: The Case of Lake Naivasha, Kenya. Water Resources Management. 2013, 27, 9, 3477-3492.

Odongo, V. O., van der Tol, C., van Oel, P. R., Becht, R., \& Su, Z (2016). Estimating the evaporative water loss of different land use and land cover in the upper Lake Naivasha Basin (submitted for consideration in Hydrology and Earth System Sciences) 